\title{
Landscape analysis of the family planning situation in Pakistan
}

Population Council

Follow this and additional works at: https://knowledgecommons.popcouncil.org/departments_sbsr-rh

Part of the Demography, Population, and Ecology Commons, Family, Life Course, and Society Commons, and the International Public Health Commons How does access to this work benefit you? Let us know!

\section{Recommended Citation}

"Landscape analysis of the family planning situation in Pakistan." Islamabad: Population Council, 2016. 


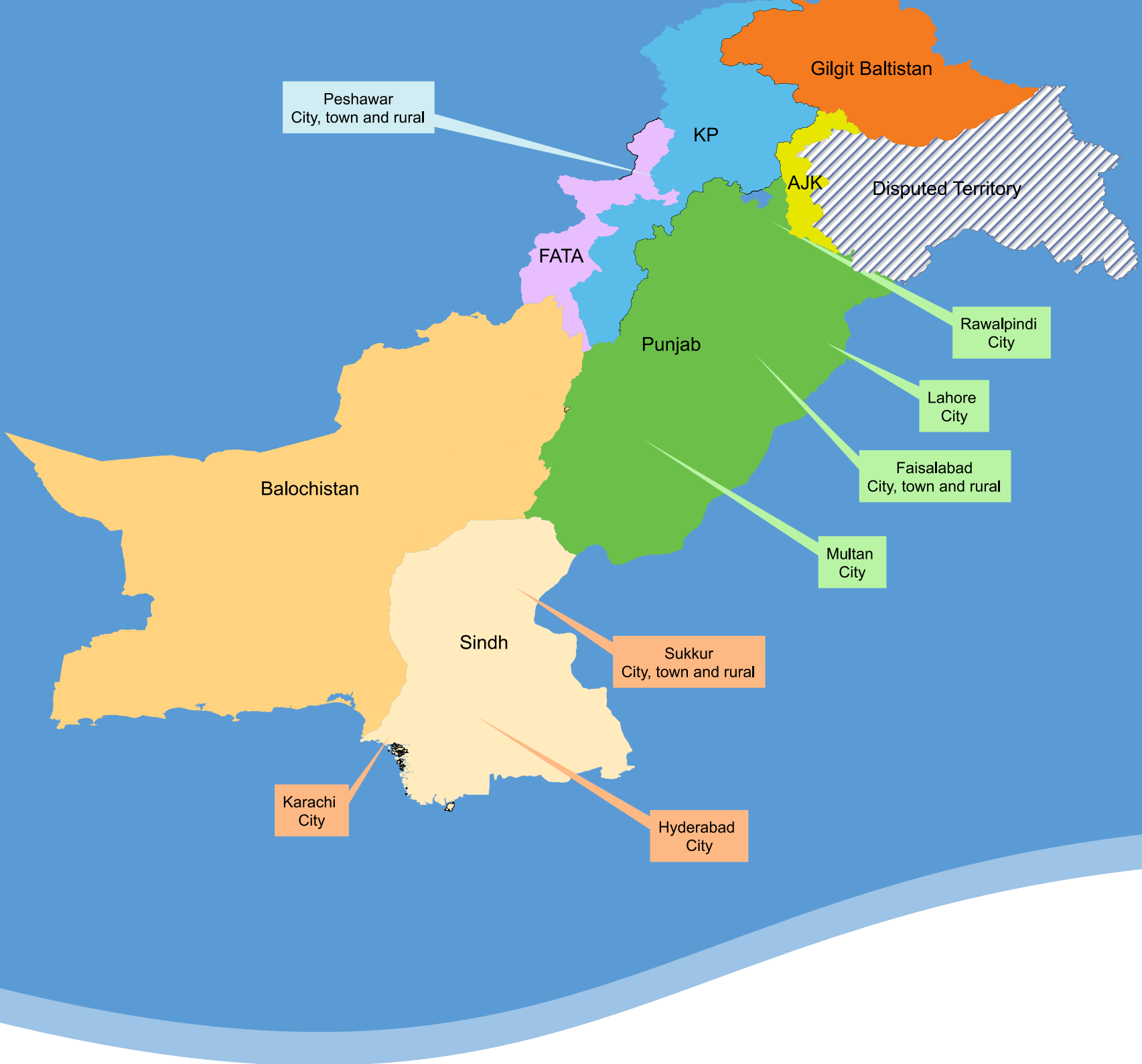

\section{LANDSCAPE ANALYSIS OF THE FAMILY PLANNING SITUATION IN PAKISTAN SEPTEMBER 2016}




\section{ponumanow \\ COUNCIL \\ Ideas. Evidence. Impact.}

The Population Council confronts critical health and development issues-from stopping the spread of HIV to improving reproductive health and ensuring that young people lead full and productive lives. Through biomedical, social science, and public health research in 50 countries, we work with our partners to deliver solutions that lead to more effective policies, programs, and technologies that improve lives.

(c) 2016 The Population Council, Inc. 


\section{Table of Contents}

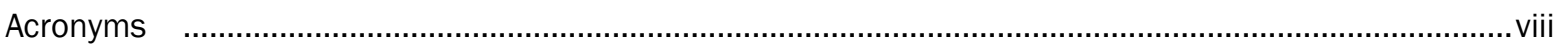

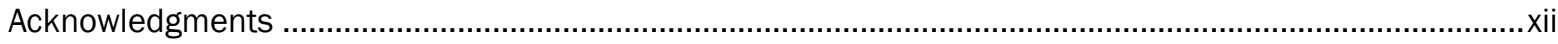

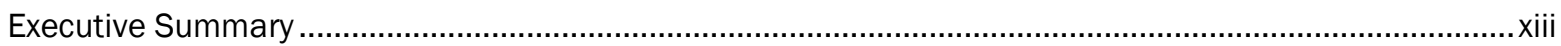

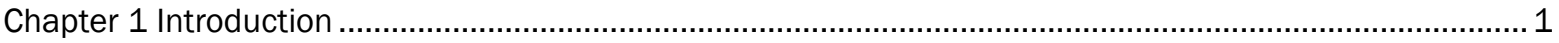

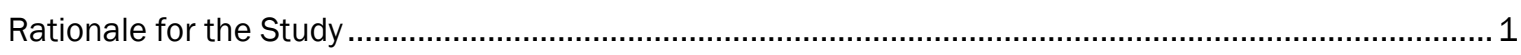

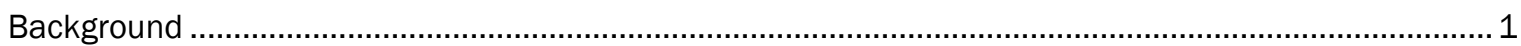

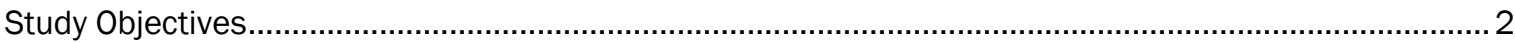

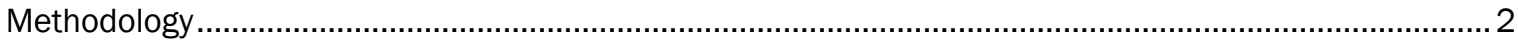

Chapter 2 Use of Family Planning: Barriers and Potential for Growth among Different Consumer

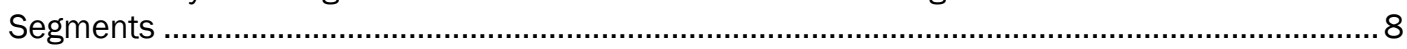

Assessing Unmet Need among Past, Never, and Current Users ........................................................ 9

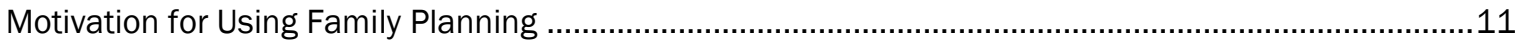

Profiles of Potential Users-and Their Barriers.................................................................................14

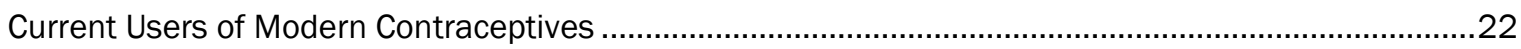

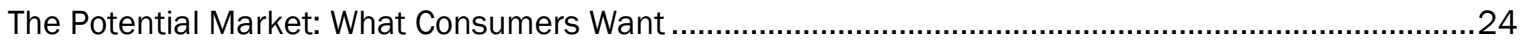

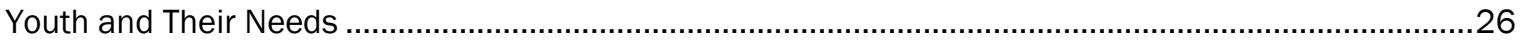

Summary of Key Points Use of Family Planning: Barriers and Potential for Growth among

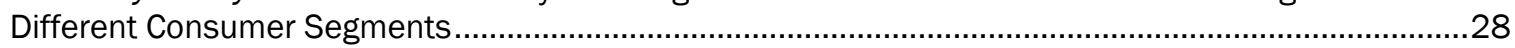

Chapter 3 Channels for Service Provision: Availability, Adequacy, and Potential for Expansion ..................30

The Main Channels for Family Planning Services and Products ...........................................................30

Health Facilities and Pharmacies in the Study Districts ................................................................32

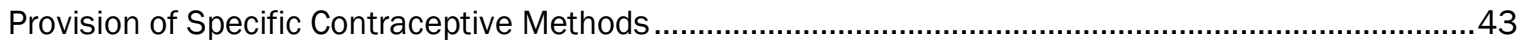

Service Quality in the Public and Private Sectors ........................................................................48

Barriers to Increased Service and Method Provision at Public and Private Facilities ...........................54

Potential for Expanding Channels of Family Planning Provision and Choice ..........................................56

Summary of Key Points Channels for Service Provision: Availability, Adequacy, and Potential for

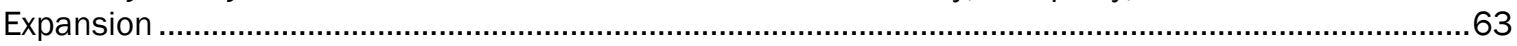

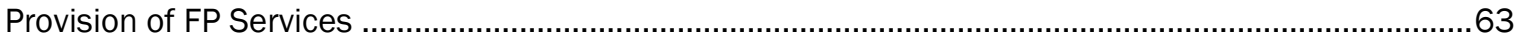

Chapter 4 Contraceptive Supply in the Public and Private Sectors.........................................................65

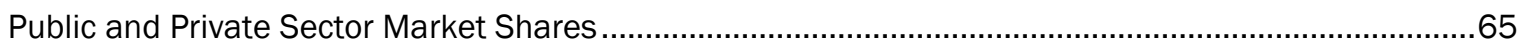

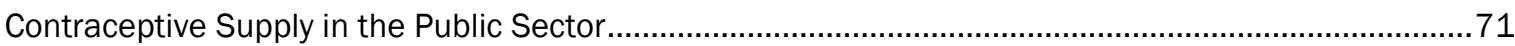

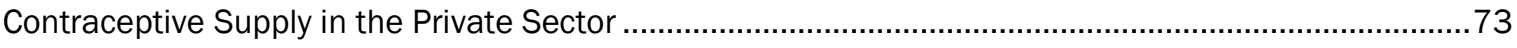

Summary of Key Points Contraceptive Supply in the Public and Private Sectors ..................................87

Chapter 5 Policy Landscape and Scale of Donor Investments in Family Planning .....................................89

Provincial Population Policies and Health Strategies- The Beginning of a New Era .............................89

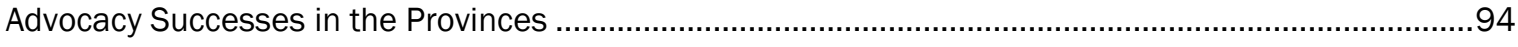

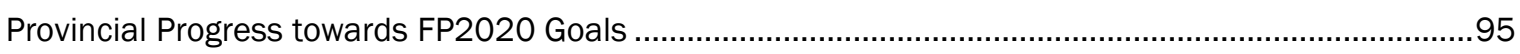


Fiscal Allocations for Family Planning ................................................................................... 103

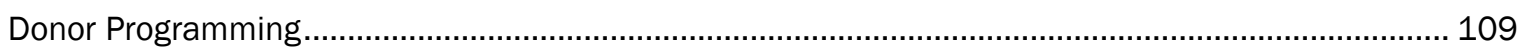

Summary of Key Points Policy Landscape and Scale of Donor Investments in Family Planning........ 113

Positive Provincial Policy Commitment ........................................................................................... 113

Chapter 6. Recommended Areas for Investment ......................................................................... 114

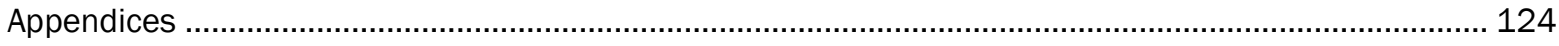

Appendix 1: List of Interviewed Policy Makers ............................................................... 124

Appendix2: Profile of Never Users with Unmet Need at Provincial Level ..........................................125

Appendix 3: Barriers of Never Users with Unmet Need by Segment ............................................. 126

Appendix 4: Profile of Past Users with Unmet Need at Provincial Level ...........................................127

Appendix 5: Barriers of Past Users with Unmet Need by Segment ...............................................128

Appendix 6: Profile of Current Traditional Users at Provincial Level ................................................ 129

Appendix 7:Barriers of Traditional Users to Adopt Modern Contraceptives by Segment ......................130

Appendix 8: Profile of Current Modern Contraceptive Users at Provincial Level ............................... 131

Appendix 9: Development Partners, Projects, Focus, Location, and Funding................................... 132 


\section{List of Tables}

Table 1.1: Number of IDIs and FDGs by location

Table 1.2: Number of Public/Private Facilities and Pharmacies Covered in the Four Study Districts* .........5

Table 1.3: Number of IDIs with Private Stakeholders in Contraceptive Supply ........................................... 6

Table 1.4: Number of IDls with Private Service Providers........................................................................ 6

Table 2.1: Ideational Factors Influencing the Views of Men and Women on FP, by Location .....................12

Table 2.2: Key Life Points at which FP Use may Commence, by Location ...............................................13

Table 2.3: Variation in intensity of barriers to modern contraceptive use among potential users ..............22

Table 3.1: Types of Services Provided by Different Levels of Public Sector Facilities..................................31

Table 3.2: Types of Services Provided/Can be Provided by Different Levels of Private Sector Facilities ....32

Table 3.3: Public Health Facilities and LHWs: Provincial Universe and Numbers in Study Districts...........33

Table 3.4: Estimated Provincial Universe and Private Health Facilities Covered in Study Districts .............33

Table 3.5: Urban-rural Distribution of Health Facilities, Community Workers, and Pharmacies in the

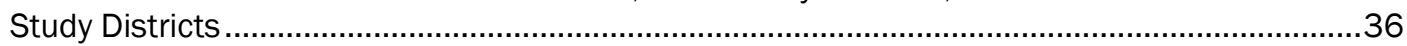

Table 3.6: Proportion of Channels Offering any FP Services in Study district rural and urban areas ..........39

Table 3.7: Provision of Specific FP Methods by Major Channels in Study Districts (\%) ..............................43

Table 3.8: Provision of Specific FP Methods by Facilities and Providers in the Study Districts (\%) ............44

Table 3.9: Provision of FP Services by Population Size in the Study Districts .........................................46

Table 3.11: Availability of Functional General Medical Equipment at Public and Private Facilities in the Study Districts (\%)......

Table 3.12: Availability of Infection Prevention Arrangements at Public and Private Facilities in the Study Districts (\%)

Table 3.13: Availability of Female Doctors and Mid-level Providers to Provide Family Planning Services at Public and Private Facilities in the Study Districts (\%) .........................................52

Table 3.14: Major Reasons Cited by Providers for Not Providing FP Methods, by Location $(N=5,291) \ldots . . .55$

Table 4.1: Percentage of Public Health Facilities/Workers reporting Stock-outs in Punjab, Sindh and KP in December 2015. 72

Table 4.2: Major Condom Brands, their Prices, and Profit Margins of Distributors and Retailers ...............74

Table 4.3: Major COC and EC Brands, Prices, and Profit Margins, of Distributors and Retailers ..................79

Table 4.4: Major Injectable Brands, Prices, and Profit Margins, of Distributors and Retailers . .79

Table 4.5: Major IUD and Implant Brands, their Prices, and Profit Margins of Distributors, Retailers, Providers 85

Table 5.1: Objective of Provincial Population Policies and Sindh Costed Implementation Plan ..................90

Table 5.2: Provincial Health Sector Strategy Objectives ...................................................................92

Table 5.3: National and Provincial Commitments to Achieve FP2020 Targets .........................................94

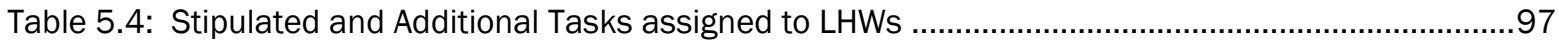

Table 5.5: Family Planning Methods Service Providers Can Provide per National Standards ....................98

Table 5.6: Existing Coordination Mechanisms at the Provincial and District Levels..................................100 
Table 5.7: Federal Government Allocation for Provincial Population Welfare Program and Vertical National Programs Through PSDP FY 2011-2012 to FY 2014-2015 104

Table 5.8: Federal Allocation and Provincial Resources for 2012-2015 ................................................ 105

Table 5.9: Provincial Departments of Health Budgets from 2011-2012 to 2014-2015.......................... 105

Table 5.10: Provincial Budgets for Population from 2011-2012 to 2014-2015 ...................................... 106

Table 5.11: Per Capita Public sector Budget Allocation from 2011-12 to 2014-15 by province............... 106

Table 5.12: Direct and indirect support to FP activities by donors in Pakistan ......................................... 107

Table 5.13: Programmatic Focus of Donors ……................................................................................ 110 


\section{List of Figures}

Figure 1.1: Locations Covered Under Landscape Assessment

Figure 2.1: Estimated Numbers of Currently Married Women in Pakistan by Never, Ever, Past, and Current use of Contraceptives and Unmet Need, 2007 and 2015.

Figure 2.2: Percentage of Currently Married Women in Pakistan by Never, Ever, Past and Current Use of Contraceptives and Unmet Need, 2006-07 and 2012-13

Figure 2.3: Growth Potential among Current, Past and Never Users of FP in Pakistan .10

Figure 2.4: Number of Potential Users of Modern Contraceptives among Current, Past, and Never Users.

Figure 2.5: Potential Users of Pakistan by residence.

Figure 2.6: Percent Distribution of Currently Married Women Who Are Never Users with Unmet Need by Background Characteristics

Figure 2.7: Distribution of Currently Married Women Who are Never Users with Unmet Need by Background Characteristics, Number of Women

Figure 2.8: Percent of Currently Married Women who are Past Users with Unmet Need by Background Characteristics...

Figure 2.9: Number of Currently Married Women who are Past User of any FP Method with Unmet Need for FP Services by Background Characteristics

Figure 2.10: Percent of Currently Married Women Using Traditional Contraception Methods by Background Characteristics

Figure 2.11: Number of Currently Married Women Using Traditional Contraception Methods by Background Characteristics

Figure 2.12: Percentage of Currently Married Women Using Modern Contraception Methods by Background Characteristics

Figure 2.13: Number of Currently Married Women Using Modern Contraception Methods by Background Characteristics

Figure 3.1: Distribution of Static Health Facilities in the Public and Private Sectors in the Study Districts

Figure 3.2: Distribution of Facilities Including LHWs and Pharmacies in the Study Districts

Figure 3.3: Maps showing geographical location of public and private facilities in individual study districts.

Figure 3.4: Location and proportion of public and private facilities providing any FP services

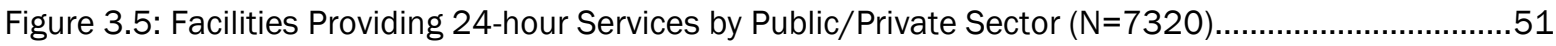

Figure 3.7: Providers' Knowledge of Specific FP Methods .....................................................................53

Figure 3.8: Increase in Access to ECPs and Injectables if LHWs can Provide them, Faisalabad .................57

Figure 3.9: Maps with Locations of Pharmacies in the Study Districts ........................................................61

Figure 3.10: Maps with Locations of Pharmacies Selling FP Products in the Study Districts .....................61

Figure 3.11: Pharmacies' Reasons for Not Selling FP Products in Study Districts $(\mathrm{N}=2127)$....................63

Figure 4.1: Share of Public and Private Sector Sources for Condoms, Pills, Injectables, and IUDs.............65

Figure 4.2: Use of Major Sources of Any Method (Condoms, Oral Pills, Injectables or IUDs) by Wealth Quintile...... 
Figure 4.3: Share of Public and Private Sector Sources in Supply of Condoms 66

Figure 4.4: Use of Major Sources of Condoms by Wealth Quintile ..........................................................67

Figure 4.5: Share of Public and Private Sector Sources in Supply of Oral Contraceptive Pills ....................67

Figure 4.6: Use of Major Sources of Oral Pills by Wealth Quintile ......................................................68

Figure 4.7: Share of Public and Private Sector Sources in Supply of Injectable Contraceptives ................68

Figure 4.8: Use of Major Sources of Injectable Contraceptives by Wealth Quintile .....................................69

Figure 4.9: Share of Public and Private Sector Sources in Supply of IUDs ..............................................69

Figure 4.10: Use of Major Sources of IUDs by Wealth Quintile ...........................................................

Figure 4.11: Supply of Contraceptives in the Public Sector....................................................................71

Figure 4.12: Volume of Weekly Sales of Condoms at Pharmacies in Four Districts ..................................74

Figure 4:13: Supply of Condoms in the Private Sector ....................................................................... 75

Figure 4.14: Selected Condom Brands in Pharmacies in Four Districts ..................................................77

Figure 4.15: Weekly Sales of Selected OCP Brands at Pharmacies in Four Districts ................................80

Figure 4.16: Weekly Sales of Selected Injectable Brands at Pharmacies in Four Districts ..........................80

Figure 4.17: Weekly Sales of Selected ECP Brands at Pharmacies in Four Districts..................................81

Figure 4.18: Supply of COCs, ECPs and Injectables in the Private Sector ...............................................81

Figure 4.19: Selected OCP and Injectable Brands in Pharmacies in Four Districts .................................83

Figure 5.1: Comparison between Federal Allocations vs. Provincial Budgets/Accounts of Punjab, Sindh and KP for FY2012-12 to 2014-15.......................................................................... 104

Figure 5.2: Provincial Departments of Health Budgets from 2011-2012 to 2014-2015 ....................... 106

Figure 5.3: Donor Investment in RH, including FP (In USD) ....................................................... 108

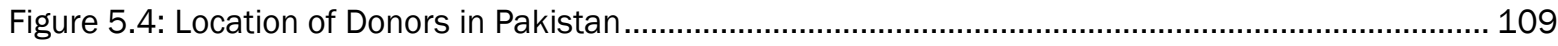

Figure 5.5: Location of Donor Initiatives in Sindh, Punjab and KP .................................................... 111 


\section{Acronyms}

\begin{tabular}{|c|c|}
\hline ADP & Annual Development Plan \\
\hline ASRH & Adolescent Sexual and Reproductive Health \\
\hline AID & Acquired Immune Deficiency Syndrome \\
\hline $\mathrm{BCC}$ & Behavioral Change Communications \\
\hline $\mathrm{BHU}$ & Basic Health Unit \\
\hline CBOs & Community Based Organizations \\
\hline $\mathrm{CCP}$ & Center for Communications Programs \\
\hline $\mathrm{CIP}$ & Costed Implementation Plan \\
\hline CLMIS & Contraceptive Logistics Management Information System \\
\hline CMW & Community Midwife \\
\hline CPR & Contraceptive Prevalence Rate \\
\hline DFID & Department for International Development \\
\hline DHPMT & District Health and Population Management Team \\
\hline DHQ & District Headquarters Hospital \\
\hline DKT & Dharmendra Kumar Tyagi \\
\hline DLI & Disbursement Linked Indicator \\
\hline DMPA & Depo-Medroxy Progesterone Acetate \\
\hline $\mathrm{DoH}$ & Department of Health \\
\hline DOTS & Directly Observed Therapy Strategy \\
\hline DRHR & Delivering Reproductive Health Results \\
\hline DTC & District Technical Committee \\
\hline ECP & Emergency Contraceptive Pill \\
\hline EmOC & Emergency Obstetric Care \\
\hline EPHS & Essential Health Service Package \\
\hline FALAH & Family Advancement for Life and Health \\
\hline FGD & Focus Group Discussion \\
\hline $\mathrm{FHC}$ & Family Health Center \\
\hline FHTs & Female Health Technicians \\
\hline FLCF & First Level Care Facility \\
\hline FMCG & Fast-Moving Consumer Goods \\
\hline $\mathrm{FP}$ & Family Planning \\
\hline FPAP & Family Planning Association of Pakistan \\
\hline FWC & Family Welfare Center \\
\hline
\end{tabular}




\begin{tabular}{|c|c|}
\hline $\mathrm{GIZ}$ & Deutsche Gesellschaft für Internationale Zusammenarbeit \\
\hline GSM & Greenstar Social Marketing \\
\hline HCE & Health Care Establishment \\
\hline HIV & Human Immunodeficiency Virus \\
\hline $\mathrm{HR}$ & Human Resource \\
\hline HSRU & Health Sector Reforms Unit \\
\hline HTSP & Healthy Timing and Spacing of Pregnancy \\
\hline ICPD & International Conference on Population Development \\
\hline IDI & In-Depth Interview \\
\hline IUD & Intra-Uterine Device \\
\hline Jhpiego & $\begin{array}{l}\text { Johns Hopkins Program for International } \\
\text { Education in Gynecology and Obstetrics }\end{array}$ \\
\hline KFW & German Development Bank \\
\hline LAD & Large Anonymous Donor \\
\hline LHV & Lady Health Visitor \\
\hline LHW & Lady Health Worker \\
\hline MCH Center & Mother and Child Health Center \\
\hline MCHIP & Maternal and Child Health Integrated Program \\
\hline mCPR & Modern Contraceptive Prevalence Rate \\
\hline MICS & Multiple Indicator Cluster Survey \\
\hline $\mathrm{MIO}$ & Media Information Officer \\
\hline MHSP & Minimum Health Service Package \\
\hline $\mathrm{MNCH}$ & Maternal, Neonatal and Child Health \\
\hline MNT & Maternal Neonatal Tetanus \\
\hline $\mathrm{MoH}$ & Ministry of Health \\
\hline MoPW & Ministry of Population Welfare \\
\hline MSDS & Minimum Service Delivery Standard \\
\hline MSI & Management System International \\
\hline MSS & Marie Stopes Society \\
\hline MSU & Mobile Service Unit \\
\hline MVA & Manual Vacuum Aspiration \\
\hline $\mathrm{NCH}$ & National Council for Homeopathy \\
\hline NCT & National Council for Tibb \\
\hline NGO & Non-Governmental Organization \\
\hline NID & National Immunization Day \\
\hline NFC & National Finance Commission \\
\hline
\end{tabular}




\begin{tabular}{|c|c|}
\hline OCP & Oral Contraceptive Pill \\
\hline P\&D & Planning and Development \\
\hline PAC & Post-Abortion Care \\
\hline PAPAC & Pakistan Alliance for Post-Abortion Care \\
\hline PC-1 & Project Cycle-1 \\
\hline PDHS & Pakistan Demographic and Health Survey \\
\hline PEMRA & Pakistan Electronic Media Regulatory Authority \\
\hline $\mathrm{PHC}$ & Primary Health Care \\
\hline PMDC & Pakistan Medical and Dental Council \\
\hline PNC & Pakistan Nursing Council \\
\hline $\mathrm{PPHI}$ & People's Primary Healthcare Initiative \\
\hline PPP & Public-Private Partnership \\
\hline PRHN & Pakistan Reproductive Health Network \\
\hline PRSP & Punjab Rural Support Program \\
\hline PSDP & Public Sector Development Programme \\
\hline PSLMS & Pakistan Social and Living Standards Measurement Survey \\
\hline PSPU & Policy and Strategic Planning Unit \\
\hline PTC & Provincial Technical Committee \\
\hline PTV & Pakistan Television \\
\hline PWD & Population Welfare Department \\
\hline PWTI & Population Welfare Training Institute \\
\hline QoC & Quality of Care \\
\hline RBM & Roll Back Malaria \\
\hline $\mathrm{RH}$ & Reproductive Health \\
\hline $\mathrm{RHC}$ & Rural Health Center \\
\hline RHSC-A & Reproductive Health Services Center-A type \\
\hline RMNHP & Reproductive, Maternal and Newborn Health Project \\
\hline RSP & Rural Support Programmes \\
\hline RTI & Regional Training Institute \\
\hline SBA & Skilled Birth Attendant \\
\hline SDG & Sustainable Development Goal \\
\hline SDM & Standard Days Method \\
\hline SDP & Service Delivery Point \\
\hline SMO & Social Marketing Organization \\
\hline SMO & Senior Medical Officer \\
\hline SMU & Special Monitoring Unit \\
\hline
\end{tabular}




$\begin{array}{ll}\text { SPSS } & \text { Statistical Package for the Social Sciences } \\ \text { SRH } & \text { Social and Reproductive Health } \\ \text { STD } & \text { Sexually Transmitted Disease } \\ \text { THQ } & \text { Tehsil Headquarters Hospital } \\ \text { TRF } & \text { Total Fertility Rate } \\ \text { UAH } & \text { Unani, Ayurvedic and Homoeopathic } \\ \text { UDL } & \text { United Distribution Limited } \\ \text { UN } & \text { United Nations } \\ \text { UNFPA } & \text { United Nations Fund for Population Activities } \\ \text { USAID } & \text { United States Agency for International Development } \\ \text { WHO } & \text { World Health Organization } \\ \text { WMO } & \text { Women Medical Officer } \\ \text { WRA } & \text { Women of Reproductive Age }\end{array}$




\section{Acknowledgments}

This landscape analysis of the family planning situation in Pakistan was commissioned by the Bill and Melinda Gates Foundation, for identifying opportunities for investments to improve access to modern family planning methods consistent with provincial and national targets for FP2020.

We thank the following colleagues from the Gates Foundation who guided us through this landscape exercise: Dr.Lester Coutinho, Ms. Wynn Bubnash, Ms. Trisha Wood Santos, Dr.Win Brown, Ms. Marlo Hartung, and Dr. Yasmeen Qazi.

In addition to our Population Council Islamabad authors, we could like to acknowledge the assistance of Dr. John Ross, an independent consultant, who helped compile the previously submitted Client Profile. Imran Zafar contributed to the analysis in Chapter 4. We would also like to thank Mr. Ashfaq Rahman, Managing Director at Social Marketing Company, Bangladesh, for his extremely useful suggestions and guidance, particularly for his insights for Chapter 4. We thank Dr. Karen Hardee from the Population Council, who was involved in the landscape analysis since its inception, in particular her guidance and recommendations for this final report. We also appreciate Dr. John Townsend's final review.

We offer our appreciation and gratitude to the officials of the Health and Population Welfare departments of Punjab, Sindh, and Khyber Pakhtunkhwa provinces for their full support and recommendations, issued permissions and provided full facilitation in the implementation of this study.

The Population Council is really pleased to have had this opportunity to interact with a large number of individuals from wide ranging backgrounds, including policy makers, manufacturers, suppliers, providers and consumers of FP located across Pakistan.

We are thankful to all the interviewers, translators and data entry staff for their hard work in producing quality data.

We owe special thanks to all the study participants, the policy makers, distributors, importers and Health facility staff who spared their time to answer our questions and provided useful insights which will hopefully help in influencing the future policies and FP programs in each of the provinces of Pakistan. 


\section{Executive Summary}

\section{Rationale for the Landscape Analysis}

This report presents the findings of a landscape analysis of family planning (FP) in Pakistan by the Population Council in 2015 and 2016, with the support of the Bill and Melinda Gates Foundation.

Pakistan faces a number of challenges for increasing modern contraceptive use. Although there are encouraging signs, such as improved male participation, the addition of about four million current FP users, from 2007 to 2013, and a more responsive policy environment with demonstrated political and financial commitment to meeting the country's FP2020 goals, the task that lies ahead is still huge. While 55 percent of currently married women of reproductive age have tried a contraceptive method at some point in their lives, only 35 percent are currently using any method, and only 26 percent are using modern methods.

Discontinuation rates are high, especially for the intrauterine device (IUD), and use of hormonal female methods is either stagnant or declining. Meanwhile there are around 2.1 million abortions annually for unwanted pregnancies. There is a daunting gap in service coverage in most parts of the country, including a semi-functional public health sector that is not fully responsible for FP within its services, along with suboptimal FP provision in the private sector.

This landscape analysis assesses both demand and supply side shortcomings in the FP market, and provides a comprehensive assessment of consumers, service provision, contraceptive supply, and policy and regulations to help identify opportunities for investment that could catalyze an escalation in contraceptive prevalence, enabling Pakistan to meet its FP2020 goals.

The five objectives of the study are to:

1. Comprehensively assess the coverage of FP services, constraints of different segments of consumers, the limitations of contraceptive choice, particularly out-of-pocket costs of contraceptive methods, and opportunities to expand access and choice in three Pakistan provinces in a market segmentation approach;

2. Identify, analyze, and address supply and demand barriers in the public and private sectors;

3. Assess the market for commodities and services for FP, especially suppliers' perspectives;

4. Assess the policy landscape and scale of donor investments in FP; and

5. Suggest future strategies and areas of investment for FP in three provinces in Pakistan.

\section{Methods}

The landscape analysis was conducted in eight districts of three provinces: Peshawar in Khyber Pakhtunkhwa (KP), Punjab's Rawalpindi, Faisalabad, Lahore and Multan districts, and Sukkur, Hyderabad and Karachi districts in Sindh. This landscape analysis focused on eight cities in these districts-Peshawar, Rawalpindi, Faisalabad, Lahore, Multan, Hyderabad, Sukkur, and Karachi. Further investigations were conducted in one town and one rural location in Peshawar, Faisalabad, and Sukkur districts-one in each province-with FP service availability mapped in its entirety in these districts, and in three townships in Lahore, with 14 locations total studied for a comparative perspective.

Data for this landscape analysis were obtained through secondary data analysis, qualitative studies of consumer demand for FP and contraceptive supply in the private sector, mapping and assessment of health facilities, and document review and key informant interviews on the policy environment and donor mapping. 


\section{Use of Family Planning: Barriers and Potential for Growth Among Different Consumer Segments}

\section{Contraceptive Users}

- There are an estimated 31 million married women of reproductive age (15 to 49 years old) in Pakistan. Among these women, 35.4 percent are using any contraceptive method, with 26.1 percent using modern contraceptives and 9.3 percent using traditional methods. A further 20.1 percent of women, both past and never users, are living with unmet FP need.

- There are nine million potential users in Pakistan-around one third each are:

- Never users with unmet need;

- Past users with unmet need; and

- Current users of traditional methods who may be persuaded to use modern methods.

\section{Growth Potential Among Current, Past and Never Users of Family Planning in Pakistan}

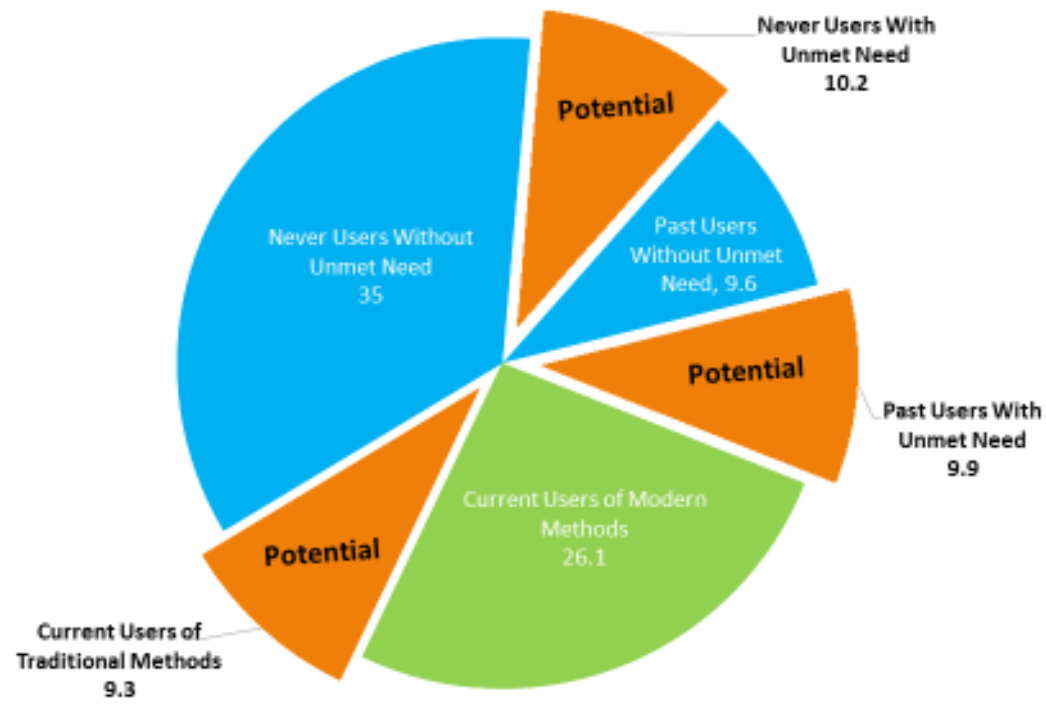

Source: Pakistan Demographic and Health Survey 2012-2013

- Translating demand for FP into use of modern contraceptives among these nine million potential users would raise the national modern contraceptive prevalence rate (mCPR) to 55.5 percent.

- The three groups of potential users exhibit different profiles that have implications for programming.

- Never users with unmet need have a median age of 29 years, tend to be uneducated and in the lowest wealth quintiles. They have one to two children.

- Past users with unmet need are the oldest segment (median age 35), tend to be uneducated, and are represented in all wealth quintiles. This group has the highest parity, with four children and more. 
- Traditional users with unmet need have a median age of 33, are most educated, likely with secondary education, and in the highest wealth quintiles, with two to four children, on average.

- In reaching these three groups of potential users, it is important to understand the barriers each group faces:

- Never users with unmet need noted three primary barriers. Lack of information of contraceptive methods is the major barrier, particularly for men, who do not have any direct source or mechanism for reliable information. Low access to health services is a hurdle, especially in rural communities not served by Lady Health Workers (LHWs). The third major barrier is fear of side effects perpetuated by lack of information and negative testimonials from past users.

- Past users with unmet need described their past experience of side effects such as heavy bleeding, anemia, infection, backache, and malaise, which affected not only their health but other aspects of their lives, as the most entrenched barrier. They are also deterred by experience of poor quality of health services, which has convinced them they will not find adequate support from the health system should they experience side effects again. Finally, cost of side effect management, which this group knows from experience to be potentially high, is a barrier to resumed FP use.

- Among traditional method users, fear of side effects is a main barrier to modern contraceptive use, along with lack of information about specific methods. Myths and misconceptions that abound about almost all modern FP methods, particularly long acting contraceptives, affect this group's view of FP, leading older women to prefer traditional methods.

- Of the nine million potential users, about six million live in rural areas and three million in urban areas.

- Current users of modern contraception are:

- Mostly in urban areas and in Punjab, followed by Sindh and KP;

- Tend to belong to higher wealth quintiles, with education beyond primary school, older, with higher levels of parity; and

- Include completely satisfied users, users with mild side effects, and users living with severe side effects; the latter category is at high risk of discontinuation and needs special attention, especially quality FP services.

\section{Factors Affecting Family Planning Use}

- A number of factors affect men and women's views of FP use. These factors include exposure to LHWs, NGOs and the media; female education and employment; desire to emulate those perceived to be better off; economic factors; and religious perceptions (especially in KP). The intensity with which some of these factors influence perceptions varies across districts.

\section{Needs for Family Planning Information and Services}

- Women and men want their need of FP information to be addressed by providing detailed and methodspecific information, through community workers; information materials, Internet, social media, and mobile phone services. Group meetings and mass media can be used to highlight the link between FP and maternal health. Service providers can allay people's fears about modern methods.

- In terms of service provision, men and women strongly call for doorstep delivery of services, and for LHWs to have sufficient contraceptive stocks and the capacity to help them cope with side effects. They want public and private sector static facilities to be available in their vicinity, offering separate spaces for men and women to get FP services, and at nominal cost. In particular, they want services for side effect management available. 


\section{Views of Youth on Family Planning}

- Young people have a very positive view of FP and express unqualified readiness to adopt it regardless of gender, school status, and rural or urban residence. Young people want to be equipped with FP information, and receive it privately, preferably through the internet, social media, and mobile voice messages including videos or pictures for the uneducated. They also suggest promoting FP through TV and radio, employing local languages for remote communities.

\section{Channels for Family Planning Service Provision: Availability, Adequacy, and Potential for Expansion}

\section{Provision of Family Planning Services}

- This analysis, based mainly on census findings in four highly urbanized districts, shows that while the numbers and distribution of major channels of health services in the public and private sectors is quite impressive, the full potential of these channels is not being utilized to deliver FP services. This is especially applicable to the rural areas of these districts but even in the urban settings, both the public and the private sector are quite far from offering a full range of contraceptives to clients.

- The public sector, which has an explicit mandate to provide FP services, is providing services in both urban and rural areas. In particular, the Population Welfare Department (PWD) and People's Primary Healthcare Initiative (PPHI) are quite active in FP services, as are LHWs.

- Department of Health (DoH) facilities are providing only a limited range of FP services, which need to be increased. The PWD also needs to increase level of service provision for emergency contraceptive pills (ECPs) both in urban and rural areas.

- In comparison, the private sector, although it contains the larger numbers in their respective channels, is less likely to be providing FP services. Only 41 percent of private sector providers in urban areas and 29 percent in rural areas are providing FP services.

- Pharmacies are performing better in terms of availability of FP products, rising to 69 percent in urban and 53 percent in rural areas, but they are mostly selling condoms.

- The largest potential for expansion lies in increasing the role of the private sector providers, pharmacies and dispensers to include more trained providers and contraceptive products to expand choice and availability of FP services. 


\section{Location of Private Facilities and Pharmacies in Faisalabad District}
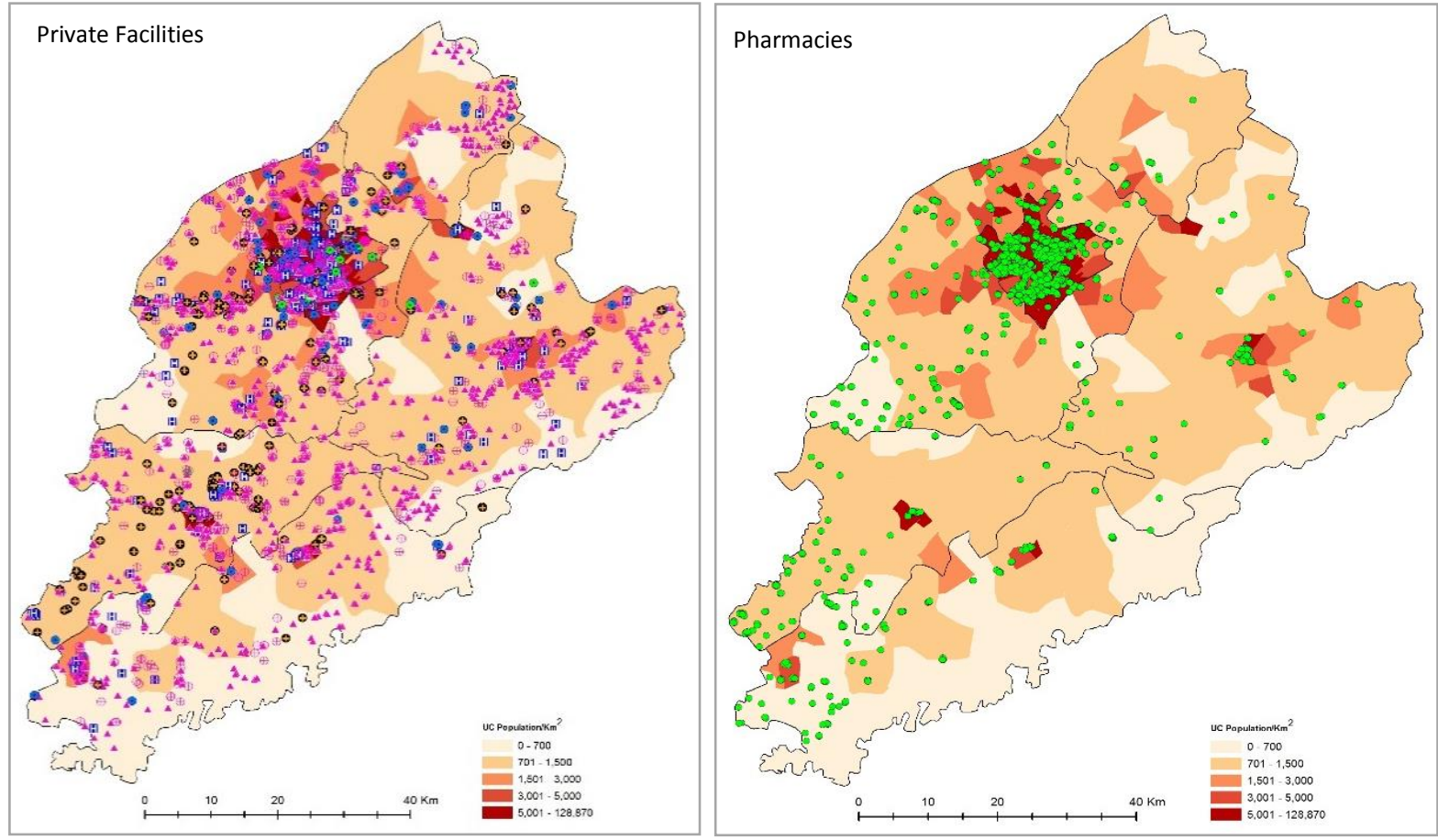

If Private Hospitals

- LHV/Nurse/Midwife Clinics

- Male Doctor Clinics

4. Dispenser Clinics

- Female Doctor Clinics

$\oplus$ Homeopath/Hakeem Clinics

\section{Provision of Specific Contraceptive Methods}

- While there is an impressive availability of condoms and oral contraceptive pills (OCPs) across the major channels in the public sector and in pharmacies, figures dip when it comes to the supply of injectables, which might have been expected to be more widely available.

- Only 10 percent of private facilities in urban areas and even less than that in the rural areas are providing a combination of condoms, OCPs, injectables, and ECPs.

- Across pharmacies, 38 percent stock condoms and 29 percent stock OCPs in rural areas, but only 17 percent carry injectables in rural areas.

- Expanding the range of methods that can be provided and is available to different cadres will enable existing channels to offer choice, which is critical aspect of expanding access.

- LHWs must be allowed to administer the first dose of injectables and carry ECPs, which would immediately increase access to these methods, due to the sheer size of this cadre.

- Male dispensers, currently not allowed to provide FP services, are distributed widely, especially in rural areas. Some way has to be devised to allow them to offer counseling and basic FP like condoms, oral OCPs, ECPs, and injectables.

- Hakeems and homeopaths are providing FP in Punjab, Sindh and KP but they can be enabled to increase the level of provision. 


\section{Quality of Care}

- The quality of FP services may be more important than physical access. It is one of the most important needs, from the client perspective, for enhancing utilization and sustained use of services.

- Although facility readiness for service provision is slightly better in the public sector, provider attitudes and behaviors towards clients are much better in the private sector, attracting clientele.

- Trainings in providing client-centered services should be an integral part of both pre- and in-service trainings, and these should equip providers with the technical capabilities and skills to counsel clients on a wide choice of methods.

- Other aspects of quality of care also need to be considered and measures taken to ensure privacy, respectful and friendly interactions, proper seating, cleanliness, and expanded timings.

\section{Supply of Contraceptives in the Public and Private Sector}

\section{Public and Private Shares in Meeting Contraceptive Needs}

- Consumers' main sources of contraceptives are pharmacies, shops, and commercial or NGO hospitals in the private sector, and LHWs and larger public hospitals in the public sector.

- Pharmacies are a key source of condoms, OCPs, and ECPs, but have a very low role in providing injectables, IUDs or implants, while shops only sell condoms.

- LHWs are major sources for all three methods in their repertoire-condoms, OCPs, and injectables.

- Public hospitals and private/NGO hospitals are the leading sources of injectables and IUDs; the former is also a major source of OCPs.

- Condoms are the only method for which we observe the expected pattern of wealthier clients preferring the private sector, and poorer clients preferring public sources; for all other methods, usage by wealth is mixed.

\section{Supply Chain for Contraceptives and Stock Outs}

- In the public sector, incidence of contraceptive stock out remains high at service delivery points (SDPs) across all sectors in Punjab, Sindh, and KP.

- Efficient distribution of commodities is hindered by: requisitioning delays; lack of arrangements for delivery from district stores to SDPs; rationing of supplies, especially in the case of LHWs; and inadequate use of electronic reporting systems, among other issues. There is some leakage to the private market.

- Ensuring that private providers have adequate stocks is a challenge across all methods, especially injectables and long-acting methods, which are less available at pharmacies and cannot be selfadministered. Distributors are generally not interested in engaging directly with service providers, except the larger facilities, so individual clinics have to be supplied through medical information officers. 
Supply of OCPs, ECPs, and Injectables in the Private Sector

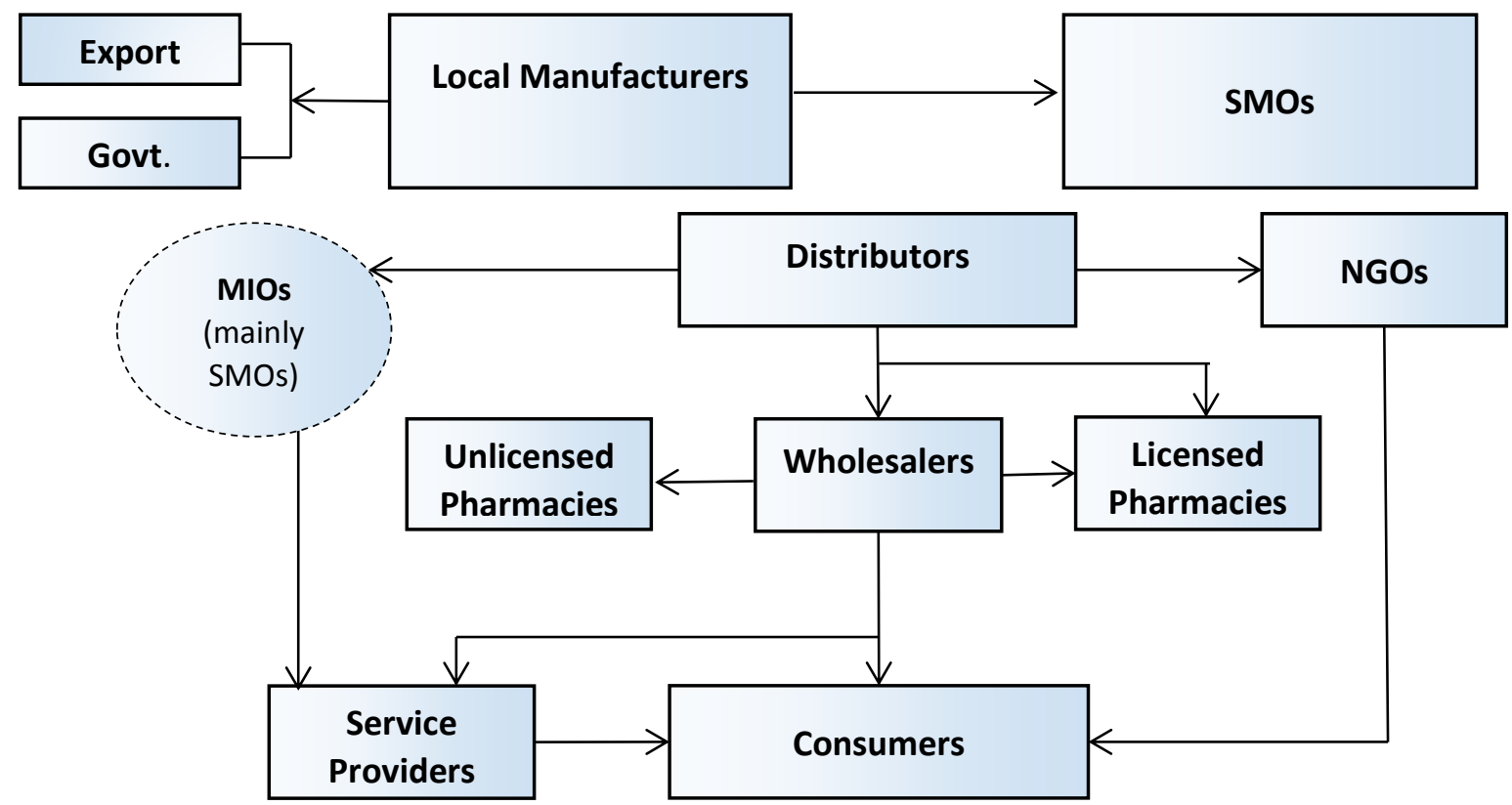

\section{Markets for Contraceptives}

- The private condom market is maturing. However, commercial importers complain it is difficult to compete against social marketing organizations (SMOs), especially due to their subsidized products and the high profit margins they offer to retailers on some brands. Some importers are unable to make adequate use of consumer goods distribution channels, restricting coverage of shops.

- In the market for OCPs, ECPs, and injectables, low demand-mainly associated with side effects-and the resultant low sales volumes are a key challenge. The need to address consumer fears about side effects is acknowledged by all, but the job is not owned by commercial or social marketing entities. One main local manufacturer claims to meet 70 percent of demand. Import of competing products is restricted, and there is a narrower range of products and pricing options.

- Private supply of IUDs and implants is mainly through SMOs or NGOs, with negligible availability at pharmacies. Demand is low, with fear of side effects perpetuated by inadequate counsel and follow up.

- Presence and sales of all contraceptive brands is lower in rural settings. Distributors are less interested because the rural market is diffused, and there are fewer licensed pharmacies and providers. Pharmacists complain of stock outs and having to purchase from wholesalers.

- While a significant proportion of pharmacists and shopkeepers still believe it is religiously impermissible to sell contraceptives, many are willing and eager to play a role in informing and counseling clients.

\section{Procurement by Provinces}

- The governments of Punjab, KP and Sindh have started procuring contraceptives, which was previously the responsibility of the Federal Government. 


\section{Policy Landscape and Scale of Donor Investments}

\section{Positive Provincial Policy Commitments}

- Post-devolution, provinces have demonstrated many positive changes to accelerate efforts to improve access to FP services:

- There is visible provincial political commitment, including from Chief Ministers, and a consensus on provincial FP2020 CPR goals;

- Provinces have in place FP-focused policies, and some have or are developing FP costed implementation plans; and

- The provincial health strategies also give due importance to delivering FP services.

\section{Need for a Focus on Policy Implementation and Coordination}

- There is, however, an urgent need to focus on implementation of the policies, including through stronger coordination mechanisms that monitor progress in policy implementation and make adjustments, as needed, to ensure achievement of policy goals, including achieving FP2020 CPR goals.

- Coordination among departments, especially PWD and DoH, is weak, which is leading to less than optimal complementarity and, at times, duplication of efforts.

\section{The Fiscal Landscape for Family Planning Is Shifting}

- While donors are supporting Pakistan and some provinces in particular in meeting their FP goals, donor investments are not currently equitably distributed among provinces, leaving some provinces with little funding for FP.

- Despite a budgetary crunch due to capping of federal funding that the provinces are to receive until 2018, through provincial bridge financing, the provinces have initiated a number of development schemes. 


\section{Location of Relevant Donor Interventions in Pakistan}

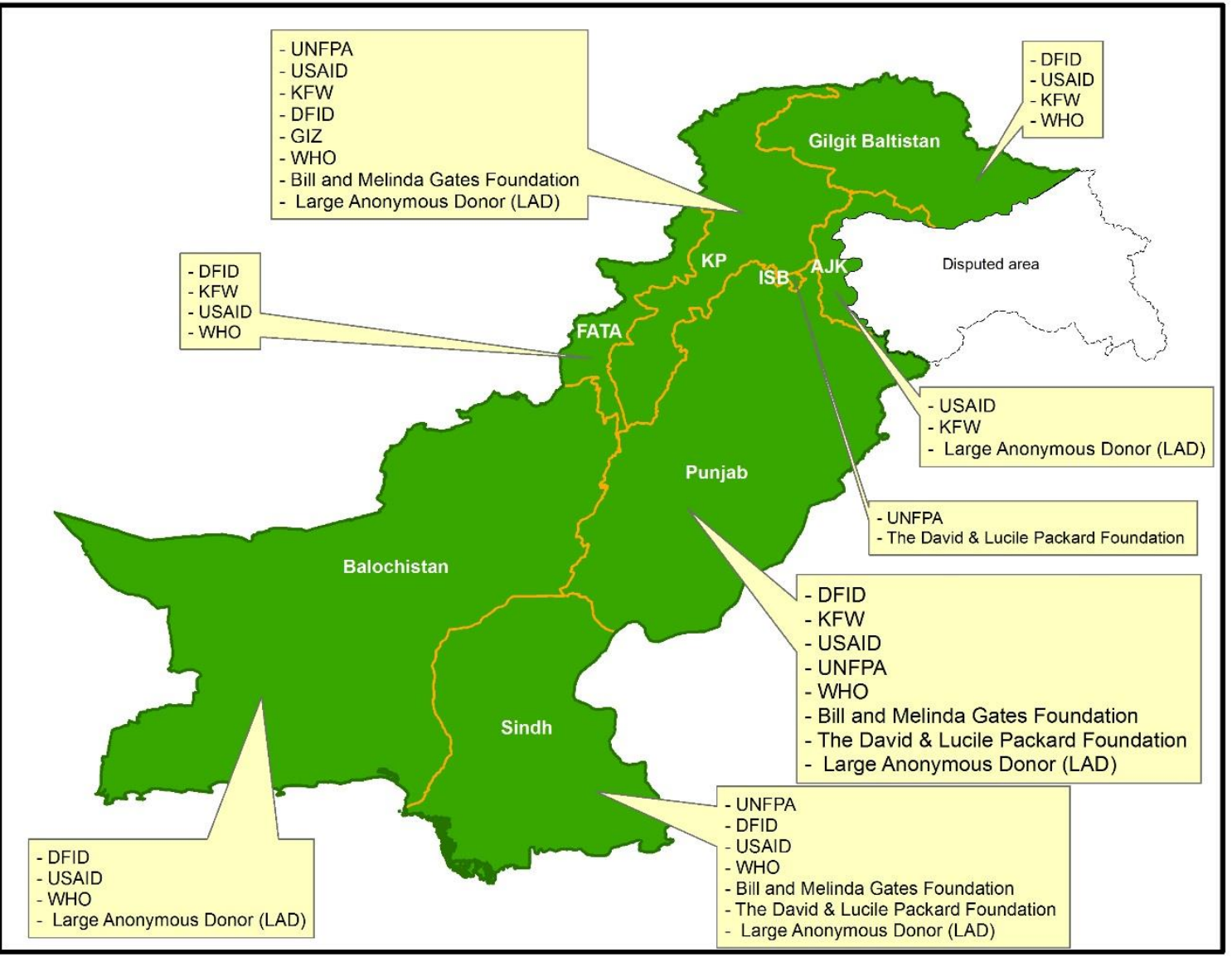

- The three major provinces are allocating more of their own resources for FP services. At the moment, the lion's share of allocations that can be utilized for FP is in the provincial Health programs.

- Very recently, the provincial population welfare programs have increased their allocations for the procurement of contraceptives, mainly for the public sector.

- Government spending on FP per capita has increased in Punjab, KP, and Sindh.

\section{Remaining Provincial Challenges}

- As the provinces accelerate efforts to reach their FP2020 goals, they face the following challenges:

- Nearly 40 percent of areas are not covered by LHWs, posing a major obstacle in achieving universal access to FP services, which will require a well thought out strategy to resolve.

- While the provincial policies acknowledge a role for the private sector in delivering FP services, mechanisms to operationalize private sector provision remain unresolved.

- Communications efforts, especially in terms of reaching out to men and youth, are weak.

- Provincial capacities need to be improved, particularly for preparing Annual Development Plans (ADPs), to secure funding for development schemes. 


\section{Recommendations}

Based on the landscape, we are proposing 13 areas of major investments for addressing demand and supply side challenges to FP in Pakistan.

1. Launch a transformative communication strategy targeting all stakeholders

2. Engage men with family planning information and services

3. Undertake youth-friendly approaches to reach the next generation with family planning information

4. Catalyze private service provision to expand access

5. Conduct implementation research and advocacy for task shifting to midlevel providers, male providers, and traditional providers to expand access as well as choice

6. Groom pharmacies as the first stop for family planning advice and counseling

7. Introduce new methods while ensuring high quality of care

8. Ensure a strong supply chain of contraceptives for the public and private sectors

9. Support commercial marketing and distribution of condoms

10. Improve quality of counseling and method provision

11. Mainstream ownership of the family planning mandate in the health system

12. Develop a multi-sectoral coordination mechanism for provincial policy implementation and underpin strategies with strong monitoring, evaluation and learning

13. Prioritize family planning at the highest policy levels and in investments

Further elaboration of these recommendations is provided in Chapter 6 of the report. 


\section{Chapter 1 Introduction}

\section{Rationale for the Study}

This report presents the findings of a landscape analysis of the family planning (FP) situation in Pakistan, which was carried out by the Population Council in 2015-2016 with the support of the Bill and Melinda Gates Foundation. The landscape analysis assesses both demand side barriers and supply side shortcomings and provides a comprehensive assessment of consumers, contraceptive service provision, contraceptive supply, and policy and regulations. The primary aim of the landscape analysis is to identify opportunities for investment, including the private sector, that could catalyze an escalation in contraceptive prevalence, enabling Pakistan to meet its FP2020 goals.

\section{Background}

Within the past year, after the $18^{\text {th }}$ Amendment and recent advocacy efforts that culminated in a landmark consensus statement by policymakers and religious leaders at the 2015 National Population Summit, the policy environment affecting FP in Pakistan has improved. Provincial governments are beginning to take more responsibility for FP, and provinces have set their own FP2020 goals; are drafting their respective population policies; and have allocated resources for purchasing contraceptive commodities beyond 2015. The federal government's rising awareness of the consequences of rapid population growth and high fertility is manifested in its allocation of additional resources for efforts to lower population growth.

Pakistan faces a number of challenges for increasing modern contraceptive use. In the last five years, there have been a few encouraging signs, such as approximately four million additional current users of contraception, and a growth in the share of male methods in the method mix, indicating men's more positive attitude towards FP. At the same time, while 55 percent of currently married women of reproductive age (WRA) have tried a FP method at some point in their lives, only 35 percent are currently using any method, and only 26 percent are using modern methods. Discontinuation rates are very high, especially for the intrauterine device (IUD) and use of hormonal female methods is either stagnant or declining. At the same time, a high level of unmet need persists, showing only a slight decrease in the last five years, and this need is not restricted to rural areas but also exists in urban areas. Meanwhile there are around 2.1 million abortions annually to avoid unwanted pregnancies.

The high abortion rate, high unmet need, increasing prevalence of traditional method use, and high discontinuation levels are signs that the market is failing consumers of modern contraception.

There is a daunting gap in service coverage in most parts of the country, including a semi-functional public health sector that is not fully responsible for FP in its service package, along with sub-optimal provision of FP in the private sector.

The landscape exercise begins with an examination of the demand-side barriers-identified from the perspectives of various segments of potential consumers, including both married men and women, and younger people-that contribute to the persistence of unmet need, high levels of discontinuation, and rising preference for the less reliable traditional FP methods. This component of the study complements the secondary data-based Consumer Profile submitted earlier to the Gates Foundation.

The analysis of demand side barriers is followed by a comprehensive assessment of service coverage within the public and private sectors in three Pakistan provinces and, specifically, eight major cities, focusing on constraints to access, limitations of contraceptive choice, other obstacles, and opportunities for expanding 
access and choice. The roles of the commercial sector, social marketing organizations, and NGOs, and the public sector in delivering FP services are explored, and the issues hindering availability of contraceptives at public and private sector service and method delivery channels are identified. The study then looks at the policy environment affecting FP, as well as the investment priorities of the governments and donors.

\section{Study Objectives}

The five objectives of the landscape exercise are to:

- Provide a comprehensive assessment of the coverage of FP services, the constraints of different segments of consumers, the limitations of contraceptive choice, particularly out of pocket costs of contraceptive methods, and opportunities to expand access and choice in the three provinces of Pakistan through a market segmented approach;

- Identify, analyze, and address supply and demand barriers both in the public and private sectors;

- Assess the market for commodities and services for FP-especially suppliers' perspectives;

- Assess the policy landscape and scale of donor investments in FP; and

- Make suggestions about future FP strategies and areas of investment in three provinces in Pakistan.

To further elaborate the objectives, the landscape analysis included six components:

1. Consumers: Construct a profile of consumer demand for FP, including barriers and facilitators to increasing demand.

2. Contraceptive Methods: Analyze current method mix, potential for shifting method mix, and the service channels that do, or could, provide those methods.

3. Contraceptive Method Pricing: Document cost to consumers of each product in the public and private sectors, assess people's willingness to pay for those services, and cost barriers to FP.

4. Contraceptive Marketing: Analyze the method-specific facilitators and barriers to marketing of contraceptive products.

5. Contraceptive Service Provision: Map and analyze the current main service and method delivery channels and describe their potential for growth.

6. Regulation, Policy, and Donor Coordination: Describe the policy, regulation, and donor environment as it impacts and curtails contraceptive use, marketing, and service delivery.

\section{Methodology}

This landscape analysis was carried out in 2015-2016 in eight districts of three provinces of Pakistan, including Peshawar in Khyber Pakhtunkhwa (KP); Rawalpindi, Faisalabad, Lahore, and Multan in Punjab; and Sukkur, Hyderabad and Karachi in Sindh. The landscape analysis focused on eight cities-Peshawar, Rawalpindi, Faisalabad, Lahore, Multan, Hyderabad, Sukkur, and Karachi. In addition, we conducted investigations at one town and one rural location within one district in each province, specifically, Peshawar, Faisalabad, and Sukkur, and the availability of FP services was mapped in its entirety in these three districts. A total of 14 locations were thus studied for a comparative perspective. These are shown in Figure 1.1. 
Figure 1.1: Locations Covered Under Landscape Assessment

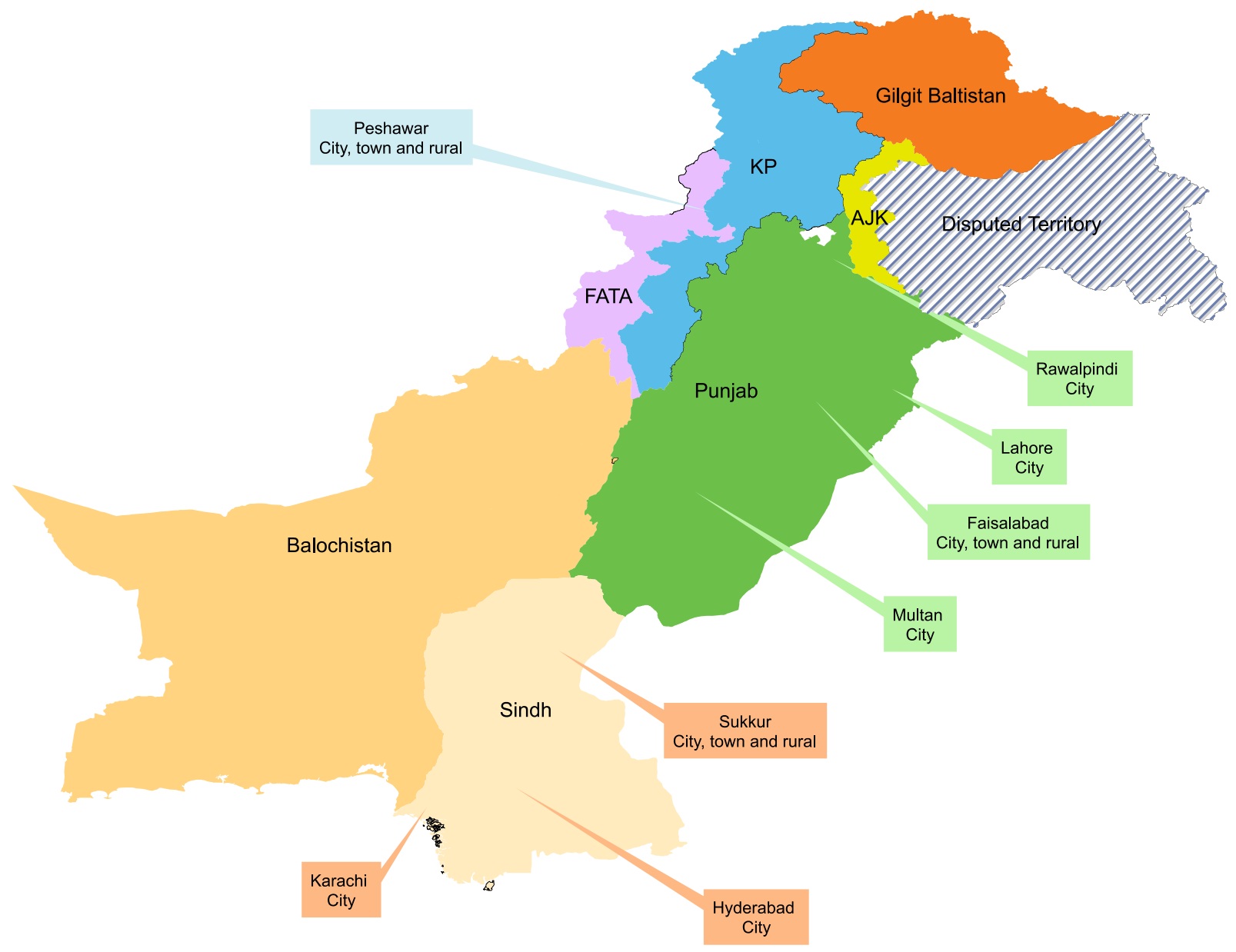

To meet the objectives of the landscape analysis and to provide evidence for the six components listed above, multiple forms of data collection and secondary analysis were undertaken, including:

- Secondary data analysis,

- Qualitative study of consumer demand for FP,

- Mapping and assessment of health facilities,

- Qualitative study of contraceptive supply in the private sector, and

- Review of the policy environment and donor mapping.

The methodology adopted in each component study is outlined in the following sections.

Secondary data analysis: This analysis included data from the Pakistan Demographic and Health Survey (PDHS) data series, Pakistan Social and Living Standards Measurement Survey (PSLMS) 2014-15 and Multiple Indicator Cluster Survey (MICS) Punjab and Sindh (2014). Exhaustive analysis of data provided a complete background for understanding the FP situation in Pakistan, particularly from the consumers' perspective, in terms of preference and behaviors surrounding current use, discontinuation and unmet need for spacing and limiting, sources of contraceptive methods, and method use by different segments of consumers by province, residence, wealth, education, and other demographic characteristics. 
In addition, a number of recent Population Council studies concerning FP were covered in the analysis:

- The Availability and Quality of FP Services across Eight Districts in Pakistan: The Potential and the Constraints

- Investigating the Low Patterns of Modern Contraceptives Use in Pakistan

- Birth Spacing and FP Uptake in Pakistan: Evidence from FALAH

- Role of Private Sector in Delivering Birth Spacing Services in FALAH Districts

- Post-Abortion Care in Pakistan: A National Study

The secondary data analysis has been documented in a separate report, Consumer Demand for FP in Pakistan: Review of Secondary Data-Landscape Analysis of FP Demand and Delivery in Selected Areas of Pakistan (2015).

Qualitative study on consumer demand for FP: A comprehensive qualitative study was conducted based on in-depth interviews (IDIs) and focus group discussions (FGDs) with married men and women and single youth, including both school-going and out-of-school girls and boys. The purpose of the study was to extend and deepen the consumer profile developed during the secondary analysis, and further probe demand for FP, current and potential consumers' social networks and communication channels, barriers of different segments of consumers, including financial barriers, and to collect consumers' receptivity to the relatively new methods, specifically, the Standard Days Method (SDM), Sayana ${ }^{\circledR}$ Press, implants, and emergency contraceptive pills (ECP). In addition, assessment of youth perspectives on FP and how youth should be involved in communication programs, was a unique feature of the study.

The qualitative study covered all 14 study locations, with 257 IDIs and 84 FGDs conducted with 1,013 respondents, including men, women and youth. For data collection, facilitation was sought from a variety of channels, such as the health and population welfare departments and NGOs in the study area.

IDIs and FGDs with men and women: IDIs with currently married men and women (not couples) focused on their method-specific use as current and past users; a few males never users were also interviewed to identify reasons underlying non-use and unmet need. The main purpose of the IDIs was to learn about method-specific experiences of different segments of users in terms of access, sources, role of influencers in making the decision to use a particular method, side effects, management of side effects, cost, etc. FGDs were conducted separately with men (166 men participated in 20 FGDs) and women (213 women participated in 22 FGDs) at community level from cities and rural and town areas. These discussions were conducted to understand community preferences and perceptions about existing as well as new FP methods.

FGDs with boys and girls: Breaking the mold of previous studies in Pakistan that focus on married women and men, the study also sought the perspectives of single young people (aged 16 to 20 years), including school-going as well as out-of-school boys and girls, to explore the perspectives of these future potential users on FP. A total of 206 girls and 171 boys participated in 22 and 20 FGDs, respectively.

Table 1.1: Number of IDIs and FDGs by location

\begin{tabular}{|c|c|c|c|c|c|c|c|c|c|c|}
\hline & & Faisalabad & Multan & Lahore & Rawalpindi & Peshawar & Karachi & Sukkur & Hyderabad & Total \\
\hline \multirow{2}{*}{$\underline{0}$} & Women & 33 & 23 & 18 & 6 & 49 & 26 & 34 & 0 & 189 \\
\hline & Men & 14 & 6 & 12 & 3 & 13 & 7 & 13 & 0 & 68 \\
\hline \multirow{4}{*}{$\begin{array}{l}\text { D̃ } \\
\text { ن }\end{array}$} & Women & 4 & 2 & 4 & 2 & 4 & 1 & 4 & 1 & 22 \\
\hline & Men & 4 & 1 & 4 & 1 & 3 & 2 & 4 & 1 & 20 \\
\hline & Girls & 4 & 3 & 3 & 1 & 4 & 2 & 3 & 2 & 22 \\
\hline & Boys & 4 & 2 & 2 & 1 & 4 & 2 & 3 & 2 & 20 \\
\hline
\end{tabular}

Findings of this study are presented in Chapter 2 of this report. 
Mapping and assessment of health facilities: This study used a questionnaire, based on a hand held device, to assess the numbers and locations of FP services in Faisalabad, Sukkur, Peshawar and three towns of Lahore (Samanabad, Data Gunj Bakhsh, Shalimar). A total of 12,496 interviews were conducted under this huge exercise. The exercise was essentially a census of health facilities $(7,180)$ and pharmacies $(5,316)$ available in the districts to analyze their status in terms of providing FP services in both public and private sectors. The presence of LHWs was mapped, though these workers were not interviewed in these districts. Information about facility timings, amenities, staff availability, stock availability and its sources, readiness of health facilities and service providers to provide FP services was also collected. The primary aim of this undertaking was to examine the availability of FP services and the potential to expand coverage further.

The Population Council used Android-based mobile devices to collect data through face to face interviews with healthcare providers and pharmacists. Data collection through mobile devices provided instant access to data being collected in the field to study manager, and greatly helped in monitoring the field to improve data quality. Since data uploading was instant, the online monitoring of the data and movement of the field teams helped in ensuring speed and quality of data collection. Data was downloaded and exported into Excel for initial cleaning, etc., and then exported to SPSS for detailed analysis.

\section{Table 1.2: Number of Public/Private Facilities and Pharmacies Covered in the Four Study} Districts*

\begin{tabular}{lrrrrr}
\hline Sector & Faisalabad & Lahore & Peshawar & Sukkur & \multicolumn{1}{c}{ Total } \\
\hline DoH & 106 & 75 & 55 & 90 & 326 \\
PPHI/PRSP & 177 & - & 52 & 30 & 259 \\
PWD & 86 & 23 & 63 & 44 & 216 \\
LHWs** & 2246 & 225 & 863 & 887 & 4221 \\
Private & 3906 & 1355 & 628 & 490 & 6379 \\
Pharmacies & 1945 & 819 & 2175 & 377 & 5316 \\
\hline
\end{tabular}

* Mapping and assessment of health facilities was not carried out in the districts of Rawalpindi and Hyderabad

**LHWs are located and not interviewed.

Chapter 3 presents the findings of this extensive study.

Apart from this recent assessment of health facilities, the Population Council has also conducted this exercise in 35 other districts of Pakistan, including Karachi and Multan. Data for these two districts are presented in the district profiles developed under this landscape assessment. The assessment in Karachi was conducted in seven towns during 2009 and 2010, covering a total of 3,995 health facilities including Gadap Town (802 facilities), Lyari Town (395 facilities) and Orangi Town (767 facilities), Gulberg Town (376 facilities), Liaqatabad Town (549 facilities), North Karachi Town (596 facilities) and North Nazimabad (510 facilities). The exercise in Multan district was conducted in 2010, covering 6,465 health and reproductive health $(\mathrm{RH})$ facilities.

Qualitative study of contraceptive supply in the private sector: This study was carried out in Lahore, Faisalabad, Karachi, Sukkur, and Peshawar. Qualitative in-depth interviews were conducted to seek insights about the availability of contraceptive products and their supply flows and constraints. In particular, this study focused on the less known private sector contraceptive supply system.

A total of 186 IDIs with providers were conducted to assess supply of contraceptives as well as their stated constraints and bottlenecks. Interviews were conducted with representatives of nine major contraceptive importers, manufacturers, and social marketing organizations; 10 major distributors and 18 wholesalers; 
and owners or staff at 24 pharmacies, 24 general stores, and 22 paan shops (kiosks), including outlets that were selling contraceptives as well as those that were not.

Since service providers are a crucial link for exerting a "pull" for contraceptive products in the private sector, 25 male and female doctors, 18 Lady Health Visitors (LHVs), 16 dispensers, and 20 hakeems and homeopaths were also interviewed, including providers as well as non-providers of FP services.

Tables 1.3 and 1.4 present the numbers of IDIs conducted during the study by location and respondent. Chapter 4 presents the findings of the study.

Table 1.3: Number of IDls with Private Stakeholders in Contraceptive Supply

\begin{tabular}{lcccccc}
\hline Respondent & Faisalabad & Lahore & Peshawar & Sukkur & Karachi & Total \\
\hline Manufacturer/ Importer/SMOs/NGOs & - & 1 & - & - & 8 & 9 \\
Distributer & 2 & 2 & 2 & 2 & 2 & 10 \\
Wholesaler & 4 & 4 & 4 & 4 & 2 & 18 \\
Pharmacy & 6 & 2 & 6 & 8 & 2 & 24 \\
General store & 6 & 4 & 6 & 6 & 2 & 24 \\
Paan shop & 4 & 2 & 6 & 6 & 4 & 22 \\
Total & 22 & 15 & 24 & 26 & 20 & 107 \\
\hline
\end{tabular}

Table 1.4: Number of IDIs with Private Service Providers

\begin{tabular}{lcccccc}
\hline Respondent & Faisalabad & Lahore & Peshawar & Sukkur & Karachi & Total \\
\hline RMP (male) & 4 & 1 & 4 & 3 & 1 & 13 \\
RMP (female) & 2 & 1 & 3 & 3 & 3 & 12 \\
LHV & 4 & 2 & 4 & 4 & 4 & 18 \\
Dispenser & 4 & 2 & 4 & 4 & 2 & 16 \\
Hakeem/Homeopath & 6 & 2 & 6 & 4 & 2 & 20 \\
Total & 20 & 8 & 21 & 18 & 12 & 79 \\
\hline
\end{tabular}

Review of the policy environment and donor mapping: This exercise was conducted to identify policy and programmatic gaps and map donor investment in Pakistan. The analysis of the policy environment examines the current FP policy with regards to the Health and Population sectors, existing legislation to improve the health and wellbeing of women and families, and the regulations being applied to standardize public private sector services. The analysis commenced with a desk review of population and health policies and strategies; growth strategies, vision documents, and related road maps; relevant legislation; relevant reports and publications. This review was followed by qualitative interviews with key stakeholders, including senior policy makers, representatives of donors, development partners, and NGOs, commercial sector representatives, government officials, program managers, etc. (A complete list of the 41 stakeholders interviewed is presented in Appendix 1.)

The donor mapping activity was carried out to identify the major donors who are working in Pakistan in the area of RH and FP and to geographically map the major projects and activities being implemented in each 
province and district. The methodology included a desk review of existing donor profiles developed by UN agencies and information available on donors' websites. This helped identify and list those donor organizations with a social sector mandate. These organizations were then approached and the existing information was verified and expanded through face-to-face and telephonic interviews. A pro forma questionnaire was also sent out that was duly filled in by the relevant representatives of the development partners to get information about their existing donor supported projects, the thematic focus being pursued in the area of FP and $\mathrm{RH}$, the geographical areas by province where they are working, a brief description of the project activities, implementing partners (if any), and the total budget allocated.

Findings of the policy analysis and donor mapping activity are presented in Chapter 5 of this report. 


\section{Chapter 2 \\ Use of Family Planning: Barriers and Potential for Growth among Different Consumer Segments}

It is estimated that Pakistan's population of 191 million currently includes 48.2 million women of reproductive age ( 15 to 49 years old), of whom 31 million are currently married. This number, which virtually represents the total potential FP market, has increased from 24.4 million in 2007 (Population Council projections 2015).

At present, the majority of currently married women of reproductive age (WRA) are not using any FP method. Pakistan's contraceptive prevalence rate (CPR) is 35.4 percent, including users of modern contraceptive methods (26.1\%) and of traditional methods (9.3\%). The remaining 64.6 percent of currently married WRA are non-users, though not always by choice; according to the Pakistan Demographic and Health Survey (PDHS) 2012-2013, 20.1 percent of currently married WRA have unmet FP need. In other words, of the 31 million currently married WRA in Pakistan, eight million are using modern contraceptives, 2.9 million are using traditional FP methods, and an additional 6.2 million WRA have unmet FP need.

Figure 2.1 shows that, between 2007 and 2015, the number of current users of contraception in the country rose by 3.7 million, with 2.7 million women adopting modern FP methods, and another 1 million joining the pool of traditional method users. However, a larger number of users -4.9 million-had tried to use FP during this period. The 1.2 million women who did not continue use joined the ranks of past users, which swelled from 4.7 to 6 million. Meanwhile, the number of women with unmet need declined by only about half a million women.

Figure 2.1: Estimated Numbers of Currently Married Women in Pakistan by Never, Ever, Past, and Current use of Contraceptives and Unmet Need, 2007 and 2015

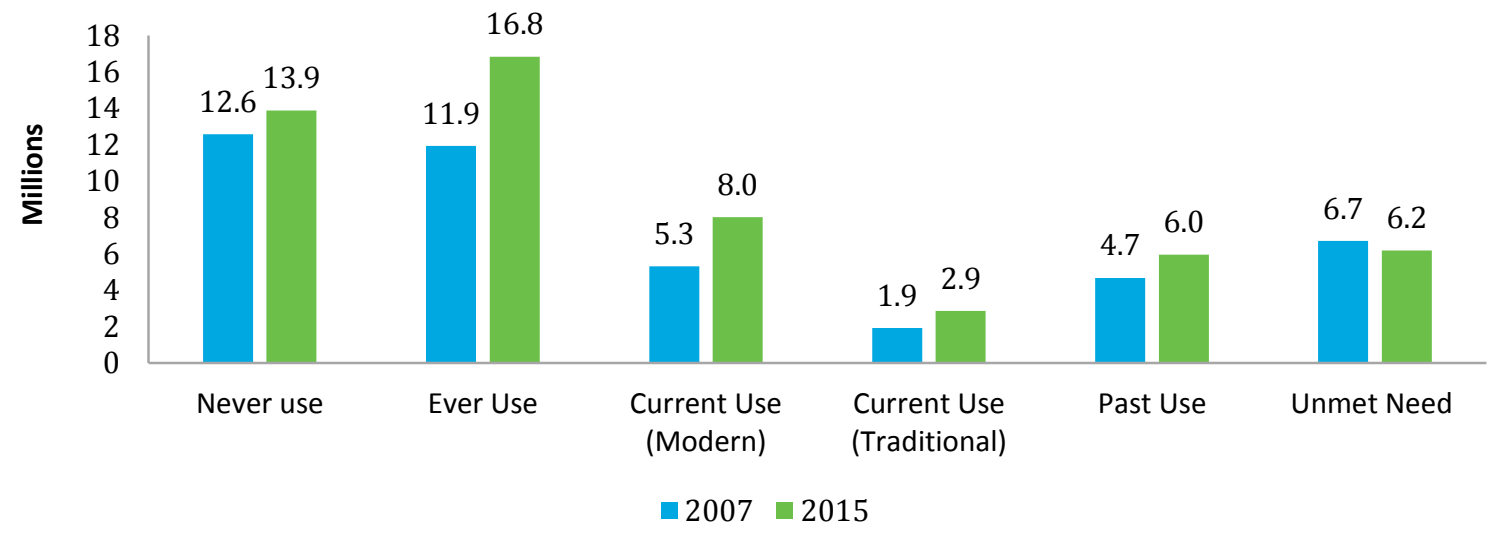

Source: PDHS 2006-07 \& 2012-13, Population Council Revised Population Projections

In percentage terms, current use of both modern and traditional methods has increased, and unmet need has declined by about 5 percentage points, despite an increase in the number of currently married WRA (Figure 2.2). Never use has also declined as ever use has risen, indicating that a rising proportion of women is giving FP a try. However, the proportion of past users has crept upwards, which means the trend of discontinuation remains strong, steadily offsetting the gains achieved in taking new users on board and reducing unmet need. 
Figure 2.2: Percentage of Currently Married Women in Pakistan by Never, Ever, Past and Current Use of Contraceptives and Unmet Need, 2006-07 and 2012-13

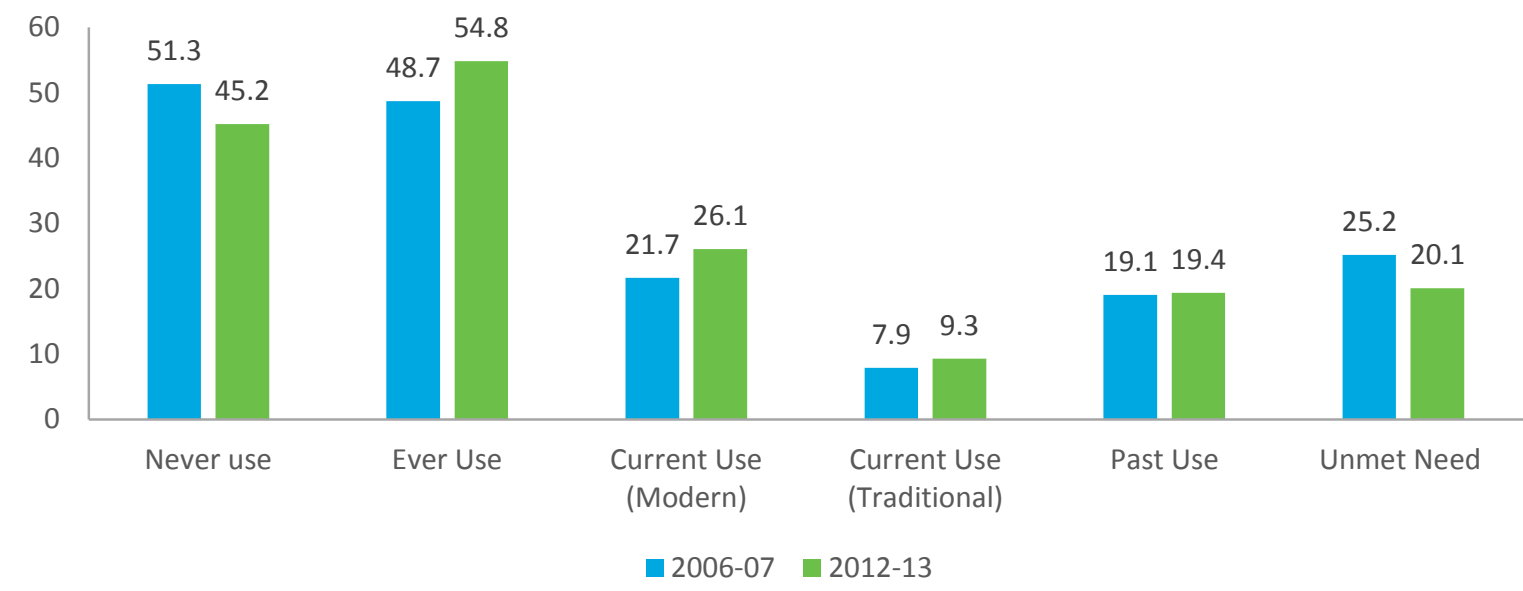

Source: PDHS 2006-07 and 2012-13

The persistence of unmet FP need, combined with fairly high willingness to try FP at least once (demonstrated by growing ever use) and a consistently high rate of discontinuation (demonstrated by the stable rate of past use), raises many questions about the factors that motivate couples to try FP and persuade some of them to stay in the market as users while compelling others to discontinue prematurely. To answer these questions, and better understand the potential for expanding the FP market, this study segmented consumers by their use status into 1 ) current users, 2) never users, and 3) past users, and then looked within each segment at the form and extent of unmet need; the profile of potential users; and the barriers hindering them from meeting their FP need. In view of the persistent high levels of discontinuation, current users and the challenges they experience in continuing the use of modern methods are also explored. This is followed by a discussion of the measures men and women say should be taken to help them adopt-and maintain use of-modern contraceptive methods. In the end, the section touches on receptivity to FP among the next generation of consumers-the youth-and the ways in which they would like to be equipped with information for future FP use.

\section{Assessing Unmet Need among Past, Never, and Current Users}

As mentioned, among the 31 million currently married WRA in Pakistan, 35.4 percent are current FP users, 19.4 percent are past users, and 45.2 percent are never users. Both past users and never users can be further divided into two categories: women with unmet FP need, and women not interested in FP. Those who have unmet need, whether past users or never users, are potential users inasmuch as they do not require convincing to adopt FP; they are, so to speak, the low-hanging fruit of the FP market. A third category of potential users is comprised of current users of traditional methods, who could be persuaded to shift to the more reliable modern contraceptive methods to meet their FP needs.

Figure 2.3 shows the relative proportions of these consumer segments. The potential segments-never users with unmet need, past users with unmet need, and current users of traditional methods-comprise 10.2 percent, 9.9 percent, and 9.3 percent respectively, i.e., 29.4 percent collectively, of currently married WRA. 
Figure 2.3: Growth Potential among Current, Past and Never Users of FP in Pakistan

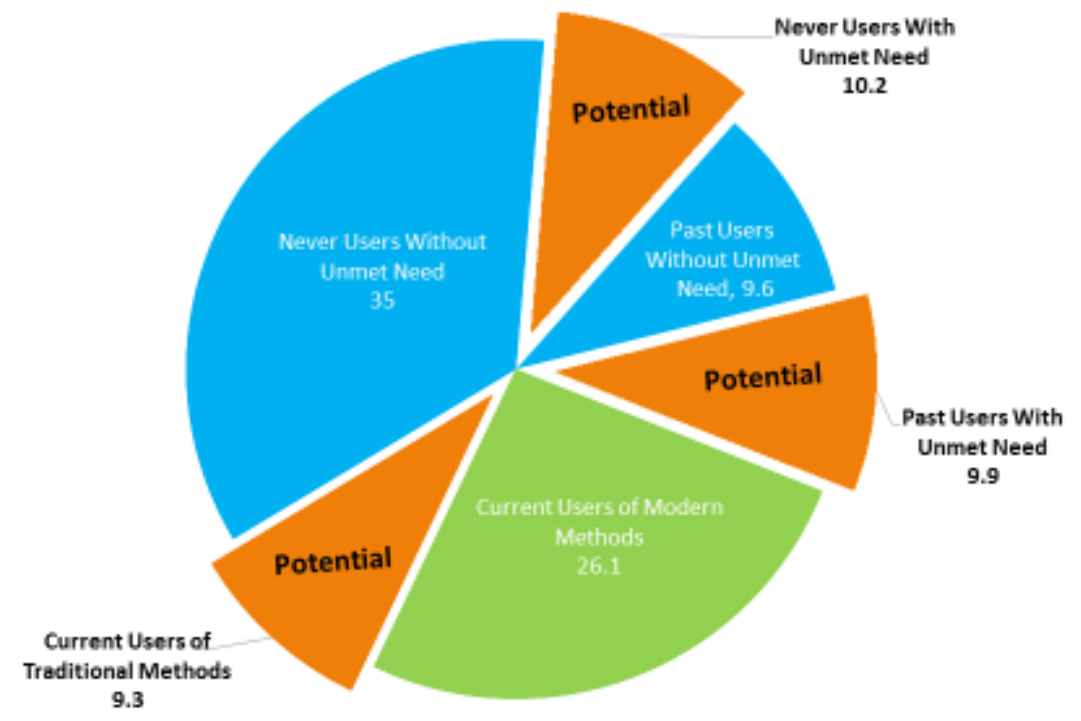

Source: Pakistan Demographic and Health Survey 2012-13

In number terms, as shown in Figure 2.4, potential consumers include 3.1 million never users with unmet need, 3.0 million past users with unmet need, and 2.9 million current users of traditional methods. Adding these 9 million potential users would more than double the current number of modern contraceptive users (from the present 8 million), and raise the national modern contraceptive prevalence rate (mCPR) to 55.5 percent.

Figure 2.4: Number of Potential Users of Modern Contraceptives among Current, Past, and Never Users
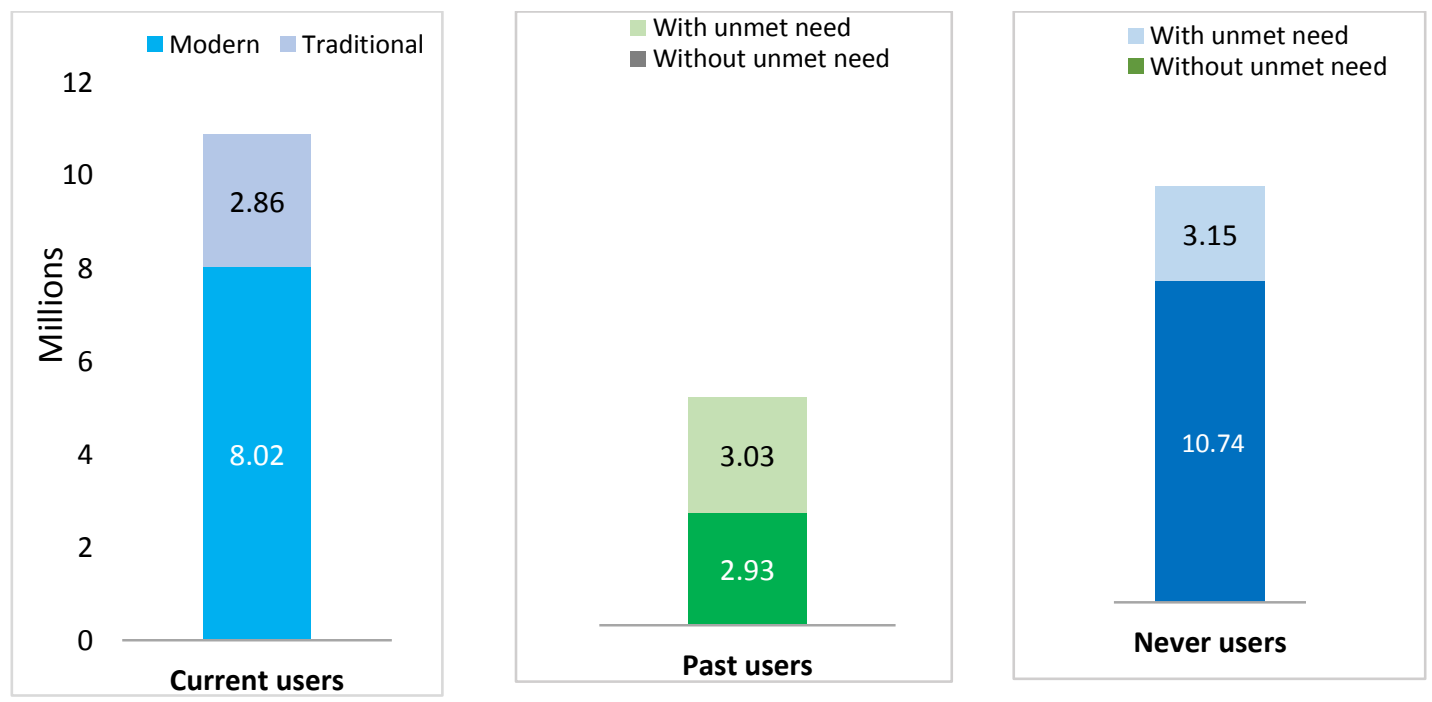

Source: Pakistan Demographic and Health Survey 2012-13 


\section{Where Potential Users Reside}

The majority-65 percent-of Pakistan's population resides in rural areas, and this pattern is reflected among potential users (Figure 2.5). Calculations for each consumer segment suggest that, out of the 9 million potential users, about 6 million live in rural areas, including 2.4 million never users with unmet need, 2 million past users with unmet need, and 1.6 million current users of traditional method users. The remaining three million potential users reside in urban areas, and here the relative sizes of the potential segments are reversed, with current users of traditional methods comprising the majority (1.2 million), followed by past users with unmet need ( 0.9 million), and never users with unmet need comprising the smallest potential segment (0.7 million).

Figure 2.5: Potential Users of Pakistan by residence

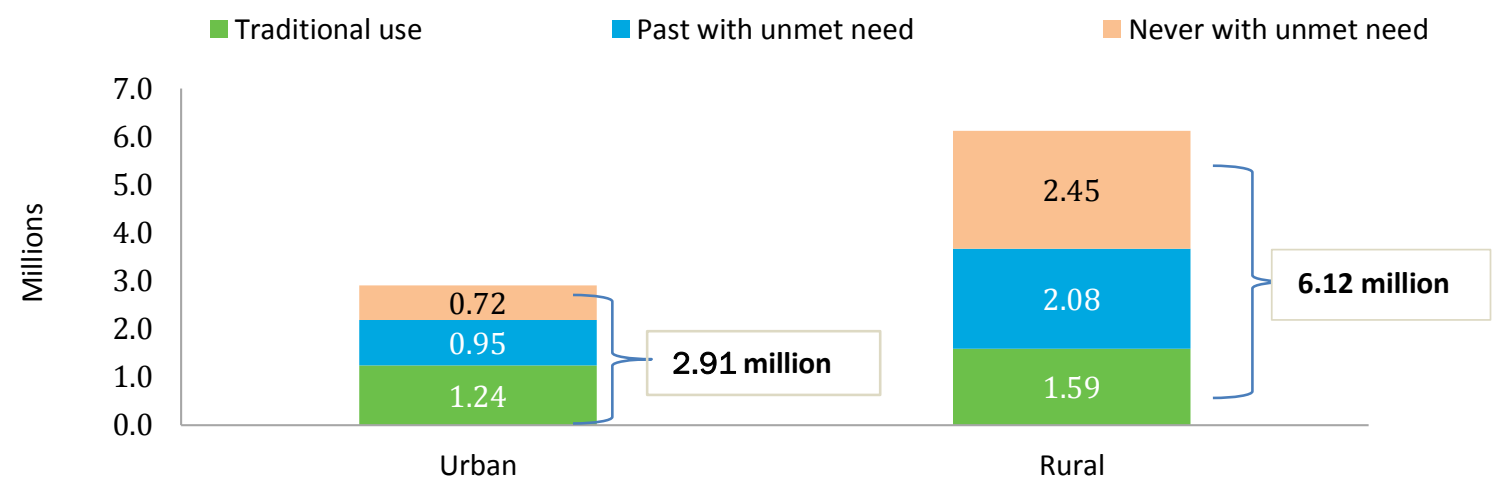

Source: Pakistan Demographic and Health Survey 2012-13

Notably, in terms of numbers, the pool of potential users also mirrors other dominant demographic features of the national population: the majority live in Punjab (home to 57 percent of Pakistanis), are 25-29 years old, and have no education.

\section{Motivation for Using Family Planning}

A number of ideational factors underlie the desire to use FP among potential users, and the dominant factors and their intensity varies by across districts and urban and rural areas, as shown in Table 2.1.

Economic pressure is a common, and strong ideational factor that makes men and women from all segments amenable to birth spacing and limiting. The media is also a common positive influence across all segments, although it is not as strong a factor as inflation.

In rural areas, the presence of and visits from LHWs constitute a strong factor affecting the perspectives of men and women about FP. LHWs have gained huge respect and trust of communities and are a major source of birth spacing methods in rural areas.

Female education and involvement in economic activity are further factors that are positively associated with FP among educated and uneducated women, and poor and middle income segments, and in major cities such as Lahore, Sukkur and Karachi. In addition, in Peshawar and Karachi, the provision of FP information and services by NGOs also influences couples' FP behavior.

In urban and rural Peshawar, religion exerts a negative influence on perspectives of men and women on FP, mainly due to limited knowledge, which results in confusion regarding the permissibility of FP in Islam. 
Table 2.1: Ideational Factors Influencing the Views of Men and Women on FP, by Location

\begin{tabular}{|c|c|c|c|c|c|c|c|c|c|}
\hline & $\begin{array}{l}\text { Faisalabad } \\
\text { rural }\end{array}$ & $\begin{array}{c}\text { Faisalabad } \\
\text { urban }\end{array}$ & $\begin{array}{c}\text { Multan } \\
\text { urban }\end{array}$ & $\begin{array}{l}\text { Lahore } \\
\text { urban }\end{array}$ & $\begin{array}{l}\text { Peshawar } \\
\text { rural }\end{array}$ & $\begin{array}{c}\text { Peshawar } \\
\text { urban }\end{array}$ & $\begin{array}{l}\text { Sukkur } \\
\text { rural }\end{array}$ & $\begin{array}{l}\text { Sukkur } \\
\text { urban }\end{array}$ & $\begin{array}{c}\text { Karachi } \\
\text { urban }\end{array}$ \\
\hline \multicolumn{10}{|l|}{ Ideational Factors } \\
\hline LHWs role & 1 & 3 & 3 & 3 & 1 & 1 & 1 & 2 & 3 \\
\hline NGO role & 3 & - & - & - & - & 2 & 3 & 3 & 1 \\
\hline Media & 2 & 2 & 2 & 2 & 2 & 2 & 2 & 2 & 2 \\
\hline Female education & - & 2 & - & 2 & - & - & - & - & - \\
\hline $\begin{array}{l}\text { Female } \\
\text { employment }\end{array}$ & - & - & - & 2 & - & - & - & 2 & 2 \\
\hline $\begin{array}{l}\text { Effort to follow } \\
\text { better off people }\end{array}$ & - & - & - & 3 & - & - & - & 3 & - \\
\hline $\begin{array}{l}\text { Unemployment of } \\
\text { men }\end{array}$ & - & - & - & - & - & - & - & 2 & - \\
\hline Increasing inflation & 1 & 1 & 1 & 1 & 1 & 1 & 1 & 1 & 1 \\
\hline $\begin{array}{l}\text { Religion (negative } \\
\text { influence) }\end{array}$ & - & - & - & - & 2 & 2 & - & - & - \\
\hline
\end{tabular}

The key life points at which men and women feel most driven to adopt FP vary across different segments. Young, urban couples are more likely to delay the earlier pregnancies. Delaying the first pregnancy is very uncommon and only a few cases were observed in the major cities of Punjab. However, the birth of the first child frequently triggers use among young urban couples in KP, Punjab, and Sindh. In rural areas, use is more likely to commence after two children among young couples.

Onset of women's health problems and economic problems are two major life points at which use of FP may be initiated. Economic concerns are the more dominant point for urban couples, while health concerns are a more significant life point among rural couples. In urban areas, economic pressure is more intense than in rural areas due to house rentals, high education expenses etc.; for poor urban couples, meeting basic expenses can become a main challenge, while among middle income couples, economic challenges may manifest more as the need to provide better educational and other life opportunities to their children.

Health concerns that can trigger FP use include severe health conditions, delivery through C-section, complicated delivery, experience of unwanted pregnancy, and repeated pregnancies.

"After the birth of our first child, we could not afford the expense of more children and decided to adopt birth spacing, using injectables." Female, Multan city

"After my first child was born, the doctor advised us to delay the next pregnancy because my wife was weak...I followed his advice and decided to use condoms." Male, Karachi city

Increase in family size to three to four children is a key life point for all segments (except people with son preference) across all study locations. Couples are much more highly motivated to use FP after three to four children due to economic pressures and health concerns. At this stage, everyone tries to use some FP method, whatever their income level, age, education status, and residence. 
Table 2.2 indicates the frequency with which different life points were reported as most likely to trigger FP use by consumers across districts and residence.

Table 2.2: Key Life Points at which FP Use may Commence, by Location

\begin{tabular}{|c|c|c|c|c|c|c|c|c|c|}
\hline & $\begin{array}{c}\text { Faisalabad } \\
\text { rural }\end{array}$ & $\begin{array}{c}\text { Faisalabad } \\
\text { urban }\end{array}$ & $\begin{array}{c}\text { Multan } \\
\text { urban }\end{array}$ & $\begin{array}{c}\text { Lahore } \\
\text { urban }\end{array}$ & $\begin{array}{l}\text { Peshawar } \\
\text { rural }\end{array}$ & $\begin{array}{c}\text { Peshawar } \\
\text { urban }\end{array}$ & $\begin{array}{c}\text { Sukkur } \\
\text { rural }\end{array}$ & $\begin{array}{c}\text { Sukkur } \\
\text { urban }\end{array}$ & $\begin{array}{c}\text { Karachi } \\
\text { urban }\end{array}$ \\
\hline $\begin{array}{l}\text { After } \\
\text { marriage }\end{array}$ & - & 3 & - & 3 & - & - & - & - & - \\
\hline $\begin{array}{l}\text { After one } \\
\text { child }\end{array}$ & 3 & 2 & 2 & 1 & 2 & 1 & 3 & 2 & 1 \\
\hline 2 Children & 2 & 1 & 1 & 1 & 1 & 1 & 2 & 1 & 1 \\
\hline $\begin{array}{l}3-4 \\
\text { children }\end{array}$ & 1 & 1 & 1 & 1 & 1 & 1 & 1 & 1 & 1 \\
\hline $\begin{array}{l}\text { Women } \\
\text { health } \\
\text { concerns }\end{array}$ & 1 & 2 & 1 & 2 & 1 & 2 & 1 & 2 & 2 \\
\hline $\begin{array}{l}\text { Economic } \\
\text { concerns }\end{array}$ & 2 & 1 & 2 & 1 & 2 & 1 & 2 & 1 & 1 \\
\hline $\begin{array}{l}\text { Unwanted } \\
\text { pregnancy }\end{array}$ & - & 3 & 3 & 2 & - & - & - & 3 & 2 \\
\hline Abortion & - & - & - & 2 & - & - & - & 3 & 2 \\
\hline
\end{tabular}

1 = High, $2=$ Medium, 3= Low 


\section{Profiles of Potential Users-and Their Barriers}

The above sections have looked at the overall proportion and numbers of potential FP users, and outlined the main factors motivating them to adopt FP. In this subsection, the three segments of potential usersnever users with unmet need, past users with unmet need, and current users of traditional methods-are profiled in further depth, followed by an examination of the obstacles that hinder the conversion of their need for FP into actual use of modern contraceptive methods.

\section{Never Users with Unmet Need}

\section{Profile}

Figure 2.6 shows the percentage distribution of never users with unmet need by different background characteristics. The presence of this category of potential users is higher in rural areas than in urban areas; by province, they are most concentrated in Sindh, followed by KP and Punjab. Never users with unmet need are more likely to be among the poorest consumers and to have no education; their proportion decreases steadily with increasing levels of education. Never users with unmet need are more likely to be young (1524 years) and have one to two children.

Figure 2.6: Percent Distribution of Currently Married Women Who Are Never Users with Unmet Need by Background Characteristics

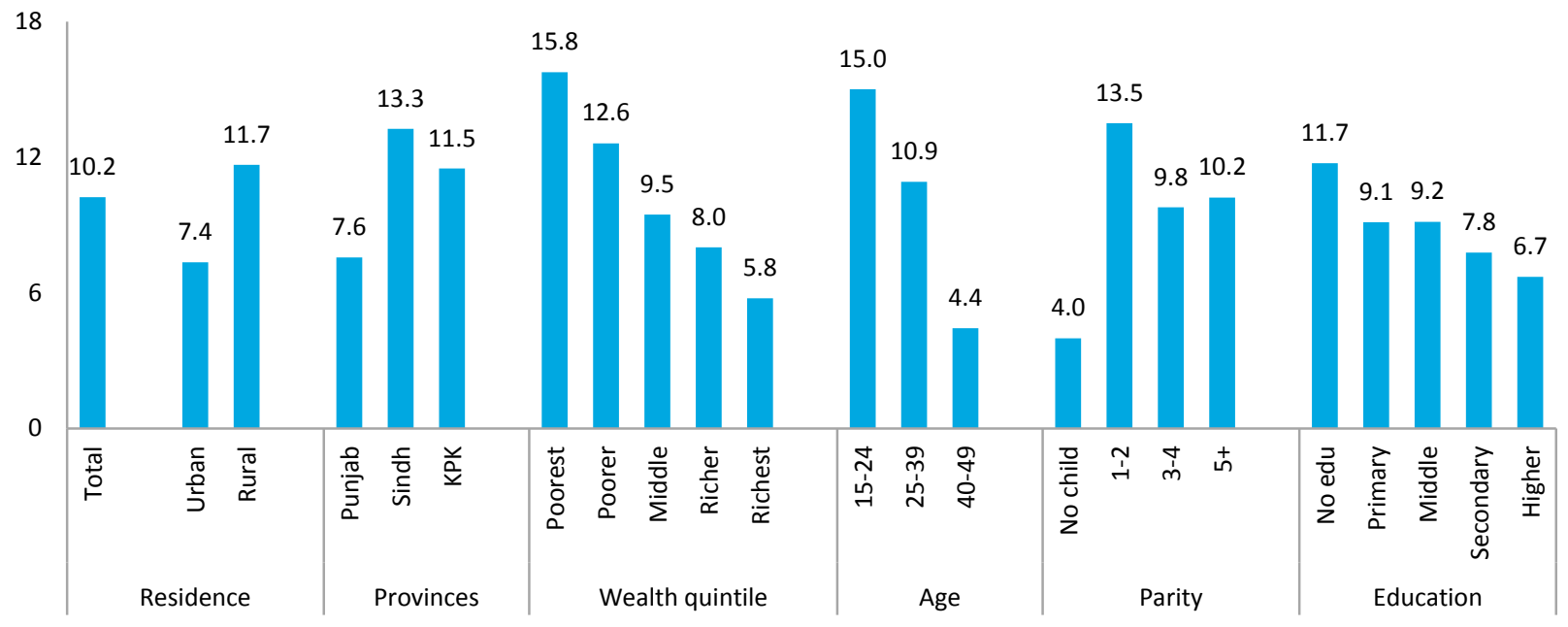

Source: Pakistan Demographic and Health Survey 2012-13

Numbers of never users with unmet need (Figure 2.7) present a slightly different picture, the main differences relating to distribution by province and age. The number of never users with unmet need is highest in Punjab (due to the high population concentration in the province) and among young to middle aged women ( 25 to 39 years old). On other demographic variables, such as residence, wealth, parity, and education, numbers reflect the same picture as percentages. 
Figure 2.7: Distribution of Currently Married Women Who are Never Users with Unmet Need by Background Characteristics, Number of Women

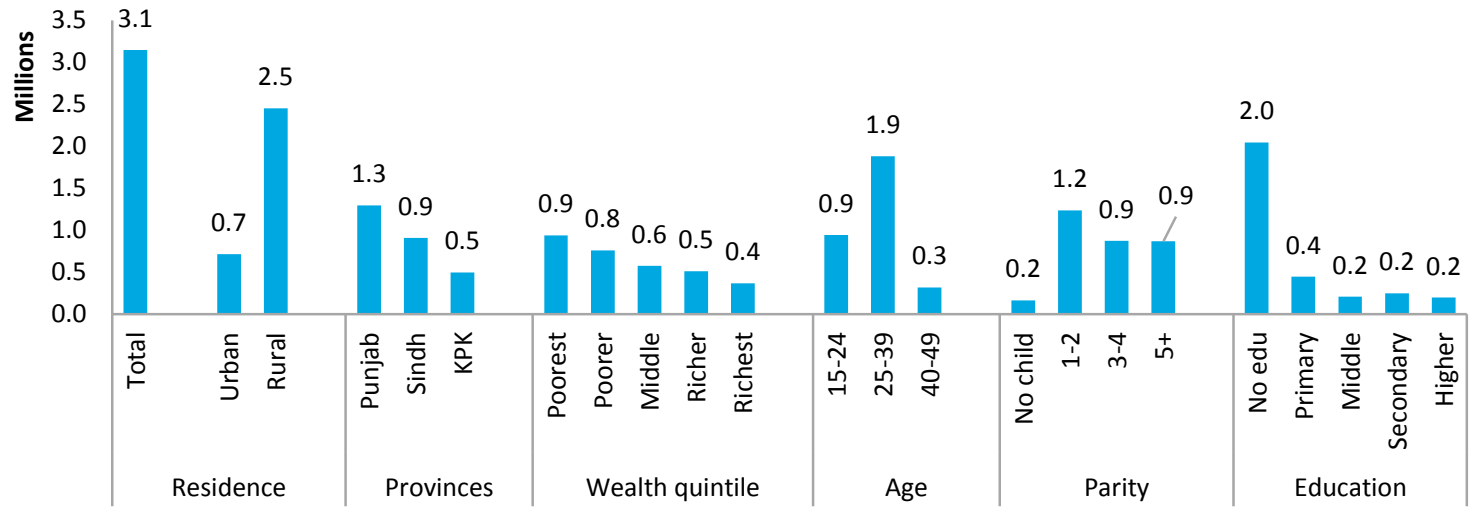

Source: Pakistan Demographic and Health Survey 2012-13

The following differences can be observed across provinces among never users with unmet need (Appendix 2):

- Among never users, unmet need is highest in Sindh (13.3\%), followed by KP (11.5\%) and Punjab (7.6\%)

- In all the provinces, unmet need among never users is highest in rural areas.

\section{Barriers to Adopting Family Planning}

Lack of information about contraceptive methods is the major barrier for never users with unmet need. While this is a major impediment across all segments, it is a particularly serious issue for men, who, despite being the main decision makers in adoption of FP, do not have any direct source or mechanism for obtaining reliable information. In contrast, most women, at the very least, have access to LHWs. Men are in urgent need of information on specific details of each method, where to get each method, the possible side effects associated with each method, and how the side effects are to be managed.

\section{"I don't know about FP methods. Nobody told me about this. You are the first person to talk to me on this topic." Male, rural Faisalabad}

LHWs are the main source of information about methods for women, in rural and even urban areas. Many communities are not served by LHWs, however, and there the information barrier is felt even more keenly.

Moreover, young married couples can also be acutely affected by this obstacle when they want to delay their earlier pregnancies.

Physical access is another serious barrier for never users, who are more likely to be rural. The issue is exacerbated for those living in communities that are remotely located and where no LHWs or other sources of FP services are available. Transportation is less available in rural areas, and an entire day may be required to get FP services due to the distances involved. The problem is compounded in regions with difficult terrain, such as the mountainous regions of KP, making it even harder for women to access health services. Moreover, users have to bear the cost of travel and for FP services as well if they seek them from the private sector.

"Sometimes, there is no transport available. Some people are poor and can't pay for it. How can they go when the charges of transport are so high? For a poor household even ten rupees mean a lot. This is why they do not use it [FP]. " Female, rural Faisalabad

"Yes, this is an issue-who will go to Umerkot? First they need to have money in their hand. Then, they will go to Umerkot for spacing between pregnancies." Female, rural Sukkur 
Fear of side effects of specific methods such as pills, injectables, IUDs, and implants is another barrier for potential users. Locally prevalent myths, misconceptions, and negative advocacy related to methods play a strong role in discouraging women and couples from use of FP. This barrier is more pronounced for long acting methods. The problem persists due to the dearth of sources of accurate information and channels of advocacy to counter the negative testimonials. People who are living in urban areas also have this issue, particularly men, who do not frequently discuss FP in their social circles, and find such discussions embarrassing (Appendix 3).

"Doctors advised us to use it but family members said FP methods are harmful so we didn't. I feel shy discussing FP so I could not take advice from any one." Male, Karachi city

"As a rickshaw driver, l've seen the terrible state of many women with side effects when they hire me to get to the health facility. Seeing them made me change my initial plan to use family planning."

Male, Peshawar city

\section{Past Users with Unmet Need}

\section{Profile}

It is important to note that the percentage distribution of unmet need among past users has no strong association with type of residence, wealth, or education (Figure 2.8). However, there are large differences across provinces, with 14 percent unmet need in KP and only 7.5 percent in Sindh. Past users with unmet need are more likely to be middle to older aged (median age 35.2 years) and at higher parity; at this key life point, couples are more likely to want to use any FP method and mostly want to use long acting methods.

Figure 2.8: Percent of Currently Married Women who are Past Users with Unmet Need by Background Characteristics

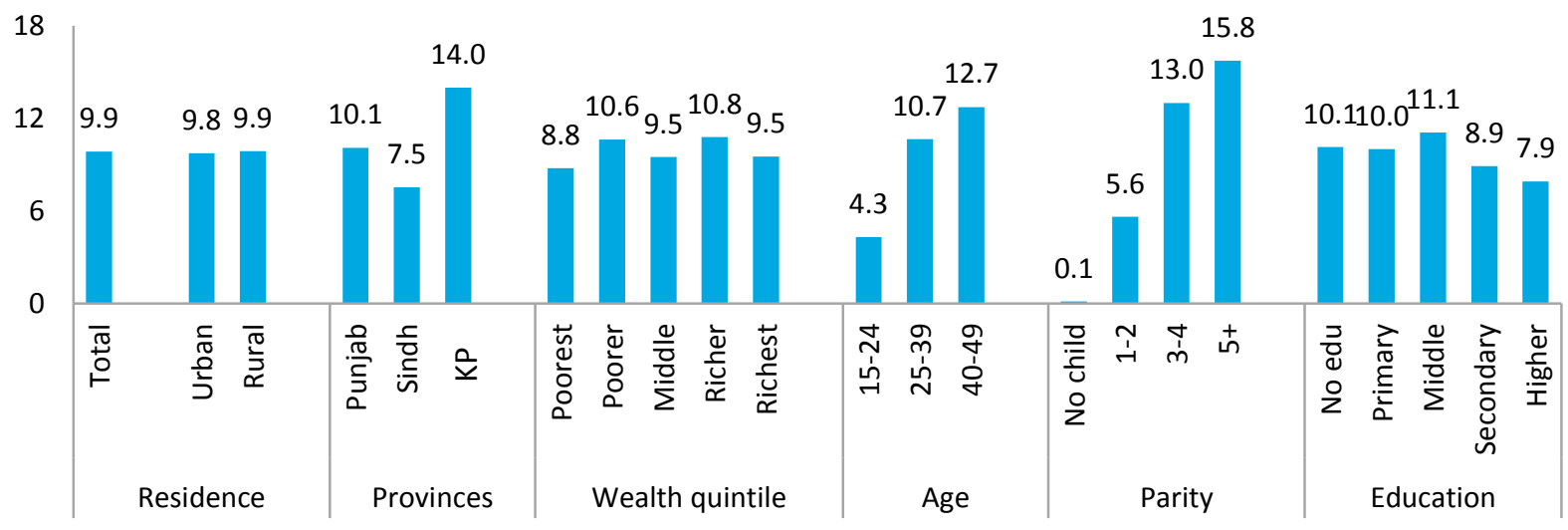

Source: Pakistan Demographic and Health Survey 2012-13

In terms of numbers, the profile of past users with unmet need changes significantly (Figure 2.9), resembling the numbers-based profile of never users with unmet need. As mentioned earlier, this is because numbers reflect the dominant traits of the overall population. 
Figure 2.9: Number of Currently Married Women who are Past User of any FP Method with Unmet Need for FP Services by Background Characteristics

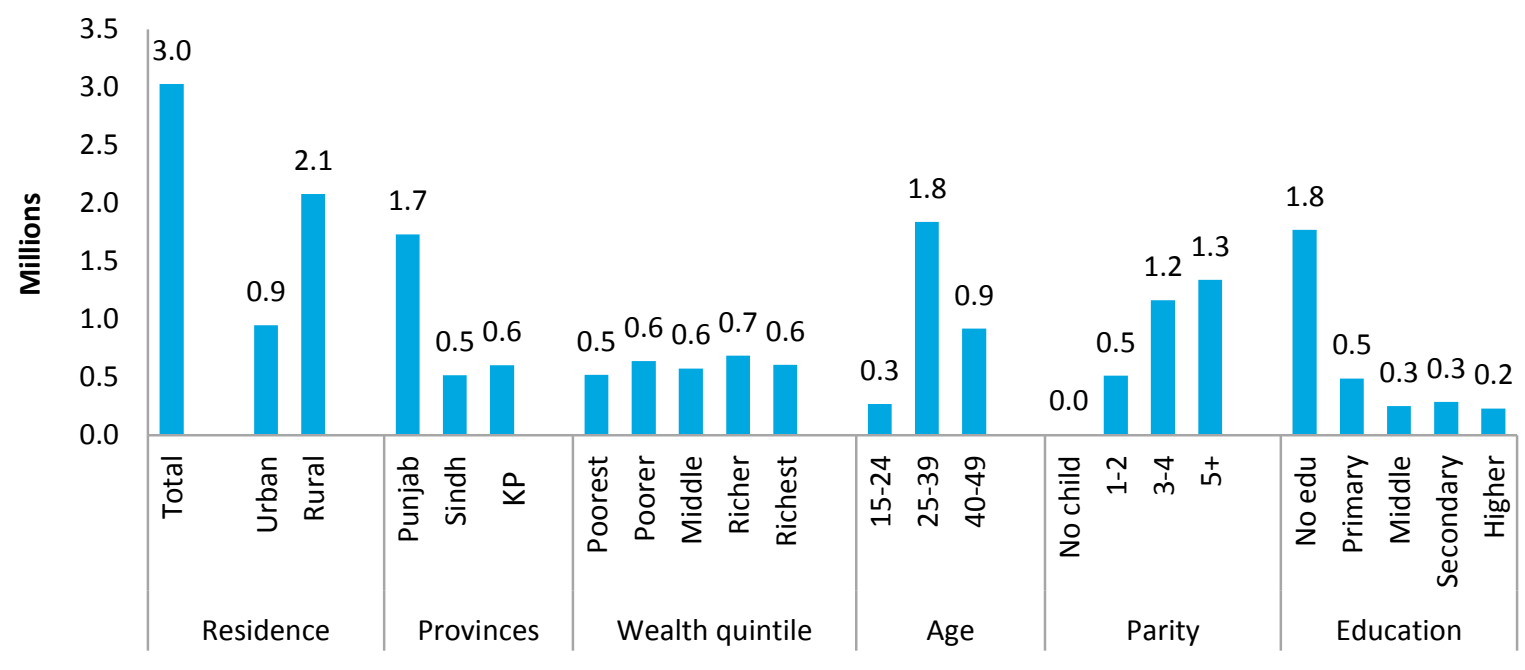

Source: Pakistan Demographic and Health Survey 2012-13

Differences observed among provinces in past users with unmet need (Appendix 4) include:

- Unmet need among past users is highest in KP (14\%) followed by Punjab (10.1\%) and Sindh (7.5\%);

- In Sindh and KP, unmet need among past users is higher in urban areas, unlike Punjab, where it is higher in rural areas;

- In Sindh and KP, unmet need among past users is highest in the middle income group, while in Punjab it is highest among the poor; and

- While unmet need increases with age in all provinces, the rate of increase is greater in KP.

\section{Reasons for Discontinuation}

Side effects are the major reason for discontinuing the last method among past users with unmet need (30\%), followed by desire to become pregnant (20\%), and "became pregnant," in other words, method failure (19\%). Past users who do not have unmet need report that they discontinued contraceptive use predominantly due to a desire to become pregnant (62\%), with side effects comprising the next biggest reason (16\%). Among past users with unmet need, side effects remain the major reason for discontinuing the last method across all age groups. However, wealth seems to make some difference: while side effects remain the major reason for discontinuing the last method among poor (46\%) and middle class (41\%) past users, those who are in the wealthiest class report "became pregnant" (27\%) as the top reason, although it is closely followed by "side effects" (23\%).

\section{Barriers in Resuming Family Planning}

Past users represent a segment of potential users who have already proved their motivation and willingness to use FP. Among the reasons they mention for discontinuing use, the most prominent is severe side effects. Since they have already had a negative experience of using FP, the barriers faced by past users with unmet need are different and stronger than those faced by other potential users.

Experience of side effects is the strongest barrier for past users with unmet need across all segments. While some women may try other methods when they experience side effects, for some the side effects are severe and they may be reluctant to experiment further, fearing that similar problems could arise. 
The major side effects associated by past users with particular methods include:

- Heavy bleeding, associated especially with injectables, IUDs and implants;

- Anemia, associated with use of pills, injectables and IUDs;

- Infection, associated with implants and IUDs;

- Severe backache, with use of IUDs; and

- Weakness, associated with pills, injectables and IUDs.

Of all the side effects mentioned above, heavy bleeding emerges as the most serious problem that not only affects the health of the women but also their routine life, ultimately pushing them to discontinue. Severe side effects reduce women's capacity to perform household chores and take care of their children; prevent them from performing religious activities, such as prayer, fasting, and reading of the Quran; and disrupt their sexual relations with their husbands. Alongside the health toll, the expected impact of side effects on these other spheres of life holds women back from adopting FP again, despite their willingness to space or limit pregnancies.
"I had excessive bleeding with injectables. Every time I stood up, I could see blood trickle to the floor. So I warn women not to use the injectable or they might end up like me. It is better to have a child than to bear the method's side effects. One day, I fainted; my husband found me and took me to the doctor...after that I decided I would not use contraceptives." Female, rural Sukkur
"After my last child, I started injectables again but they caused heavy bleeding for eight months, every 15 days. I had such bad leg pain I couldn't even sit in the toilet. I had low blood pressure and was so weak I couldn't get out of bed for my husband and to get my children ready for school in the morning. Nothing is more important than your health; so what could I do? I stopped using, though I didn't want to." Female, Multan city

Experience of poor quality of services, especially at public facilities, is more of a barrier for poor and rural women who are more likely to seek FP services from the public sector. Since public facilities are usually not located in their vicinity, reaching them can take a lot of time, and the limited timings of these facilities further minimizes the opportunity for women to avail services. These past users also have experience of impolite behavior and inadequate attention from service providers, which contributes to their reluctance to seek services.

While this problem is felt most acutely by poor and rural women, it poses a barrier for other segments too. Even if middle income or urban women seek services from private sector facilities, service providers are not as skilled as required. Women have to make repeated visits for treatment of side effects, and if side effects do not subside, they are left with no option but to leave the method.

Unfortunately, LHWs, who are more trusted providers and whose presence resolves many of the access issues, have limited knowledge about side effect management; they are unable to manage the initial side effects even of the methods they are providing.

This lack of support from the health system not only discourages past users from resuming FP use but also negatively influences other potential users.

"I took this method from a private lady doctor. The government hospital is very far away and treatment is not satisfactory there. They treat women like animals and do not give proper attention. In the private clinic, everything is nice and easy." Female, Karachi city

"The LHW advised me to wean my baby because the implant would affect his brain. We could not afford milk, so my husband and I decided to get the implant removed. I really regretted this when the LHW told me later that she had been mistaken." Female, rural Peshawar 
Poor quality of services is also reported by women who received implants from camps. This is more of an issue where camps are organized by the public sector. Women complain that camps are overcrowded and no proper counseling is done because service providers are in hurry; they also perceive service providers as having inadequate skills. The biggest problem is that there is no follow up mechanism after insertion; if a user experiences complications or side effects, there is nowhere for her to go. She eventually has to locate a facility that can help her, and pay the heavy price of reaching there and getting treatment. This not only discourages the client herself but also other women who witness her difficulties in using implants.

"Staff at the camp were unskilled and made a faulty insertion. It was difficult to remove [as it was inserted in the muscles]. I had got the implant for free but I had to spend 50,000 to 60,000 rupees [to get from Sukkur to Karachi] for treatment, and even after that I am not completely well. I would never recommend this method to anyone." Female, Sukkur city

Cost of side effect management is a primary and strong barrier for past users. Prior experience makes them more acutely aware of the possibility that they might have to incur heavy expenses, including both travel and treatment costs, if they experience side effects. This makes them wary of any new method.

This barrier is also an important barrier for all of the other segments, even for women in urban areas and those belonging to the middle income group.

"Due to the IUD, my wounds were getting worse every day. Every month, I had to go to the doctor and purchase medicines worth 500 to 600 rupees. My husband got irritated. He said "Whatever I earn, I spend on your treatment." It was not easy for us to manage the medicine cost. I also got fed up with the chronic health issues and expense so I had the IUD removed." Female, rural Peshawar

"In my opinion, it is better to stop using the method than to bear the side effects and keep making repeated visits to doctors for treatment." Female, rural Faisalabad

"I got treated twice for side effects but [the problems persisted and] it was not possible to keep getting treatment again and again because we don't have the money. So I had the Copper-T removed." Female, Multan city

Although they have used FP methods, lack of information remains a barrier for past users with unmet need. Among the huge numbers of less educated or uneducated past users, sources of information about methods are particularly limited. Most past users, particularly those living where LHWs are the main source of information, confront this issue because LHWs usually do not provide information about the larger range of possible FP methods. Lack of information leaves past users confused about which method to use, and sometimes even ignorant of available alternatives. (Appendix 5)

"I do not want more children. I have enough children. But there is no other method in my mind which I can use. If I will get pregnant again I will have an abortion." Female, rural Faisalabad

"I got pills from Baji (LHW), which I left due to side effects. I have a very limited social circle and I only know about the LHW and she only told me about pills. I don't know about any other option." Female, rural Faisalabad

\section{Users of Traditional Methods}

\section{Profile}

Users of traditional methods have great potential to be redirected towards modern contraceptives, as they already demonstrate a commitment to using FP. Unlike other potential users, a higher percentage of traditional method users are more concentrated in urban areas than in rural areas (Figure 2.10). They are also likely to have higher levels of education. Moreover, middle-income and wealthier people show higher use of traditional methods than the poor, indicating that preference for traditional methods is not driven by cost concerns. 
Users of traditional methods are more likely to be living in Punjab, followed by KP. They are young and middle aged (median age 33 years) although they keep on using these methods even after having four or five children.

\section{Figure 2.10: Percent of Currently Married Women Using Traditional Contraception Methods} by Background Characteristics

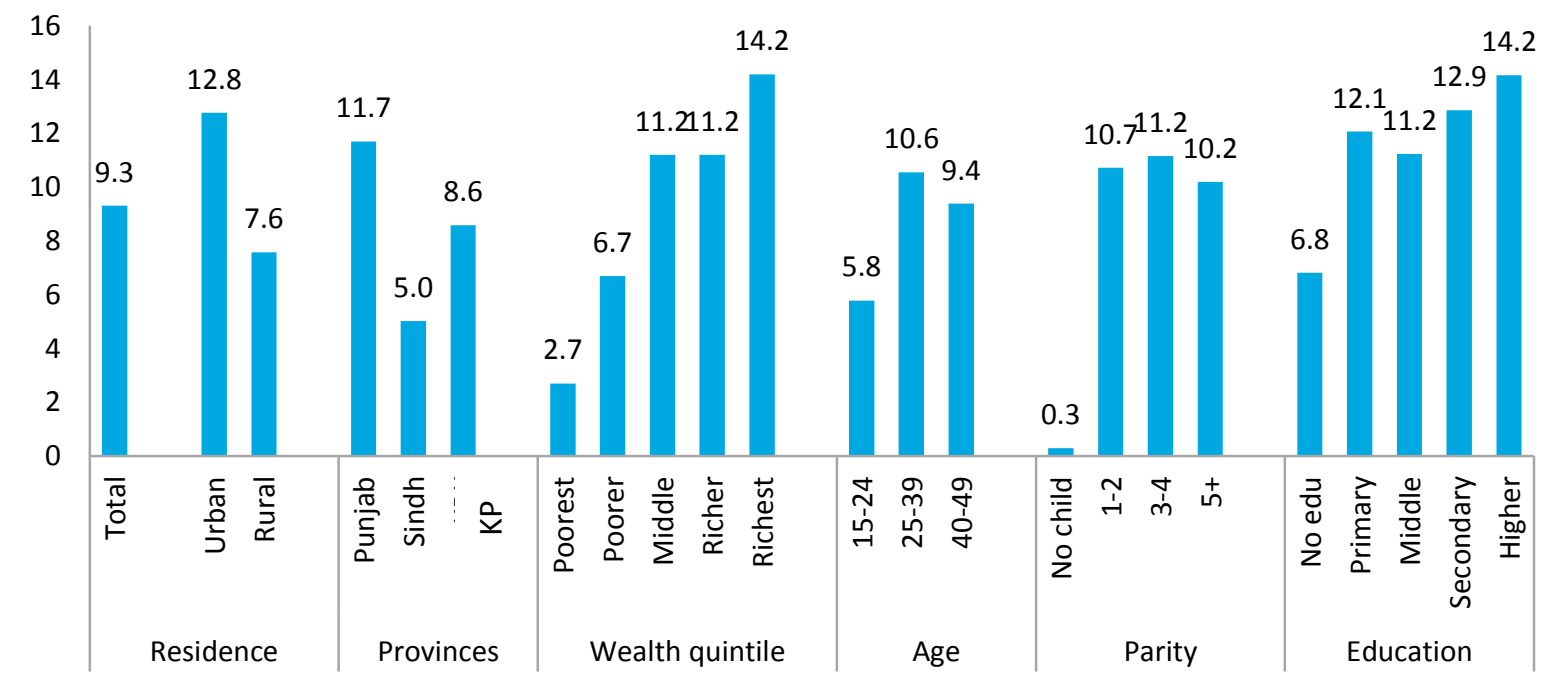

Source: Pakistan Demographic and Health Survey 2012-13

Again, in terms of numbers, the picture that emerges is slightly different, showing traditional method users to be more concentrated in rural areas and with higher numbers having no education (Figure 2.11), which reflects patterns in the general population.

Figure 2.11: Number of Currently Married Women Using Traditional Contraception Methods by Background Characteristics

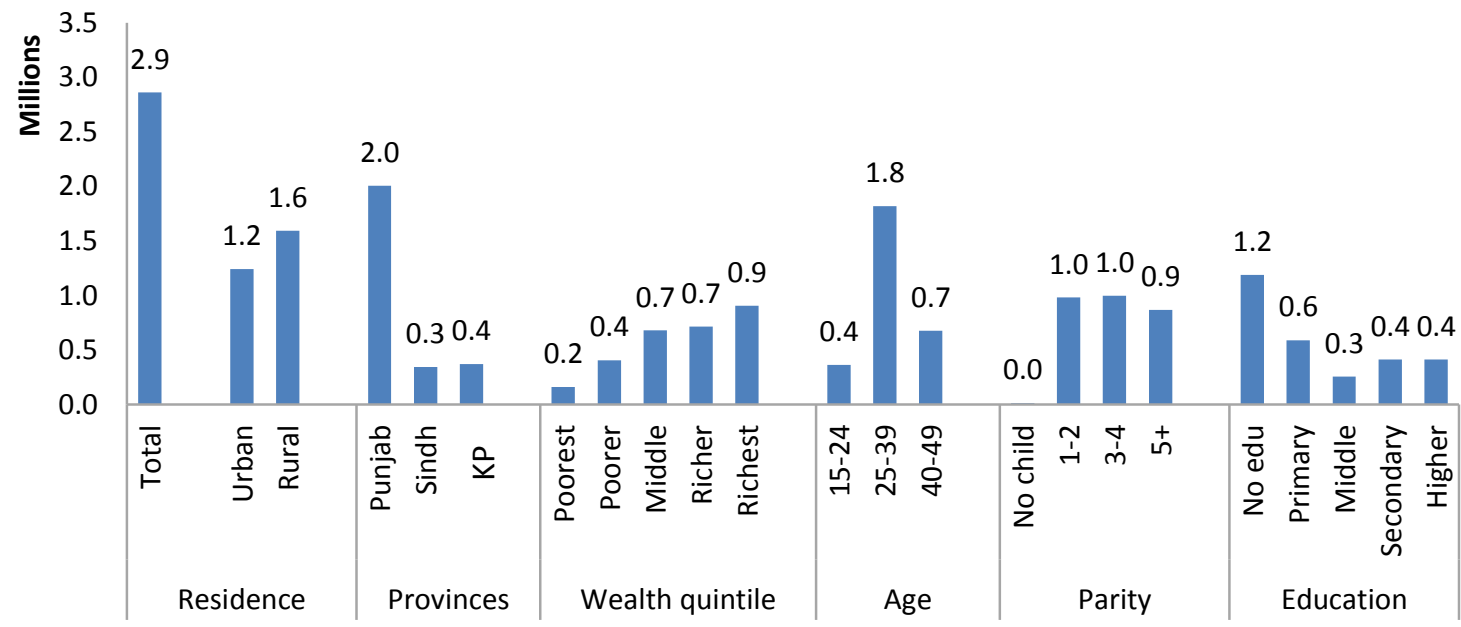

Source: Pakistan Demographic and Health Survey 2012-13 
Differences observed among provinces in traditional method users (Appendix 6) include:

- Use of traditional methods is highest in Punjab, particularly in urban areas;

- In provinces except Punjab, couples at lower parity don't use traditional methods; and

- Level of education, has no particular impact on use of traditional methods in Punjab and KP.

\section{Barriers to Adopting Modern Contraceptive Methods}

Across the segments, fear or experience of side effects of modern contraceptives is the most prominent barrier preventing traditional method users from using modern contraceptives, especially urban and educated people. While myths and misconceptions abound regarding almost all modern FP methods, they are most strongly prevalent with respect to long acting methods, which is why even older women, who should ideally be using modern methods, prefer to use traditional methods. Although traditional methods, especially withdrawal, is less used by young, rural, uneducated and poor people, those who do use it are driven by strong fear of side effects of modern methods.

"I have four children and ten years have passed since my marriage. After the birth of our first child, I used withdrawal but when our second child was born, my wife used injectables for some time. But due to health problems-bleeding-she left that and didn't use the method again after recovering. We started using the Islamic method of withdrawal once more. Islam teaches us this method. I also recommended it to other people." Male, rural Faisalabad

The second most important barrier facing users of traditional methods is lack of information about FP methods. There are limited channels of information, particularly for men, who do not usually discuss FP methods with others, except with close friends and rarely even then.

\section{"I only know about condoms and withdrawal. I do not ask anybody for any other method and nobody} told me about another method." Male, Multan city

"I did not find any opportunity in my life where I could discuss about FP. Here, no one discusses FP with anyone else...After the birth of my second daughter, I started to use withdrawal. I am still using it for birth spacing." Male, Karachi city

Access is also an issue for users living in rural areas and those who are poor because, to access modern methods and the associated services, they need to spend on travel and method or procedure cost. Affordability is an issue, especially for poor people.

"It is a simple method as it doesn't require going to any doctor and or any medicines; this is just in a person's own control." Male, rural Peshawar

The need to interact with method or service providers is also considered a barrier to using modern contraceptives. Many users prefer traditional methods because they can be used with complete privacy; this reason is more common among urban educated people. In addition, users feel embarrassment in buying condoms, so they prefer to use withdrawal (Appendix 7).

"I do not feel bold enough to buy condoms from shops. I went to the shop of a person I knew three or four times, lost courage, and turned back... Once when I went there, there was a small boy at the counter, and I just asked him for a condom and he gave it to me wrapped in a shopping bag. But I feel much too embarrassed to buy it again." Male, Multan city

\section{Comparison of Potential Users}

Differences in the profiles of three categories of potential users may be summarized, by segment, as follows:

Age: Never users with unmet need are likely to be younger (median age is 28.8) whereas past users with unmet need and traditional method users are likely to be middle aged (median ages are 33 and 35 , respectively). 
Parity: Never users with unmet need are more likely to be at low parity (1 to 2), traditional method users are more likely to be at parity two to four, while past users with unmet need are likely to be at high parities (4 and above).

Wealth: Never users with unmet need are more likely to rank among the poorest while wealth is less associated with past users; traditional method users are more likely to be among the wealthiest.

Education: Both never and past users with unmet need are more likely to be uneducated whereas traditional method users are likely to have secondary or higher levels of education.

As indicated above, users of modern contraception face a common set of barriers, including lack of information, problems of physical access in rural areas, cost issues facing the poor, low quality of services in the public sector, experience of side effects, fears of side effects, and doubts about the religious permissibility of modern contraceptive. However, the findings of our qualitative study shows considerable variation in the intensity with which each barrier affects each category of potential users. This variation is captured in Table 2.3 .

Table 2.3: Variation in intensity of barriers to modern contraceptive use among potential users

\begin{tabular}{lccc}
\hline Barriers & $\begin{array}{c}\text { Never users } \\
\text { (with unmet } \\
\text { need) }\end{array}$ & $\begin{array}{c}\text { Past users } \\
\text { (with unmet } \\
\text { need) }\end{array}$ & $\begin{array}{c}\text { Current } \\
\text { Traditional } \\
\text { users }\end{array}$ \\
\hline Lack of information & 1 & 3 & 1 \\
Access issues for rural areas & 1 & 2 & 2 \\
Cost issues for poor & 3 & 1 & 3 \\
Poor quality of services at public facilities & 3 & 1 & 3 \\
Experience of side effects of modern methods & - & 1 & 3 \\
Fear of side effects of modern methods & 1 & - & 3 \\
Religious permissibility & 3 & &
\end{tabular}

\section{Current Users of Modern Contraceptives}

The high rates of discontinuation of FP imply that growing the market for modern contraceptives requires more than simply converting potential users; existing users must be supported in continuing use, including through timely switching, to stem the chronic leakage of users from the market. A larger critical mass of satisfied users would in turn attract more potential users, especially those who avoid modern contraceptives out of fear of side effects. This section reviews the profile of current users of modern contraceptives and the challenges some of them face in maintaining the use of these methods.

\section{Profile}

Urban and rural differences in the use of any modern method by region are similar to differentials observed in the use of any traditional method. In percentage terms, the majority of modern method users are located in urban areas and in Punjab, followed by Sindh and KP (Figure 2.12). Use of modern contraceptives increases as the wealth status improves, with the richest more likely to use modern methods. Use of modern methods also has a positive association with educational attainment; however, there is not much variation across levels of education beyond primary education. Current users of modern methods are more likely to be older and at higher orders of parity, with use increasing as number of children increases. 
Figure 2.12: Percentage of Currently Married Women Using Modern Contraception Methods by Background Characteristics

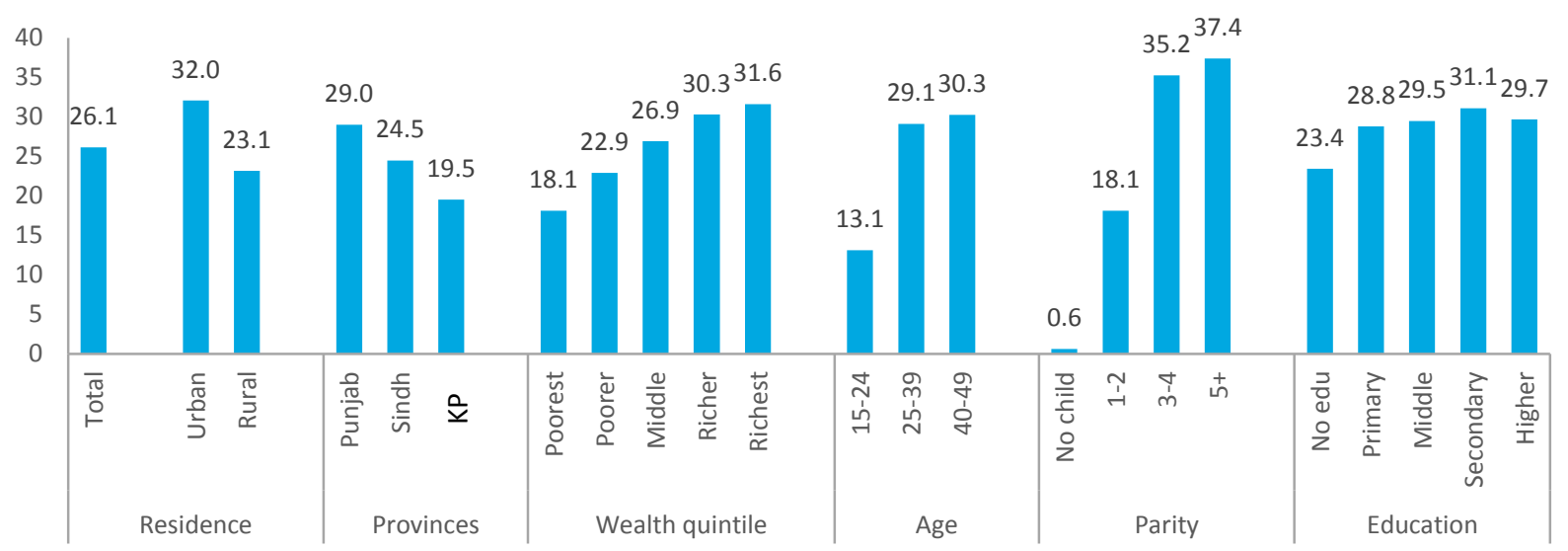

Source: Pakistan Demographic and Health Survey 2012-13

In terms of numbers, the profile remains the same as by percentages except for residence and education (Figure 2.13). This perspective reveals the majority of users to be living in rural areas and to have no education, reflecting the pattern of the general population.

Figure 2.13: Number of Currently Married Women Using Modern Contraception Methods by Background Characteristics

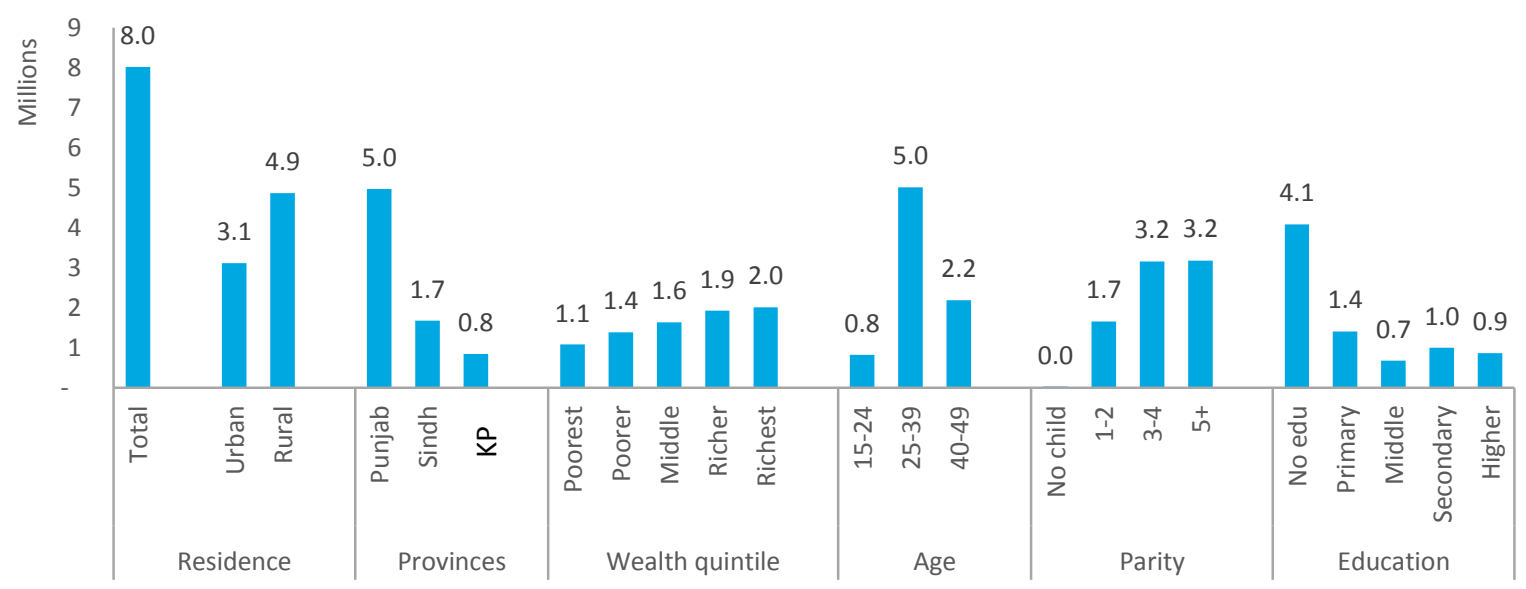

Source: Pakistan Demographic and Health Survey 2012-13

The following differences can be observed across provinces among users of modern contraceptive methods (Appendix 8):

- Modern method use is lowest in KP (19.5\%);

- Wealth has less impact in Punjab, compared to Sindh and KP;

- Level of education has no impact in Punjab. 


\section{Challenges Facing Current Users of Modern Contraceptives}

Essentially, current users of modern contraceptives face the same problems of access, cost, and service quality as potential users, but these problems affect them with less intensity. However, the issue of side effects, cited by 30 percent of past users as a reason for discontinuing FP use, deserves attention. In this respect, modern method users may be divided into the following three types:

- Satisfied users: These users do not experience any side effects and are comfortable with the methods they are using. Condom users are the most likely users to fall in this category, although some users of pills and injectables are also satisfied and continue to use the same methods, even for long-term spacing. IUD users are least likely to fall in this category.

- Users with mild side effects: These users experience mild side effects, but they find them to be bearable, and remain motivated users in the interests of avoiding unwanted pregnancies.

- Users with severe side effects: These users live with severe side effects that affect their health and life, but deem the suffering to be a lesser evil than another unwanted pregnancy. However, their high levels of determination are continually sapped as their health deteriorates, costs of treatment rise, and the pressures of neglected family and other obligations mount. Pushed to the verge of discontinuation, this committed but desperate category of modern contraceptive needs special attention, especially improved quality of FP services, to sustain use of modern methods.

"The experience [of IUD] is good in the sense that it gives long-term spacing and also gives relief from the tension of bearing more children. But I have side effects. I have infection, and such severe back pain, it's a challenge to even wash clothes. I am forced to use this method because my children are young and my husband is also in favor of two children. We have less income; we cannot afford more children." Female, rural Peshawar

\section{The Potential Market: What Consumers Want}

During the qualitative study, as men and women from all segments identified the barriers that hinder their adoption of FP, they were also asked to identify the ways in which they felt their problems could be addressed. The following discussion encapsulates the views of men and women regarding what should be done to help them adopt FP. The suggested strategies are divided into two categories, i.e. information provision and service provision.

\section{Information}

Lack of information emerged as a major issue, especially for never users with unmet need and traditional users, and both men and women came forward with ideas to tackle this issue.

Among women as well as men, there is appreciation of the positive role of LHWs, and they want this channel to be utilized in better way; LHWs can provide detailed information to women and this information can be passed to men by their wives to narrow the gap. Men particularly want that simple information materials, such as leaflets, containing method-specific details also be distributed to men and women at community level, and suggest that LHWs distribute such material to couples. Information provided through LHWs will not only fulfill the needs of couples who want to use FP, but will also attract couples who do not yet want to use FP.

"An LHW is available in our area but mostly she does polio work. She does not provide information about family planning. The LHW should visit each home and give information to people. It will help people who want to use family planning methods and even people who don't want to use will at least get information." Male, rural Faisalabad 
In urban areas, men and women, particularly those who are younger, want information about FP methods through the Internet and social media. According to them, Facebook is the new, emerging source of information, used even by uneducated people, and it can be a useful channel to address need for methodspecific details. Information could be pictorial or in short video clips. Men also would like telephone hotlines.

In both rural and urban areas, women want mobile phone services, which are commonly available to both men and women, for RH/FP information. They would like to receive voice messages on their phones.

Both men and women want to get information through group meetings where community influencers should gather men and women (in separate gatherings) and a knowledgeable person from the health department should provide details of FP methods.

Men and women are interested in getting information through TV programs and dramas with appropriate timings, although they suggest that only general information on FP can be provided because method-specific details cannot be shown on TV. Men suggest that TV programs discussing FP in the context of maternal health could be a good source of information for people.

"Media can play big part in this regard. They should make programs with the help of media like "Maa ki Sehat" [The Mother's Health]. This should be run on TV and senior persons should be invited who share their experiences. All other countries are airing different programs on birth spacing or family planning on their TV channels, and it should be done here too." Male, Peshawar city

Men particularly want that their need for direct and detailed method-specific information be addressed. They suggest that male service providers should be available at static facilities and male health workers introduced at community level from whom they can get direct and complete information.

Both men and women think it is necessary that FP information reach all men, and for this purpose they suggest that printed (pictorial) materials be placed at local shops and pharmacies where men frequently visit.

Men understand that fears and myths related to methods are a barrier. They want service providers to allay people's fears about side effects and make them amenable to using FP. Women think that myths and misconceptions can be countered if satisfied local users with successful experience of using FP methods are involved in the program.

"Someone should come to satisfy us about family planning methods. People fear side effects and treatment. They will not use any method till their fears about side effects of family planning methods are put to rest." Male, rural Sukkur

\section{Service Provision}

To address the cost and access issues, both men and women strongly want doorstep delivery of FP services. LHWs' services highly appreciated at community level, but men and women want that LHWs should not be out of stock of contraceptives, because then they, the clients, have to bear not only contraceptive costs but also travel costs, which are difficult to bear for poor users.

Men particularly want LHWs, being such an important source of FP services at community level, to have the knowledge and skills to manage side effects of modern contraceptive methods.

"Every month LHW gives me pills. She comes to my home and gives pills; it is very beneficial for me. She lives near us. I send my child to get supplies from her house as needed. I would not use pills if they were not provided by the LHW." Female, Karachi city

Men and women also want static health facilities available in their vicinity, with female service providers available, to avoid travel costs both at method adoption and for treatment of side effects. The expense of travel is at times unaffordable, and can compel users to discontinue, so ensuring adequate coverage of services would help prevent discontinuation. 
“I arranged Rs. 2,800 for the IUD with difficulty. But after experiencing side effects, I had to go back twice, spending 700 rupees each time. Ultimately, I had to discontinue-but I wouldn't have quit if there was any provider nearby and treatment was free." Female, Multan city

Women want FP services to be available not only at public health facilities but also at all private health facilities and these facilities need to be available everywhere so that they are accessible. Both men and women also say that FP services should be provided for free or at nominal cost at private clinics, and services should also include management of side effects.

Women further consider that FP services should be available integrated with general health services because it saves their time-this way, a woman can access FP services when she visits a health facility for services for any other family member, particularly children. Women moreover perceive that taking out time to go to a facility where only FP services are available is difficult for them. However, they further suggest that every health facility should have a separate section for FP services where they can get these services easily. Women also perceive camps to be a convenient source of FP services. Both rural and urban women want camps to be held in their areas so they can avoid travel and other opportunity costs.

"There should be a private section for FP in all private clinics and services should be provided cheap or free. All information should be conveyed to all women. There should be a center in every area. There should be camps and free services; only then women would get these methods."

Female, Lahore city

\section{Youth and Their Needs}

Youth are Pakistan's future potential users, and their perspectives about FP need to be known now so that strategies can be developed to mold their opinion and fulfill their information needs to facilitate them in contraception when they perceive a need for it. In-depth discussions with male and female youth, both in and out of school, revealed that, regardless of gender and schooling status, the young generation of Pakistanis has a very positive attitude towards FP; unlike the older generation, which needed to be persuaded to practice FP at the start of their reproductive lives, today's youth deeply appreciate the importance of FP, and are confidently voicing their intent to practice it.

In both rural and urban areas, youth are quite knowledgeable about the concept of FP and birth spacing. While boys know more about specific contraceptive methods than girls, both consider FP to be important and necessary for the sake of mother and child health, better rearing of children, better schooling opportunities for children, and meeting financial expenses more easily. They are strongly of the view that FP contributes to a better married life, and express an unqualified readiness to adopt FP after getting married.

"How would one not follow spacing? It is essential for good health...To be a happy family, it is necessary to have less children and to space them." Out-of-school girl, rural Sukkur

"I will be fearless in using family planning methods because this will mean my family is healthy, the children are educated and fed." In-school boy, Karachi city

"I see my father sweat at the loom all day and even then it is hard to make ends meet. I think to myself, it's because we are eight. If we were four children, it wouldn't cost so much."

Out-of-school girl, rural Faisalabad

Although youth are willing to adopt FP in the future, there is no formal mechanism to equip newlyweds with information about the methods and sources for them. Youth who participated in this study shared many suggestions regarding how they should be equipped with information. They want to have accurate FP information so that they can be completely aware and knowledgeable, but they also want to get this information in privacy.

They suggested that there should be a comprehensive strategy to provide FP information utilizing different channels. Boys and girls even specified the channels of information that should be used for different youth 
segments, educated and uneducated, rural and urban, among others. All youth, particularly those attending school, strongly suggested that FP information be provided through the internet. According to them everyone uses the Internet, so exclusive pages with FP information should be developed with details where everyone can get accurate information.

Youth also wanted to get information through social media, particularly Facebook, where they spend much of their leisure time, especially boys. They also prefer these channels to maintain their privacy.

"All available means of communication should be utilized to provide family planning information so that the maximum number of people can benefit and mother and child health can be assured."

Out-of-school girl, rural Peshawar

"Websites are more confidential because if someone cannot ask another person, he can check from a site." In-school boy, Peshawar city

Girls (both in-school and out of school) suggested that the electronic media be utilized, especially TV, to provide FP information. They suggested that morning shows and dramas can be a good source of FP information, especially if celebrities are invited to talk about FP. They further suggested that radio can be a good source of information for youth living in far flung areas. To cater to the information needs of uneducated youth, they suggested that pictorial material or videos be developed.

"For far-flung areas, use radio. For uneducated people, use pictorial material and videos. For educated people, use the Internet and billboards on the roadside."

Out-of-school girl, rural Peshawar

Youth also suggested that information be provided to them through mobile voice messages as mobile phones are accessible for the majority of youth, particularly boys; this source would also meet their need for privacy. They further suggested that FP information should be provided in local languages so all audiences, educated and uneducated, could benefit.

"Today, everyone has access to mobile phones, so it should be conveyed through messages and calls about how a small family is a happy and healthy family." Out-of-school girl, rural Sukkur 


\section{Summary of Key Points \\ Use of Family Planning: Barriers and Potential for Growth among Different Consumer Segments}

\section{Contraceptive Users}

- There are an estimated 31 million married women of reproductive age (15-49 years) in Pakistan. Among these women, 35.4 percent are using any contraceptive method, with 26.1 percent using modern contraceptives and 9.3 percent using traditional methods. A further 20.1 percent of women, both past and never users, are living with unmet need for FP.

- There are nine million potential users in Pakistan - around one third each are:

- Never users with unmet need;

- Past users with unmet need; and

- Current users of traditional methods who may be persuaded to use modern methods.

- Translating demand for FP into use of modern contraceptives among these nine million potential users would raise the national modern contraceptive prevalence rate (mCPR) to 55.5 percent.

- The three groups of potential users exhibit different profiles that have implications for programming.

- Never users with unmet need have a median age of 29 years, tend to be uneducated, and are in the lowest wealth quintiles. They have around one to two children.

- Past users with unmet need comprise the oldest segment (median age 35), tend to be uneducated, and are represented across wealth quintiles. This group has the highest parity, 4 children and above.

- Traditional users with unmet need have a median age of 33 and are the most educated; this group is likely to have secondary level education and to be in the highest wealth quintiles. This group has two to four children, on average.

- In reaching these three groups of potential users, it is important to understand the barriers each group faces to FP use:

- Never users with unmet need noted three primary barriers. Lack of information about contraceptive methods is the major barrier, particularly noted by men, who do not have any direct source or mechanism for obtaining reliable information. Low access to health services is a hurdle, especially in rural communities that are not served by Lady Health Workers (LHWs). The third major barrier is fear of side effects, which is perpetuated by lack of information and the negative buzz emanating from past users.

- Past users with unmet need described their past experience of side effects, such as heavy bleeding, anemia, infection, backache and malaise, which affected not only their health but also other aspects of their lives, as the most entrenched barrier. They are also 
deterred by experience of poor quality of health services, which has convinced them that they will not find adequate support from the health system should they experience side effects again. Finally, cost of side effect management, which this group knows from experience to be potentially high, is a barrier to resumed use of FP.

- Among traditional method users, fear of side effects is a main barrier to modern contraceptive use, along with lack of information about specific methods. The myths and misconceptions that abound regarding almost all modern FP methods, particularly long acting contraceptives, affect this group's view of FP, leading even older women to prefer traditional methods.

- Of the nine million potential users, about six million live in rural areas and the three million in urban areas.

\section{- Current users of modern contraception}

- Are mostly located in urban areas and in Punjab, followed by Sindh and KP;

- Tend to belong to higher wealth quintiles, have educational attainment beyond primary school, be older, and have higher levels of parity; and

- Include completely satisfied users, users with mild side effects, and users living with severe side effects. The latter category is at high risk of discontinuation and needs special attention, especially quality FP services.

\section{Factors Affecting FP Use}

- A number of factors affect views of men and women about FP use. These factors include exposure to LHWs, NGOs and the media; female education and employment; desire to emulate those perceived to be better off; economic factors; and religious perceptions (especially in KP). The intensity with which some of these factors influence perceptions varies across districts.

\section{Needs for FP Information and Services}

- Women and men want their need of FP information to be addressed by providing detailed and method-specific information, through community workers; information materials, Internet, social media, and mobile phone services. Group meetings and mass media can be used to highlight the link between FP and maternal health. Service providers can allay people's fears about modern methods.

- In terms of service provision, men and women strongly call for doorstep delivery of services, and for LHWs to have sufficient contraceptive stocks and the capacity to help them cope with side effects. They want public and private sector static facilities to be available in their vicinity, offering separate spaces for men and women to get FP services, and at nominal cost. In particular, they want services for side effect management available.

\section{Views of Youth}

- Young people have a very positive view about FP and express unqualified readiness to adopt it regardless of gender, schooling status, and rural/urban residence. Young people want to be equipped with information about FP, and they would like to receive it privately, preferably through the Internet, social media, and mobile voice messages, including videos/pictorial material for those who are uneducated. They also suggest promoting FP through TV and radio, employing local languages to cover needs of remote communities. 


\section{Chapter 3}

\section{Channels for Service Provision: Availability, Adequacy, and Potential for Expansion}

Both public and private sector facilities provide health services in Pakistan, with private facilities greatly out numbering public facilities. Additionally, pharmacies, both licensed and unlicensed outlets, serve as important sources of healthcare products and informal counsel to customers.

This chapter introduces the main types of public and private health facilities in the country, and then describes the presence of health facilities and pharmacies in urban and rural areas, showing the proportions of each of these channels that are providing FP services, overall and by method. We discuss the quality of care broadly in the private and public sectors and then present reasons for non-provision of any or specific types of FP services as stated by providers themselves. Finally, the ways of expanding the most promising channels for boosting FP service availability in the immediate future are identified.

The data and analysis presented in this chapter are based on a detailed census of public and private health facilities as well as pharmacies in four urban districts-specifically Faisalabad and Lahore (3 out of 9 townships and a cantonment) in Punjab; Sukkur in Sindh; and Peshawar in KP, as well as a qualitative market study involving in-depth interviews with 79 service providers and 107 suppliers of contraceptives in 5 districts, i.e., Peshawar, Faisalabad, Lahore, Sukkur and Karachi. Details of the scope and methodology of the census and qualitative market study have been provided in Section

\section{The Main Channels for Family Planning Services and Products}

An estimated 9,451 public static facilities operate in Punjab, KP, and Sindh. ${ }^{1}$ This relatively small network is augmented by 104,262 Lady Health Workers (LHWs). These community-based health workers are responsible for providing primary healthcare and FP services and are acknowledged to comprise the backbone of public healthcare in rural areas.

In the aftermath of the $18^{\text {th }}$ constitutional amendment, passed by the national parliament in 2010 , powers pertaining to the health and population sectors have been devolved from the federal to the provincial level, although the Ministry of National Health Services, Regulations and Coordination continues to play a supporting role at the federal level.

The key provincial departments responsible for administration of public health facilities include the Department of Health (DoH) and the Population Welfare Department (PWD). DoH also heads the National Program for FP and Lady Health Workers (commonly known as the LHW Programme) as well as the federally funded but provincially managed program known as People's Primary Healthcare Initiative (PPHI) in Sindh, KP and Balochistan, and the Punjab Rural Support Program (PRSP) in Punjab. DoH is mandated to provide all FP services, although the range offered varies across facility levels.

PPHI/PRSP was initiated in 2003 in Punjab and in 2007 in Sindh, Balochistan and KP. It has an important role in FP service provision as its facilities are situated in rural areas and reach the poorer communities.

From its inception, PWD has been mandated to provide all FP services.

1 This estimate is derived from figures provided in Health Facility Assessment - Pakistan National Report (TRF. 2012) and Contraceptive Performance Report, 2013-2014. 
The main types of health facilities operating in the public sector and the FP services they are mandated to offer are shown in Table 3.1.

Table 3.1: Types of Services Provided by Different Levels of Public Sector Facilities

\begin{tabular}{|c|c|c|c|c|}
\hline Sector & $\begin{array}{l}\text { Type of } \\
\text { Facility }\end{array}$ & $\begin{array}{c}\text { Approximate } \\
\text { size (\# of beds) }\end{array}$ & $\begin{array}{l}\text { Approximate \# of } \\
\text { staff }\end{array}$ & Services \\
\hline \multirow{9}{*}{ DoH } & $\begin{array}{l}\text { Teaching } \\
\text { Hospitals }\end{array}$ & $100+$ & $11,000+$ & $\begin{array}{l}\text { - } \text { Comprehensive EmOC services } \\
\text { - All FP services including contraceptive } \\
\text { surgery }\end{array}$ \\
\hline & DHQs & $100-150$ & $50+$ & $\begin{array}{l}\text { - } \text { Comprehensive EmOC services } \\
\text { - All FP services including contraceptive } \\
\text { surgery }\end{array}$ \\
\hline & THQs & $40-60$ & $20-30$ & $\begin{array}{l}\text { - Comprehensive EmOC services } \\
\text { - All FP services including contraceptive } \\
\text { surgery }\end{array}$ \\
\hline & $* \mathrm{RHCs}$ & $10-20$ & 30 & $\begin{array}{l}\text { - } \text { Basic EmOC } \\
\text { - At least } 5+\text { methods }\end{array}$ \\
\hline & *BHUs & $2-5$ & 10 & $\begin{array}{l}\text { - } \quad \text { Normal delivery } \\
\text { - } \quad F P \text { services (at least } 3 \text { methods) }\end{array}$ \\
\hline & $\mathrm{MCH}$ Centers & $1-5$ & $2-3$ & $\begin{array}{l}\text { - } \quad \text { First Aid obstetrics } \\
\text { - } \quad \text { At least } 4 \text { methods }\end{array}$ \\
\hline & $\begin{array}{l}\text { Maternity } \\
\text { Homes }\end{array}$ & $1-5$ & $2-3$ & $\begin{array}{l}\text { - } \quad \text { First Aid obstetrics } \\
\text { - } \text { At least } 4 \text { methods }\end{array}$ \\
\hline & Dispensaries & 0 & $2-3$ & $\begin{array}{l}\text { - } \quad \text { FP services (at least } 3 \text { methods) } \\
\text { - } \quad \text { Primary health care services }\end{array}$ \\
\hline & LHWs & 0 & 1 & $\begin{array}{l}\text { - Providing Pills, Condom and } 2^{\text {nd }} \text { and } \\
\text { subsequent doses of injectables } \\
\text { - Primary health care services }\end{array}$ \\
\hline \multirow{3}{*}{ PWD } & FWCs & 1 & 4-5 & $\begin{array}{l}\text { - Antenatal care services } \\
\text { - } \quad \text { FP services (at least } 4 \text { methods) }\end{array}$ \\
\hline & RHSC-A/FHCs & $5-10$ & $10-12$ & $\begin{array}{l}\text { - } \text { Antenatal care services } \\
\text { - } \quad \text { All FP services, including contraceptive } \\
\text { surgery }\end{array}$ \\
\hline & MSUs & 0 & & - $\quad$ Provide FP services in camps \\
\hline
\end{tabular}

* BHUs and some of the RHCs are managed by PPHI/PRSP

DHQ District Headquarters Hospital

THQ Tehsil Headquarters Hospital

RHC Rural Health Center

BHU Basic Health Unit

MCH Mother and Child Health (MCH) Center

LHW Lady Health Worker

FWC Family Welfare Centers FWC

\author{
RHSC-A/ \\ FHC Reproductive Health Service Center \\ of A Category/Family Health Clinic \\ MSU Mobile Service Unit \\ DoH Department of Health \\ PWD Population Welfare Department \\ PPHI People's Primary Healthcare Initiative \\ PRSP Punjab Rural Support Program (PRSP) in Punjab
}


The main types of private health facilities include a combination of purely for profit and non- profit enterprises. These vary in size and service capabilities. For the purposes of this study, they have been classified into the categories shown in Table 3.2.

Table 3.2: Types of Services Provided/Can be Provided by Different Levels of Private Sector Facilities

\begin{tabular}{|c|c|c|c|c|}
\hline $\begin{array}{l}\text { Type of } \\
\text { Facility }\end{array}$ & $\begin{array}{l}\text { Approximate } \\
\text { size } \\
\text { (\# of beds) }\end{array}$ & $\begin{array}{l}\text { Approximate } \\
\text { \# of staff }\end{array}$ & $\begin{array}{l}\text { Services can } \\
\text { be provided }\end{array}$ & $\begin{array}{c}\text { Whether permitted to } \\
\text { provide FP services/ } \\
\text { methods }\end{array}$ \\
\hline NGO Clinics & $1-2$ & $1+$ & $\begin{array}{l}\text { - } \quad \text { FP services (at least } \\
4 \text { methods) }\end{array}$ & Yes \\
\hline $\begin{array}{l}\text { Private } \\
\text { Hospitals }\end{array}$ & $20+$ & $20+$ & $\begin{array}{ll}\text { - } & \text { Comprehensive EmOC } \\
\text { services } \\
\text { - } & \text { Comprehensive FP } \\
\text { services including } \\
\text { sterilization }\end{array}$ & Yes \\
\hline $\begin{array}{l}\text { Male Doctor } \\
\text { Clinics }\end{array}$ & $1-2$ & $1-2$ & $\begin{array}{l}\text { - } \quad \text { FP services (at least } \\
4+\text { methods) }\end{array}$ & Yes \\
\hline $\begin{array}{l}\text { Female } \\
\text { Doctor } \\
\text { Clinics }\end{array}$ & $1-2$ & $1-3$ & $\begin{array}{ll}\text { - } & \text { Basic EmOC/ First Aid } \\
\text { Obstetrics } \\
\text { - } \quad \text { FP services (at least } \\
4+\text { methods and } \\
\text { potential for providing } \\
\text { all methods }\end{array}$ & Yes \\
\hline $\begin{array}{l}\text { LHV/Nurse/ } \\
\text { Midwife } \\
\text { Clinics }\end{array}$ & $1-2$ & $1-3$ & $\begin{array}{ll}\text { - } & \text { Normal delivery } \\
\text { - } & \text { FP services (at least } \\
& 4+\text { methods) }\end{array}$ & Yes \\
\hline $\begin{array}{l}\text { Dispenser } \\
\text { Clinics }\end{array}$ & 0 & $1-3$ & $\begin{array}{l}\text { FP services (at least } 3 \\
\text { methods) }\end{array}$ & Currently, no mandate \\
\hline $\begin{array}{l}\text { Homeopath/ } \\
\text { Hakeem } \\
\text { Clinics }\end{array}$ & 0 & $1-2$ & $\begin{array}{l}\text { - FP services (at least } 3 \\
\text { methods) }\end{array}$ & $\begin{array}{l}\text { Yes, if trained at a PWD } \\
\text { Regional Training } \\
\text { Institute (RTI) }\end{array}$ \\
\hline
\end{tabular}

\section{Health Facilities and Pharmacies in the Study Districts}

Table 3.3 presents estimated numbers of each type of public health facility in Punjab, KP, and Sindh and the numbers of facilities covered in the census of Faisalabad, Peshawar, and Sukkur, and three towns of Lahore, specifically Samanabad, Data Gunj Bakhsh and Shalimar. (This area is referred in the rest of this chapter as "study districts.") Table 3.3 also shows the relative proportion of different types of service delivery points in the public sector and depicts a fairly low number of public health facilities in the three provinces. With an exponential increase in population over the past decade, the demand for public health facilities has increased but, unfortunately, their number has not. In total, the census conducted in the course of this landscape assessment covered 16,714 service and method delivery points, including 801 public static facilities; 4,221 LHWs; 6,379 private health facilities; and 5,316 pharmacies (Tables 3.3, 3.4 and 3.5). 
Table 3.3: Public Health Facilities and LHWs: Provincial Universe and Numbers in Study Districts

\begin{tabular}{lccc}
\hline & Facilities & & $\begin{array}{c}\text { Proportion } \\
\text { of Surveyed }\end{array}$ \\
Sector and Type of Facility & $\begin{array}{c}\text { in Punjab, KP, and } \\
\text { Sindh }\end{array}$ & $\begin{array}{c}\text { Facilities Surveyed } \\
\text { in Study Districts }\end{array}$ & $\begin{array}{c}\text { Facilies of Study } \\
\text { Districts }\end{array}$ \\
\hline Department of Health & 35 & 16 & 46 \\
Teaching Hospitals & 66 & 5 & 8 \\
DHQs & 217 & 10 & 5 \\
THQs & 511 & 30 & 6 \\
RHCs & 4,050 & 259 & 6 \\
BHUs & 1,449 & 212 & 15 \\
Dispensaries & 428 & 53 & 12 \\
MCH Centers/ Maternity Homes & & 198 & 9 \\
\hline Population Welfare Department & 2,250 & 15 & 8 \\
FWCs & 195 & 3 & 1 \\
RHSC-A/FHCs & 250 & 801 & 8 \\
MSUs & 9,451 & 4,221 & 4 \\
\hline Total Static Facilities of Public Sector & 104,262 & 5,014 & 4 \\
\hline Lady Health Workers (LHWs) & 113,713 & & 9 \\
\hline Total Facilities of Public Sector including LHWs & & \\
\hline
\end{tabular}

Sources: Health Facility Assessment, Pakistan National Report (TRF 2012); Contraceptive Performance Report, 2013-2014; DoH and PWD provincial websites; Government of Pakistan National Program for FP and Health Care: Lady Health Worker Program 2010-2015

The total public health facilities and LHWs in the study districts represents 0.04 percent of the universe of health facilities in Punjab, KP, and Sindh (Table 3.4).

Notably, DoH boasts a much larger network of service delivery points than PWD (as shown in Tables 3.1 and 3.3 above), and static facilities of DoH currently outnumber facilities of PWD, which comprise eight percent of the service delivery points. When LHWs, which belong to the DoH are added in the mix, PWD facilities represent only four percent of the service delivery points.

The precise numbers of private health facilities operating in the country are difficult to obtain in the absence of a complete database. Using data of a census of health facilities in 34 districts in Punjab, KP, and Sindh, which were surveyed under the Family Advancement for Life and Health (FALAH) project, we estimate approximately 57,315 private health facilities in Punjab, 11,268 in KP, and 25,434 in Sindh. The total estimated number of private facilities in the three provinces comes to 94,017 .

Estimated numbers of each type of private health facility in three provinces of the country are presented in Table 3.4. The census of health facilities conducted during this study captured 0.08 percent of private facilities-in Punjab 0.09 percent, in KP 0.05 percent, and in Sindh 0.02 percent.

Table 3.4: Estimated Provincial Universe and Private Health Facilities Covered in Study Districts

\begin{tabular}{|c|c|c|c|c|c|c|c|c|c|}
\hline \multirow[b]{2}{*}{ Type of Private Facility } & \multicolumn{3}{|c|}{ Punjab } & \multicolumn{3}{|c|}{ KP } & \multicolumn{3}{|c|}{ Sindh } \\
\hline & Total & Covered & $\%$ & Total & Covered & $\%$ & Total & Covered & $\%$ \\
\hline Private Hospitals & 2382 & 402 & 0.17 & 771 & 141 & 0.18 & 1,254 & 39 & 0.03 \\
\hline $\begin{array}{l}\text { LHV/Nurse/Midwife } \\
\text { Clinics }\end{array}$ & 2,208 & 272 & 0.12 & 1,044 & 25 & 0.02 & 1,191 & 60 & 0.05 \\
\hline Dispenser Clinics & 15,903 & 1,296 & 0.08 & 5,892 & 169 & 0.03 & 6,681 & 116 & 0.02 \\
\hline Doctor (MBBS) Clinics & 7,278 & 720 & 0.10 & 1,134 & 201 & 0.18 & 9,708 & 183 & 0.02 \\
\hline $\begin{array}{l}\text { Homeopathic/Hakeem } \\
\text { Clinics }\end{array}$ & 28,917 & 2,499 & 0.09 & 2,256 & 72 & 0.03 & 5,802 & 77 & 0.01 \\
\hline TOTAL & 56,688 & 5,189 & 0.09 & 11,097 & 608 & 0.05 & 24,636 & 475 & 0.02 \\
\hline
\end{tabular}


Notably, private sector facilities include both commercial facilities as well as those managed by or affiliated with nongovernmental organizations (NGOs) and social marketing organizations (SMOs). Due to low availability of updated and centralized data, a great deal of variation in the ways SMOs and NGOs engage with provider clinics, and high levels of attrition within these partnerships, it is difficult to estimate the shares of the SMO, NGO and commercial sectors within the private sector. Using figures currently reported on the websites of the major NGOs and SMOs, specifically the FP Association of Pakistan (FPAP), Greenstar Social Marketing (GSM), the Marie Stopes Society (MSS), and DKT International (DKT), we can estimate that approximately 33 percent of private health facilities in Sukkur and six percent of private health facilities in Faisalabad are linked with SMOs or NGOs.

The relative proportion of different types of service delivery points (SDPs) in the public sector and the private sector are shown in Figures 3.1 and 3.2, respectively. Figure 3.1 focuses on static health facilities, excluding the huge numbers of LHWs in the public sector and the even larger number of pharmacies from the private sector. These two dominant categories are added in Figure 3.2 to convey the full picture of available SDPs.

As Figure 3.1 shows, PPHI/PRSP accounts for the largest share of static facilities in the public sector, followed by PWD and dispensaries. Notably, dispensaries, which are operated by $\mathrm{DoH}$, are shown separately. In the private sector, clinics of hakeems and homeopaths are available in the largest numbers, followed by dispensers' clinics, clinics of male doctors, and private hospitals. Doctors' clinics, LHV/midwife/nurse clinics and NGO clinics account for a small share of the private sector.

Figure 3.1: Distribution of Static Health Facilities in the Public and Private Sectors in the Study Districts

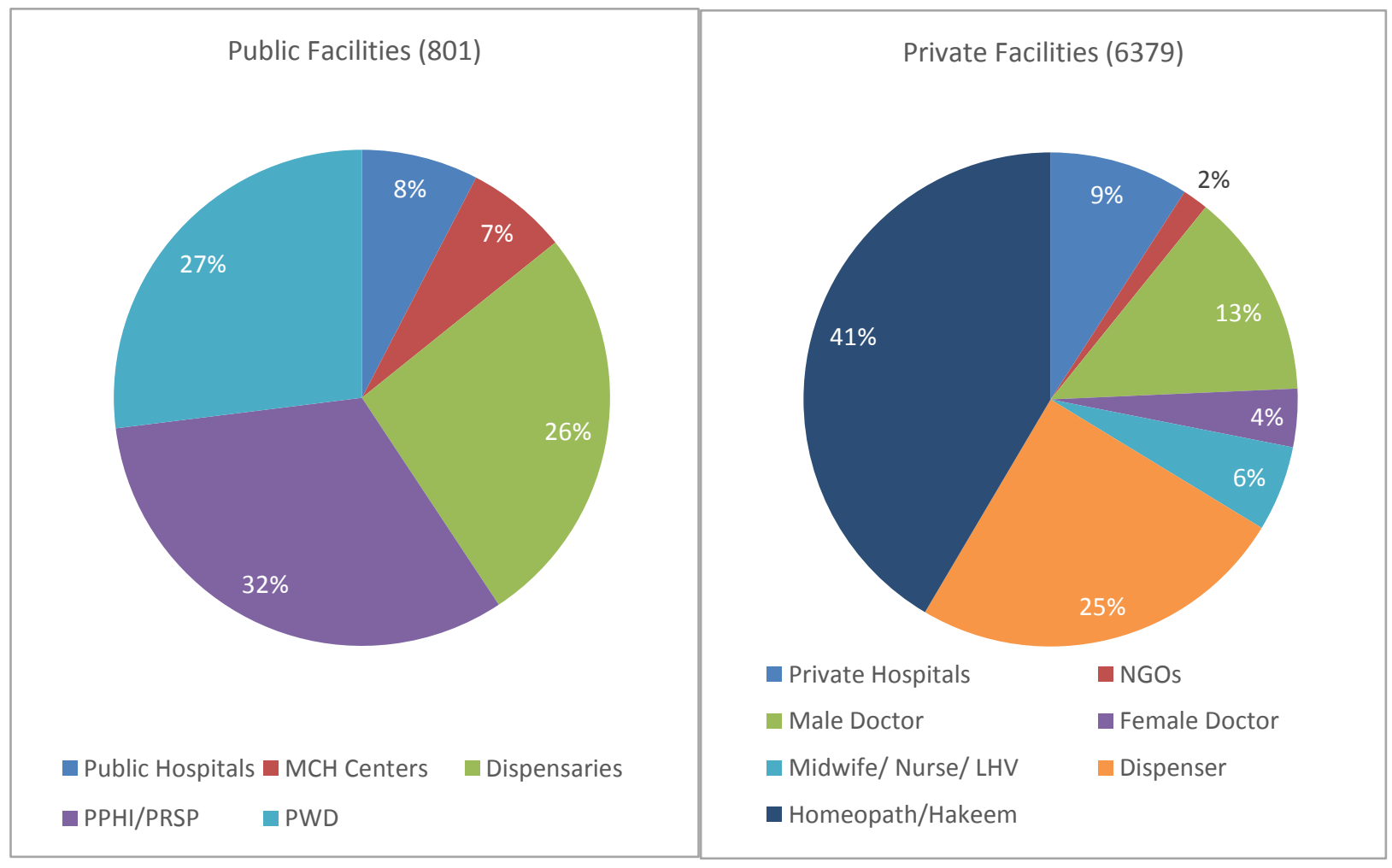


Figure 3.2 shows that LHWs and pharmacies are easily the largest channels providing and dispensing RH services and products, with LHWs comprising 84 percent of public sector SDPs, and pharmacies making up 45 percent of private sector channels.

Figure 3.2: Distribution of Facilities Including LHWs and Pharmacies in the Study Districts

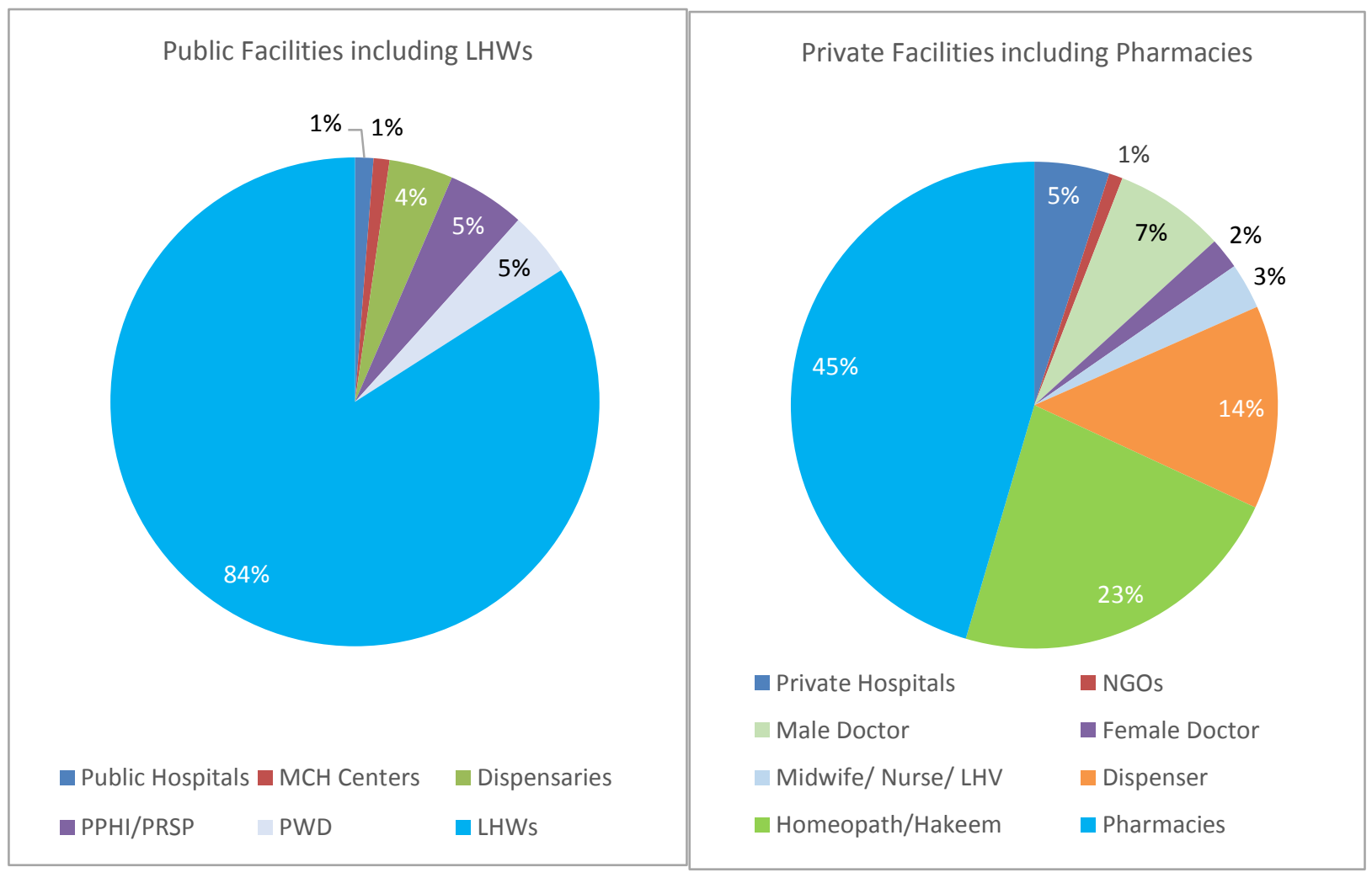

\section{Location of Health Facilities and Pharmacies in the Study Districts}

Of the 801 public static facilities surveyed, PPHI/PRSP facilities, LHWs, and dispensaries were mainly located in rural areas, while the rest were concentrated in urban areas. Most of the private facilities and pharmacies were located in urban areas, except dispenser clinics, which are more concentrated in rural areas.

Table 3.5 shows the urban/rural distribution of different types of health facilities in the study districts. The census methodology enabled the depiction and analysis of the precise geographic location of the health outlets, and this is presented in Figure 3.3. 
Table 3.5: Urban-rural Distribution of Health Facilities, Community Workers, and Pharmacies in the Study Districts

\begin{tabular}{|c|c|c|c|c|c|c|}
\hline \multirow[b]{2}{*}{ Channels } & \multicolumn{2}{|c|}{ Urban } & \multicolumn{2}{|c|}{ Rural } & \multicolumn{2}{|c|}{ Total } \\
\hline & $\%$ & $\mathrm{~N}$ & $\%$ & $\mathbf{N}$ & $\%$ & $\mathrm{~N}$ \\
\hline \multicolumn{7}{|l|}{ Department of Health } \\
\hline \multicolumn{7}{|l|}{ Category I } \\
\hline Teaching Hospitals & 100 & 16 & 0 & 0 & 100 & 16 \\
\hline DHQs & 100 & 9 & 0 & 0 & 100 & 9 \\
\hline \multicolumn{7}{|l|}{ Category II } \\
\hline THQS & 100 & 10 & 0 & 0 & 100 & 10 \\
\hline RHCs & 35 & 9 & 65 & 17 & 100 & 26 \\
\hline BHUs & - & - & 100 & 259 & 100 & 259 \\
\hline $\mathrm{MCH}$ Centers & 79 & 26 & 21 & 7 & 100 & 33 \\
\hline Maternity Homes & 90 & 18 & 10 & 2 & 100 & 20 \\
\hline \multicolumn{7}{|l|}{ Category III } \\
\hline Dispensaries & 37 & 79 & 63 & 133 & 100 & 212 \\
\hline TOTAL & 29 & 167 & 71 & 418 & 100 & 585 \\
\hline \multicolumn{7}{|l|}{ Population Welfare Department } \\
\hline RHSC-A/FHCS & 80 & 12 & 20 & 3 & 100 & 15 \\
\hline FWCs & 54 & 107 & 46 & 91 & 100 & 198 \\
\hline MSUs & 100 & 3 & 0 & 0 & 100 & 3 \\
\hline TOTAL & 56 & 122 & 44 & 94 & 100 & 216 \\
\hline \multicolumn{7}{|l|}{ Community-based Workers } \\
\hline LHWs & 30 & 1250 & 70 & 2971 & 100 & 4221 \\
\hline CMWs & 59 & 82 & 41 & 58 & 100 & 140 \\
\hline TOTAL & 31 & 1332 & 69 & 3029 & 100 & 4361 \\
\hline \multicolumn{7}{|l|}{ Private Sector } \\
\hline NGO Clinics & 74 & 79 & 26 & 28 & 100 & 107 \\
\hline Private Hospitals & 79 & 461 & 21 & 121 & 100 & 582 \\
\hline Male Doctor Clinics & 82 & 706 & 18 & 155 & 100 & 861 \\
\hline Female Doctor Clinics & 94 & 228 & 6 & 15 & 100 & 243 \\
\hline LHV/Nurse/Midwife Clinics & 50 & 178 & 50 & 179 & 100 & 357 \\
\hline Dispenser Clinics & 23 & 362 & 77 & 1219 & 100 & 1581 \\
\hline Homeopath/Hakeem Clinics & 74 & 1956 & 26 & 692 & 100 & 2648 \\
\hline TOTAL & 62 & 3970 & 38 & 2409 & 100 & 6379 \\
\hline Pharmacies & 73 & 3881 & 27 & 1435 & 100 & 5316 \\
\hline Overall & 56 & 9498 & 44 & 7359 & 100 & 16857 \\
\hline
\end{tabular}

BHUs and some of the RHCs are being managed by PPHI/PRSP.

Category I = Facilities with more than 50 beds

Category II = Facilities with 1 to 50 beds

Category III = Facilities not providing inpatient care 
Figure 3.3: Maps showing geographical location of public and private facilities in individual study districts
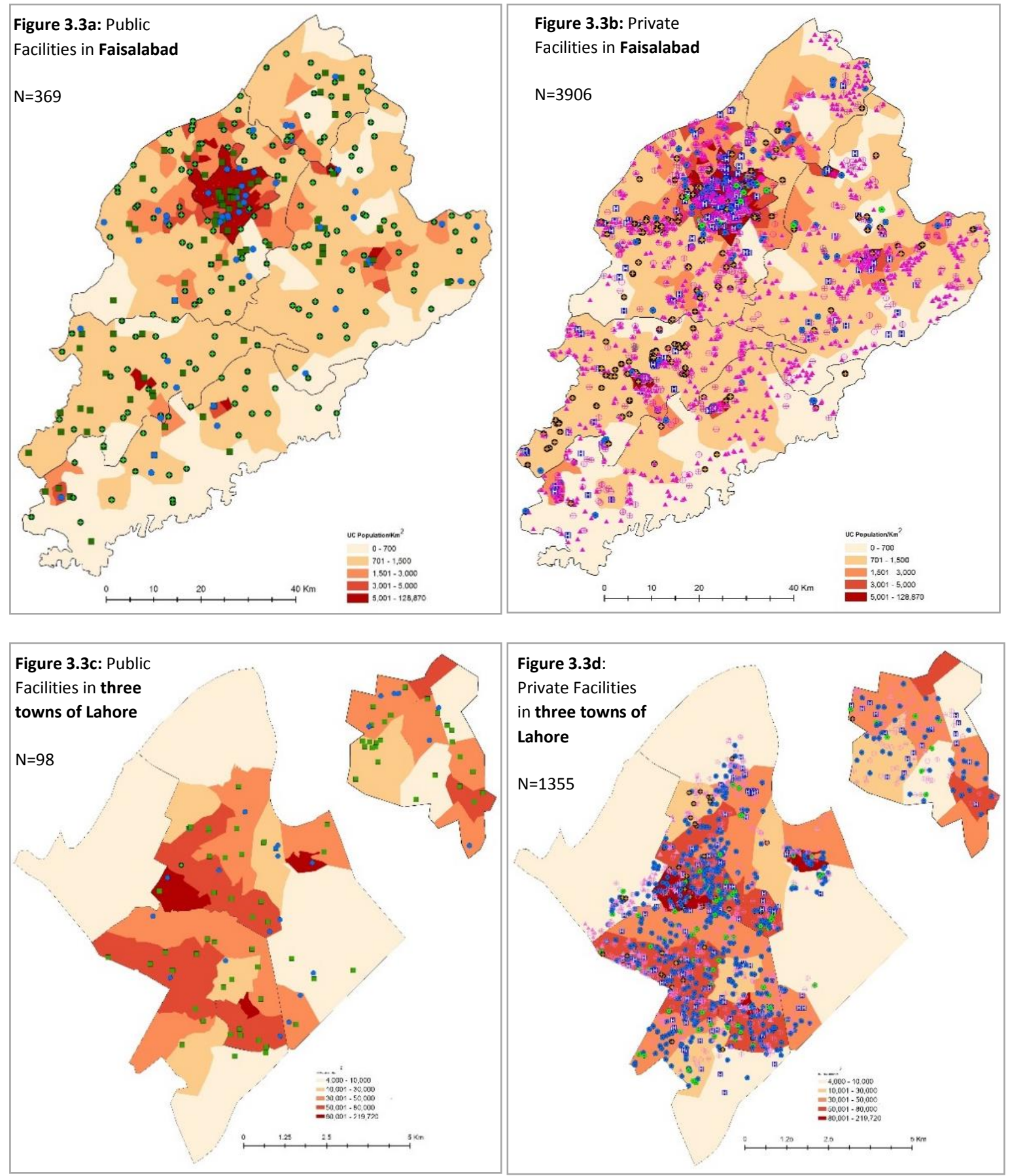

- Department of Health (DoH)

- Punjab Rural Support Programme (PRSP)

- Population Welfare Department (PWD)
(1) Private Hospitals

- Male Doctor Clinics

- Female Doctor Clinics

- LHV/Nurse/Midwife Clinics

4. Dispenser Clinics

$\oplus$ Homeopath/Hakeem Clinics 

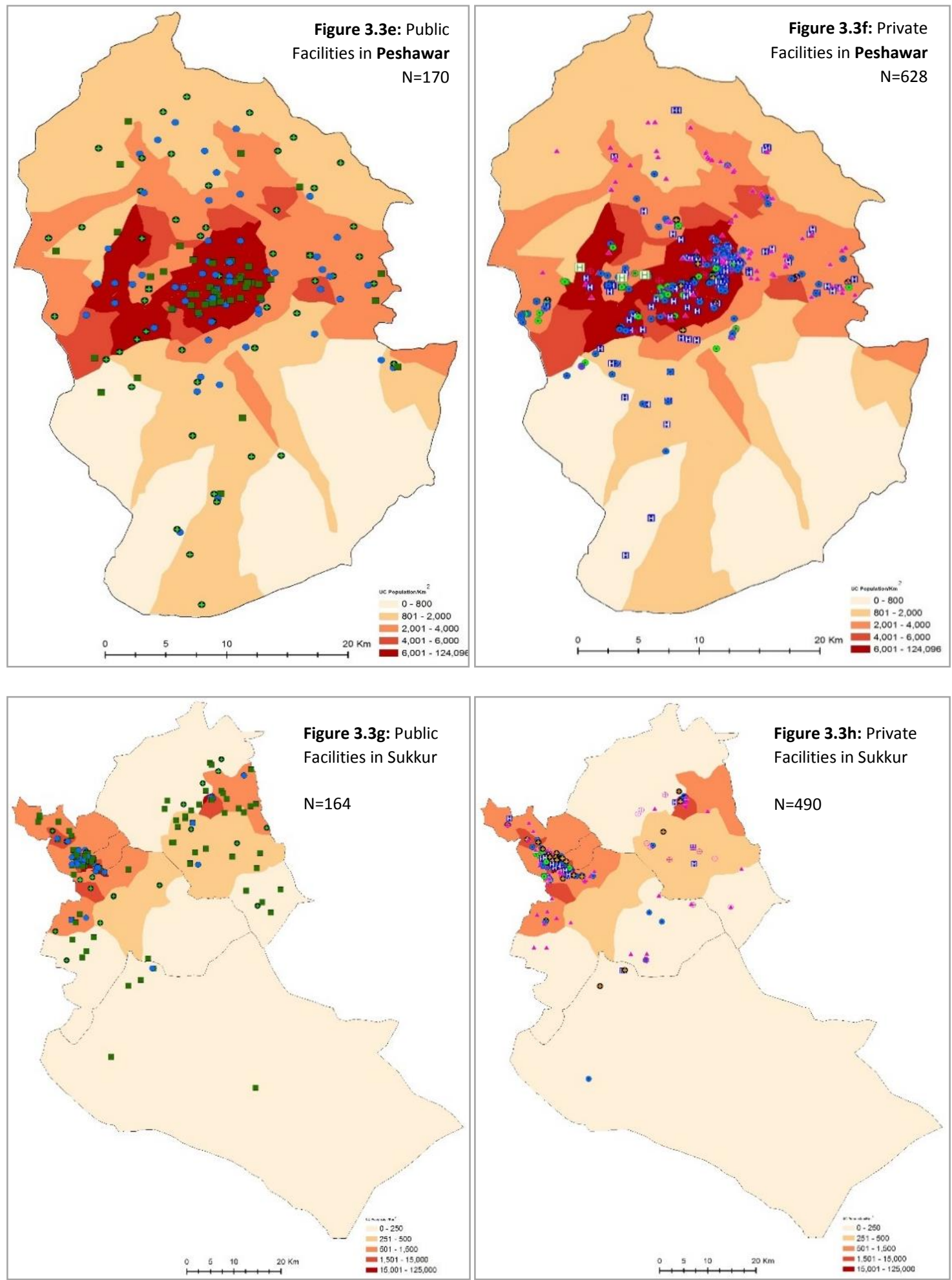

a Department of Health (DoH)

- People's Primary Health Care Initiative (PPHI)

- Population Welfare Department (PWD)

(1) Private Hospitals

- Male Doctor Clinics

- Female Doctor Clinics

- LHV/Nurse/Midwife Clinics

- Dispenser Clinics

$\oplus$ Homeopath/Hakeem Clinics 
The maps in Figure 3.3 show the wide dispersion of both public and private facilities in the primarily urban districts of Lahore, Faisalabad, Sukkur, and Peshawar. The maps convey an encouraging picture: At least in terms of physical presence, there is a sufficient spread of SDPs to provide FP services in the urbanized districts, especially when LHWs are taken into account. Presence does not guarantee provision of FP services, however. Only a small proportion of health facilities are actually involved in FP service provision, especially in the private sector, detailed in the following section; the maps in Figure 3.4 should be seen as depicting potential availability of FP services in the near future, rather than actual availability.

\section{Family Planning Services and Methods of Health Facilities and Pharmacies}

\section{Provision of Any Method}

During the census, health facilities and pharmacies were asked whether or not they were providing any FP services. Based on their responses, Table 3.6 shows the actual provision of FP services by sector, including pharmacies. The public sector, which has an explicit mandate to provide FP services, is providing services in both urban and rural areas. In particular PWD and PPHI are quite active in the dispensation of FP services, as are LHWs. However, the DoH facilities are not optimally engaged.

\section{Table 3.6: Proportion of Channels Offering any FP Services in Study district rural and urban} areas

\begin{tabular}{|c|c|c|c|c|c|}
\hline \multirow{2}{*}{ Channels } & \multicolumn{2}{|c|}{ Urban } & \multicolumn{2}{|c|}{ Rural } & \multirow{2}{*}{$\begin{array}{r}\text { Total } \\
\mathrm{N}\end{array}$} \\
\hline & $\%$ & $\mathrm{~N}$ & $\%$ & $\mathrm{~N}$ & \\
\hline \multicolumn{6}{|l|}{ Department of Health } \\
\hline \multicolumn{6}{|l|}{ Category I } \\
\hline Teaching Hospitals & 88 & 16 & 0 & 0 & 16 \\
\hline DHQs & 44 & 9 & 0 & 0 & 9 \\
\hline \multicolumn{6}{|l|}{ Category II } \\
\hline THQs & 90 & 10 & 0 & 0 & 10 \\
\hline $\mathrm{RHCs}$ & 78 & 9 & 94 & 17 & 26 \\
\hline BHUs & - & - & 100 & 259 & 259 \\
\hline MCH Centers & 85 & 26 & 100 & 7 & 33 \\
\hline Maternity Homes & 94 & 18 & 100 & 2 & 20 \\
\hline \multicolumn{6}{|l|}{ Category III } \\
\hline Dispensaries & 51 & 79 & 48 & 133 & 212 \\
\hline \multicolumn{6}{|l|}{ Population Welfare Department } \\
\hline RHSC-A/FHCs & 100 & 12 & 100 & 3 & 15 \\
\hline FWCs & 100 & 107 & 100 & 91 & 198 \\
\hline MSUs & 100 & 3 & 0 & 0 & 3 \\
\hline \multicolumn{6}{|l|}{ Community-based Workers } \\
\hline LHWs & 100 & 1,250 & 100 & 2,971 & 4,221 \\
\hline CMWs & 24 & 82 & 16 & 58 & 140 \\
\hline \multicolumn{6}{|l|}{ Private Sector } \\
\hline NGO Clinics & 59 & 79 & 39 & 28 & 107 \\
\hline Private Hospitals & 57 & 461 & 55 & 121 & 582 \\
\hline Male Doctor Clinics & 21 & 706 & 20 & 155 & 861 \\
\hline Female Doctor Clinics & 60 & 228 & 20 & 15 & 243 \\
\hline LHV/Nurse/Midwife Clinics & 70 & 178 & 56 & 179 & 357 \\
\hline Dispenser Clinics & 12 & 362 & 8 & 1,219 & 1,581 \\
\hline Homeopath/Hakeem Clinics & 5 & 1,956 & 6 & 692 & 2,648 \\
\hline Pharmacies & 69 & 3,881 & 53 & 1,435 & 5,316 \\
\hline
\end{tabular}

Category I = Facilities with more than 50 beds

Category II = Facilities with 1 to 50 beds

Category III = Facilities not providing inpatient services 
In comparison, the private sector, though it contains the larger numbers in their respective channels, is less likely to be providing FP services. Only 41 percent of static facilities in the urban areas and 29 percent in the rural areas of these combined urbanized districts are providing FP services.

With their wide network, there is huge potential to enhance provision of FP services in the private sector. In particular, it is interesting that pharmacies are performing better in terms of availability of FP products, rising to 69 percent in urban and 53 percent in rural areas.

Within the DoH large public hospitals are only located in the urban areas and providing FP services while mid-level hospitals of category II are more likely to be providing FP services in the rural areas. MCH centers and maternity homes are more located in the urban areas and a good proportion of these are providing FP services, and while there are fewer of these facilities in the rural areas, they are all providing FP services.

In the private sector, mainly LHV/nurse/midwife clinics are the most likely to be providing FP services both in urban $(70 \%)$ and rural (56\%) areas, followed by private hospitals and NGO clinics. Female doctor clinics are mainly operating as FP service providers in the urban areas, while male doctor clinics are more or less absent in that role. It is very notable that the larger channels comprised of dispensers and hakeems and homeopaths are not currently engaged in FP. This is a somewhat different finding compared to an earlier study that found dispensers to be quite involved in FP services (Haque et al. 2012). One of the reasons noted during the census was that there was a crackdown against non-registered dispensers, hakeem/homeopaths and pharmacists in Sukkur and Faisalabad districts.

The maps in Figure 3.4 (following page) show the spread of private and public health facilities actually providing FP services. A comparison with Figure 3.4 highlights the gap between actual and potential coverage of FP services. 
Figure 3.4: Location and proportion of public and private facilities providing any FP services

Figure 3.4a: Public Facilities Providing FP Services in Faisalabad

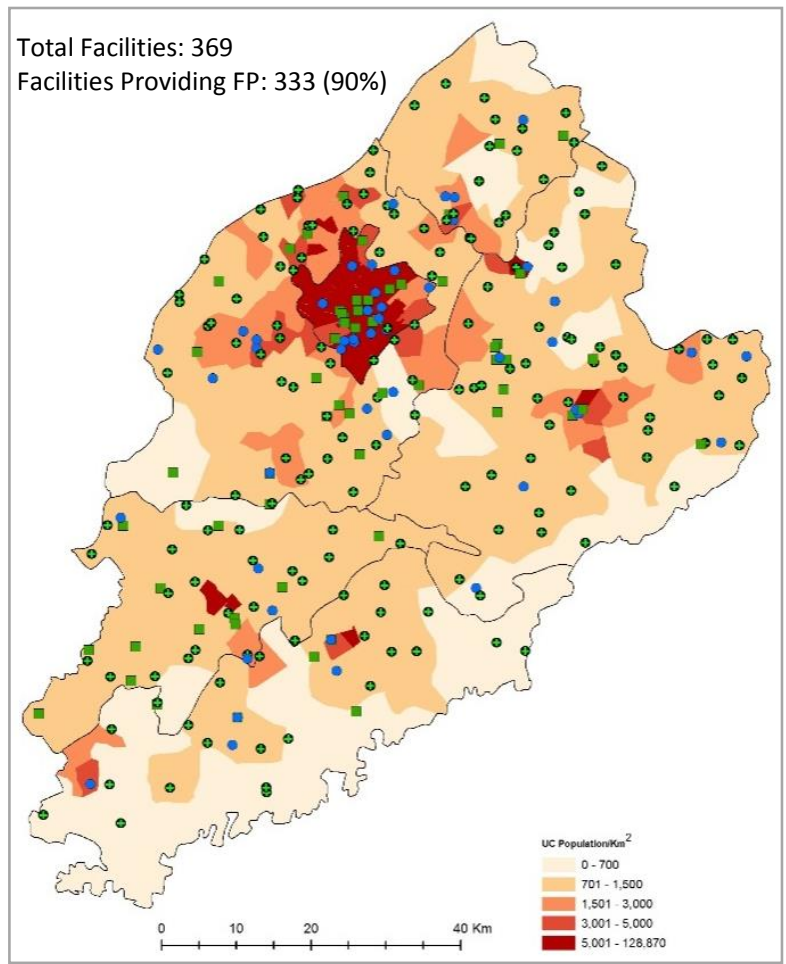

Figure 3.4c: Public Facilities Providing FP Services in three towns of Lahore

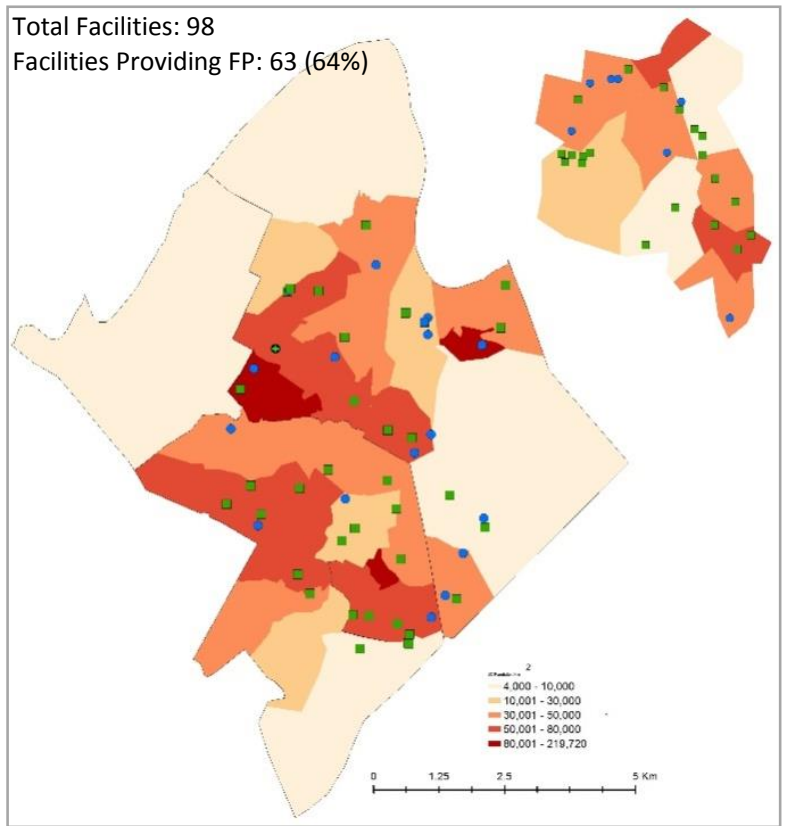

- Department of Health $(\mathrm{DoH})$

- Punjab Rural Support Programme (PRSP)

- Population Welfare Department (PWD)
Figure 3.4b: Private Facilities Providing FP Services in Faisalabad

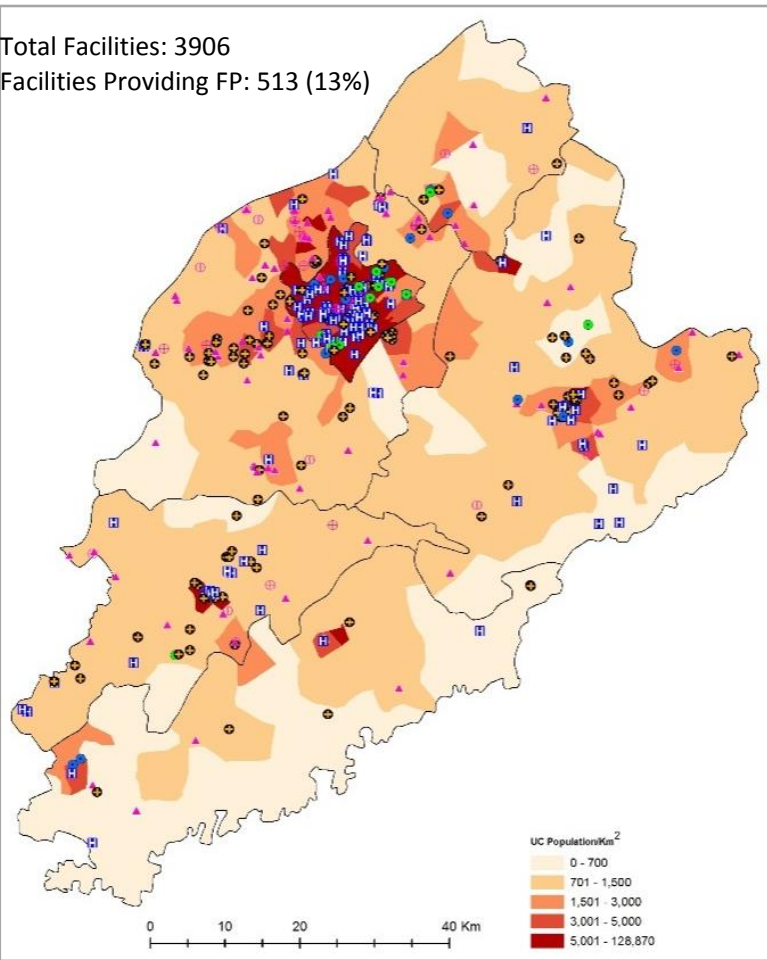

Figure 3.4d: Private Facilities Providing FP Services in three towns of Lahore

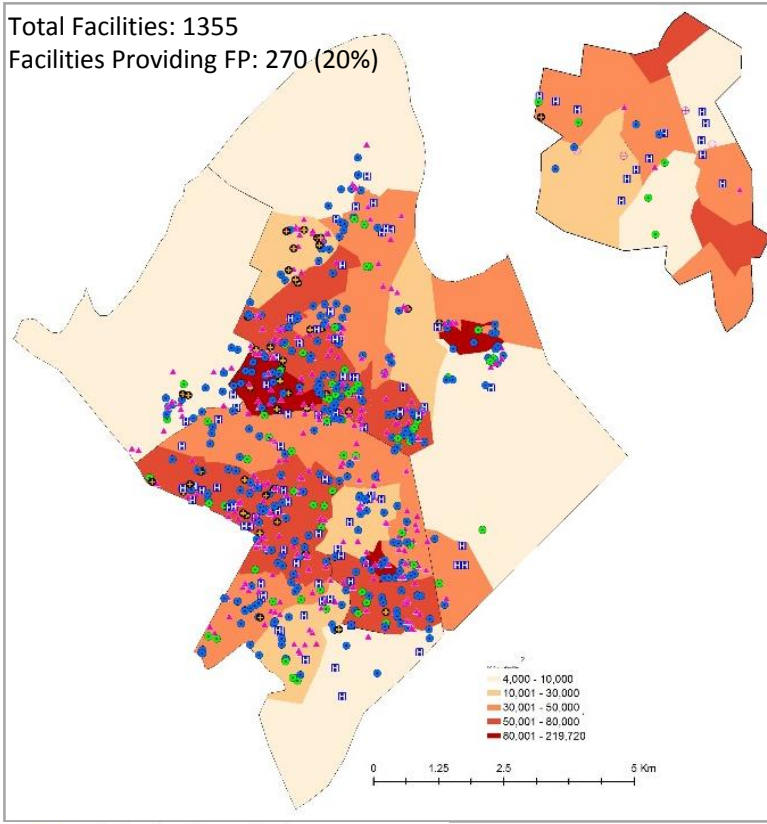

(t) Private Hospitals

- Male Doctor Clinics

- Female Doctor Clinics

- LHV/Nurse/Midwife Clinics

4. Dispenser Clinics

$\oplus \quad$ Homeopath/Hakeem Clinics 
Figure 3.4e: Public Facilities Providing FP Services in Peshawar

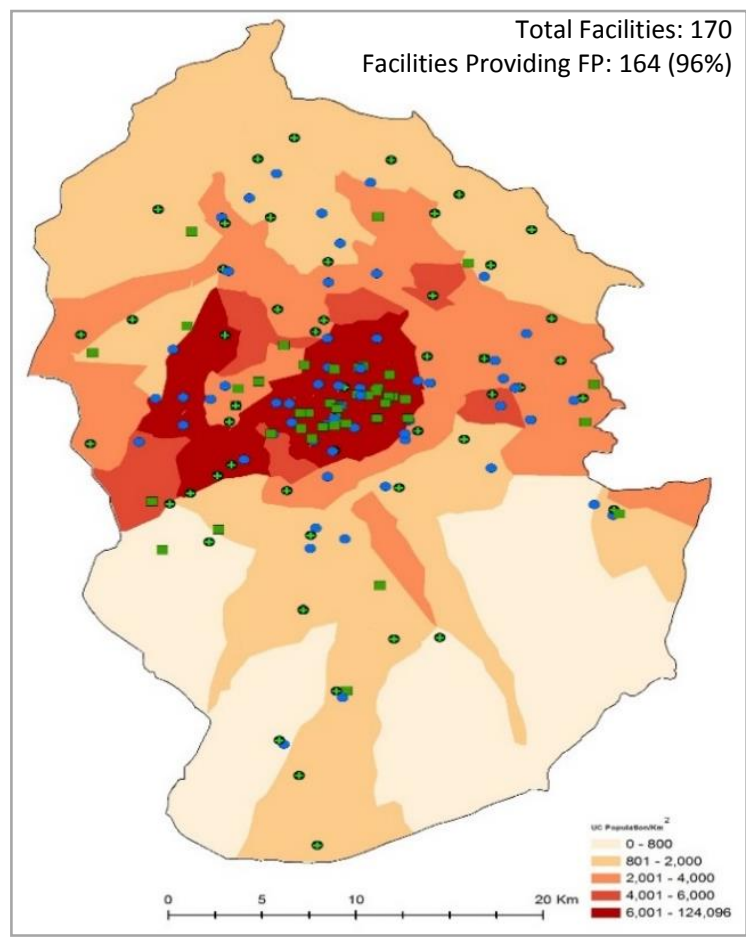

Figure 3.4g: Public Facilities Providing FP Services in Sukkur

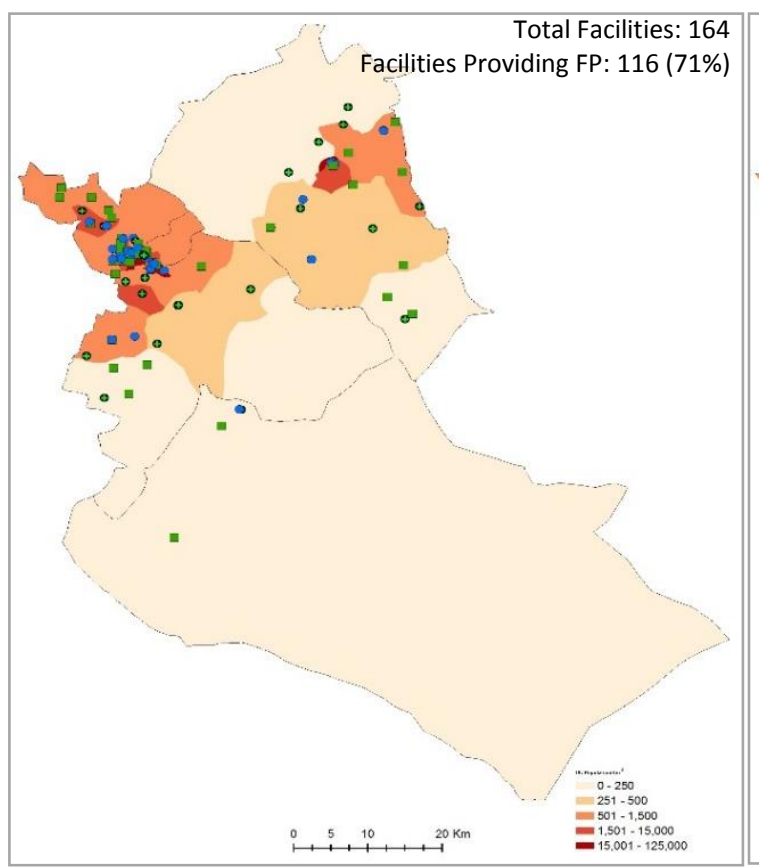

Department of Health $(\mathrm{DoH})$

- People's Primary Health Care Initiative (PPHI)

- Population Welfare Department (PWD)
Figure 3.4f: Private Facilities Providing FP Services in Peshawar

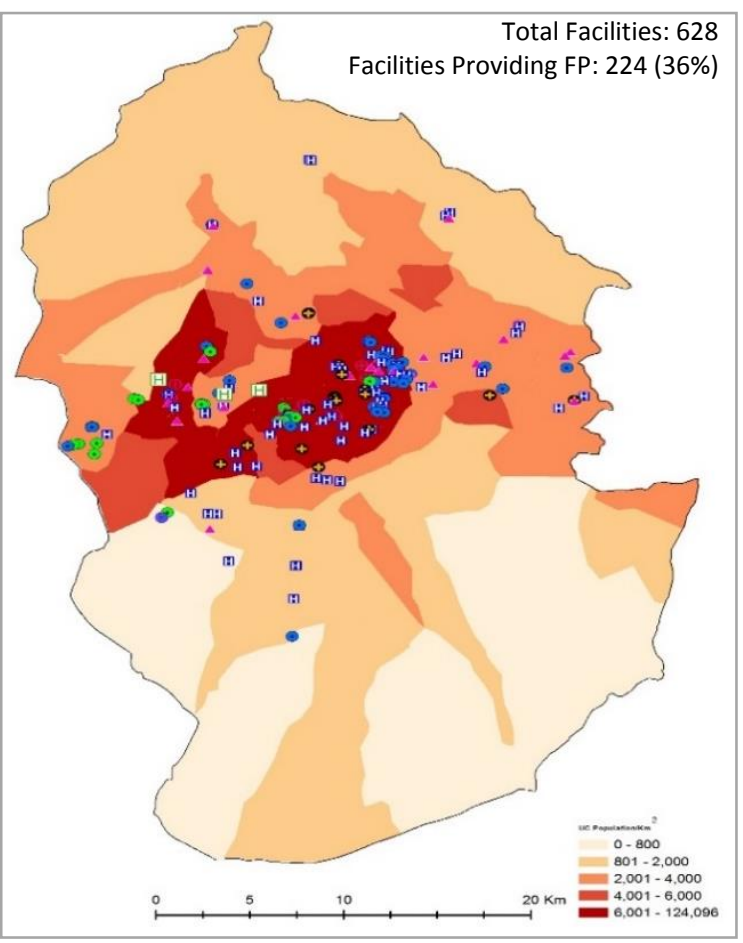

Figure 3.4h: Private Facilities Providing FP Services in Sukkur

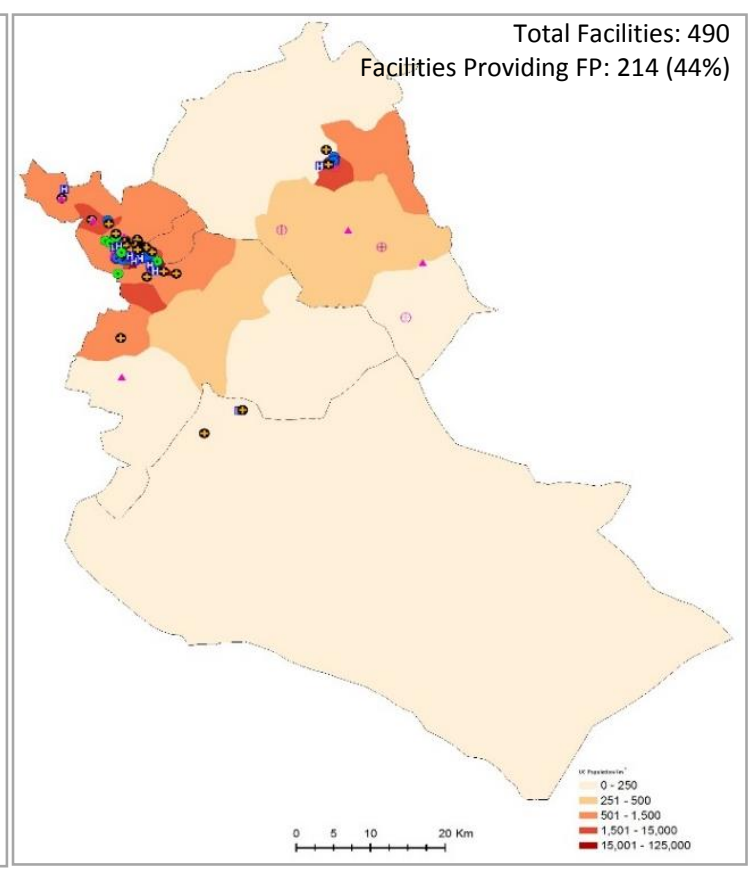

11 Private Hospitals

- Male Doctor Clinics

- Female Doctor Clinics

- LHV/Nurse/Midwife Clinics

4 Dispenser Clinics

$\oplus$ Homeopath/Hakeem Clinics 


\section{Provision of Specific Contraceptive Methods}

The earlier section presented a broad brush picture of whether service providers, clinics and facilities were providing any FP services. This picture transforms when we look at the details of what specific methods they are providing. Table 3.7 shows quite an impressive availability of condoms and pills across the major channels in the public sector and in pharmacies. The figures dip however when it comes to injectables, which could have been expected to be more widely available. Therefore, of these three methods that are expected to be almost universally available, injectable availability in rural areas is limited to LHWs, who are allowed only a second dose dispensation. Among pharmacies, 38 percent stock condoms and 29 percent stock pills in rural areas, but only 17 percent carry injectables.

Another unexpected deficiency is in the provision of ECPs, which could be more widely available in rural pharmacies and facilities. Hardly available in public facilities even in urban areas, non-available among LHWs and private facilities, they are carried by only 31 percent of urban pharmacies and a mere eight percent of rural pharmacies.

The IUD is expected to be less available in most channels since it requires trained female providers, but its low availability at both urban and rural public and private static facilities is remarkable.

Table 3.7: Provision of Specific FP Methods by Major Channels in Study Districts (\%)

\begin{tabular}{lrr|rr|rr|rr|rr|rr}
\hline \multirow{2}{*}{$\begin{array}{l}\text { Family Planning } \\
\text { Methods }\end{array}$} & \multicolumn{2}{c|}{ DoH } & \multicolumn{2}{c|}{ PPHI/PRSP } & \multicolumn{2}{c|}{ PWD } & \multicolumn{2}{c|}{ LHWs } & \multicolumn{2}{c}{ Private } & Pharmacies \\
\cline { 2 - 13 } & Urban & Rural & Urban & Rural & Urban & Rural & Urban & Rural & Urban & Rural & Urban & Rural \\
\hline Condoms & 36 & 34 & 77 & 81 & 97 & 91 & 100 & 100 & 5 & 6 & 54 & 38 \\
Oral Pills & 44 & 36 & 81 & 85 & 98 & 97 & 100 & 100 & 11 & 10 & 52 & 29 \\
Injectables* & 49 & 31 & 85 & 80 & 98 & 98 & 100 & 100 & 12 & 8 & 32 & 17 \\
IUDs & 43 & 25 & 69 & 74 & 98 & 94 & na** & na & 9 & 3 & 10 & 0 \\
ECPs & 22 & 6 & 35 & 19 & 57 & 24 & na & na & 6 & 2 & 31 & 8 \\
Implants & 9 & 3 & 31 & 8 & 11 & 3 & na & na & 1 & 0 & 0 & 0 \\
Female Sterilization & 72 & 11 & 0 & 0 & 9 & 0 & na & na & 49 & 10 & na & na \\
Male Sterilization & 22 & 0 & 0 & 0 & 4 & 0 & na & na & 17 & 1 & na & na \\
\hline
\end{tabular}

* LHWs are currently providing $2^{\text {nd }}$ and subsequent doses of injectables.

**na= Not Applicable

There is a definite need to rectify the situation in which DoH facilities are not fully providing services, and to advocate and facilitate an increased level of service provision both in urban and rural areas, which would enhance services for poorer and more remote population.

The deficit is much greater in private facilities both in urban and rural areas: only 10 percent of private facilities in the urban areas and even less than that in the rural areas are providing the most basic of contraceptive choice of condoms, pills, injectables and ECPs. Because of LHWs, private facilities seldom provide services in rural areas. However, the private sector has a huge potential and can be enabled to provide services both in urban and rural areas.

Table 3.8 shows a more detailed picture of provision of specific FP methods by each type of public and private facility. 
Table 3.8: Provision of Specific FP Methods by Facilities and Providers in the Study Districts (\%)

\begin{tabular}{|c|c|c|c|c|c|c|c|c|c|c|c|c|c|c|c|c|c|c|}
\hline \multirow[b]{2}{*}{ Channels } & \multicolumn{2}{|c|}{ Condoms } & \multicolumn{2}{|c|}{ Oral Pills } & \multicolumn{2}{|c|}{ Injectables } & \multicolumn{2}{|c|}{ IUDs } & \multicolumn{2}{|c|}{ ECPs } & \multicolumn{2}{|c|}{ Implants } & \multicolumn{2}{|c|}{$\begin{array}{c}\text { Female } \\
\text { Sterilization }\end{array}$} & \multicolumn{2}{|c|}{$\begin{array}{c}\text { Male } \\
\text { Sterilization }\end{array}$} & \multicolumn{2}{|c|}{ Total (N) } \\
\hline & U* & $\mathrm{R}^{*}$ & $U$ & $\mathrm{R}$ & $\mathrm{U}$ & $\mathbf{R}$ & $\mathrm{U}$ & $\mathrm{R}$ & $U$ & $\mathbf{R}$ & $\mathrm{U}$ & $\mathrm{R}$ & $\mathrm{U}$ & $\mathbf{R}$ & $U$ & $\mathrm{R}$ & $\mathrm{U}$ & $\mathbf{R}$ \\
\hline \multicolumn{19}{|l|}{ Department of Health } \\
\hline \multicolumn{19}{|l|}{ Category I } \\
\hline Teaching Hospitals & 44 & 0 & 69 & 0 & 69 & 0 & 69 & 0 & 56 & 0 & 44 & 0 & 75 & 0 & 25 & 0 & 16 & 0 \\
\hline DHQs & 33 & 0 & 33 & 0 & 33 & 0 & 33 & 0 & 11 & 0 & 0 & 0 & 0 & 0 & 0 & 0 & 9 & 0 \\
\hline Category II & & & & & & & & & & & & & 50 & & 10 & & & \\
\hline THQs & 70 & 0 & 70 & 0 & 70 & 0 & 70 & 0 & 30 & 0 & 20 & 0 & 0 & 0 & 0 & 0 & 10 & 0 \\
\hline RHCs & 67 & 71 & 67 & 76 & 78 & 65 & 78 & 65 & 56 & 24 & 11 & 0 & 0 & 0 & 0 & 0 & 9 & 17 \\
\hline BHUs & - & 81 & - & 85 & - & 80 & - & 74 & - & 19 & - & 8 & - & 0 & - & 0 & - & 259 \\
\hline MCH Centers & 50 & 71 & 58 & 71 & 69 & 71 & 69 & 71 & 23 & 29 & 4 & 29 & 0 & 0 & 0 & 0 & 26 & 7 \\
\hline Maternity Homes & 39 & 100 & 50 & 100 & 72 & 100 & 72 & 50 & 44 & 0 & 22 & 0 & 28 & 0 & 0 & 0 & 18 & 2 \\
\hline \multicolumn{19}{|l|}{ Category III } \\
\hline Health Post/Dispensary & 22 & 26 & 29 & 28 & 29 & 24 & 16 & 17 & 5 & 3 & 0 & 2 & 1 & 2 & 0 & 0 & 79 & 133 \\
\hline \multicolumn{19}{|l|}{ Population Welfare Department } \\
\hline RHSC-A/FHCs & 100 & 100 & 100 & 100 & 100 & 100 & 100 & 100 & 83 & 0 & 83 & 0 & 83 & 0 & 33 & 0 & 12 & 3 \\
\hline FWCs & 96 & 91 & 98 & 97 & 98 & 98 & 97 & 93 & 52 & 25 & 3 & 3 & 0 & 0 & 0 & 0 & 107 & 91 \\
\hline MSUs & 100 & 0 & 100 & 0 & 100 & 0 & 100 & 0 & 100 & 0 & 0 & 0 & 0 & 0 & 0 & 0 & 3 & 0 \\
\hline \multicolumn{19}{|l|}{ Community-based Workers } \\
\hline LHWs & 100 & 100 & 100 & 100 & 100 & 100 & na** & na & na & na & na & na & na & na & na & na & 1250 & 2971 \\
\hline CMWs & 13 & 0 & 15 & 2 & 16 & 2 & 16 & 0 & 11 & 0 & na & na & na & na & na & na & 82 & 58 \\
\hline \multicolumn{19}{|l|}{ Private Sector } \\
\hline NGO Clinics & 15 & 11 & 46 & 29 & 46 & 29 & 37 & 14 & 8 & 4 & 22 & 18 & 16 & 4 & 3 & 0 & 79 & 28 \\
\hline Private Hospitals & 16 & 21 & 33 & 40 & 40 & 36 & 39 & 25 & 7 & 4 & 18 & 9 & 15 & 6 & 4 & 1 & 461 & 121 \\
\hline Male Doctor Clinics & 5 & 8 & 8 & 10 & 8 & 5 & 2 & 2 & 0 & 0 & 3 & 1 & 0 & 0 & 0 & 0 & 706 & 155 \\
\hline Female Doctor Clinics & 10 & 0 & 34 & 7 & 43 & 7 & 38 & 7 & 4 & 0 & 21 & 0 & 6 & 0 & 1 & 0 & 228 & 15 \\
\hline LHV/Nurse/Midwife Clinics & 24 & 34 & 50 & 51 & 48 & 45 & 35 & 17 & 2 & 1 & 28 & 13 & 2 & 0 & 0 & 0 & 178 & 179 \\
\hline Dispenser Clinics & 3 & 3 & 5 & 5 & 3 & 4 & 0 & 0 & 0 & 0 & 2 & - & - & - & - & - & 362 & 1219 \\
\hline Homeopath/Hakeem Clinics & 1 & 1 & 1 & 1 & 0 & 1 & 0 & 0 & 0 & 0 & - & - & - & - & - & - & 1956 & 692 \\
\hline Pharmacies & 54 & 38 & 52 & 29 & 32 & 17 & 10 & 0 & 31 & 8 & 0 & 0 & na & na & na & na & 3881 & 1435 \\
\hline
\end{tabular}

*U=Urban, *R=Rural, **na= Not Applicable 
Large and mid-level public hospitals fare relatively better in providing oral pills followed by injectables and IUDs. MCH centers and maternity homes, with a much smaller size and clientele, are mainly providing injectables, oral pills, IUDs and condoms. Dispensaries are mainly providing oral pills followed by injectables and condoms.

PWD outlets, whose main mandate is FP and which should be providing all methods, are providing condoms, pills, injectables and IUDs both in urban and rural areas. However, these facilities need to accelerate their efforts to include ECP and implants in their repertoire. Facilities managed by the PPHI/PRSP are quite impressive in their provision of condoms, pills, injectables and IUDs but these facilities can easily include the provision of ECPS.

Once more, in the private sector, LHV/nurse/midwife clinics lead in the provision of FP services followed by private hospitals and NGOs clinics. However, all three sets of channels have huge potential to increase their level of provision.

Among the more disappointing performances are those of female doctor clinics, which are mostly functional with not even the full array of contraceptives in the urban areas, and male doctor clinics, which are hardly providing any FP services, even including condoms, in both urban and rural areas.

Dispensers are restricted to providing condoms. This cadre is the largest in size and impressive in its distribution in the rural areas, apart from being well respected in the community but its role in FP is almost negligible.

Assessing the adequacy of access in terms of available choices does not take into account the important element of the base population that facilities and providers are to service. We took the availability of services to another scale to assess the adequacy of access based on the population size of each district. Table 3.9 presents some interesting variations. In looking at the availability of services, it is clear that the private facilities outnumber public facilities in all four districts shown separately. The average number of private health facilities per 10,000 population ranges from 1.7 in Peshawar to 5.4 in Faisalabad. However, when classified by the number of facilities offering at least one FP service, the number of private facilities falls to 0.6 per 10,000 population in Peshawar and 0.7 in Faisalabad.

The overall average availability of at least one method in either public or private static facility is 1.3 facilities per 10,000 population. When looking at the availability of at least 3 contraceptive methods, availability falls to an average of 0.45 facilities per 10,000 population. Access increases considerably when LHWs are included; access increases to 4.1 per 10,000 population for at least one method and 0.25 for five or more methods due to their restricted current role of LHWs. 
Table 3.9: Provision of FP Services by Population Size in the Study Districts

\begin{tabular}{|c|c|c|c|c|c|c|c|c|c|c|c|}
\hline District & Methods & Population & $\begin{array}{c}\text { Total } \\
\text { Public } \\
\text { Static } \\
\text { facilities } \\
\text { per } \\
10,000 \\
\text { Population }\end{array}$ & $\begin{array}{l}\text { Public } \\
\text { Facilities } \\
\text { (Providing } \\
\text { FP) per } \\
\text { 10,000 } \\
\text { Population }\end{array}$ & $\begin{array}{c}\text { Total } \\
\text { Private } \\
\text { facilities } \\
\text { per } \\
10,000 \\
\text { Population }\end{array}$ & $\begin{array}{l}\text { Private } \\
\text { Facilities } \\
\text { (Providing } \\
\text { FP) per } \\
\text { 10,000 } \\
\text { Population }\end{array}$ & $\begin{array}{l}\text { LHWs } \\
\text { (Providing } \\
\text { FP) per } \\
10,000 \\
\text { Population }\end{array}$ & $\begin{array}{l}\text { CMWs } \\
\text { (Providing } \\
\text { FP) per } \\
10,000 \\
\text { Population }\end{array}$ & $\begin{array}{l}\text { Public Static } \\
\text { and Private } \\
\text { Facilities } \\
\text { (Providing } \\
\text { FP) per } \\
\text { 10,000 } \\
\text { Population }\end{array}$ & $\begin{array}{c}\text { Public } \\
\text { including } \\
\text { LHWs and } \\
\text { Private } \\
\text { Facilities } \\
\text { (Providing } \\
\text { FP) }\end{array}$ & $\begin{array}{l}\text { Public, } \\
\text { LHWs, } \\
\text { CMWs and } \\
\text { Private } \\
\text { Facilities } \\
\text { (Providing } \\
\text { FP) }\end{array}$ \\
\hline \multirow{3}{*}{ Faisalabad } & Any method & $7,247,000$ & 0.5 & 0.45 & 5.39 & 0.71 & 3.1 & - & 1.16 & 4.26 & 4.26 \\
\hline & $3+$ methods & $7,247,000$ & 0.5 & 0.24 & 5.39 & 0.29 & 3.1 & - & 0.53 & 3.63 & 3.63 \\
\hline & $5+$ methods & $7,247,000$ & 0.5 & 0.1 & 5.39 & 0.09 & - & - & 0.19 & 0.19 & 0.19 \\
\hline \multirow{3}{*}{ Lahore } & Any method & $2,685,440$ & 0.28 & 0.18 & 5.33 & 1.1 & 0.84 & 0.03 & 1.27 & 2.11 & 2.14 \\
\hline & $3+$ methods & $2,685,440$ & 0.28 & 0.06 & 5.33 & 0.34 & 0.84 & 0.01 & 0.4 & 1.24 & 1.25 \\
\hline & $5+$ methods & $2,685,440$ & 0.28 & 0.09 & 5.33 & 0.14 & - & 0.00 & 0.23 & 0.23 & 0.23 \\
\hline \multirow{3}{*}{ Peshawar } & Any method & $3,702,000$ & 0.45 & 0.44 & 1.7 & 0.61 & 2.33 & - & 1.04 & 3.37 & 3.37 \\
\hline & $3+$ methods & $3,702,000$ & 0.45 & 0.09 & 1.7 & 0.25 & 2.33 & - & 0.34 & 2.67 & 2.67 \\
\hline & $5+$ methods & $3,702,000$ & 0.45 & 0.07 & 1.7 & 0.06 & - & - & 0.13 & 0.13 & 0.13 \\
\hline \multirow{3}{*}{ Sukkur } & Any method & $1,342,000$ & 1.22 & 0.86 & 4.34 & 1.7 & 6.61 & 0.1 & 2.56 & 9.17 & 9.27 \\
\hline & $3+$ methods & $1,342,000$ & 1.22 & 0.15 & 4.34 & 0.24 & 6.61 & 0.07 & 0.39 & 0.07 & 7.07 \\
\hline & $5+$ methods & $1,342,000$ & 1.22 & 0.57 & 4.34 & 0.37 & - & 0.04 & 0.93 & 0.93 & 0.97 \\
\hline \multirow{3}{*}{ Total } & Any method & $14,976,440$ & 0.51 & 0.44 & 4.37 & 0.84 & 2.82 & 0.01 & 1.28 & 4.1 & 4.11 \\
\hline & $3+$ methods & $14,976,440$ & 0.51 & 0.16 & 4.37 & 0.29 & 2.82 & 0.01 & 0.45 & 3.27 & 3.28 \\
\hline & $5+$ methods & $14,976,440$ & 0.51 & 0.13 & 4.37 & 0.11 & - & 0.00 & 0.25 & 0.25 & 0.25 \\
\hline
\end{tabular}




\section{Service Quality in the Public and Private Sectors}

For a complete view of access to FP services, separate from examining the availability of FP services and the choice of methods, it is critical to assess the quality of available FP services, because quality of care influences users' eventual satisfaction with the services they receive and whether or not they will continue to use FP services, and thus the potential of increasing utilization of available FP services.

During the census of health facilities in the study districts, the quality of services at each facility was assessed for a range of criteria, including availability of essential amenities, functional general medical equipment, IUD insertion kits, infection prevention measures, service providers, and contraceptive stocks, knowledge of FP among service providers, as well as their behavior towards clients, and facility hours.

\section{Availability of Essential Amenities}

During the census, public and private facilities were asked if they have essential amenities such as running water, electricity, a toilet for clients, waiting room or veranda, and separate room for examination. The responses, summarized in Table 3.10, indicate that, in the public sector, essential amenities are quite adequate at larger DoH and PWD hospitals and facilities, though less so at DoH and PPHI facilities. Most amenities are also available in the private sector, but some, such as client toilets, waiting rooms, and a separate room for examination, are not available at some private facilities.

Table 3.10: Availability of Essential Amenities at Public and Private Facilities (\%)

\begin{tabular}{|c|c|c|c|c|c|c|}
\hline & $\begin{array}{l}\text { Running } \\
\text { water }\end{array}$ & Electricity & $\begin{array}{c}\text { Toilet for } \\
\text { clients with } \\
\text { water(female) }\end{array}$ & $\begin{array}{l}\text { Waiting room/ } \\
\text { veranda }\end{array}$ & $\begin{array}{l}\text { Separate } \\
\text { room for } \\
\text { examination }\end{array}$ & $\begin{array}{l}\text { Total } \\
\text { (N) }\end{array}$ \\
\hline \multicolumn{7}{|l|}{ Department of Health } \\
\hline Teaching Hospitals & 100 & 100 & 100 & 100 & 100 & 16 \\
\hline DHQs & 100 & 100 & 100 & 100 & 100 & 9 \\
\hline THQS & 100 & 100 & 100 & 100 & 100 & 8 \\
\hline RHCs & 81 & 77 & 81 & 81 & 85 & 22 \\
\hline BHUs & 86 & 86 & 75 & 70 & 68 & 228 \\
\hline $\mathrm{MCH}$ Centers & 39 & 39 & 36 & 33 & 21 & 13 \\
\hline Maternity Homes & 60 & 100 & 50 & 60 & 60 & 20 \\
\hline Health Post/Dispensary & 57 & 59 & 28 & 28 & 24 & 133 \\
\hline Total & 425 & 435 & 330 & 321 & 304 & 451 \\
\hline \multicolumn{7}{|c|}{ Population Welfare Department } \\
\hline RHSC-A/FHCS & 100 & 100 & 100 & 100 & 100 & 15 \\
\hline FWCs & 100 & 100 & 45 & 37 & 39 & 198 \\
\hline Total & 213 & 213 & 105 & 88 & 91 & 213 \\
\hline \multicolumn{7}{|l|}{ Private health facilities } \\
\hline NGO Clinics & 72 & 72 & 55 & 51 & 50 & 79 \\
\hline Private Hospitals* & 84 & 83 & 74 & 73 & 72 & 513 \\
\hline Male Doctor Clinics & 57 & 63 & 14 & 31 & 21 & 545 \\
\hline Female Doctor Clinics & 64 & 63 & 42 & 37 & 39 & 156 \\
\hline $\begin{array}{l}\text { Midwife/Nurse/LHV } \\
\text { Clinics }\end{array}$ & 84 & 87 & 46 & 25 & 33 & 315 \\
\hline Dispenser Clinics & 72 & 91 & 3 & 13 & 8 & 1,461 \\
\hline $\begin{array}{l}\text { Homeopath/Hakeem } \\
\text { Clinics }\end{array}$ & 59 & 65 & 1 & 18 & 6 & 1,753 \\
\hline Total & 4,199 & 4,729 & 958 & 1,622 & 1,155 & 4,822 \\
\hline
\end{tabular}




\section{Availability of Functional General Medical Equipment}

The availability of general equipment at larger and mid-level hospitals of $\mathrm{DoH}$ is quite adequate both in urban and rural areas, though it is lacking at other DoH facilities (Table 3.11). An overhead lamp and delivery or examination table were available at both urban and rural PWD facilities. A good proportion of NGO clinics, private hospitals, and LHV/nurse/midwife clinics reported having most general equipment available.

Table 3.11: Availability of Functional General Medical Equipment at Public and Private Facilities in the Study Districts (\%)

\begin{tabular}{|c|c|c|c|c|c|c|}
\hline & $\begin{array}{l}\text { Vacuum } \\
\text { Extractor }\end{array}$ & $\begin{array}{c}\text { Ultra } \\
\text { sound } \\
\text { machine }\end{array}$ & $\begin{array}{c}\text { X-ray } \\
\text { machine }\end{array}$ & $\begin{array}{l}\text { Overhead } \\
\text { Lamp }\end{array}$ & $\begin{array}{c}\text { Delivery/Examination } \\
\text { Table }\end{array}$ & $\begin{array}{c}\text { Total } \\
(\mathrm{N})\end{array}$ \\
\hline \multicolumn{7}{|l|}{ Department of Health } \\
\hline Teaching Hospitals & 100 & 100 & 100 & 100 & 100 & 11 \\
\hline DHQS & 100 & 100 & 100 & 100 & 100 & 9 \\
\hline THQS & 63 & 100 & 88 & 100 & 100 & 8 \\
\hline RHCs & 23 & 68 & 91 & 86 & 95 & 22 \\
\hline BHUs & 15 & 12 & 0 & 67 & 100 & 203 \\
\hline $\mathrm{MCH}$ Centers & 18 & 27 & 27 & 36 & 91 & 11 \\
\hline Maternity Homes & 50 & 50 & 13 & 75 & 100 & 8 \\
\hline Health Post/Dispensary & 14 & 9 & 0 & 71 & 91 & 35 \\
\hline Total & 71 & 78 & 52 & 218 & 302 & 307 \\
\hline \multicolumn{7}{|c|}{ Population Welfare Department } \\
\hline RHSC-A/FHCS & na* & na & na & 100 & 100 & 4 \\
\hline FWCs & na & na & na & 79 & 96 & 52 \\
\hline MSUs & na & na & na & 0 & 100 & 2 \\
\hline Total & na & na & na & 45 & 56 & 58 \\
\hline \multicolumn{7}{|l|}{ Private Hospitals } \\
\hline NGO Clinics & 36 & 62 & 22 & 70 & 82 & 50 \\
\hline Private Hospitals & 53 & 81 & 26 & 83 & 92 & 423 \\
\hline Male Doctor Clinics & 5 & 58 & 3 & 55 & 32 & 74 \\
\hline Female Doctor Clinics & 29 & 67 & 3 & 70 & 78 & 119 \\
\hline $\begin{array}{l}\text { Midwife/Nurse/LHV } \\
\text { Clinics }\end{array}$ & 4 & 18 & 1 & 47 & 96 & 187 \\
\hline Dispenser Clinics & 25 & 75 & 25 & 50 & 50 & 4 \\
\hline $\begin{array}{l}\text { Homeopath/Hakeem } \\
\text { Clinics }\end{array}$ & 0 & 0 & 0 & 0 & 0 & 0 \\
\hline Total & 289 & 532 & 129 & 599 & 730 & 857 \\
\hline
\end{tabular}




\section{Infection Prevention Measures}

Infection prevention measures were found to be weak, especially at private facilities, only half of which had suitable protocols. In the public sector, larger DoH hospitals and PWD facilities had a relatively better level of infection prevention measures than other facilities.

Table 3.12: Availability of Infection Prevention Arrangements at Public and Private Facilities in the Study Districts (\%)

\begin{tabular}{|c|c|c|c|c|c|}
\hline & $\begin{array}{l}\text { With chlorine/ } \\
\text { bleach }\end{array}$ & $\begin{array}{l}\text { With soup } \\
\text { and water }\end{array}$ & $\begin{array}{l}\text { Sterilizing by } \\
\text { boiling/ } \\
\text { disinfection }\end{array}$ & Autoclave & Total (N) \\
\hline \multicolumn{6}{|l|}{ Department of Health } \\
\hline Teaching Hospitals & 73 & 73 & 45 & 100 & 11 \\
\hline DHQs & 56 & 33 & 56 & 100 & 9 \\
\hline THQS & 63 & 75 & 38 & 100 & 8 \\
\hline RHCs & 55 & 55 & 32 & 82 & 22 \\
\hline BHUs & 63 & 55 & 50 & 62 & 208 \\
\hline $\mathrm{MCH}$ Centers & 55 & 45 & 82 & 36 & 11 \\
\hline Maternity Homes & 71 & 71 & 57 & 57 & 7 \\
\hline Health Post/Dispensary & 46 & 65 & 69 & 18 & 89 \\
\hline Total & 213 & 212 & 199 & 198 & 365 \\
\hline \multicolumn{6}{|l|}{ Population Welfare Department } \\
\hline RHSC-A/FHCs & 75 & 75 & 38 & 100 & 8 \\
\hline FWCs & 73 & 62 & 76 & 19 & 79 \\
\hline MSUs & 100 & 0 & 100 & 0 & 2 \\
\hline Total & 66 & 55 & 65 & 23 & 89 \\
\hline \multicolumn{6}{|l|}{ Private health facilities } \\
\hline NGO Clinics & 57 & 52 & 59 & 53 & 58 \\
\hline Private Hospitals* & 58 & 52 & 52 & 59 & 441 \\
\hline Male Doctor Clinics & 42 & 68 & 67 & 13 & 293 \\
\hline Female Doctor Clinics & 67 & 45 & 64 & 38 & 126 \\
\hline Midwife/Nurse/LHV Clinics & 64 & 55 & 66 & 18 & 214 \\
\hline Dispenser Clinics & 31 & 73 & 41 & 3 & 461 \\
\hline Homeopath/Hakeem Clinics & 36 & 72 & 21 & 1 & 194 \\
\hline Total & 842 & 1109 & 914 & 428 & 1787 \\
\hline
\end{tabular}




\section{Facility Hours}

Only a limited number of public and private facilities are open 24 hours, which limits FP and other health service availability for women (Figure 3.5). The public sector is slightly better in urban areas, because major facilities are located there, but in rural areas public facilities are almost non-functional in the evenings.

Figure 3.5: Facilities Providing 24-hour Services by Public/Private Sector ( $N=7320)$
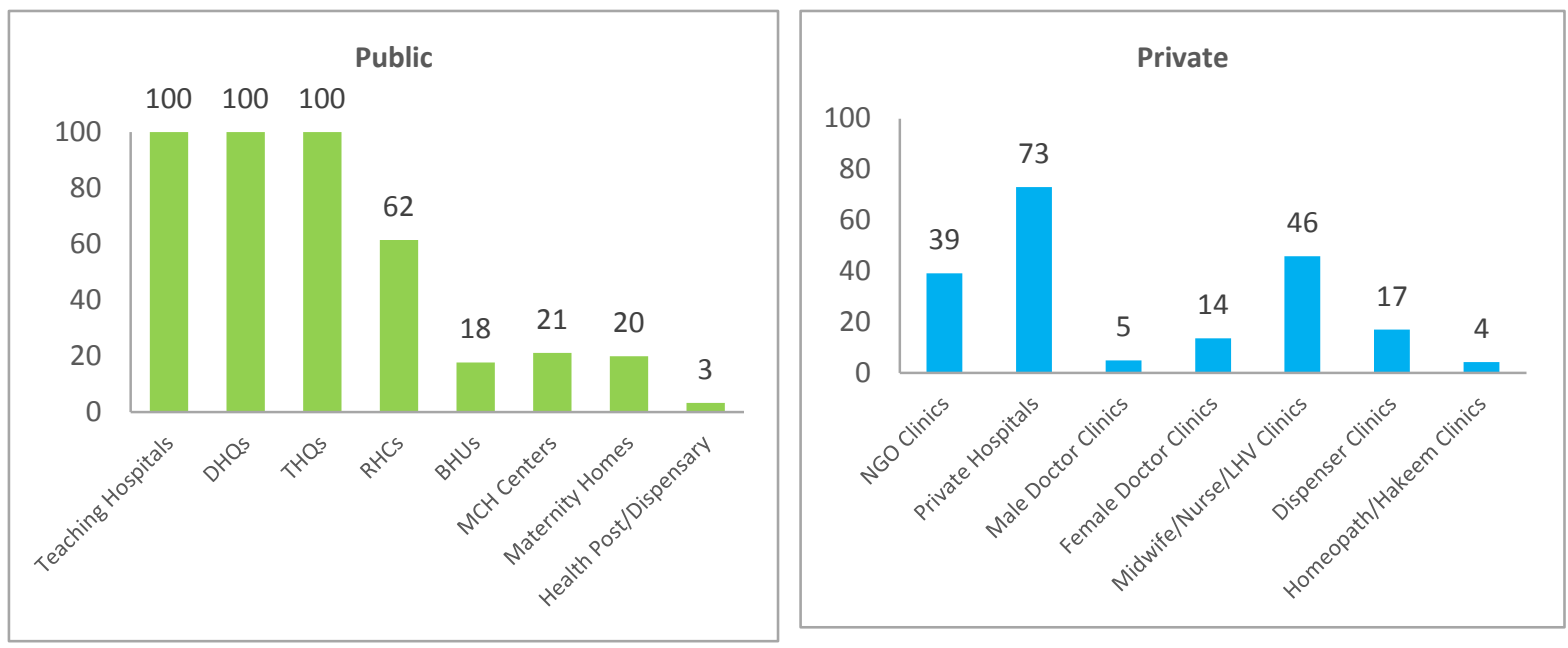

Only larger and mid-level DoH hospitals provide 24 hour services, despite DoH mandates for remaining open around the clock. PWD facilities are only open in the mornings, however.

Fewer private sector facilities remain open 24 hours; however, a good proportion of private hospitals, LHV/nurse/midwife clinics, and NGO clinics operate around the clock.

\section{Availability of Doctors and Mid-Level Providers}

All larger DOH hospitals reported both female doctors and mid-level providers. A good proportion of mid-level hospitals also reported female doctors and mid-level providers, with the exception of BHUs, MCH centers, and dispensaries, which are substantial in number. Most PWD RHSC-A/FHC facilities reported both female doctors and mid-level providers available (Table 3.13).

A good proportion of NGO clinics, private hospitals, and female doctor clinics reported female doctors or mid-level providers available.

This study also found, that while female service providers were available at DoH and PPHI/PRSP facilities, they were mainly present only in mornings, and their availability dropped significantly in the evenings. This corroborates similar findings of an earlier Population Council study that found that only private sector facilities have at least mid-level female service providers available both morning and evening shifts, while public facilities have low availability of female providers in the evenings (Rashida et al. 2015). 
Table 3.13: Availability of Female Doctors and Mid-level Providers to Provide Family Planning Services at Public and Private Facilities in the Study Districts (\%)

\begin{tabular}{lccc}
\hline & $\begin{array}{c}\text { At least } \\
\text { one female } \\
\text { doctor available in facility }\end{array}$ & $\begin{array}{c}\text { At least one female } \\
\text { paramedic } \\
\text { available in facility }\end{array}$ & Total (N) \\
\hline Department of Health & & & \\
Teaching Hospitals & 100 & 100 & 16 \\
DHQs & 100 & 100 & 9 \\
THQs & 100 & 100 & 10 \\
RHCs & 81 & 85 & 26 \\
BHUs & 26 & 78 & 259 \\
MCH Centers & 12 & 88 & 33 \\
Maternity Homes & 85 & 60 & 20 \\
Health Post/Dispensary & 9 & 27 & 212 \\
Total & 28 & 61 & 585 \\
Population Welfare Department & & & \\
RHSC-A/FHCs & 80 & 100 & 15 \\
FWCs & - & 100 & 198 \\
Total & 6 & 99 & 216 \\
Private health facilities & & & 107 \\
NGO Clinics & 48 & 58 & 582 \\
Private Hospitals & 70 & 80 & 861 \\
Male Doctor Clinics & 8 & 8 & 243 \\
Female Doctor Clinics & 88 & 39 & 357 \\
Midwife/Nurse/LHV Clinics & 1 & 100 & 1,581 \\
Dispenser Clinics & 0.3 & 1 & 2,648 \\
Homeopath/Hakeem Clinics & 0.2 & 0.5 & 6,379 \\
Total & 12 & 17 & \\
\hline
\end{tabular}

\section{Availability of IUD Insertion Kits}

Availability of IUD kits is higher at larger hospitals and at BHUs. Availability of complete IUD insertion kits is quite inadequate at $\mathrm{MCH}$ centers and maternity homes (less than $50 \%$ ), and even lower at private health facilities (less than 60\%). In the absence of the complete IUD kit, at least an essential kit should be available; however, more than half of the private facilities also lack this basic commodity (show in Figure 3.6). 
Figure 3.6: Availability of Complete IUD Insertion Kit at Public and Private Facilities
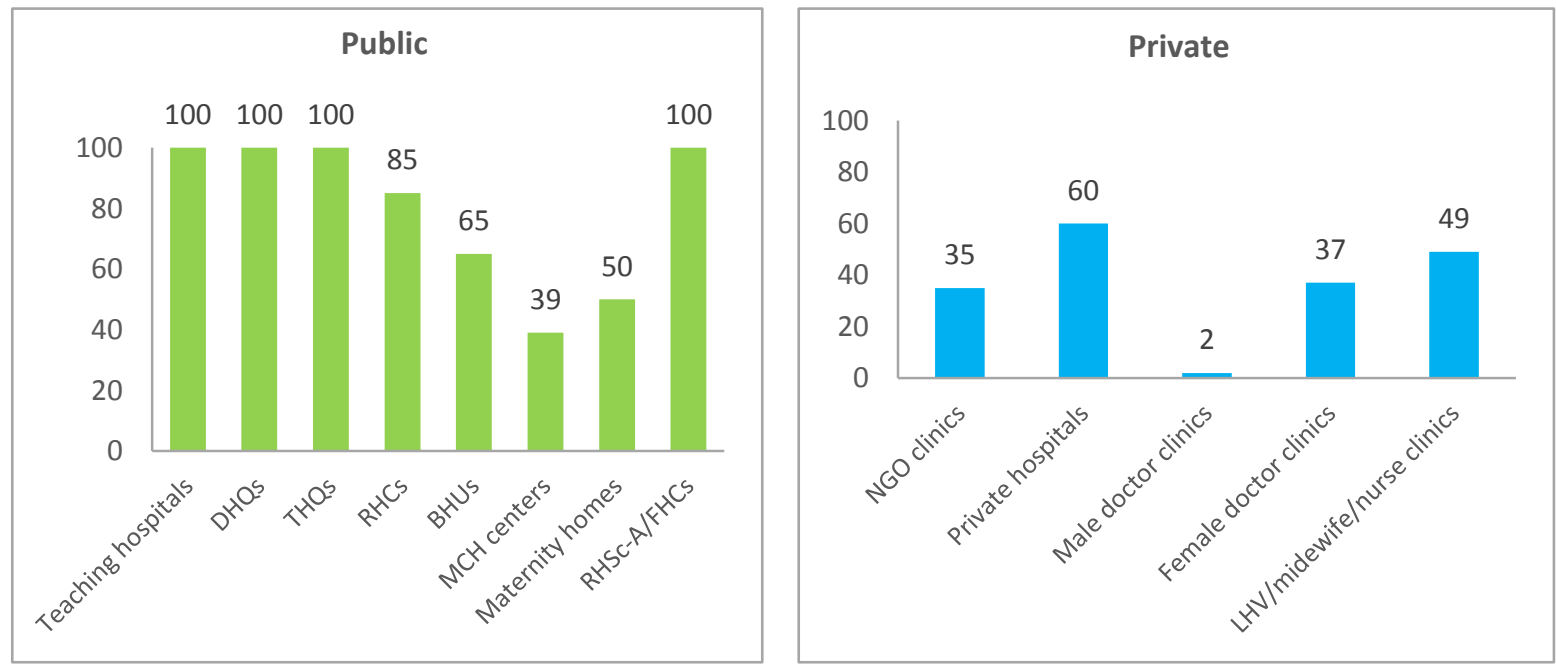

\section{Providers' Knowledge of Specific Family Planning Methods}

Knowledge among service providers regarding pills, injectables, and IUDs was assessed in an earlier study conducted in eight districts by the Population Council (Rashida et al. 2015). Figure 3.7 shows the proportions of providers who correctly answered the questions posed to them about the three methods. Knowledge of IUDs was higher among all cadres except LHVs/Female Health Technicians (FHTs), who were more knowledgeable about injectables.

Figure 3.7: Providers' Knowledge of Specific FP Methods

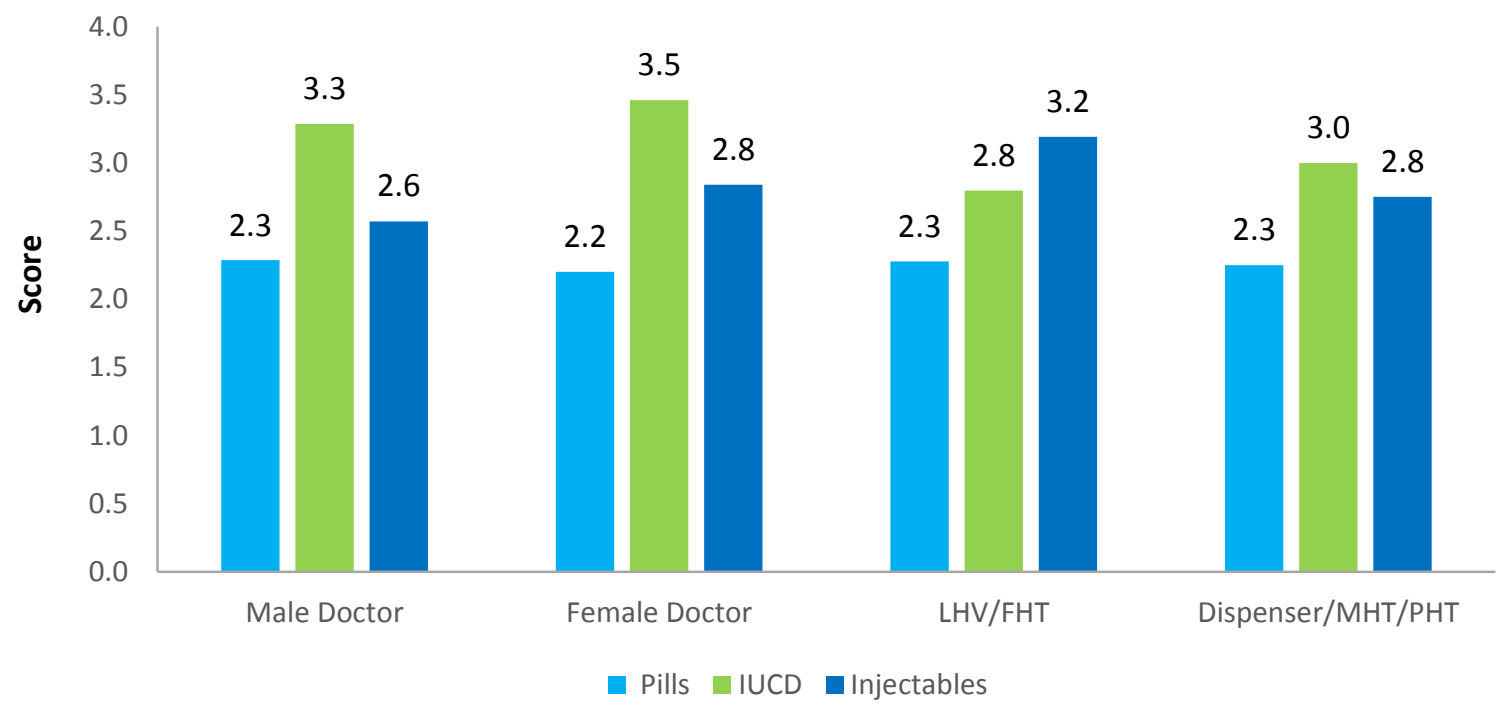

Source: Rashida et al. 2015.

Note: Providers were asked 6 questions about IUDs, 4 questions about injectables, and 9 questions about pills. 


\section{Provider Behavior Towards Clients}

Clients were asked in the qualitative component of this study about how they were treated by providers. The results show that behaviour of the public sector providers towards clients is often impolite and rude. More details are given in Chapter 2 of this report.

\section{Contraceptive Availability at Public and Private Facilities}

Although the situation has improved mainly because of the USAIDIDELIVER Project which has been supplying contraceptives across country in the recent years, the supply/non-availability of contraceptives has been reported as a frequent reason for not providing FP services both at public and private facilities in urban and rural areas.

In the private sector, there are supply issues mainly because they do not have an established system of supply. Therefore, when there is a demand, private providers try to manage on their own to make contraceptives available at their facilities.

\section{Barriers to Increased Service and Method Provision at Public and Private Facilities}

During the census of health facilities and pharmacies, and the qualitative study of FP service providers and suppliers, respondents who were not providing FP services were asked what was preventing them from providing FP services or methods. The main reasons they gave included the following:

- Contraceptive not supplied/not available

- Cannot manage the side effects

- Lack of demand for FP services or for a specific contraceptive method

- Non-availability or poor supply of contraceptives to their facility

- No trained staff available (IUDs and implants)

- Gaps in the providers' capacity to provide services safely

- Low financial incentives for providers to provide FP services/methods

- Perceived cultural barriers facing male providers

- Doubts about the religious permissibility of FP

- Policy barriers to the provision of any or specific FP services

The intensity of these barriers varied by type of provider and method. Table 3.14 lists the barriers that were cited most frequently by service providers for each method. In both the public and the private sector, supply/non-availability of methods was reported as a frequent reason for not providing FP methods at public facilities both in urban and rural areas. In public/private facilities, this reason was followed by "no tradition of FP' and 'referred to pharmacy.' 
Table 3.14: Major Reasons Cited by Providers for Not Providing FP Methods, by Location $(\mathrm{N}=5,291)$

\begin{tabular}{|c|c|c|c|c|c|c|c|c|c|}
\hline \multirow[b]{3}{*}{ Method } & \multirow[b]{3}{*}{ Reasons } & \multicolumn{4}{|c|}{ Public } & \multicolumn{4}{|c|}{ Private } \\
\hline & & \multicolumn{2}{|c|}{ Urban } & \multicolumn{2}{|c|}{ Rural } & \multicolumn{2}{|c|}{ Urban } & \multicolumn{2}{|c|}{ Rural } \\
\hline & & $\%$ & $\mathrm{~N}$ & $\%$ & $\mathrm{~N}$ & $\%$ & $\mathrm{~N}$ & $\%$ & $\mathrm{~N}$ \\
\hline \multirow[t]{2}{*}{ Condoms } & No tradition of FP here/ No need & - & - & - & - & 20 & 102 & 29 & 30 \\
\hline & Contraceptive not supplied/not available & 76 & 19 & 92 & 80 & 36 & 167 & 46 & 132 \\
\hline \multirow[t]{3}{*}{ Oral Pills } & No tradition of FP ere/ No need & - & - & - & - & 15 & 39 & 27 & 16 \\
\hline & Contraceptive not supplied/not available & 6 & 4 & 28 & 20 & 20 & 82 & 38 & 8 \\
\hline & Cannot manage the side effects & 12 & 4 & 0 & 0 & 10 & 24 & 9 & 45 \\
\hline \multirow[t]{2}{*}{ Injectables } & No tradition of FP here/ No need & - & - & - & - & 14 & 26 & 32 & 20 \\
\hline & Contraceptive not supplied/not available & 50 & 8 & 57 & 21 & 38 & 118 & 37 & 36 \\
\hline \multirow[t]{4}{*}{ IUDs } & No tradition of FP here/ No need & - & - & - & - & 7 & 21 & 37 & 27 \\
\hline & Contraceptive not supplied/not available & 63 & 12 & 27 & 13 & 36 & 122 & 19 & 37 \\
\hline & Cannot manage the side effects & 8 & 3 & 4 & 3 & 7 & 45 & 10 & 74 \\
\hline & No trained staff available & 13 & 9 & 35 & 21 & 16 & 59 & 20 & 29 \\
\hline \multirow[t]{4}{*}{ Implants } & No tradition of FP here/ No need & - & - & - & - & 7 & 27 & 24 & 29 \\
\hline & Contraceptive not supplied/not available & 44 & 20 & 51 & 86 & 22 & 91 & 24 & 42 \\
\hline & Cannot manage the side effects & 9 & 7 & 4 & 3 & 12 & 63 & 12 & 58 \\
\hline & No trained staff available & 37 & 39 & 44 & 56 & 37 & 227 & 26 & 47 \\
\hline \multirow[t]{3}{*}{ ECPs } & No tradition of FP/No need & - & - & - & - & 15 & 53 & 21 & 23 \\
\hline & Contraceptive not supplied/not available & 80 & 25 & 100 & 100 & 46 & 100 & 52 & 70 \\
\hline & Referred to pharmacy & 13 & 7 & 0 & 0 & 13 & 63 & 8 & 48 \\
\hline
\end{tabular}

Lack of supply or non-availability of methods was the most frequently mentioned reason for non-provision of most specific methods by both public and private facilities, in both rural and urban areas. In the public sector, this problem was reported more frequently in rural areas for all methods except IUDs, where lack of training in dealing with side effects was a prominent concern. Supply problems seem to be strongest reason for not providing ECPs (80 to 100\%) and condoms (76 to $92 \%$ ). This reason is also cited by roughly half of all public health facilities that are not providing injectables, IUDs and implants.

Among private health facilities, non-supply as a reason for non-provision of any method is mentioned far less frequently than in the public sector. The issue is mentioned more frequently in rural areas than in urban areas for all methods except injectables and IUDs (both methods for which lack of demand is mentioned as the dominant reason in rural areas). Among urban facilities, non-supply is mentioned most frequently for ECPs (46\%), followed by injectables, condoms and IUDs (36 to 38\%), and least frequently for oral pills and implants (20 to $22 \%$ ). Since supply of implants in the country is currently very limited, it is likely that the low reporting of supply issues for implants is due to the predominance of another more primary reason for nonprovision: lack of provider capacity.

Notably, ECP is the only method for which "referring clients to the pharmacy" is reported as a frequent reason for non-provision, in both the public and the private sector.

Side effect management was expressed as a concern from all providers, especially for LHVs (and LHWs), who are at the forefront of the health system/client interface. This issue was also reported for oral pills, IUDs, and implants. However, this issue was cited far less frequently than the problems of low demand and non-supply-the highest frequency was 12 percent, for implants (Table 3.14). 
Lack of training was a key issue underlying non-provision of both IUDs and implants. The need for training is expressed more for implants, across rural and urban areas in both the public and private sectors; attribution of non-provision of implants to lack of trained staff is lowest among rural private facilities (26\%) and highest among rural public facilities (44\%), with 37 percent of urban facilities of both sectors citing this obstacle.

The frequency with which lack of trained staff was mentioned as a reason for non-provision of IUDs was lower, but nevertheless significant, ranging from 13 percent (urban) to 35 percent (rural) in the public sector, and from 16 percent (urban) to 20 percent (rural) in the private sector (Table 3.14).

Barriers of specific cadres of providers are discussed in more depth later in this chapter, in the context of potential for expanding FP provision and choice through private service providers.

\section{Potential for Expanding Channels of Family Planning Provision and Choice}

\section{Public Health Facilities}

Different public sector facilities are providing most methods. Their levels of provision need to be increased, however, in particular DoH facilities. PWD and PPHI/PRSP facilities are fully providing most methods, but both can increase their ECP provision. Moreover, RHCs should also provide implants because these facilities have male and female doctors as well as mid-level staff. Teaching hospitals, DHQs, and THQs should all provide the full range of contraceptives, including contraceptive surgery.

\section{Lady Health Workers}

In the public sector, the LHW Program has played a catalytic role in expanding the reach and use of FP services since the 1994s, mainly in rural areas. Unlike most other public health service providers, LHWs are largely perceived as friendly and reliable by the communities they serve (Kamran et al. 2015). They are a vital and trusted source of household services and connect clients with health facilities.

LHWs' effectiveness is compromised by low supplies of contraceptives, resulting in frequent stock outs of some or all the three methods they provide (condoms, oral pills, and second/subsequent doses of injectables); lack of training in side effect management, which limits LHWs' capacity to support current users in continuing use of modern methods; and involvement in a host of non-FP related tasks, such as polio vaccination, which diverts a great deal of time and energy away from their primary role of FP service provision (Population Council 2015). Importantly, even now, coverage of the LHW Program remains limited to about 60 percent of the population; the remaining population is not covered by the LHWs. In the aftermath of the $18^{\text {th }}$ Amendment, under which health and population welfare services were decentralized from the federal to the provincial governments, issues have also cropped up regarding regularization of LHWs and delays in the payment of their salaries.

Despite these challenges, LHWs are still the most promising channel to expand both availability and choice of methods among the large part of the population that they do serve. Because of their huge numbers, their involvement increases availability of FP services several fold, even in the primarily urban study districts.

Currently, LHWs are mainly providing condoms, oral pills, and the second and subsequent doses of injectables in both urban and rural areas. If they were enabled to also provide ECPs and the first dose of injectables, access to these two methods would undergo a quantum leap in most districts. The effect of this change in the case of Faisalabad is shown in Figure 3.8. 
Figure 3.8: Increase in Access to ECPs and Injectables if LHWs can Provide them, Faisalabad

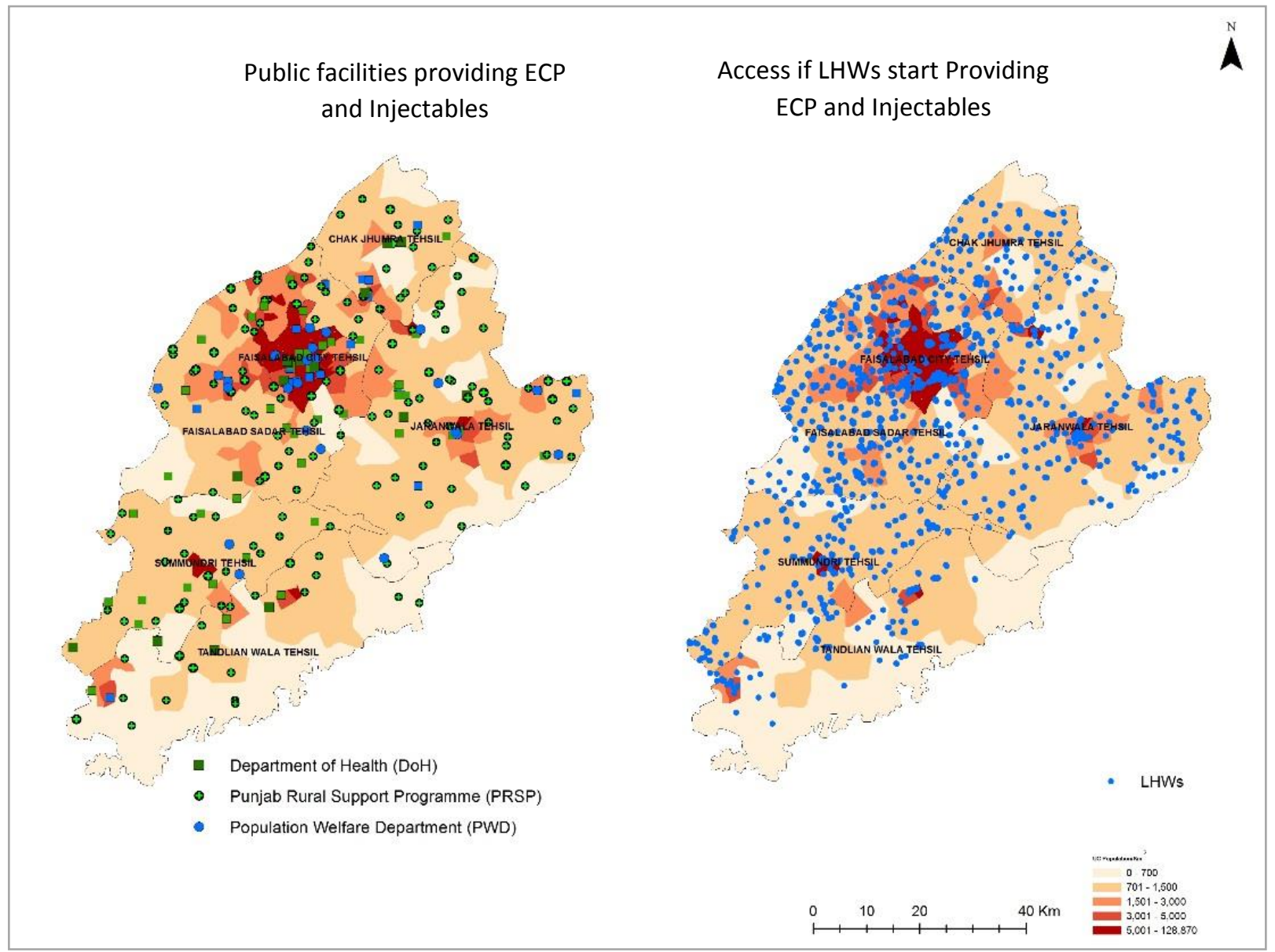




\section{Private Service Providers}

There is huge potential for the private sector to expand its role in FP service provision. Regarding which private channels should be prioritized to expand FP services, female doctors seem to be an obvious choice since they are commonly sought and are likely to have received FP training; they are also considered the main providers both in public and SMO sponsored services. However, interviews conducted with providers during the qualitative study of contraceptive supply in the private sector revealed that female doctors are often stretched for time and rushed with other pressing demands, like deliveries, which are more lucrative. Considerable number of LHVs/nurses/midwifes are currently providing services and this cadre is also interested in providing FP services. Potential of this cadre can be fully utilized by providing them with contraceptives and training to increase their level of service provision.

"I do not provide family planning services because of short hours for my clinic. I am busy hence have no time to council clients for family planning. I have attended training on family planning."

Female Doctor, Karachi

"It is not possible for me to counsel FP client for contraceptive methods in detail, because it is time consuming; also I have many other patients for whom I have to manage time."

Female Doctor, urban Faisalabad

Moreover, qualified female doctors are in short supply in rural areas. Therefore there seems to be consensus among the major stakeholders in contraceptive supply that mid-skilled providers, especially LHVs and community midwives, offer the most motivated and promising channel.

"Female doctors are not widely available in urban as well in rural areas so mid-level LHVs hold the most potential for FP programming." Representative of Greenstar Social Marketing (GSM)

"With the help of the FALAH project, we conducted LHV training, which is how we have been able to sustain the market till now. It increased our market sales by 50 to 60 percent."

Zafa Pharmaceuticals, manufacturer of pills, ECPs, injectables

"LHVs are the best mid-level service providers. We need to train them and design a prudent strategy for their active involvement in private sector service provision." Biogenics, condom importer

"Involve CMWs in FP network, and provide them training, equipment and contraceptives."

Family Planning Association of Pakistan (FPAP)

It appears that with minimal additional training, particularly in implants and IUD, and with the necessary arrangements of contraceptive supply, these cadres (Midlevel), though not numerous, could be influential in increasing FP service availability. They are already the go to providers for other RH needs, such as delivery, ANC, and abortion care, and can also be used as a bridge for providing FP counseling and training.

"In the beginning I was against offering family planning services, considering it against Islam. Gradually I realized that a large number of women approaching my clinic with unwanted pregnancies and demanding induced abortions." LHV, rural Faisalabad

"I am practicing in poor locality where women with unwanted pregnancies visit my clinic and ask for induced abortion. They claim that their spouse forced them...due to poverty and their poor health." LHV, urban Karachi

But two obstacles-lack of training and supplies-have to be tackled. Several statements from mid-level providers reflect their readiness for this role.

"If any company provides me training and support me to establish my setup and provides me family planning products, I will start offering FP services." LHV, Sukkur

A major shift in the FP landscape could result from male provider provision of FP, which has been seen as the domain of female providers. Men in Pakistan are increasingly involved and interested in FP choices and use, however, and are asking male providers for information and counseling needs. Male doctor clinics are substantial in number and could be enabled with minimal training to counsel and provide all methods, 
except IUDs. Efforts to include at least a significant proportion of male doctors in FP would require a shift in traditional mores. It would require that male doctors be involved and provided relevant trainings for FP service provision, including BCC, and be provided a regular supply of FP products.

"I have not received any proper training on contraceptive methods and management of side effects;

this is... why I am not taking much interest in offering FP services." Male Doctor, rural Peshawar

Dispensers, hakeems, and homeopaths, mainly male providers, are present in large numbers but are not currently utilized for FP. Dispensers comprise a key cadre among private channels that are not officially permitted to provide FP services. In their study of 34 districts, Haque et al. (2012) found that 54 percent of dispensers were providing FP services, however-primarily condoms, pills, and even injectables-compared to 49 percent of male doctors, 92 percent of LHVs, and 92 percent of female doctors. Dispensers outnumbered female doctors and LHVs by a ratio of 7:1, and male doctors by a ratio of 2:1; in rural areas, they are providing more FP services, even to female clients, than LHVs and male and female doctors. Dispensers are strongly motivated to be formally enabled and involved in FP service provision. In this study, however, as mentioned, dispensers' involvement in FP service provision was found to be much lower. This could be due to provincial governments' recently increased efforts to enforce regulations prohibiting dispensers from operating independent clinics.

Dispensers comprise a well-respected cadre in poor and rural communities that can be enabled to provide some methods. Notably, women already seek FP services-including injectables-from dispensers, especially in rural areas, where in most places they are the sole providers. They can easily provide pills, ECPs, injectables, and condoms. Apart from regulatory permission, to mainstream dispensers, they will have to be given training in FP service provision, especially to remove misperceptions and enhance skills for side effect management. Moreover, regular supply of contraceptives, which is a common issue among private sector providers, will have to be addressed.

The large presence of dispensers, especially in rural areas, and their readiness to be involved in FP would contribute greatly in expanding access to FP services through the private sector.

"I don't have any issue with offering family planning services if I am provided proper training and facilities. I do not consider social or religious concerns as a hurdle for people adopting family planning. I am willing and can make time to provide family planning services."

Dispenser, rural Sukkur

Traditional providers-hakeems and homeopaths-are also present in very large numbers, even in rural areas, and they offer outreach to the significant numbers of consumers who prefer traditional to allopathic medicine. Recently, PWD regulations have been modified to permit this cadre to provide FP services after a specified round of training. Most hakeems and homeopaths, both male and female, are keen to provide FP services. Generally, they are providing herbal and homeopathic FP products; a few homeopaths are already providing modern FP methods (injectables) as well. These cadres have the potential to provide FP counseling and some methods, including condoms, ECP, oral pills, and injectables, following training.

\footnotetext{
"Homeopaths, LHVs, and dispensers are there in huge numbers; they can be involved in family planning." GSM

"Nobody from the Government or any NGO consulted us or guided us regarding family planning services. The reason I am not providing family planning services is that I have not received any training..." Homeopath, rural Sukkur
}

2 Dispensers are certified male paramedics who serve in both the public and private health sectors. They mainly manage stores, pharmacies, equipment, buildings, and front desks; maintain records; and dispense medicines as prescribed by doctors. However, in rural unserved areas, they mainly run private clinics as health service providers. 


\section{Pharmacies}

There is a substantial number of pharmacies in both urban and rural areas. Currently, pharmacies are selling some methods-mainly condoms, oral pills, ECP, and injectables-but there is potential for them to sell more.

Figure 3.9 shows the location of pharmacies in the study districts, while Figure 3.10 shows only the pharmacies that are selling contraceptives.

Figure 3.11 shows the frequency with which different reasons were cited by pharmacies for not selling contraceptives during the census of pharmacies and health facilities. Among rural pharmacies, the most frequently cited reason is non-supply or non-availability of commodities (59\%), while perceived absence of demand is cited by 39 percent. The third largest reason for not selling contraceptives is the perception that FP is against Islam, a reason cited by 22 percent of outlets.

Among urban pharmacies that are not selling contraceptives, the most frequently cited reason is perceived absence of demand (55\%), followed by non-supply or non-availability of contraceptives (44\%). Interestingly, 38 percent of these outlets mention perceived religious impermissibility as a reason for not selling contraceptives. Additional reasons mentioned during IDIs with pharmacists during the qualitative study include low profit potential in contraceptive sales, and local shortage of service providers for prescribing contraceptives and referring customers to pharmacies. These reasons, and the wider context of supply issues confronting pharmacists and service providers, are discussed in the next chapter.

Encouragingly, several pharmacists interviewed, especially in urban Faisalabad, expressed their interest in more training for basic customer counseling, recognizing that this can help them respond to customer needs.

"Pharmacies are approached by males and youth and therefore the staff of pharmacies must possess adequate family planning knowledge and counseling skills to guide and prescribe an appropriate method." Pharmacist, urban Faisalabad

It is likely that if they are ensured adequate profits-either through larger profit margins or through larger sales volumes-more pharmacies will be interested in selling contraceptives, especially if efforts are made to dispel their doubts about the permissibility of FP in Islam. 
Figure 3.9: Maps with Locations of Pharmacies in the Study Districts
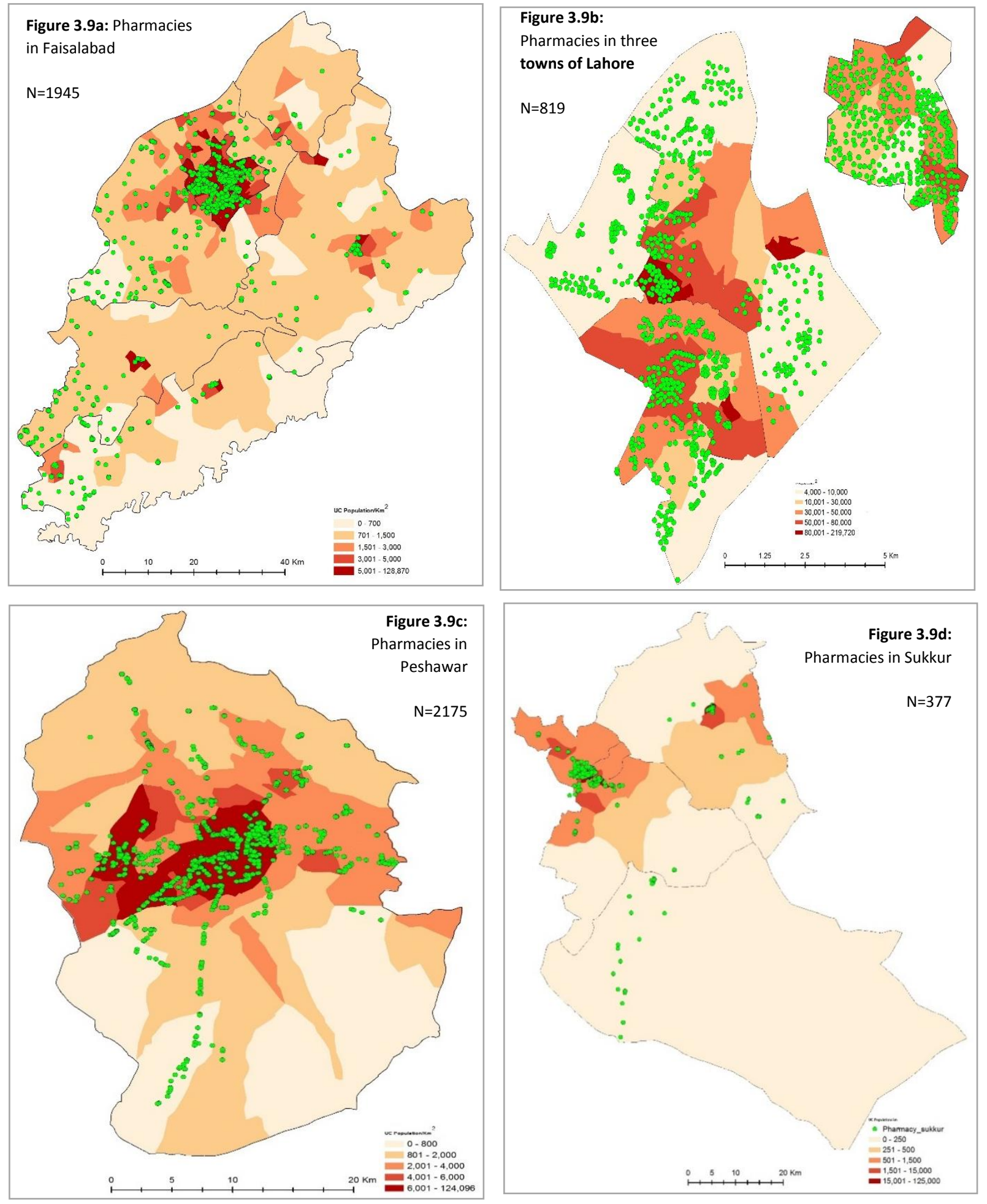
Figure 3.10: Maps with Locations of Pharmacies Selling FP Products in the Study Districts

Figure 3.10a: Pharmacies Selling FP Products in Faisalabad

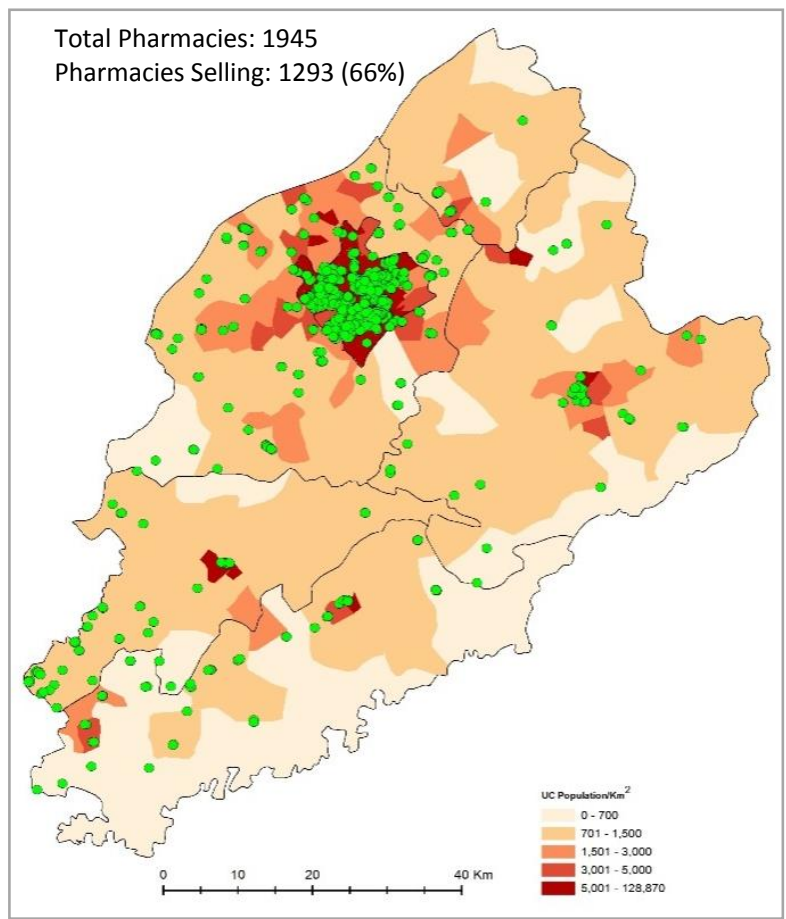

Figure 3.10c: Pharmacies Selling FP Products in Peshawar

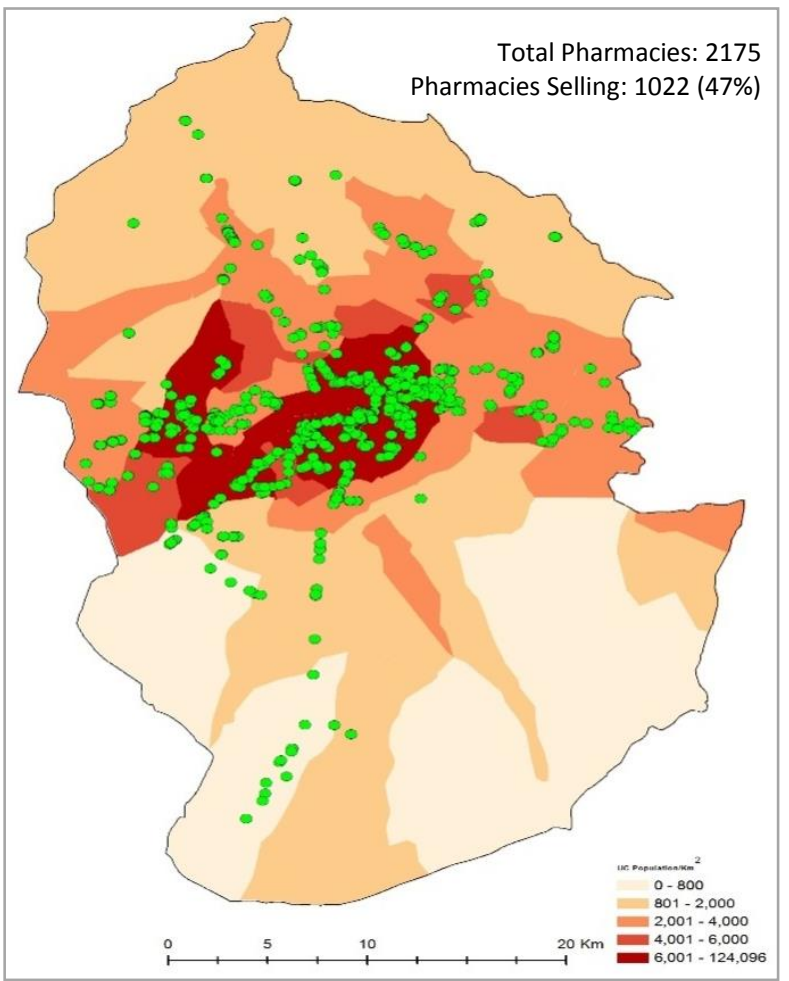

Figure 3.10b: Pharmacies Selling FP Products in three towns of Lahore

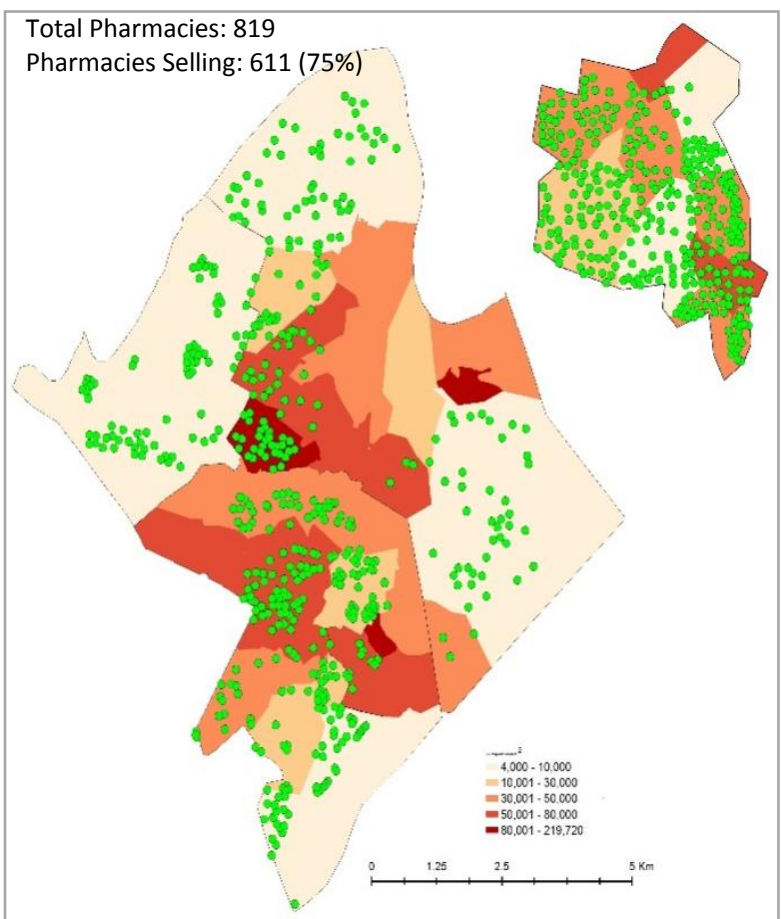

Figure 3.10d: Pharmacies Selling FP Products in Sukkur

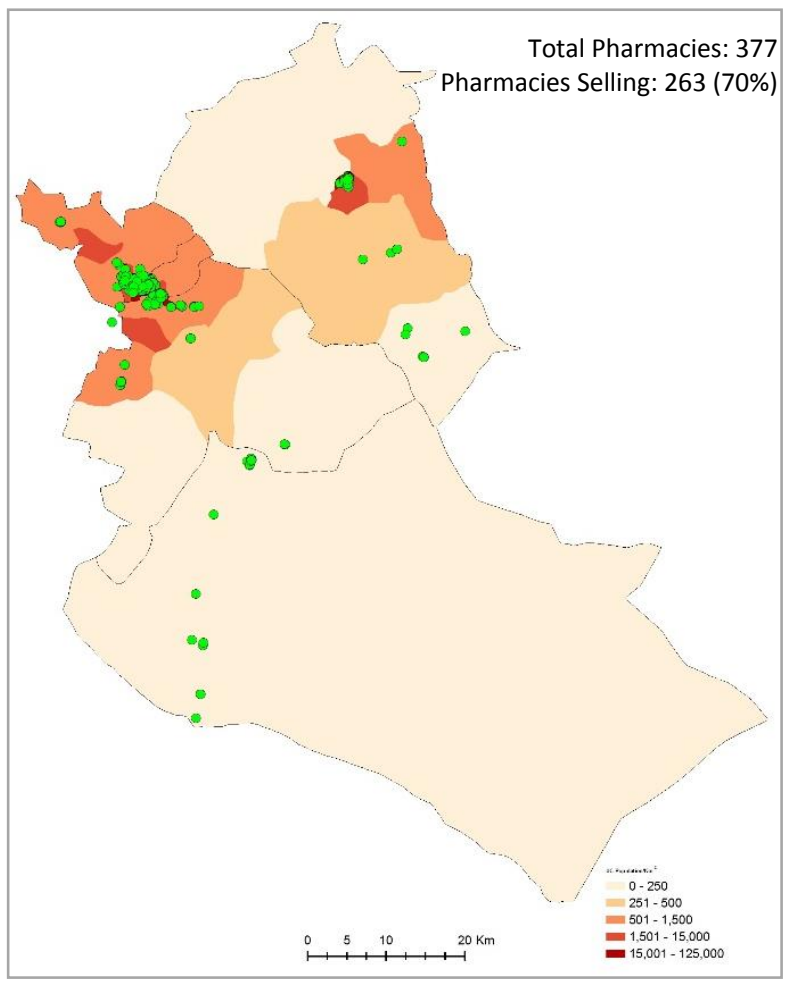


Figure 3.11: Pharmacies' Reasons for Not Selling FP Products in Study Districts $(\mathrm{N}=\mathbf{2 1 2 7})$

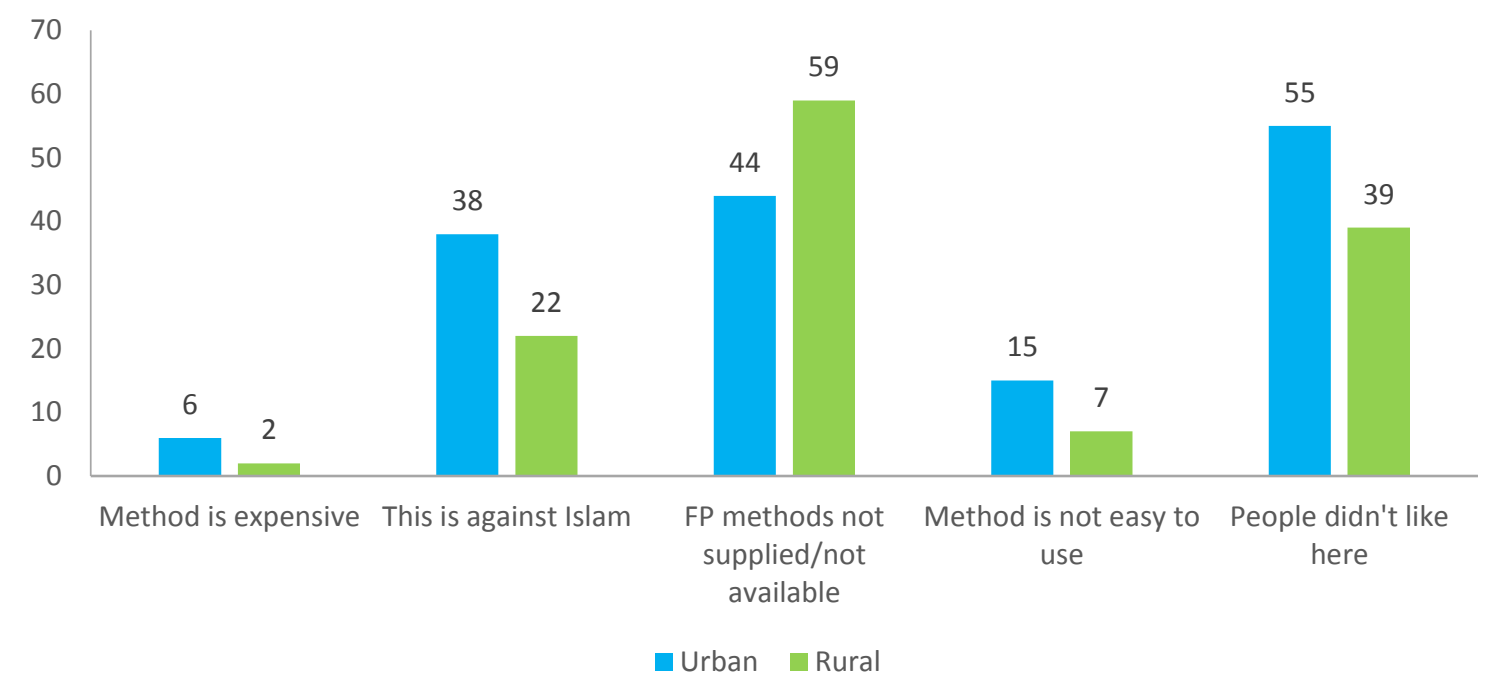

\section{Summary of Key Polnts}

Channels for Service Provision: Availability, Adequacy, and Potential for Expansion

\section{Provision of FP Services}

- This analysis, based mainly on the findings of our census in four highly urbanized districts, shows that while the numbers and distribution of major channels of health services in the public and private sector is quite impressive, the full potential of these channels is not being utilized to deliver FP services. This is especially applicable to the rural areas of these districts but even in the urban settings, both the public and the private sector are quite far from offering a full range of contraceptives to clients.

- The public sector, which has an explicit mandate to provide FP services, is providing services in both urban and rural areas. In particular, the Population Welfare Department (PWD) and People's Primary Healthcare Initiative (PPHI) are quite active in the dispensation of FP services, as are LHWs.

- Department of Health (DoH) facilities are providing only a limited range of FP services, which need to be increased. The PWD also needs to increase level of service provision for emergency contraceptive pills (ECPs) both in urban and rural areas.

- In comparison, the private sector, though it contains the larger numbers in their respective channels, is less likely to be providing FP services. Only 41 percent of private sector providers in urban areas and 29 percent in rural areas are providing FP services.

- Pharmacies are performing better in terms of availability of FP products, rising to 69 percent in urban and 53 percent in rural areas, but they are mostly providing condoms. 
- The largest potential for expansion lies in increasing the role of the private sector providers, pharmacies and dispensers to include more trained providers and contraceptive products to expand choice and availability of FP services.

\section{Provision of Specific Contraceptive Methods}

- While there is an impressive availability of condoms and oral contraceptive pills (OCPS) across the major channels in the public sector and in pharmacies, figures dip when it comes to the supply of injectables, which might have been expected to be more widely available.

- Only 10 percent of private facilities in urban areas and even less than that in the rural areas are providing a combination of condoms, OCPs, injectables, and ECPs.

- Across pharmacies, 38 percent stock condoms and 29 percent stock OCPs in rural areas, but only 17 percent carry injectables in rural areas.

- Expanding the range of methods that can be provided and is available to different cadres will enable existing channels to offer choice, which is critical aspect of expanding access.

- LHWs must be allowed to administer the first dose of injectables and carry ECPs, which would immediately increase access to these methods, due to the sheer size of this cadre.

- Male dispensers currently not allowed to provide FP services are distributed widely especially in rural areas. Some way has to be devised to allow them to offer counseling and basic FP, like condoms, OCPs, ECPs and injectables.

- Hakeems and homeopaths are already involved in FP in Punjab, and could be engaged at the very least for counseling in other provinces.

\section{Quality of Care}

- The quality of FP services may be more important than just physical access. It is one of the most important needs from the clients' perspective to enhance utilization and sustained use of services. The analysis shows that:

- Although readiness of facilities for service provision is slightly better in the public sector than in the private sector, the attitude and behavior of providers towards clients is much better in the private sector, attracting clientele.

- Trainings in providing client-centered services should be an integral part of both pre- and in-service trainings, and these should equip providers with the technical capabilities and skills to counsel clients on a wide choice of methods.

- Other aspects of quality of care also need to be considered and measures taken to ensure privacy, respectful and friendly interactions, proper seating, cleanliness, and expanded timings. 


\section{Chapter 4 \\ Contraceptive Supply in the Public and Private Sectors}

Pakistan's public sector supply chain, which is formally structured and has received considerable attention in recent years under the auspices of the USAID IDELIVER project, was reviewed based on secondary data, as well as information from the Contraceptive Logistics Management Information System (CLMIS). To understand the private sector's less documented and more diffused mechanism of contraceptive supply, and inextricably associated market dynamics, primary data were collected in a qualitative study with IDIs with 79 service providers (doctors, mid-skilled providers, traditional providers) and 107 stakeholders involved in contraceptive supply (manufacturers and importers, distributors and wholesalers, pharmacists, shop owners) in rural and urban settings in Peshawar, Karachi, Sukkur, Lahore, and Faisalabad districts.

The chapter begins with a review of the role of various public and private sector sources in meeting the needs of users of modern contraceptive methods in urban and rural areas based on PDHS 2012-2013 data. In the absence of complete or reliable supply-side data, this information is indicative of the public and private sector shares in the FP market. We then outline how the contraceptive supply chains are organized in the public and private sector; assess the performance of the supply chains in terms of reported stock-outs or non-availability of contraceptives at health facilities and pharmacies; and probe the reasons underlying supply problems. In the public sector, which is mandated to provide FP services, supply issues are primarily rooted in inadequate supply chain management capabilities and resource constraints. However, in the private sector, where profitability is an additional driving concern, supply issues must also be understoodand are therefore discussed within-the specific context of the market for each method.

\section{Public and Private Sector Market Shares}

A combined position of provision of the major contraceptive products, i.e. condoms, pills, injectables and IUDs, is presented in Figure 4.1. Pharmacies, followed by shops, are the major urban sources of contraceptives, while in rural areas LHWs are primary sources, followed by shops and public hospitals.

Figure 4.1: Share of Public and Private Sector Sources for Condoms, Pills, Injectables, and IUDs

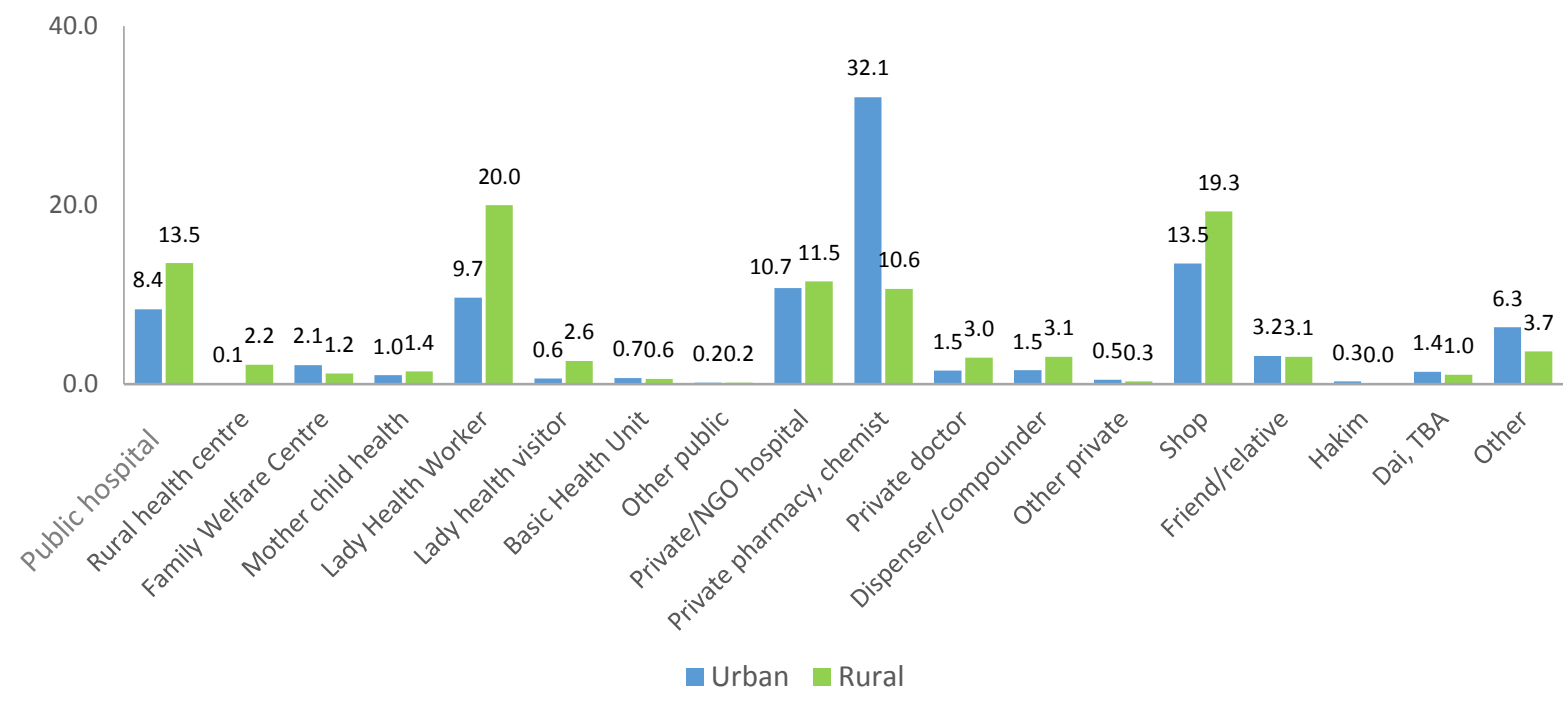


Given the expectation that the public sector, including LHWs, are supposed to cater to the poorer population, it is important that this is confirmed at least in the case of public hospitals. What is of some concern is the utilization of LHWs even among those belonging to richer quintiles, and the use of private hospitals by a considerable portion of poorer groups.

Figure 4.2: Use of Major Sources of Any Method (Condoms, Oral Pills, Injectables or IUDs) by Wealth Quintile

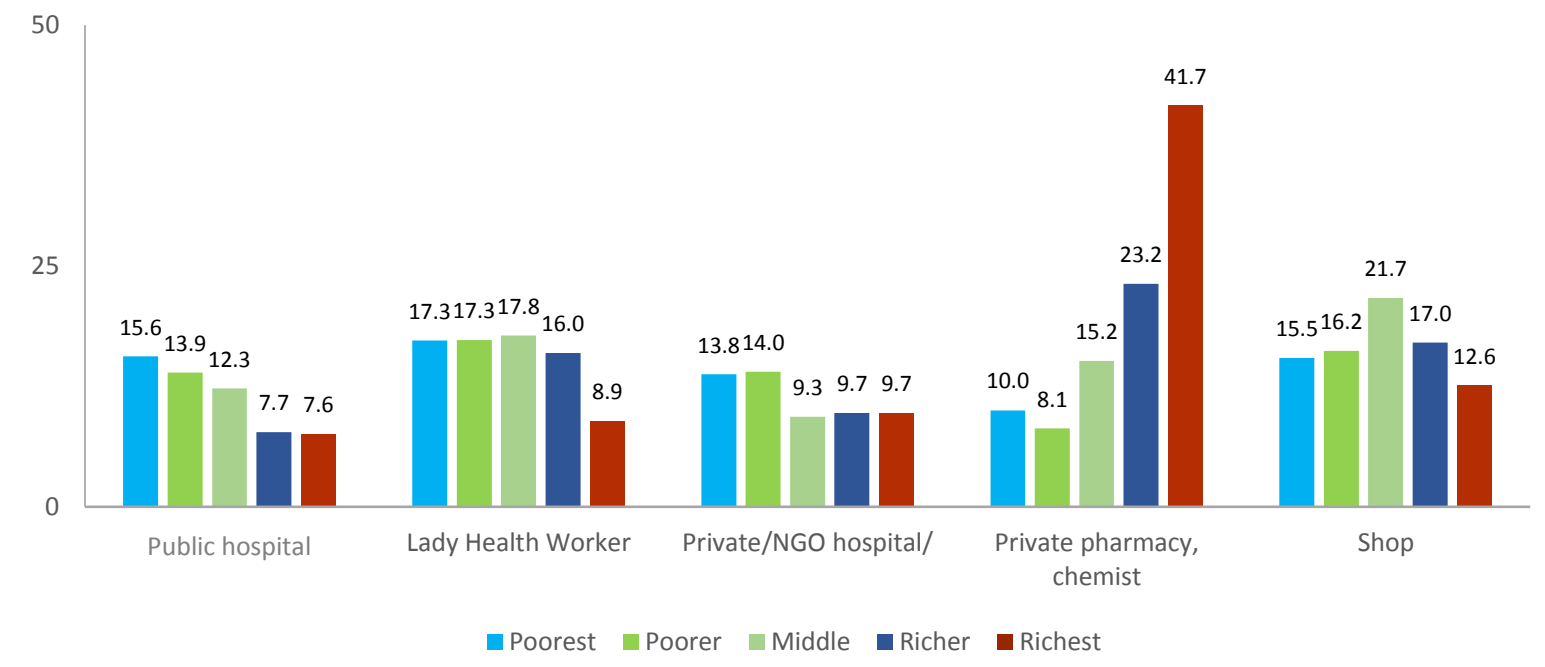

Disaggregating the sources by individual methods helps unravel these patterns further. As shown in Figure 4.3, the provision of condoms seems to be dominated by the private sector, with the exception of LHWs in the rural areas. Leading sources of condoms include private pharmacies and shops, with pharmacies dominating in urban areas, and the shops and LHWs in rural areas. In Figure 4.4, it is clear that the rich prefer to obtain condoms from pharmacies while poorer clients get them from LHWs and shops. The role of public and private health facilities in providing condoms is conspicuously low.

\section{Figure 4.3: Share of Public and Private Sector Sources in Supply of Condoms}

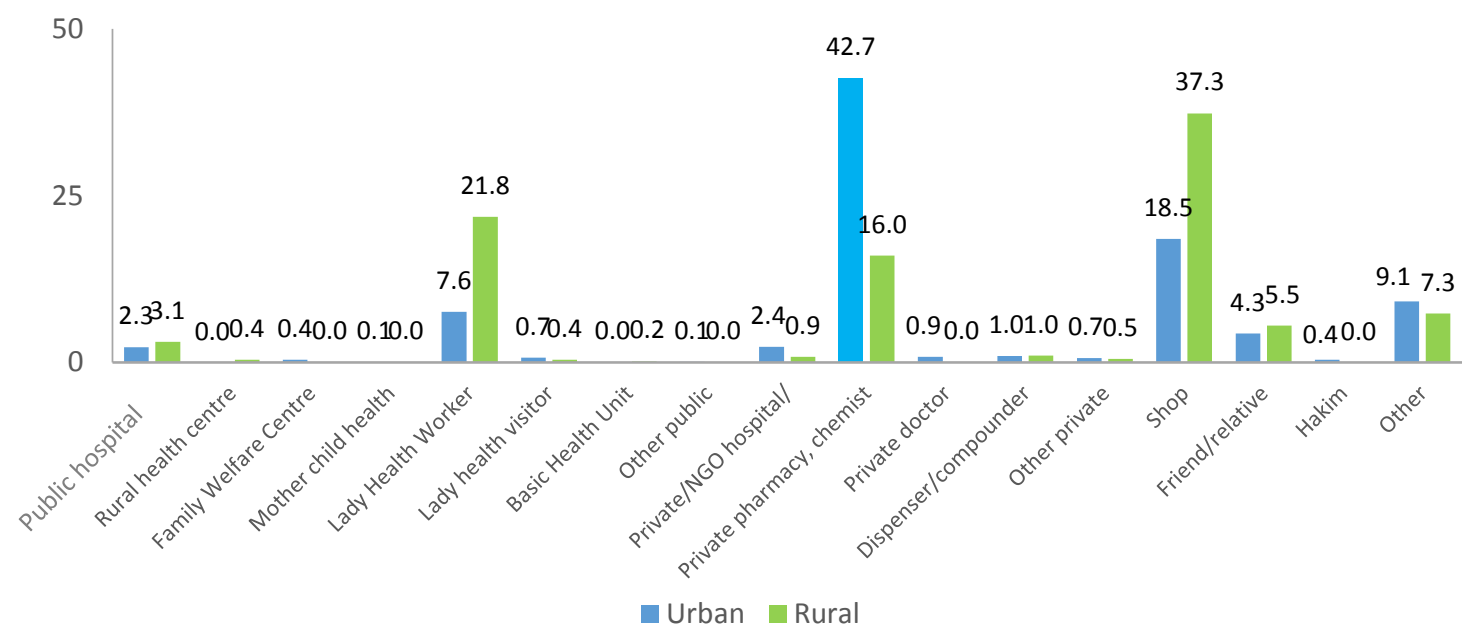


Figure 4.4: Use of Major Sources of Condoms by Wealth Quintile

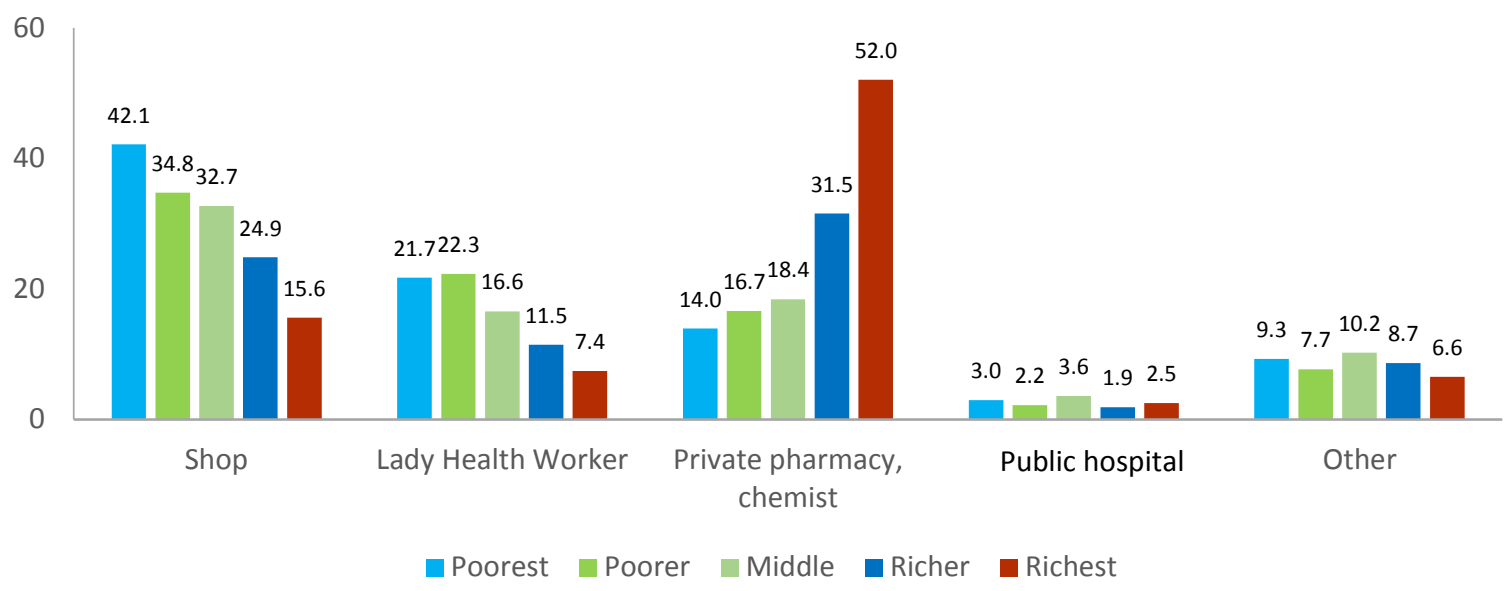

The availability of OCPs and its market is quite different to that of condoms. Leading public sources include hospitals and LHWs, while the main private sources, again, are pharmacies and shops (Figure 4.5). Compared to the condom market, the public sector plays a more significant role in the market for oral pills. The role of private service providers remains very limited, although private/NGO hospitals, private doctors, and dispensers are relatively more involved than for condoms, mainly in rural areas.

Figure 4.6 shows quite a significant proportion of the wealthier users to be accessing the free or nominally priced pills available at public hospitals and, especially, with LHWs, while pharmacies and shops cater to similar levels of poor users as LHWs.

Figure 4.5: Share of Public and Private Sector Sources in Supply of Oral Contraceptive Pills

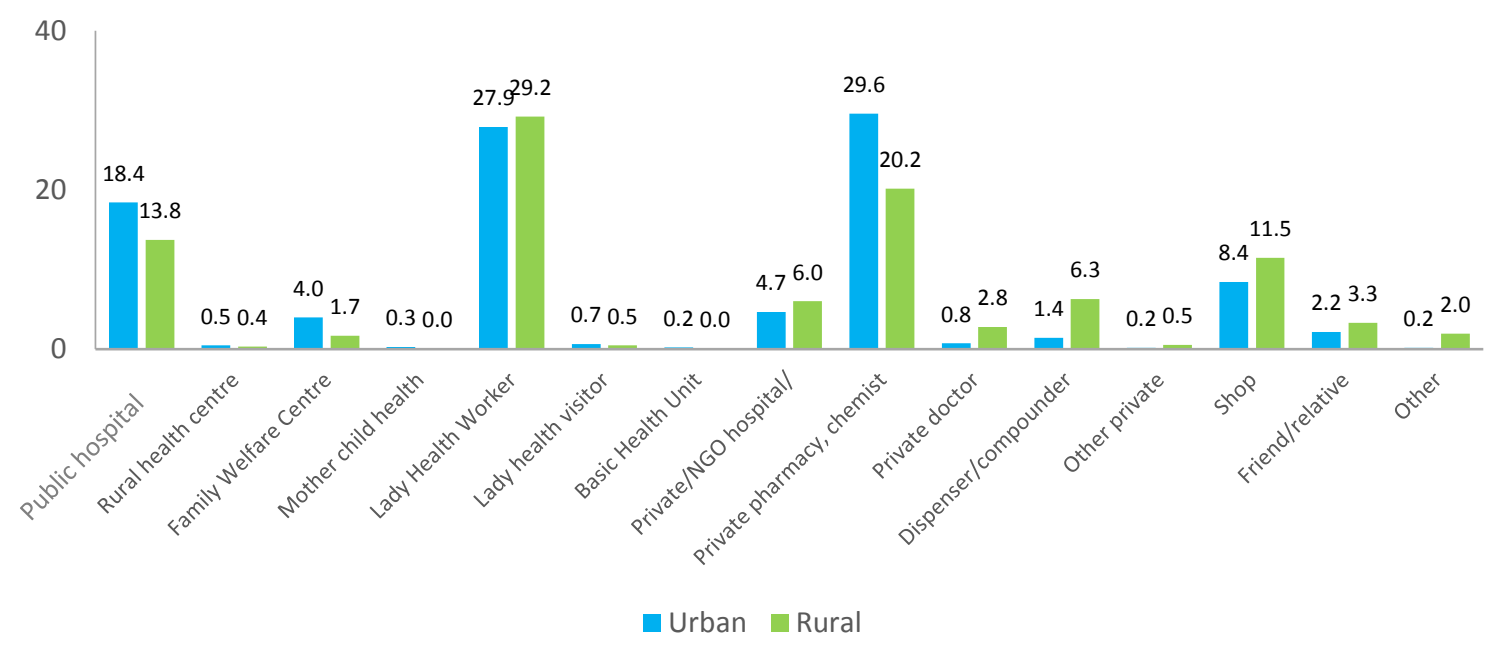


Figure 4.6: Use of Major Sources of Oral Pills by Wealth Quintile

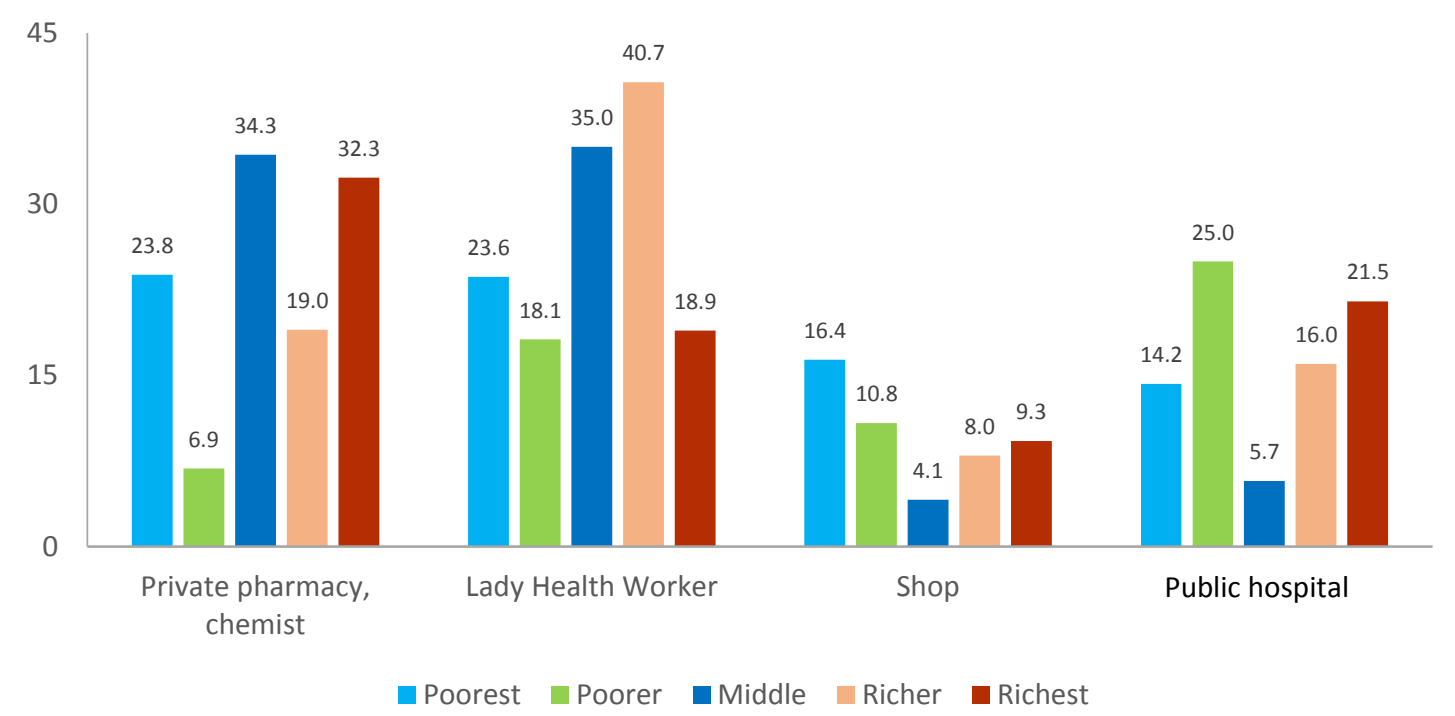

Among users of injectable contraceptives, hospitals and LHWs are the leading sources in the public sector, while the main private source are private/NGO hospitals (Figure 4.7). Notably, smaller health facilities in both sectors, such as rural health centers and private doctors are more actively involved in the provision of injectables than in the case of pills and condoms. The involvement of dispensers-who are male providers, and not permitted to provide any contraceptive method-in rural areas is also notable. On the hand, pharmacies-leading sources of both pills and condoms-have a very low share, perhaps reflecting users' preference to go directly to providers who can administer this method.

Figure 4.7: Share of Public and Private Sector Sources in Supply of Injectable Contraceptives

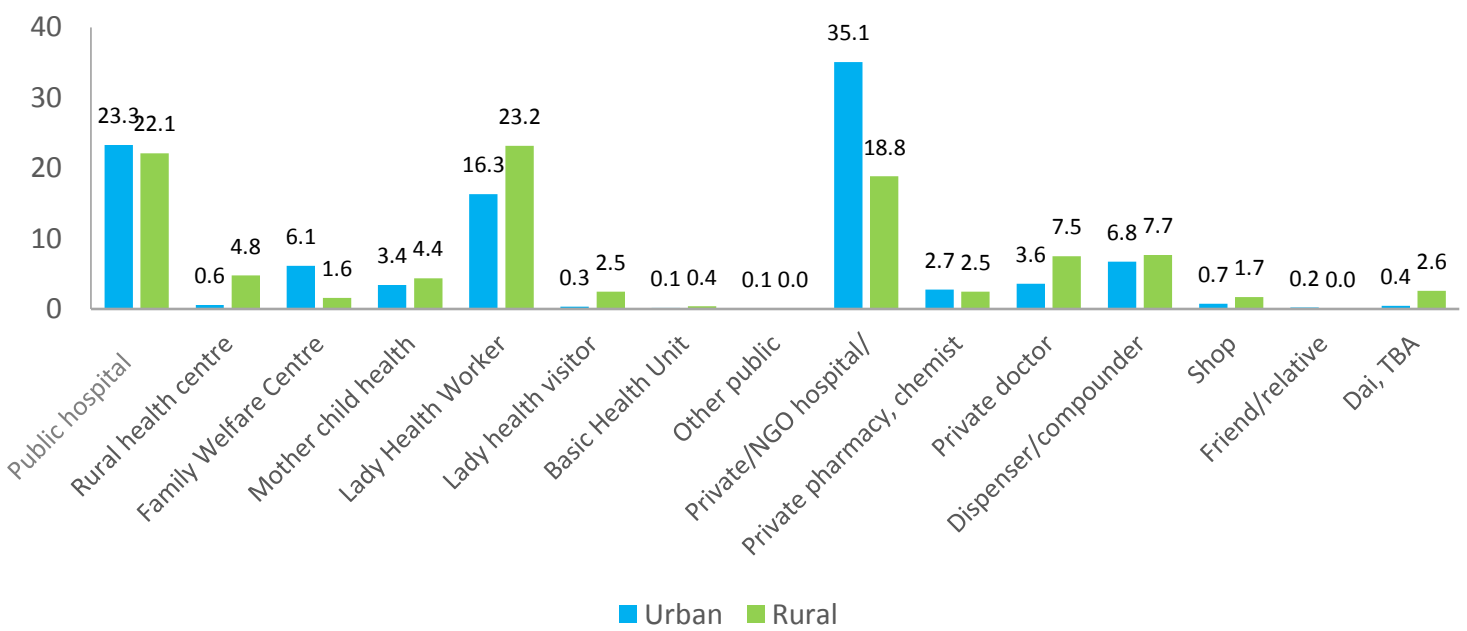

Figure 4.8 shows injectable users in the middle and higher wealth quintiles to have a marked preference for private/NGO hospitals and clinics, but their use of public hospitals and LHWs is also quite high, exceeding the proportions of the lowest quintiles. On the other hand, fairly high proportions of users in the lowest quintiles are using private sources-surprisingly, they are more likely to get injectables from private doctors than the richest users. Also noteworthy is the significant role of dispensers in meeting the injectables needs of poorer clients. 
Figure 4.8: Use of Major Sources of Injectable Contraceptives by Wealth Quintile

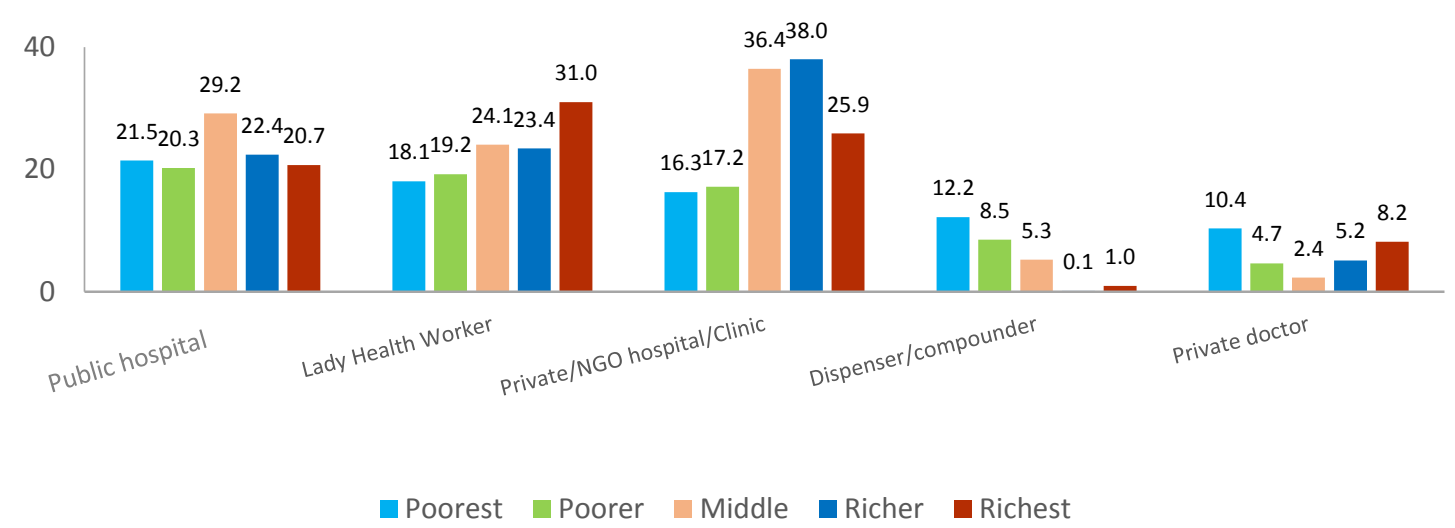

Private and public hospitals are the dominant sources for IUD insertions (Figure 4.9). Worryingly, private doctors operating in clinics have a smaller role in IUD provision in urban areas than traditional birth attendants, who are not permitted to insert IUDs; similarly, in rural areas, LHVs are more active in IUD provision than doctors. Provision of IUDs by LHWs, who are neither permitted not trained to insert IUDs, is troubling. Notably, pharmacies have an even more limited role in selling IUDs to users than in selling injectables.

When broken down by wealth quintiles (Figure 4.10), it is apparent that both public channels for IUD insertion are used by the relatively better off and private channels are used by the relatively poor consumers. The assumption that services that are subsidized for the poor are being used by them is not supported by our analysis, though the public sector is playing more of a role in the rural areas and the private sector in the urban areas.

Figure 4.9: Share of Public and Private Sector Sources in Supply of IUDs

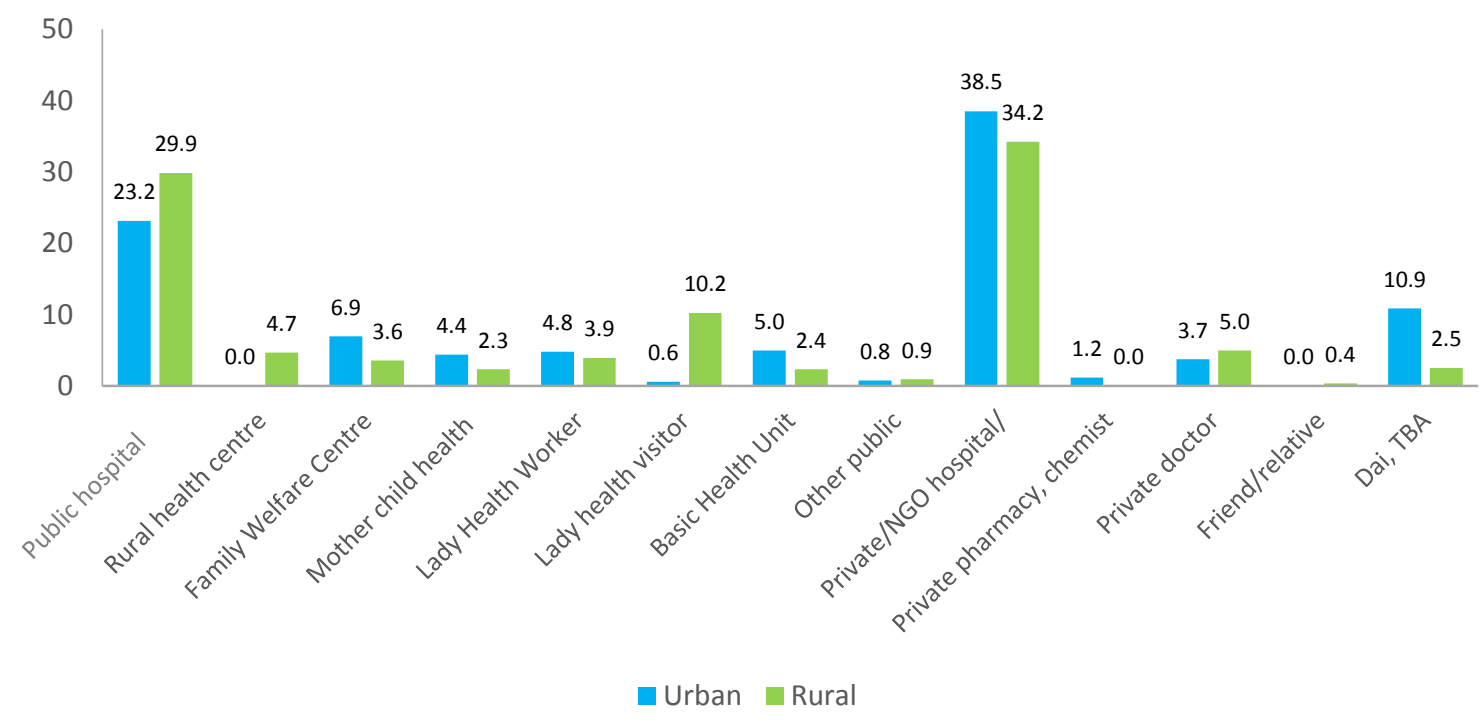


Figure 4.10: Use of Major Sources of IUDs by Wealth Quintile

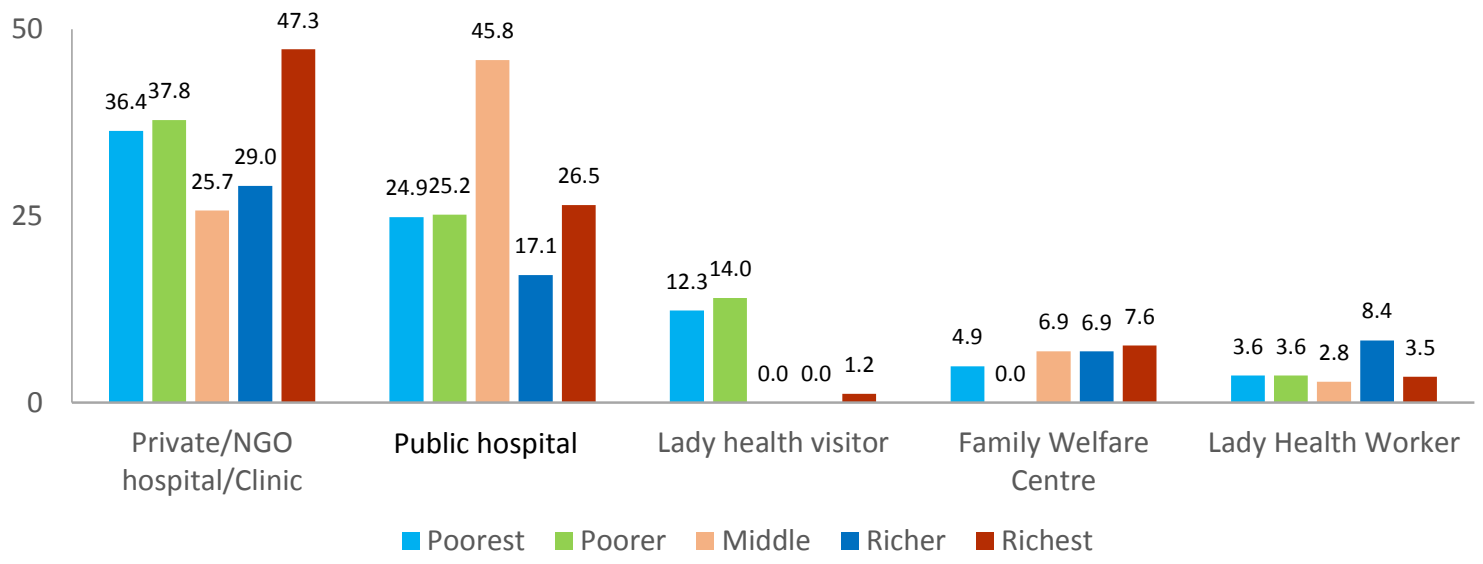

To sum up, the public and private sectors are cited as sources by roughly the same numbers of users. Public and private hospitals, pharmacies, shops, and LHWs are the most frequently cited channels.

Pharmacies and shops are important sources of condoms and for pills. ${ }^{3}$ However, they have a negligible role in providing those methods to users that have to be dispensed by a provider.

Among service providers, LHWs appear to be the only cadre actively providing condoms. In pill provision, only LHWs and large public hospitals have a significant role. With injectables, we see a sudden increase in the involvement of private/NGO hospitals, and smaller providers in both the public and private sectors finally begin to show more activity. Of all four methods, this sees the most involvement from doctors with private clinics. Finally, in IUD provision, we see a much reduced role of LHWs, as they are not mandated to provide this method, leaving private/NGO hospitals/clinics and public hospitals as the predominant sources, followed by LHVs in rural areas, and-most worryingly-untrained birth attendants (dais) in urban areas.

The data indicates that the free (or virtually free) public sector sources are being availed by quite a high proportion of richer clients. On the other hand, private hospitals and shops are catering to many of the poorest users; regrettably, since DHS data does not distinguish between NGO and commercial hospitals/clinics, it is difficult to link this with willingness or ability to pay among poorer users.

Taking a closer look by method, we find that wealthier users prefer to obtain condoms from pharmacies while poorer clients get them from LHWs and shops. However, the distribution is less rational for pills, with a significant proportion of the rich using public hospitals and LHWs, while pharmacies and shops cater to similar levels of poor users as LHWs. Similarly, utilization of injectables sources presents a mixed picture, with richer clients preferring private/NGO hospitals and clinics, but nevertheless availing public hospitals and LHWs to a high degree, while poorer clients show higher use of some private sources than the rich. Finally, with IUDs, we find recourse to public and private hospitals nearly evenly balanced among rich and poor clients (though the public sector is playing more of a role in the rural areas and the private in the urban areas). A main difference is that poor clients are also being catered by LHWs, who are not trained or permitted to dispense this method.

3 Since shops are not permitted to sell contraceptive pills, their large role is puzzling; none of the shops surveyed during the current study mentioned stocking this commodity. It may be speculated that some DHS respondents were unable to distinguish between shops and pharmacies in their reported sources. 


\section{Contraceptive Supply in the Public Sector}

Recent years have seen considerable investment in improvements in the public contraceptive supply chain management, primarily through the USAID I DELIVER project, which, among other important contributions, ensured the availability of adequate contraceptive commodities-at least at the top of the public sector supply chain-to meet demand in the country. Figure 4.11 shows a simplified schematic of the public sector contraceptive supply chain.

Contraceptive commodities available in the public sector include condoms, oral contraceptive pills (progestin-only as well as combined oral pill), emergency contraceptive pills (ECP), IUDs (Copper-T-380A and multiload), injectables ( 2 and 3 month varieties), and implants. These methods are provided free of cost by DoH and the LHWs, while at PWD and PPHI/PRSP facilities, clients have to pay very nominal charges of less than five rupees.

Unfortunately, the timely and adequate distribution of contraceptive commodities to service delivery points (SDPs) has remained a challenge. The public sector supply chain was investigated in detail by Rashida et al. (2015). Among the main problems, the study found that the district stores tend to issue to SDPs insufficient contraceptives to meet demand. Rations of contraceptives to LHWs often run out before the resupply interval of one month. Another study found many LHWs in Sindh to be chronically undersupplied, with adverse effects on their perceived usefulness among communities (Population Council 2015). Moreover, late or faulty requisitioning by district stores can delay shipments from the $\mathrm{CWH}$ to district stores. The order form CLR6 is meant to be submitted electronically but is still being filled on paper, indicating weak progress towards automation (Rashida et al. 2015). The need to collect supplies from district stores can also pose difficulties for individual SDPs, especially where staff lack access to private or official vehicles, as is often the case (Population Council 2015).

Figure 4.11: Supply of Contraceptives in the Public Sector

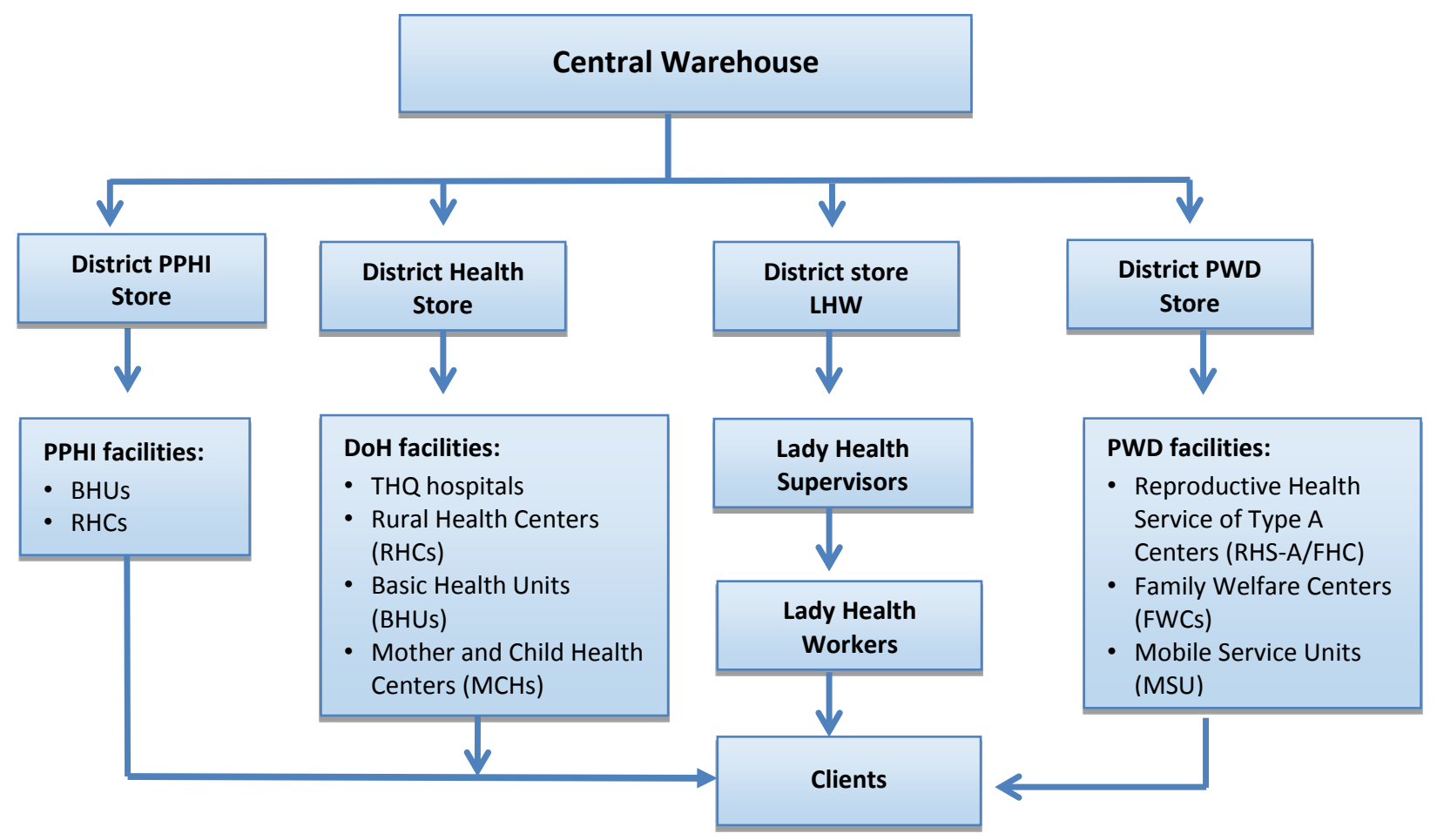


For a more recent picture, we referred to the cLMIS, established through the USAID | DELIVER Project, to gauge the availability of contraceptive stocks at health facilities in the three provinces. Table 4.1 shows the findings, which correspond to the same period during which public and private health facilities were mapped. The data depicts a far from adequate picture of availability across all sectors and in all three provinces, with the highest levels of stock-outs being reported for progestin-only pills (POP), ECP, two month injectables, multiload IUDs, and implants.

Table 4.1: Percentage of Public Health Facilities/Workers reporting Stock-outs in Punjab, Sindh and KP in December 2015

\begin{tabular}{|c|c|c|c|c|c|c|c|c|c|c|c|}
\hline \multirow[b]{2}{*}{ Products } & \multicolumn{3}{|c|}{ Punjab } & \multicolumn{4}{|c|}{ Sindh } & \multicolumn{4}{|c|}{ Khyber Pakhtunkhwa } \\
\hline & PWD & $\mathrm{DoH}$ & LHWs & PWD & $\mathrm{DoH}$ & LHWs & $\mathrm{PPHI}$ & PWD & $\mathrm{DoH}$ & LHWs & PPHI \\
\hline Condom & 10 & 27 & 42 & 34 & 14 & 58 & 29 & 42 & 32 & 34 & 48 \\
\hline POP & 38 & 95 & - & 73 & 100 & - & 86 & 74 & 100 & - & 83 \\
\hline $\mathrm{COC}$ & 12 & 22 & 24 & 42 & 23 & 58 & 15 & 40 & 28 & 38 & 53 \\
\hline $\begin{array}{l}\text { ECP } \\
\text { Copper-T- }\end{array}$ & 45 & 100 & na & 74 & 100 & na & 100 & 87 & 100 & na & 100 \\
\hline $380 \mathrm{~A}$ & 12 & 25 & na & 47 & 19 & na & 24 & 44 & 41 & na & 41 \\
\hline Multiload & 99 & 99 & na & 95 & 87 & na & 91 & 99 & 100 & na- & 100 \\
\hline 2-Month Inj & 100 & 100 & - & 100 & 96 & - & 96 & 100 & 100 & - & 100 \\
\hline 3-Month Inj & 12 & 24 & 33 & 41 & 19 & 62 & 53 & 39 & 32 & 30 & 46 \\
\hline Implanon & 98 & 100 & na & 99 & 91 & na & 96 & 100 & 100 & na- & 100 \\
\hline Jadelle & 99 & 100 & na & 97 & 100 & na & 39 & 100 & 100 & na & 100 \\
\hline
\end{tabular}

Source: Contraceptives Logistics Management Information System

na= Not applicable

Notably, Rashida et al. (2015) had found that stock-outs of contraceptives were far more common at DoH facilities (especially tertiary care hospitals) than at PWD facilities. This could be because FP is the primary objective of PWD, while DoH has a far wider range of priorities, many of which are perceived to be more urgent. This is reflected, for example, in the extensive use of LHWs in immunization and polio campaigns, which diverts these DoH workers away from their primary role of providing doorstep FP services. Unfortunately, PWD does not have as extensive a network of facilities as DoH (including PPHI/PRSP); the latter has a much larger opportunity to offer and provide FP services to the public.

We found some indications of leakage of products from the public sector to the commercial sector. During interviews in Lahore, the study team found that the Butterfly brand of condoms, officially supplied only in the public sector, was being repackaged and sold as the Cobra brand. An SMO's distributor in Peshawar also complained that injectables from the public sector were being sold at attractive profit margins for retailers in the local market, making it hard to compete.

By June 2016, stocks remaining from the now closed USAID IDELIVER Project will have been exhausted, and contraceptive availability will be dependent on the fresh supplies procured by provincial governments. In this regard, the Government of Punjab, with the assistance of the Department for International Development (DFID), has already procured contraceptives for public sector needs, excluding tertiary care facilities due to resource constraints. In KP and Sindh, funds have been allocated for contraceptives, but the procurement process faces delays due to capacity issues.

Until recently, the public contraceptive supply chain also included large NGOs such as the FP Association of Pakistan (FPAP) and Marie Stopes Society. The shift to provincial procurement affected these arrangements. Procurements in Punjab and planned procurements in Sindh do not include a share for NGOs. The financial ramifications for private, not-for-profit entities could be considerable: according to a representative of FPAP, 
in the absence of supplies from the government, the NGO will need to purchase contraceptives from the private market, which will raise its estimated procurement costs from Rs. 10 million to Rs. 100 million. Chapter 5 includes further discussion about financing for FP in the provinces.

USAID |DELIVER played an important role in increasing recognition of supply chain management as a core element of contraceptive security, and putting in place critical elements of the required physical, information, and human infrastructure, most notably through development of the Contraceptive Logistics Management Information System (cLMIS); capacity building in forecasting, information management, and other SCM functions; and development of the Central Warehouse in Karachi into a state-of-the-art facility. Going forward into the decentralized contraceptive supply arrangements, it is critical that provincial governments recognize the importance of continuing such efforts. Investments could be considered in areas such as:

- Building capacity to ensure LMIS is fully utilized for improved reporting, monitoring, and decisionmaking;

- Building capacities and improving processes for forecasting and procurement at all levels;

- Improving storage arrangements at provincial and district levels; and

- Minimizing the need for facilities to collect supplies from district stores by ensuring delivery of supplies to the last mile-if necessary, through innovative practices such as the informed push model of contraceptive supply piloted recently in Senegal ${ }^{4}$ (Daff et al. 2014) and similar cooperative arrangements with the private sector.

\section{Contraceptive Supply in the Private Sector}

All contraceptive methods provided in the public sector are also available in the private sector. The major suppliers of contraceptives are:

- Local pharmaceutical manufacturers including Zafa Pharmaceutical Ltd., Medipharm, and Hansel Pharma, among others, with Zafa leading the market for combined oral contraceptive pills (COCs), emergency contraceptive pills (ECPs), and depo-medroxy progesterone acetate (DMPA)injectables;

- Major commercial importers of condoms who market their own brands, including United Distribution Limited (UDL), Reckitt Benkiser, and Biogenics, as well as a large number of smaller importers; and

- Social marketing organizations (SMOs), including Greenstar Social Marketing (GSM), Marie Stopes Society (MSS), and DKT, which mainly import condoms, IUDs, and implants.

\section{Condoms}

Condoms are the leading modern reversible method. According to PDHS, condom use grew from 6.8 percent to 8.8 percent from 2006-2007 to 2012-2013. Current demand is sufficient for multiple brands and variations, in a wide range of prices and widespread availability, albeit with low rural coverage.

Biogenics reports offering over 90 brands, and its reported sales volume for 2014 was 2.5 million. UDL has continued to grow its volumes despite limited initial support and no current support; it claims the second largest share of the market, with sales of 10 million condoms in 2014. GSM's subsidized brand Sathi leads the market, with over 100 million condoms sold every year. Other social marketing brands have gained market share, while some have perished in the competitive market. There is a plethora of mid- and highpriced condoms, many of them smuggled into the country.

4 See also, Intra Health International, Senegal Wins 2015 Resolve Award for Informed Push Model of Contraceptive Distribution, May 22, 2015, available at www.intrahealth.org/page/senegal-wins-2015-resolve-award-for-informed-push-model-ofcontraceptive-distribution. 
Many condom brands have multiple variants, which are not listed in Table 4.2. Moreover, the numerous brands that were present at fewer than 10 percent of surveyed pharmacies, or are marketed by smaller importers, often through informal channels, are also not shown. The range of condom products available includes low priced and subsidized products to meet the needs of low and middle income users, as well as higher priced products that appeal to the wealthier segments. The significant presence of commercial sector products bodes well for the sustainable future of the market.

Table 4.2: Major Condom Brands, their Prices, and Profit Margins of Distributors and Retailers

\begin{tabular}{llccc}
\hline Importer & Brand & $\begin{array}{c}\text { Retail Price } \\
\text { (per unit), } \\
\text { Rs. }\end{array}$ & $\begin{array}{c}\text { Distributor's } \\
\text { Profit Margin, } \\
\%\end{array}$ & $\begin{array}{c}\text { Retailer's } \\
\text { Profit Margin, } \\
\%\end{array}$ \\
\hline United Distribution Limited (UDL) & Happy Life & 7 & 8.7 & 33.3 \\
& Intense & 8 & 8.7 & 33.3 \\
Biogenics & Ham dam & 10 & 7.5 & 25.0 \\
GSM & Touch & 17 & 13.6 & 42.9 \\
& Sathi & 5 & 13.6 & 25.0 \\
DKT & Josh & 5 & 11.1 & 25.0 \\
& Prudence & 27 & 11.1 & 25.0 \\
MSS/Creative Social Marketing (CSM) & Excite & 13 & 13.6 & 25.0 \\
MSS/Creative Social Marketing (CSM) & Ecstasy & 20 & 13.6 & 33.0 \\
Reckitt Benckiser & Durex & 53 & 11.1 & 25.0 \\
\hline
\end{tabular}

The cheaper, subsidized condom brand Sathi predominates. Other brands cater to different niches, but Table 4.2 shows considerable margin for both distributors and retailers to profit on sales.

Figure 4.12: Volume of Weekly Sales of Condoms at Pharmacies in Four Districts

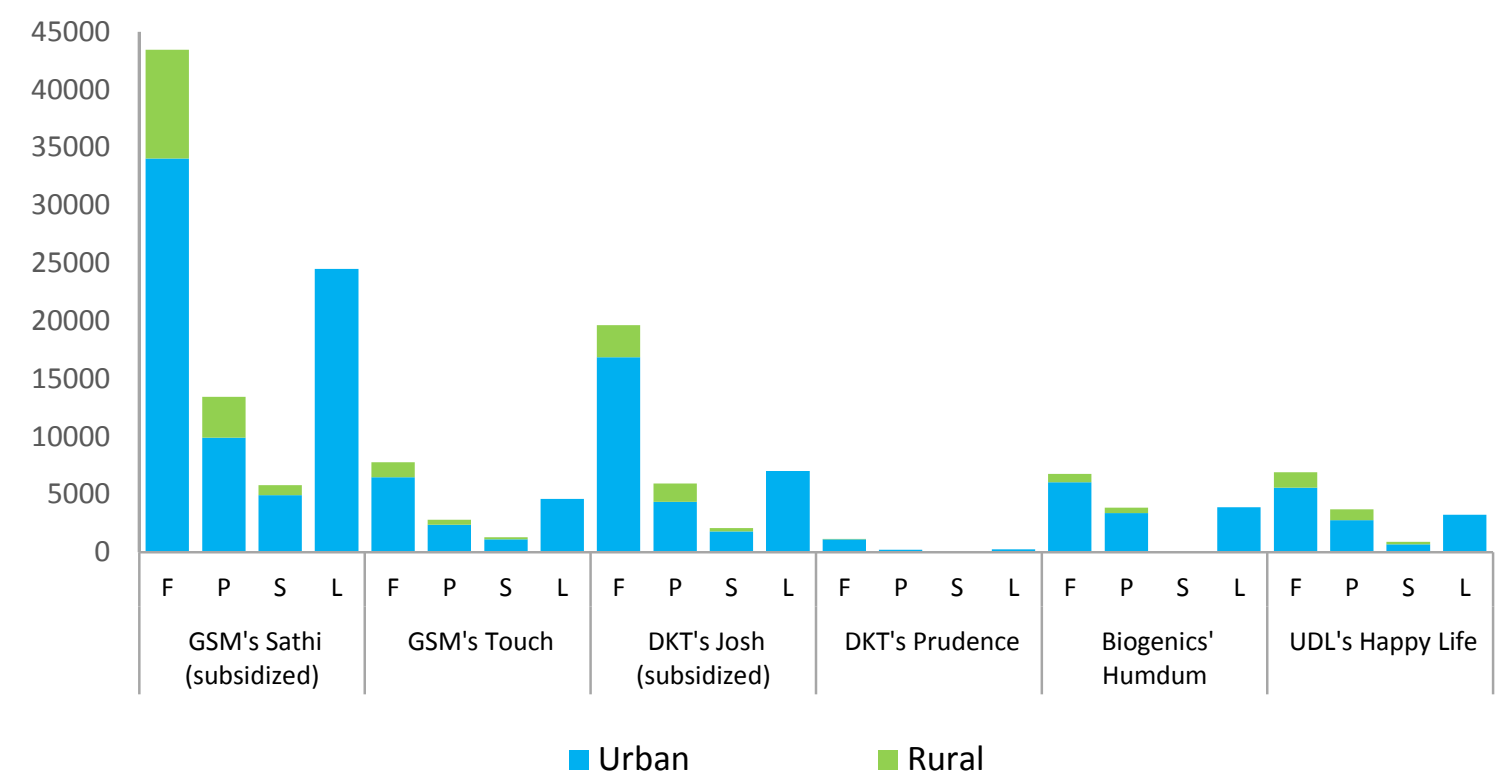

Source: Data from census of pharmacies in districts Faisalabad, Peshawar, Sukkur, and three towns in Lahore district

Notably, sales of all brands of condoms are substantially higher in urban pharmacies than those in rural areas, reflecting the pattern, illustrated in Figure 4.3, of pharmacies as the primary source in urban areas, while shops and LHWs dominate in rural areas. 
Condoms are the only method that can be supplied to non-pharmacy shops and through consumer goods channels, making it possible for them more widely available, especially in rural areas, where pharmacies may be in short supply but consumer goods are traded through different suppliers.

Figure 4:13: Supply of Condoms in the Private Sector

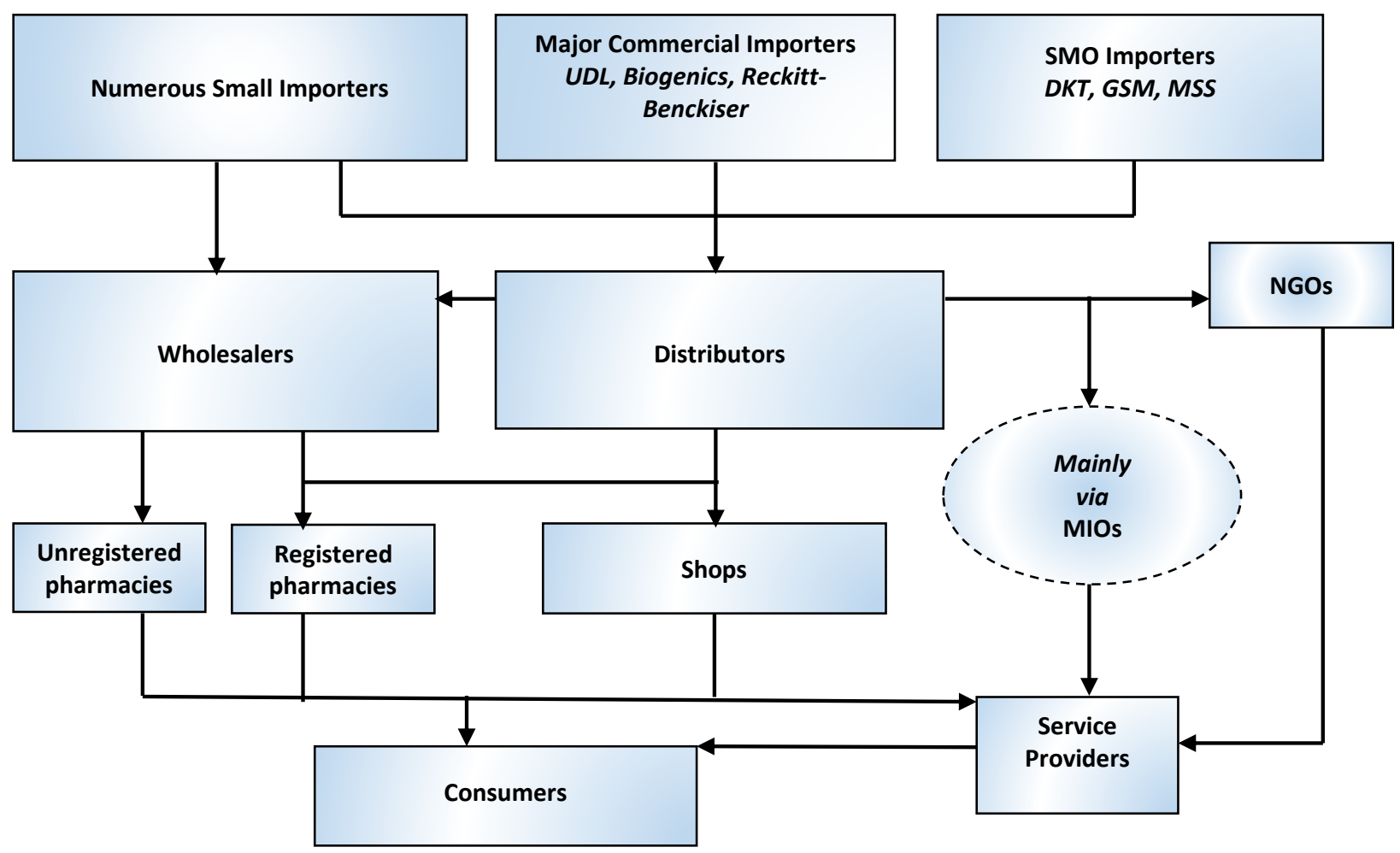

Earlier sections of the report have shown the low proportions of health facilities providing condoms. Among those not providing condoms, 20 percent cited lack of demand as a reason in urban areas, and 29 percent in rural areas. Given that condoms account for the highest modern method use, it is possible that providers mean that there is no demand at health facilities, and users-mainly men-expect to get these methods from pharmacies, shops, or LHWs.

However, even among the pharmacies, 54 percent are not selling condoms. While method-specific reasons are not available for pharmacies, we know that of those not selling any contraceptives, 55 percent in urban areas and 39 percent in rural areas feel there is no demand for contraceptives.

Data about shops was not collected during the census, but a sample of 159 shops was surveyed in Lahore. It was found that 69 percent were selling condoms, including a third of the paan shops who were part of the survey. Of the shops that were not selling condoms in Lahore, 51 percent said there was no demand for condoms, while another 18 percent felt demand was adequately met by outlets in the vicinity, leaving no space for their own involvement. Likewise, in Faisalabad, there was generally less interest in selling condoms among paan shops, who felt customers would prefer to buy from pharmacies and general stores.

Another perception limiting demand within pharmacies and shops is proprietors' own confusion about FP's acceptability: 38 percent of urban pharmacies, 22 percent of rural pharmacies, and 21 percent of shops surveyed in Lahore were not selling contraceptives because it was perceived as impermissible in Islam. Echoes of this misperception reverberated further up the supply chain, such as during an interview with a wholesaler who asked if his involvement in contraceptive sales meant he was not making a halal living. 
This widespread perception of low demand and religious impermissibility among pharmacists and shopkeepers needs to be addressed. As businessmen, they are likely aware that condoms are a selling commodity with a growing demand; indeed, condom sales were acknowledged to be growing by general stores in Faisalabad and Sukkur, with the subsidized GSM brand Sathi in the lead. However, it could be that retailers are less aware of the unmet need for contraceptives and their own potential role in translating it into demand. Among issues in selling condoms, shopkeepers in Peshawar shared that customers are shy about asking for these products, and it is also difficult to display condoms because of the suggestive pictures on some of the packaging. ${ }^{5}$ In urban Sukkur, shopkeepers were of the view that they can play a role in growing the demand for condoms:

"Proper counseling and awareness to the shopkeepers will be very useful and beneficial; it will enable us to understand the importance of FP and accordingly we can guide our customers." Shopkeeper, urban Sukkur

Condom importers also said there is a need to apprise retailers and wholesalers of the demand for condoms, and to encourage and support them in playing a role in growing the market:

"There is a need for trade seminars for sub distributors, product promotions, demand generation, and awareness activities. In rural areas, trade seminars should involve grocery shops and chemists-simply pushing the methods without such activities will be ineffective." UDL

As Figure 4.13 shows, private service providers may obtain condoms from multiple sources, including pharmacies, shops, NGOs, and the medical information officers (MIOs) assigned by importing organizationsmainly social marketing organizations (SMOs)-to maintain stocks of condoms at their clinics. Yet, nonavailability or non-supply of condoms is cited as the reason by 36 percent of urban and 46 percent of rural private facilities for not providing this method. The issue of supply to providers is complex and common across all methods. (Since it is most pertinent to methods that are not widely available at pharmacies and shops, and for which private health facilities are major sources, this problem is discussed in the section dealing with IUD supply.)

Among pharmacies not selling contraceptives, 44 percent of urban and 59 percent of rural pharmacies cite non-supply as a reason. This complaint was frequently raised during interviews with pharmacists, particularly from rural and peri-urban pharmacies. Availability is particularly low in rural pharmacies. Figure 4.12 shows the great contrast between urban and rural sales of condoms, while Figure 4.14shows the brand differences for urban and rural areas.

5 This issue was commonly reported for the less formally marketed brands of small importers. 
Figure 4.14: Selected Condom Brands in Pharmacies in Four Districts
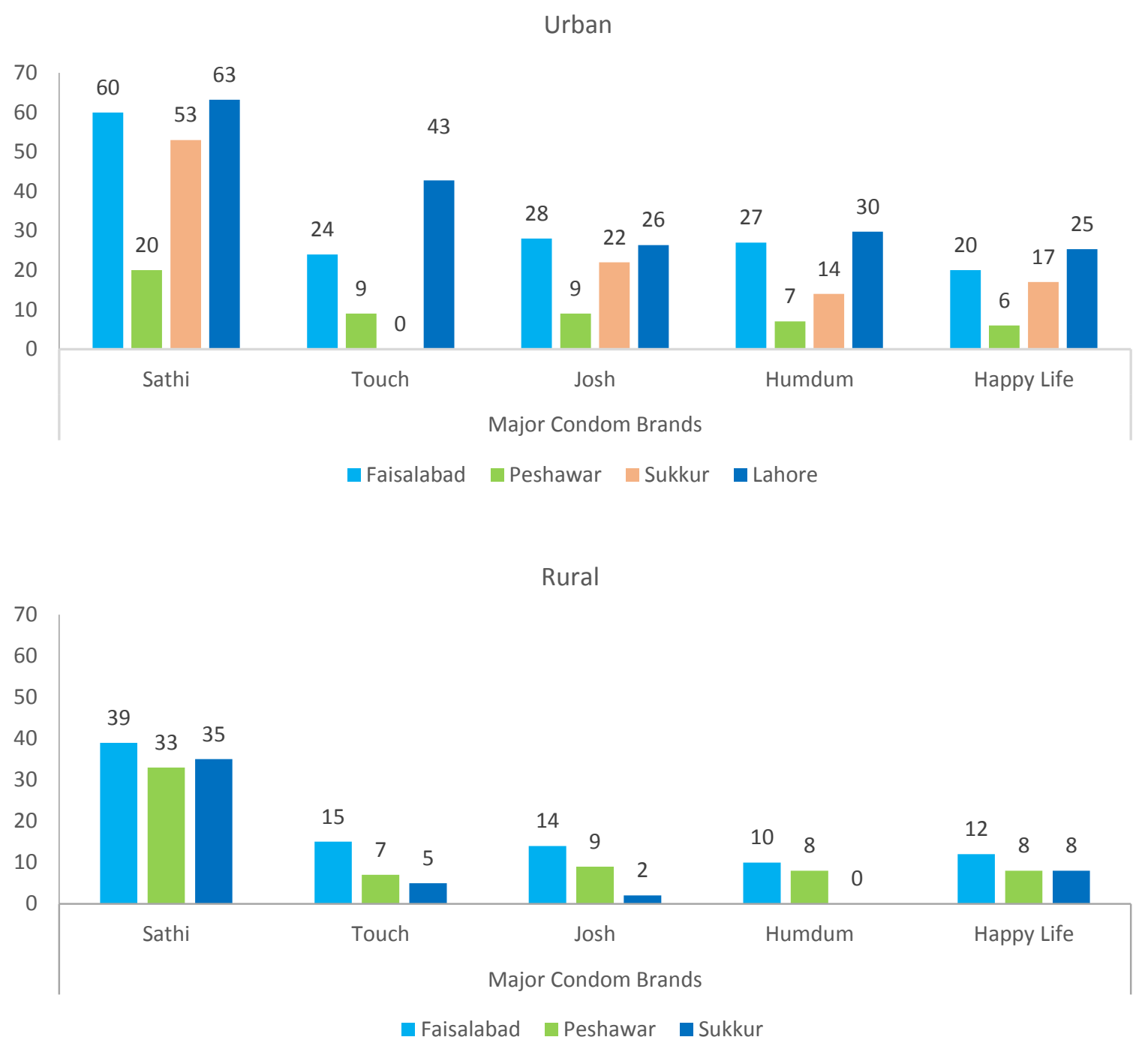

Note: Only urban data was collected for Lahore

Moreover, about 16 percent of shops not selling condoms in Lahore also cited supply constraints. In Peshawar, some general stores not selling condoms said they did not know where to procure them, while many of those selling condoms complained of frequent and protracted stock outs.

These problems highlight some of the weak links in the condom supply chain. As shown in Figure 4.13, two kinds of pharmacies are present in the market-those that are licensed and those that are not. By policy, distributors are unable to supply the latter. While this may actually help improve overall quality in the sector, it also means that the large proportion of unlicensed pharmacies is left without regular contraceptive supply. In the absence of supply by distributors, these pharmacies can approach wholesalers to procure condoms but in this case they would need to invest in collecting supplies and forego a proportion of their profit margins; sales volumes must be high enough to justify the undertaking.

Similar choices face rural and peri-urban pharmacies and shops, as distributors generally have less interest in these markets. Cities offer a concentrated market, which can be penetrated more cost effectively. Interestingly, not only commercial suppliers, but even SMOs are reluctant to invest in rural areas. This issue, which manifests more acutely for hormonal methods, is examined further later in this chapter. 
Interviews showed some general stores to be supplied by distributors, while others, and the majority in rural areas, had to procure from wholesalers. In this regard, a distribution issue unique to the market for condoms relates to the use of consumer goods channels. As mentioned above, condoms are the only method that can be supplied to shops, which comprise the second biggest source of condoms in urban areas and the top source in rural areas (Figure 4.3). While other contraceptive methods must be conveyed through pharmaceutical distributors, condoms can be distributed through fast-moving consumer goods (FMCG) channels, which far better cover shops. Interviews with major condom suppliers, however, revealed that some rely solely on pharmaceutical distribution channels, severely limiting their capacity to reach shops.

"We basically supply only to pharmacies because we have mainly pharmaceutical products; so we miss a large number of consumer goods shops like general stores and paan shops. We need a separate team to ensure supply to the consumer market but we can't afford that." UDL

"There are nearly 500 paan shops in Sukkur and around 4,200 general stores; we only cover 40 to 50 paan shops and general stores" UDL

"We only supply pharmacies and not shops." Marie Stopes distributor

On the other hand, Muller and Phipps, the distributor for the leading SMO GSM, offers sophisticated capabilities in both FMCG and pharmaceutical distribution, which likely contribute to the conspicuously better availability of the GSM brand Sathi.

Constraints in tapping efficiently into the FMCG channels are more commonly exhibited in the commercial sector; they should be better understood and addressed to increase condom presence at shops.

The condom market in Pakistan is showing signs of maturing: condoms are more widely available than any other method; stigma associated with selling them is declining; pharmacies are stocking multiple brands; there is brand awareness among consumers; and commercial brands are claiming a significant share of sales, despite having to compete against donor-supported SMOs.

In interviews, representatives of commercial importers also expressed "growing pains" associated with a growing condom market. Biogenics and UDL expressed concern that SMOs have the funds available to market their products more aggressively, which they feel is crowding them out. Two subsidized brands, GSM's Sathi and DKT's Josh, enjoy higher sales volumes than any commercially available brands.

"Our sale volume declined this year due to subsidized products of DKT, which offers too much discount on their products." Biogenics

While SMOs point out that low prices are necessary for reaching the poorest users and habitual use, commercial importers believe it would be more sustainable in the long run to launch low cost brands in the commercial sector. UDL expressed interest in launching such a brand with short-term donor assistance.

In interviews, UDL and Biogenics also drew attention to the high profit margins offered by SMOs to distributors, and especially to retailers, on brands such as GSM's Touch, which are targeted at the upper end of the market (Table 4.2). They perceive this to distort the field for commercial players, who cannot provide such generous incentives to retailers.

"Subsidies in condoms to a large extent affect the commercial market as the larger share of the subsidy goes to the retailers; then they show less interest in selling commercial products which offer lower profit margins." UDL

The commercial sector has demonstrated a high level of tenacity, given the competition it faces from free commodities in the public sector; subsidized commodities from SMOs, who also have more funds to market their own brands; and the variety of additional, often cheap, smuggled and/or substandard commodities that make their way into the market. Its strong interest and efficiency, combined with the current climate of reduced donor subsidies, signals the need to explore a fresh total market approach (TMA) strategy to position the commercial sector at the forefront of private condom supply. 


\section{Pills and Injectables}

The demand for OCP and injectables is much lower than for condoms. According to the PDHS, between 2006-2007 and 2013-2014, injectable use increased from 2.3 percent to 2.8 percent, while pill use has actually declined from 2.1 percent to 1.6 percent. The latest PDHS did not report use of ECP; as indicated in the previous chapter, this method has low availability at both public and private facilities.

There are fewer stakeholders involved in the manufacturing and distribution of pills and injectables. Unlike other methods, all OCP and ECP brands (Table 4.3) and most injectables (Table 4.4) are locally manufactured. Import of competing products is restricted; currently only GSM is permitted to import the Pfizer brand Depo-Provera, which it is marketing at a subsidized rate.

The market for OCP, ECP and injectables is more consolidated than for other methods, with one main local manufacturer, Zafa Pharmaceutical, claiming to meet 70 percent of demand. Zafa's product line has received considerable donor support in the past and remains profitable on a purely commercial basis. Other noteworthy manufacturers in the market include a relatively new Lahore-based firm, Hansel Pharma, from which the Punjab government has recently procured supplies of pills, and Medipharm, which is supplying injectables to GSM.

Table 4.3: Major COC and EC Brands, Prices, and Profit Margins, of Distributors and Retailers

\begin{tabular}{lllccc}
\hline Method & Brand & Marketer & $\begin{array}{c}\text { Retail Price } \\
\text { (per unit), Rs. }\end{array}$ & $\begin{array}{c}\text { Distributor's } \\
\text { Profit Margin, } \\
\%\end{array}$ & $\begin{array}{c}\text { Retailer's } \\
\text { Profit Margin, } \\
\%\end{array}$ \\
\hline COCs & Famila 3 cycle & Zafa, DKT & 60.0 & 45.9 & 51.0 \\
& Novadol 3 cycle & GSM & 55.0 & 41.1 & 46.8 \\
\multirow{2}{*}{ ECPs } & Em-Kit 1's & Zafa, DKT & 15.0 & 11.5 & 12.8 \\
& ECP 2's & GSM & 15.0 & 11.2 & 12.8 \\
\hline
\end{tabular}

Table 4.4: Major Injectable Brands, Prices, and Profit Margins, of Distributors and Retailers

\begin{tabular}{lllccc}
\hline Method & Brand & Marketer & $\begin{array}{c}\text { Retail Price } \\
\text { (per unit), } \\
\text { Rs. }\end{array}$ & $\begin{array}{c}\text { Distributor's } \\
\text { Profit } \\
\text { Margin, \% }\end{array}$ & $\begin{array}{c}\text { Retailer's } \\
\text { Profit } \\
\text { Margin, \% }\end{array}$ \\
\hline Injectables & Famila(3 months) & Zafa, DKT & 90.0 & 68.4 & 76.0 \\
& Norifam(1 month) & Zafa, DKT & 40.0 & 30.6 & 34.0 \\
& Femiject(1 month) & GSM & 51.0 & 41.7 & 47.4 \\
& Novaject(2 months) & GSM & 68.0 & 50.9 & 57.8 \\
& Depo-Provera (3 months) & GSM & 99.0 & 74.1 & 84.2 \\
\hline
\end{tabular}

The different social marketing approaches of DKT and GSM are evident in these tables, with DKT promoting the commercial products, and GSM marketing its own.

Data about sales volumes of the more commonly sold brands was collected during the census of pharmacies in districts Peshawar, Sukkur, Faisalabad, and Lahore (three towns of the district). Among OCP brands, the brand marketed by Zafa (and DKT) shows significantly higher sales (Figure 4.15). Rural pharmacies' pill sales are mostly negligible, except for the Zafa/DKT brand in Faisalabad and Peshawar. The pattern across districts is common for both brands, with Lahore and Faisalabad showing the highest sales, and Sukkur the lowest. During interviews, pharmacists in Peshawar reported that sales of OCP were rising. 
Figure 4.15: Weekly Sales of Selected OCP Brands at Pharmacies in Four Districts

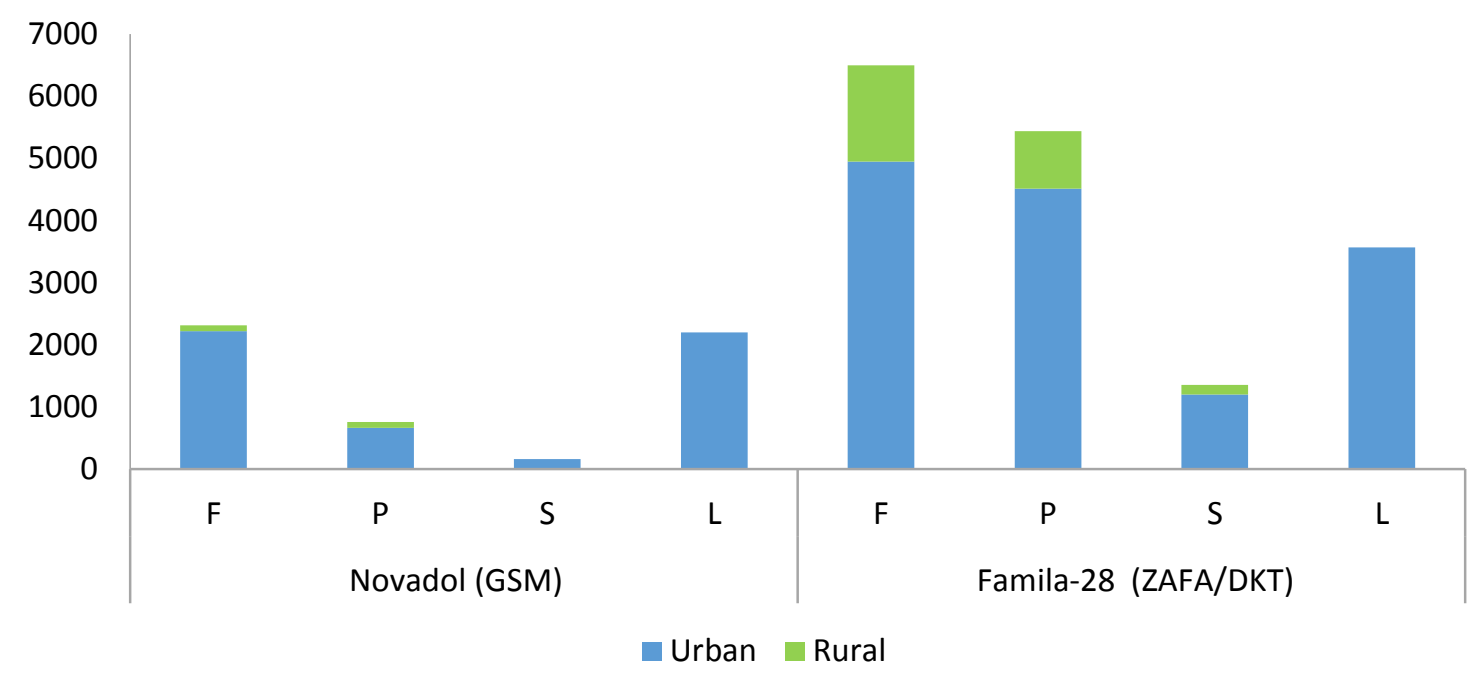

$\mathrm{F}=$ Faisalabad, $\mathrm{P}=$ Peshawar, $\mathrm{S}=$ Sukkur, $\mathrm{L}=$ Lahore

Sales of injectables indicate much lower demand at pharmacies in Lahore, about the same levels in Peshawar and Sukkur, and highest levels in Faisalabad (Figure 4.16). GSM's imported three month product shows the highest sales. Rural sales remain far lower than urban sales for all districts and brands. Pharmacists interviewed in Peshawar also said they sense a rising demand for injectables, although it is increasing more slowly than for OCP.

Figure 4.16: Weekly Sales of Selected Injectable Brands at Pharmacies in Four Districts

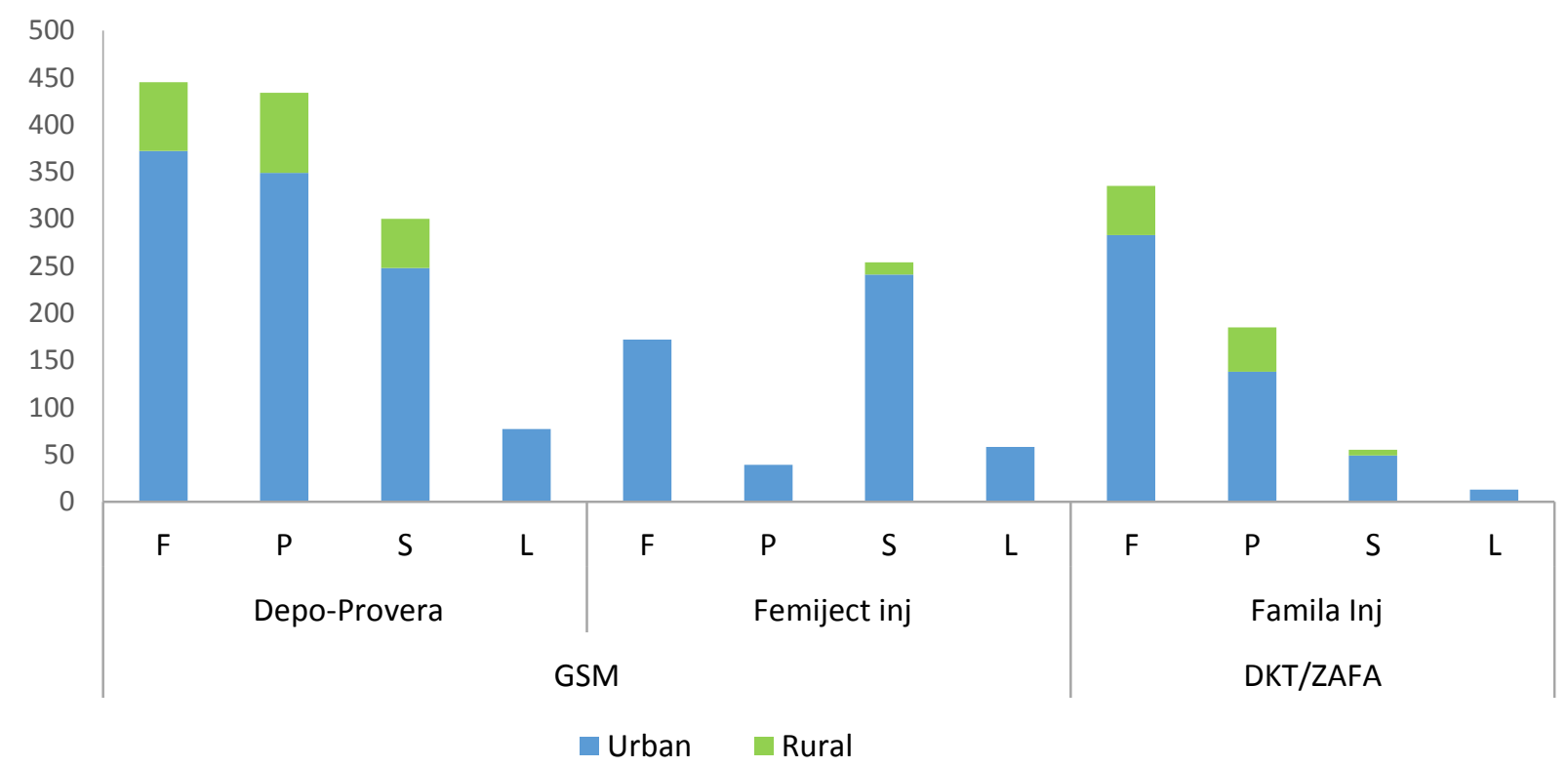

$\mathrm{F}=$ Faisalabad, $\mathrm{P}=$ Peshawar, $\mathrm{S}=$ Sukkur, $\mathrm{L}=$ Lahore

Sales of ECP indicate that this method is more used in the two districts from Punjab-Faisalabad and Lahore-than in other areas. ECP sales in Peshawar are considerably lower than sales of OCP. In Sukkur, 
sales of both brands are negligible. Most notably, sales of ECP in Faisalabad are at par with sales of OCP in the district, in both urban and rural areas.

Figure 4.17: Weekly Sales of Selected ECP Brands at Pharmacies in Four Districts

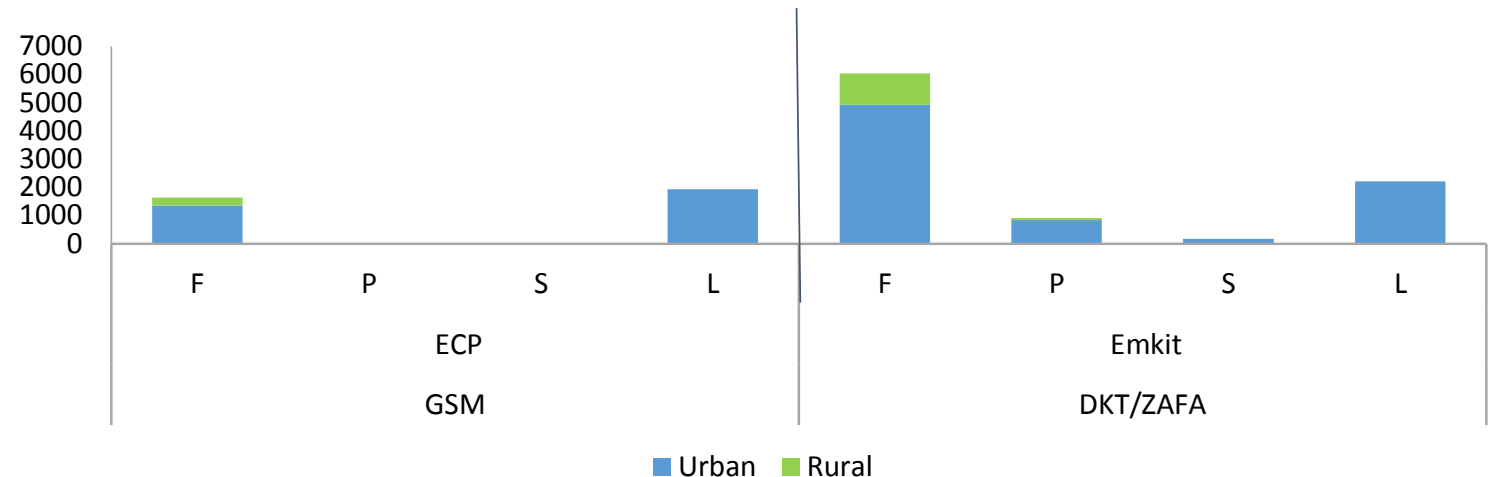

$\mathrm{F}=$ Faisalabad, $\mathrm{P}=$ Peshawar, $\mathrm{S}=$ Sukkur, $\mathrm{L}=$ Lahore

OCP, ECPs and injectables are supplied to delivery points via the same supply chain, shown in Figure 4.18 .

Figure 4.18: Supply of COCs, ECPs and Injectables in the Private Sector

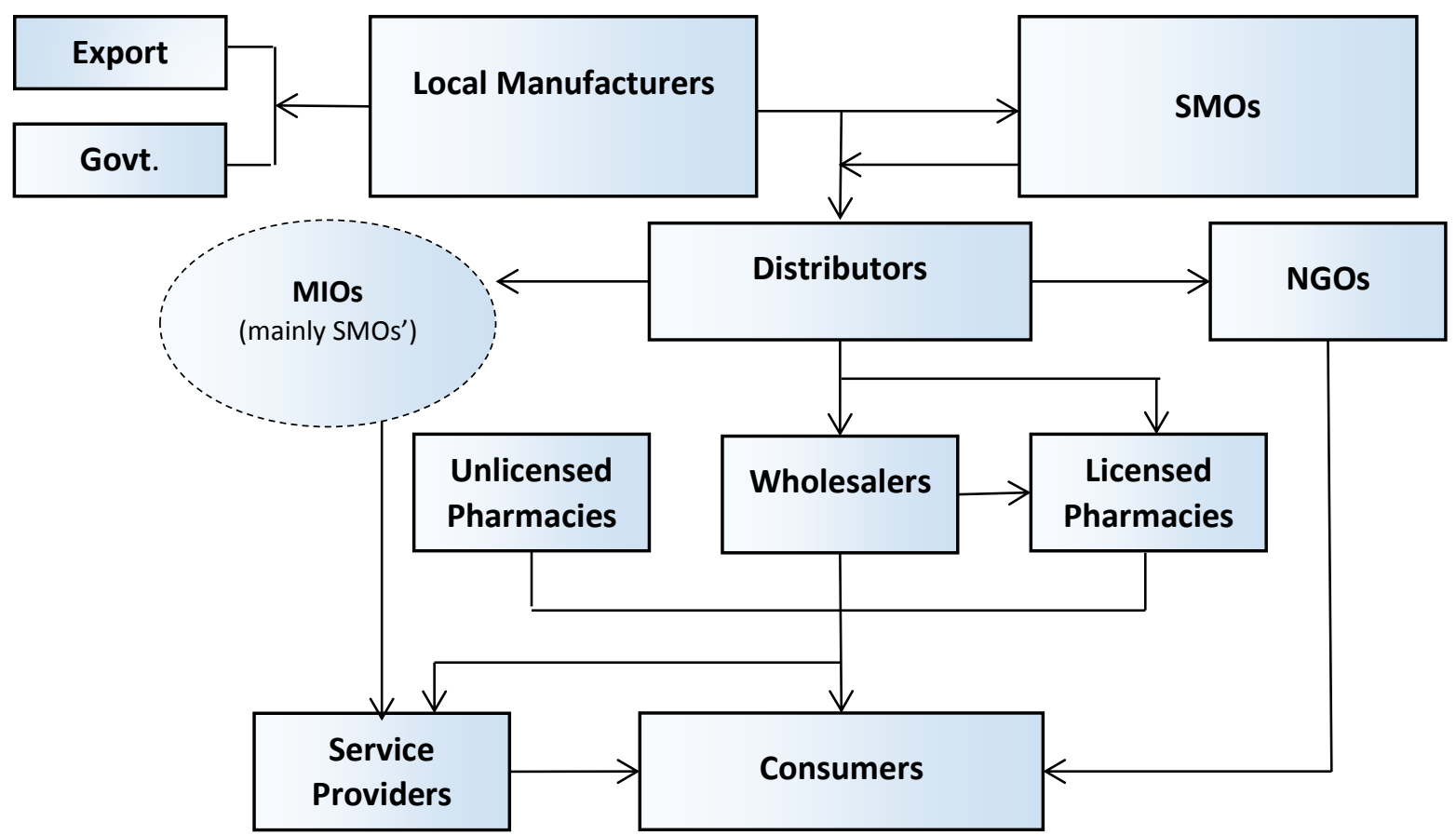

As detailed in the previous chapter, in our census of health facilities in four districts, provision of OCP by private providers was found to be quite low, about 10 percent overall in both rural and urban areas. However, provision was higher among the LHV/midwife/nurse clinics, female doctors (in urban areas), private hospitals, and NGO clinics. The first of these four categories had the highest provision of about 50 percent. Among pharmacies, 41 percent were selling OCP. 
Injectables followed a similar pattern, with slightly higher provision among urban providers (12\%) than rural providers (8\%), and the same four cadres showing the highest availability, peaking at 48 percent of urban LHVs. Among pharmacies, 25 percent were selling this method.

On the other hand, ECP provision was only six percent of urban providers and two percent of rural providers in the private sector, with only some private hospitals and NGO clinics providing this method. The main source in the private sector appears to be pharmacies, 20 percent of which were selling ECP.

The perception that there was no demand for the method was voiced by 15 percent of urban and 27 percent of rural non-providers of OCP; 14 percent of urban and 32 percent of rural non-providers of injectables; and 15 percent of urban and 21 percent of rural non-providers of ECP. As mentioned earlier, while we do not have method-specific demand perception data for pharmacies, we know that, overall, 55 percent of urban and 39 percent of rural non-sellers cite this reason for not selling any method.

In the case of oral pills and injectables, it is likely that the large share of public sector sources is seen to limit the demand for private sources. Analysis reveals LHWs and public hospitals as the major sources of OCP and injectables, alongside pharmacies for OCP and private/NGO hospitals for injectables, with little effect of wealth on choice of public sector. In the absence of PDHS data, it may be speculated that low provision of ECP is due to the fact that the method has only recently been recognized to be safe for regular use, and may be less known to consumers.

Low demand for these methods and resultant low sales volumes are a key challenge. During interviews, some pharmacists said they are less motivated to stock contraceptive products because they are not very profitable. Moreover, in Peshawar and Faisalabad, pharmacists complain there is a shortage of providers to prescribe hormonal methods, which constrains demand at pharmacies, particularly in rural areas.

Encouragingly however, pharmacists in urban Faisalabad were of the view that they can play a positive role in counseling men and youth:

"Pharmacies are approached by males and youth and therefore the staff of pharmacies must possess adequate family planning knowledge and counseling skills to guide and prescribe appropriate method." Pharmacist, urban Faisalabad

The main constraint in the growth of hormonal method use is side effects, associated with poor service quality, which has led to the development of a negative perception among consumers and consequently tepid demand (discussed in detail in Chapter 2). Distribution systems are aware of these limitations. In interviews, SMO representatives expressed concern about the rising trend of traditional methods in cities, linking it with the absence of a strong communication strategy for addressing users' apprehensions about the possible side effects of hormonal methods.

"Users of traditional methods are growing even among urbanized, well-educated and wealthier segments; even the religious people are supporting traditional methods. The educated people think: why should they introduce alien materials in their body? We do not have a strong communication strategy for modern methods in our country. We need to introduce modern methods through strong influencers and clear messages." SMO representative

However, while all stakeholders acknowledged the need to generate demand for hormonal methods, views differed regarding who should take the lead. Zafa's distributors felt that the manufacturer needs to invest more in promoting its products, and some SMO representatives echoed the same idea.

"Demand for Zafa's products is not growing because Zafa is not investing enough in product promotion." Zafa distributor

"We need to involve pharmaceutical companies...in product promotion, instead of investing donor money on promoting their products." SMO representative 
From Zafa's point of view, the responsibility rests primarily with service providers, who should allay the fears of clients and be more proactive in proposing these methods.

"Seminars should be arranged for doctors...to enhance the provision of FP services. We should especially motivate those who have misperceptions regarding side effects of FP products."

Zafa representative

The commercial sector is expected to take the lead in generating demand, but is not very active. Among possible reasons, the costs of product promotion are prohibitive, and government support, such as tax exemptions on advertisements, is lacking. Low presence of competing products, and the fact that contraceptives comprise only a small part of the main manufacturer's product range could be further reasons for low motivation to invest in promotional activities. The previous chapter detailed the significant proportions of private service providers not offering OCP (20\% urban, $38 \%$ rural), injectables (38\% urban, $37 \%$ rural), and ECP (46\% urban, $52 \%$ rural) because the methods are not supplied to them.

Among pharmacies not selling contraceptives, 44 percent of urban and 59 percent of rural pharmacies cite non-supply as a reason. In interviews, pharmacists in peri-urban and rural areas complained that they were not catered by distributors or catered less regularly. Those in rural Faisalabad and Sukkur complained about OCP and injectable stock outs, and having to purchase supplies from wholesalers.

The problem of low rural penetration is evident from the sales volume data as well as the comparison of brand presence in rural and urban settings, shown in Figure 4.19.

Figure 4.19: Selected OCP and Injectable Brands in Pharmacies in Four Districts
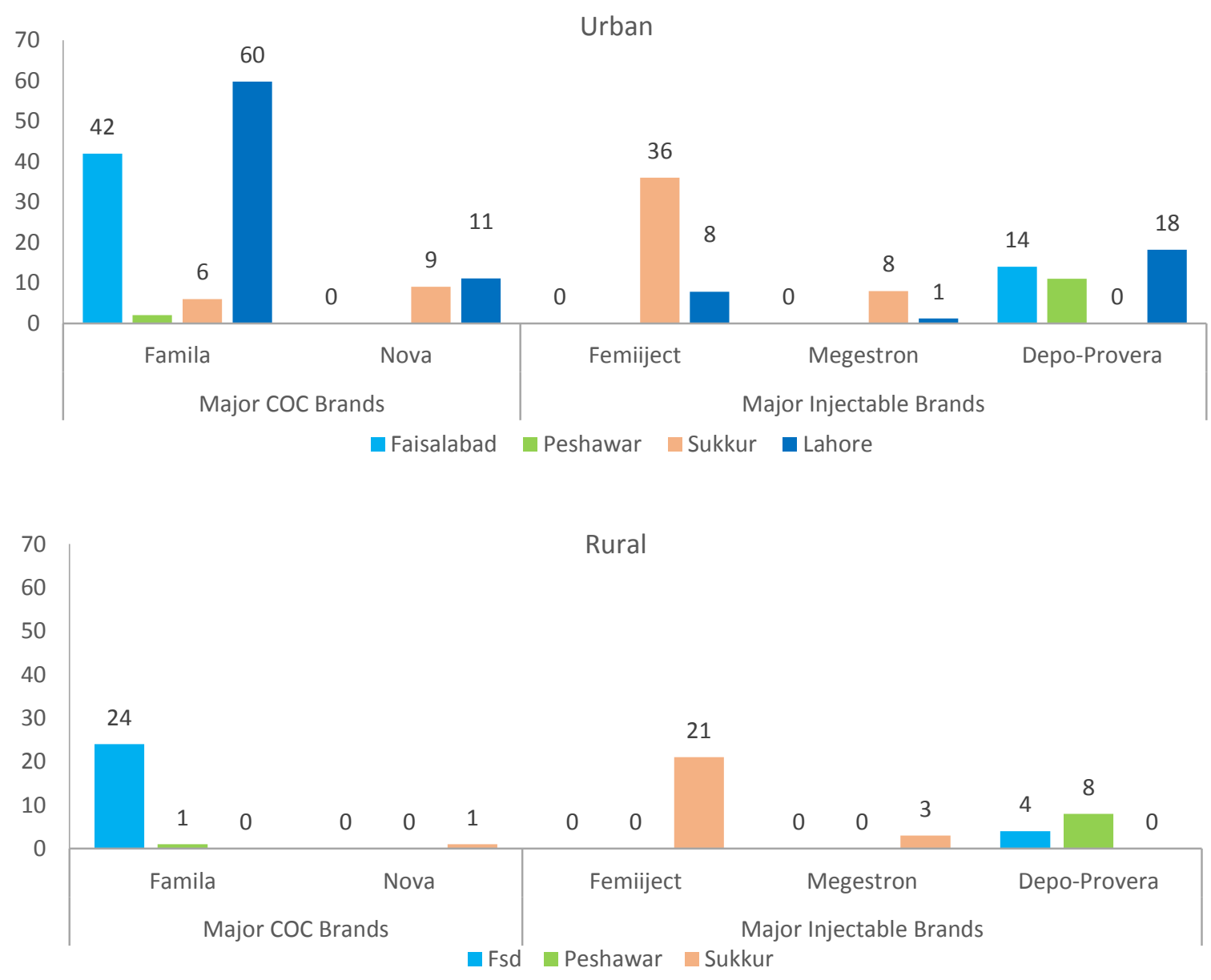

Note: Only urban data were collected for Lahore 
In interviews, OCP and injectable distributors reported that their own supplies are regular, and that they supply regularly where there is adequate demand. However, it should be borne in mind that, just as contraception services are a less prioritized, "add-on," service among many providers, contraceptive products comprise a relatively small component of distributors' range of pharmaceutical products. According to interviews, distributors do not commonly experience protracted stock outs. However, temporary breaks can arise in their capacity to provide to service delivery points due to unexpectedly large orders, for example, from an NGO or a wholesaler. ${ }^{6}$ Some delays in supplies are reported by DKT, which uses Zafa products at its clinics. Usually, distributors are able to resolve such interruptions promptly.

Leakage of injectables from the public sector is reported by some distributors, particularly in Peshawar.

The problem of distributors' inability to reach the large proportions of unlicensed pharmacies, and their reluctance to penetrate rural areas was touched upon in the previous section. In addition to the dispersed nature of demand in the rural market, distributors are also discouraged by the relatively lower presence of qualified service providers to prescribe methods, and of licensed pharmacies to stock those methods in rural areas.

These difficulties make it prohibitive even for SMOs to break into rural areas. Until the market is more developed and demand increases, some subsidies may be necessary for improved rural penetration.

"We do not supply to the un-licensed pharmacies and have less access to the rural areas
although we do our maximum to supply licensed pharmacies. However, DKT's Social Organizers
and Medical Information Officers have penetrated to the CMW level in rural areas."

DKT distributor

"To focus on thinly populated areas, you need to have lot of resources. The only way to tackle this issue is to involve small NGOs at community level." GSM representative

While their involvement reduces profit margins for others in the supply chain, ${ }^{7}$ wholesalers play an important role in the pills and injectables market, serving to bridge the gap between pharmaceutical distributors and unlicensed pharmacies, which cannot be catered by distributors and comprise a large proportion of the market. Wholesalers are also important for reaching rural providers and pharmacies, and are used by both the commercial and the social marketing chains.

"The wholesalers have more demand of pills, injectables and ECPs than the retailers as the wholesalers supply to both unregistered and registered pharmacies in rural and remote areas."

Zafa distributor

Compared to the condom market, the market for OCP, and to a lesser extent, injectables, seems somewhat listless. The commercial sector is present but complacent; the main manufacturer, Zafa, is seen to have a traditional, small business approach, and to be benefiting from its monopolistic position in the low-cost category. Meanwhile, SMO representatives express concern over the profound need to counter consumers' fear of side effects, and to promote hormonal methods, but have not been able to play a strong role in this matter, in part, due to the perception that this is the commercial sector's job. Notably, social marketing firms have traditionally been more active than commercial entities in efforts to increase demand among consumers; they typically have more resources to invest in TV advertisements; community outreach; and training, equipping and supply of providers. Commercial concerns do invest in sales teams to market

6 Orders from wholesalers usually cater to unlicensed and peri-urban/rural pharmacies. In addition, some commodities, including pharmaceutical products, may be procured by wholesalers for shipping to other countries, such as Afghanistan. The diversion of these supplies can cause a shortage, especially in areas where local demand tends to be low.

7 Generally, the margins earned by wholesalers range between 5 and 7 percent. The precise figure is negotiated in each situation, and reduces the profit margins of other suppliers involved. At times, it is only the manufacturing/importing concern that absorbs the additional margin of wholesalers; in other situations, distributors reduce their own margins in the interests of higher-volume sales, or retailers forego a part of their price to ensure that the product is available on their shelves. 
products to providers and pharmacists, but find extensive campaigns for generating consumer demand to be cost-prohibitive.

While OCP use shows a downward trend, the rise in injectable use, though slow, is encouraging. Injectables have potential to meet the needs of women in rural and remote communities in particular, who cannot afford to make frequent trips for resupply. As indicated in the previous chapter, mid-level providers can be enabled to provide this method; in combination with strong communication, product promotion, focused engagement with distributors and pharmacists, and assured quality of care, there is potential to expand the share of this method in the method mix.

\section{IUDs and Implants}

According to the PDHS, IUD prevalence has remained constant at 2.3\% between 2006-07 and 2012-13. As discussed in section 4.2, the main sources of this method are public and private hospitals for both poorer and wealthier users.

The private market for this method is quite different to other methods, in terms of a much heavier dominance of social marketing organizations, with a very limited import on a commercial basis. A modest but adequate range of brands and variations is available (Table 4.5).

Implants are relatively new in Pakistan, particularly the single and two-rod versions, and primarily supplied by the public sector, including to social marketing organizations. Service access and availability for this method is highly limited, although the government, particularly in Sindh, has begun an aggressive roll-out program. GSM has conducted a pilot and MSS is providing regular supply at its own centers.

Table 4.5: Major IUD and Implant Brands, their Prices, and Profit Margins of Distributors, Retailers, Providers

\begin{tabular}{lllccc}
\hline Method & Brand & $\begin{array}{c}\text { Marketed } \\
\text { by }\end{array}$ & $\begin{array}{c}\text { Retail Price (per } \\
\text { unit), Rs. }\end{array}$ & $\begin{array}{c}\text { Distributor's Profit } \\
\text { Margin, } \%\end{array}$ & $\begin{array}{c}\text { Retailer's Profit } \\
\text { Margin, \% }\end{array}$ \\
\hline IUDs & Multiload & GSM & 85.0 & 100.0 & 120.0 \\
& Safeload & GSM & 85.0 & 100.0 & 120.0 \\
& Heer & DKT & 45.0 & 50.0 & 100.0 \\
\multirow{2}{*}{ Implants } & Femplant & MSS & N/A & 1012.0 & 1100.0 \\
\hline
\end{tabular}

While reported volume sales by market players show rapid growth in use of IUDs, actual use as reported by consumers in the latest DHS is far lower. ${ }^{8}$ Despite significant investments over the last 20 years, the method has not achieved wide acceptance. Side effects and counseling remain key obstacles to more rapid acceptance and the general perception for the methods is negative-in fact, maligned.

Due to low overall volume of demand for IUDs, pharmacies are largely uninterested in stocking this method; in our census of four districts, only $10 \%$ of urban pharmacies were found to be selling IUDs. Totally dependent on insertion skills and infection prevention protocol, IUDs are primarily supplied to service providers.

As mentioned, the challenge of ensuring that private service providers have contraceptives on hand is common across all methods, but it attains greater significance for methods that have to be administered by providers or are not available at local pharmacies. Both of these constraints apply to IUDs and implants.

8 A recent study by the Population Council pointed out that issuance of IUDs in the public sector, as reported by the Logistics Management Information System (LMIS) and the Bureau of Statistics, is nearly ten times higher than the level of IUD consumption (including wastage) indicated by PDHS 2012-13. 
Ensuring distribution to private providers is acknowledged to be a weak link in the private contraceptive supply chain. Distributors are generally not interested in engaging directly with service providers, except the larger facilities, because it is expensive and complicated to regularly visit a greater number of small customers, who may or may not need more supplies. Moreover, most providers are unwilling to pay upfront for contraceptives; they prefer to stock products on credit, and there can be potential difficulties in recovering payments.

To fill this gap, both commercial and social marketing entities (but mainly SMOs) typically engage medical information officers (MIOs) who are assigned to work with distributor teams, marketing products to service providers and placing orders on their behalf to their local distributors. This mode of distribution naturally limits distribution of commodities to the number that can be catered through MIOs.

"We have separate social organizers to supply products to the CMWs, in project-based rural settings...Distributors do not supply directly to our clinics, so we manage through our own sales teams. It is a challenge." DKT representative

There is a need to find innovative solutions to improve the efficiency of local distribution to providers, such as linking clusters of private facilities with a common source, which could be a pharmacy.

Growth in the market for long-acting methods is restricted by the same fears of side effects that affect the market for OCP and injectables. In the case of IUDs, the problem is exacerbated by negative messages about the method, inspired by the difficulties experienced by past users. In addition to the type of strong communication intervention discussed in the previous section, there is a strong need to ensure that provision of IUDs-and implants-is coupled with quality care, and users are informed about possible side effects, and receive adequate follow-up support. Regrettably, this is often not the case. A long-term perspective will be needed to grow use of IUDs and implants as acting hastily might worsen the problem. In interviews, representatives of some SMOs referred to the strong donor interest in promoting use of IUDs and implants, which translates into pressure on affiliated providers to push these methods to users. It was hinted during interviews that the pressure to achieve CYPs through long-acting methods may at times infringe on users' right to make a fully informed choice of a method that best suits their circumstances, which contributes to early discontinuation.

"If donors require that we push IUDs, we push the program to achieve that target. Providers don't even counsel clients much or provide them all the facts about IUDs. Theoretically, they give them a choice, but they push the long acting methods. That can eventually lead to discontinuation."

SMO representative

The approach of rushed roll out might boost use of longer term methods in the short run, but if follow up is inadequate, these gains are likely to be reversed-and demand-side barriers worsened-as users discontinue. The high discontinuation rates reported by the PDHS for IUDs signal a strong need to improve its provision. Repeating the same approach with implants-a relatively new method that is not yet as widely feared-could lock the prevalence of this option at the same low levels. Therefore, improving the market for longer-term methods requires, first and foremost, improved service quality to ensure user satisfaction and continuation. 


\section{Summary of Key Polnts Contraceptive Supply in the Public and Private Sectors}

\section{Public and Private Shares in Meeting Contraceptive Needs}

- Consumers' main sources of contraceptives are pharmacies, shops, and commercial/NGO hospitals in the private sector, and LHWs and larger public hospitals in the public sector.

- Pharmacies are a key source of condoms, OCPs, and ECPs, but have a very low role in providing injectables, IUDs or implants, while shops only sell condoms.

- LHWs are major sources for all three methods in their repertoire-condoms, OCPs, and injectables.

- Public hospitals and private/NGO hospitals are the leading sources of injectables and IUDs; the former is also a major source of OCPs.

- Condoms are the only method for which we observe the expected pattern of wealthier clients preferring the private sector, and poorer clients preferring public sources; for all other methods, usage by wealth is mixed.

\section{Supply Chain for Contraceptives and Stock Outs}

- In the public sector, incidence of contraceptive stock out remains high at service delivery points (SDPs) across all sectors in Punjab, Sindh, and KP.

- Efficient distribution of commodities is hindered by: requisitioning delays; lack of arrangements for delivery from district stores to SDPs; rationing of supplies, especially in the case of LHWs; and inadequate use of electronic reporting systems, among other issues. There is some leakage to the private market.

- Ensuring that private providers have adequate stocks is a challenge across all methods, especially injectables and long-acting methods, which are less available at pharmacies and cannot be self-administered. Distributors are generally not interested in engaging directly with service providers, except the larger facilities, so individual clinics have to be supplied through medical information officers.

\section{Markets for Contraceptives}

- The private condom market is maturing. However, commercial importers complain it is difficult to compete against social marketing organizations (SMOs), especially due to their subsidized products and the high profit margins they offer to retailers on some brands. Some importers are unable to make adequate use of consumer goods distribution channels, restricting coverage of shops.

- In the market for OCPs, ECPs, and injectables, low demand-mainly associated with side effects-and the resultant low sales volumes are a key challenge. The need to address consumer fears about side effects is acknowledged by all, but the job is not owned by commercial or social marketing entities. One main local manufacturer claims to meet 70 percent of demand. Import of competing products is restricted, and there is a narrower range of products and pricing options. 
- Private supply of IUDs and implants is mainly through SMOs/NGOs, with negligible availability at pharmacies. Demand is low, with fear of side effects perpetuated by inadequate counsel and follow-up.

- Presence and sales of all contraceptive brands is lower in rural settings. Distributors are less interested because the rural market is diffused, and there are fewer licensed pharmacies and providers. Pharmacists complain of stock outs and having to purchase from wholesalers.

- While a significant proportion of pharmacists and shopkeepers still believe it is religiously impermissible to sell contraceptives, many are willing and eager to play a role in informing and counseling clients.

\section{Procurement by Provinces}

The governments of Punjab, KP and Sindh have started procuring contraceptives, which was previously the responsibility of the Federal Government. 


\section{Chapter 5 \\ Policy Landscape and Scale of Donor Investments in Family Planning}

After the passage of the $18^{\text {th }}$ Constitutional amendment in 2010 , certain key functions of the government, including the health and population welfare portfolios, were decentralized and devolved to the provinces. Pakistan's provinces face opportunities and challenges in the post-devolution period. Major opportunities include the prospects of locally owned policies and programs, based on provinces' specific needs and priorities; the widening of fiscal space; and the ability of provincial departments to negotiate directly with development partners, to enact relevant legislation, and enforce regulations.

In the area of FP, the provinces have made considerable use of these opportunities; however, at the same time, certain challenges have also emerged. In this chapter, we review the population policies of KP, Sindh, and Punjab, as well as related provincial strategies, to identify their strengths and weaknesses as tools for steering progress towards accelerated FP uptake. We then take an in-depth look at the progress the three provinces have achieved towards their FP goals in terms of enhancing access to FP services; improving the quality of the services available; ensuring contraceptive security; evolving improved communication approaches to promote FP; forging effective partnerships with the private sector; responding to advocacy efforts, especially through social legislation; and improving coordination and monitoring mechanisms. Finally, we take stock of the financial commitments made by various government stakeholders for FP, and the role of donors. The analysis is based on a review of key policy and strategy documents produced after devolution, as well as in-depth interviews with a large number of senior stakeholders.

\section{Provincial Population Policies and Health Strategies- The Beginning of a New Era}

Pakistan was among the few countries in the region to recognize as early as in the 1960s the negative impact of a rapidly growing population on all aspects of development. Pakistan's first comprehensive FP scheme was included in the Third Five-Year Plan (1965-70), with an autonomous FP program launched in 1965. The country's first national Population Policy, promulgated in 2002, was influenced by the agenda of the International Conference on Population and Development (ICPD) 1994. The 2002 policy proposed a paradigm shift, moving away from pursuing purely demographic targets towards improving people's quality of life, an important aspect was recognition of the role of the private sector in enhancing FP service delivery. The policy was complemented by a Perspective Plan (2002-2012), which provided a roadmap for implementing its directives. However, in due course, the policy was considered to be overambitious and a need to develop a new, more realistic, policy was felt in 2009. A draft policy was developed but before it could be approved by the Cabinet, devolution occurred, shifting population-related functions to the provinces.

\section{Post-Devolution Provincial Population Policies and Costed Implementation Plans}

Post-devolution, in 2010, all the provinces became responsible for develop their own sectoral policies. It took them nearly six years to develop their population policies based on their priorities and needs. To date, however, KP's is the only population policy that has been approved, and it was launched in 2015. Sindh has developed a draft population policy and a complementary Costed Implementation Plan (CIP), Punjab has drafted its population policy and development of its CIP is underway. One reason for the delay, as mentioned in the Punjab policy, was "the unprecedented haste with which devolution was implemented leaving no time for the provinces to properly plan and implement this momentous change nor was any guidance provided to them in this regard by the federal government." In the interim, the provinces have been guided, as per the $18^{\text {th }}$ Constitutional requirement, by the Population Policy of 2002. 
In KP, the PWD has already started implementing some of the broad guidelines described in the provincial population policy a process that began even while the policy's approval was pending.

Table 5.1: Objective of Provincial Population Policies and Sindh Costed Implementation Plan

\begin{tabular}{|c|c|c|}
\hline $\begin{array}{c}\text { Punjab } \\
\text { Draft Population Policy }\end{array}$ & $\begin{array}{c}\text { Sindh } \\
\text { Draft Population Policy }\end{array}$ & $\begin{array}{c}\text { KP } \\
\text { Population Policy2015 }\end{array}$ \\
\hline $\begin{array}{l}\text { Goals } \\
\text { - Reduce population momentum and } \\
\text { fertility through improvement in } \\
\text { access and quality of reproductive } \\
\text { health (RH) services through } \\
\text { integrated health service delivery } \\
\text { Objectives } \\
\text { - Achieve universal access to safe } \\
\text { and quality RH/FP services by } \\
\text { 2018, striving to attain } \\
\text { replacement level fertility by } 2030 \\
\text { - Enhance access to services and } \\
\text { improve quality of services of all } \\
\text { stakeholders } \\
\text { - Inter-departmental coordination for } \\
\text { consolidation of services } \\
\text { - Contraceptive commodity security } \\
\text { - Demand generation and advocacy } \\
\text { - Training and capacity building } \\
\text { - Mainstreaming population in } \\
\text { development planning }\end{array}$ & $\begin{array}{l}\text { Long-Term Objectives } \\
\text { - Attain a decrease in fertility level from } 3.9 \\
\text { (2013) to } 3.0 \text { births per woman by the year } \\
2020 \\
\text { - Raise contraceptive prevalence rate (CPR) } \\
\text { from } 29.5 \% \text { in } 2012-13 \text { (baseline) to } 45 \% \\
\text { by } 2020 \\
\text { Short-Term Objectives } \\
\text { - Increase access to FP/RH services to the } \\
\text { most remote and farthest areas of the } \\
\text { province by } 2017 \\
\text { - Increase efforts to reduce unmet need for } \\
\text { FP from } 21 \% \text { to } 15 \% \text { by } 2020 \\
\text { - Ensure contraceptive commodity security at } \\
\text { all service outlets by } 2018 \\
\text { - Achieve universal access to safe and quality } \\
\text { RH/FP services by } 2020\end{array}$ & $\begin{array}{l}\text { Objective } \\
\text { - To attain replacement } \\
\text { level fertility, promote } \\
\text { FP as a basic human } \\
\text { right } \\
\text { - } \quad \text { To reduce unmet need } \\
\text { through universal } \\
\text { access and improved FP } \\
\text { services } \\
\text { - To achieve universal } \\
\text { access to safe and } \\
\text { quality RH/FP services } \\
\text { by } 2020 \\
\text { - Increase CPR from } 28 \% \\
\text { to } 42 \% \text { by } 2020 \text {; } \\
\text { - Reduce unmet need } \\
\text { from } 26 \% \text { to } 15 \% \text { by } \\
2032 \text { and lower fertility } \\
\text { from } 3.9 \text { in } 2013 \text { to } 2.1 \\
\text { by } 2032\end{array}$ \\
\hline & $\begin{array}{l}\text { Sindh } \\
\text { Costed Implementation Plan (CIP) }\end{array}$ & \\
\hline & $\begin{array}{l}\text { - Functional integration of services at the } \\
\text { local level, ensuring good quality services, } \\
\text { improving providers' skills, giving } \\
\text { importance to provider-client perspective } \\
\text { - Improving supply chain management } \\
\text { - Expanding services with supply and demand } \\
\text { side interactions } \\
\text { - Promoting positive behaviors with regards } \\
\text { to birth spacing } \\
\text { - Instituting performance monitoring and } \\
\text { accountability as a means to improve } \\
\text { stewardship and governance. }\end{array}$ & \\
\hline
\end{tabular}

A National Policy Framework has been developed at the federal level for improving inter-provincial coordination and harmonizing efforts. The framework has been sent out to the provinces for their inputs. In addition, Pakistan's Planning Commission developed Pakistan 2025: One Nation, One Vision, a development vision document that recognizes the potential demographic dividend available to Pakistan, and recommends investments in human capital to reap it. In addition, a National Vision for Coordinated Priority Actions to address challenges of Reproductive, Maternal, Newborn, Child and Adolescent Health and Nutrition (2016-2025) has been developed that calls upon declaring a "Population Emergency" in the country. 


\section{Provincial Population Policy Strengths}

While they respond to their specific provincial priorities and circumstances, the three provincial population policies also have some similar features, such as a common underlying vision, which is important from the perspective of national cohesion. All three policies acknowledge the potential in the youth bulge for reaping a demographic dividend, if the necessary prerequisites are met. The Sindh policy delves into this topic in much greater detail. Other areas of commonality include a focus on multi-sectoral approaches; involvement of the private sector in communications (Sindh) in service delivery; male involvement; improved quality of care; training of providers in FP; attention to youth; and monitoring and supervision.

All three policies have an adequate focus on FP and lowering population growth rate. The Sindh and KP policies include CPR targets that are in concordance with the recently announced FP2020 goals, while Punjab is updating and revising its target to bring it in conformity to the FP2020 goals. All three policies also acknowledge the need for expanding RH services so as to achieve universal access before 2020. There is unanimity in the policies regarding the need to ensure that all health facilities provide FP services. A major and welcome deviation from past national polices is a shift from advocating the small family norm to a new paradigm of Healthy Timing and Spacing of Pregnancies, and linking FP to health outcomes.

The Sindh Population Policy is quite comprehensive and provides detailed guidelines for the Population Welfare Department to pursue. It is also linked to a Costed Implemented Plan that the province had developed in 2015 with support from the Bill and Melinda Gates Foundation. The CIP is anticipated to guide implementation of the province's population policy and is linked to the provinces FP2020 CPR goal of 45 percent. Punjab is also being supported in developing a CIP, which is linked to its population policy and FP2020 CPR goal of 55 percent.

\section{Provincial Population Policy Gaps}

While these provincial policy developments are encouraging, all three policies have gaps. In all three, the long- and short-term objectives articulated deal with only one component of population growth, i.e., lowering fertility, ignoring other important parameters such as mortality (especially child survival) and migration, both internal and external. In the broader perspective, this narrow focus limits effectiveness as lower fertility cannot be achieved until conditions are created that are conducive for having small families. These conditions relate to reducing gender disparities in health, employment and education; ensuring child survival and lowering infant mortality; improving opportunities for girls to complete at least secondary education; legislation for raising age at marriage; and economic development. Hence, the policies lack the broad-based integration within development and economic growth strategies.

Furthermore, the three policies could have had more focus on indicating the broad modalities of how they will attain their objectives; specifically, for example, how to reach out to youth with the correct kind of information and services, and how grassroots accountability can be enhanced. Likewise, more directions could have been included on the mechanisms to be put in place to incentivize and bring on board the urgently needed private sector, as well as to improve synergies with the health department, such as through task shifting and task sharing. The policies notably lack a strategy for how to include services for the poor, marginalized, and vulnerable groups.

The policies do not include any provisions for rationalizing contraceptive pricing in the public and private sectors, e.g., doing away with the dual pricing policy of the DoH and PWD, or approaches for increasing the total market share of contraceptives. However, although this is not mentioned in its population policy, the Government of Punjab has recently decided to have a uniform contraceptive price policy: contraceptives will be provided free of cost at both DoH and PWD health outlets.

Rising unemployment, rural-to-urban migration, and aging are emerging as new demographic realities. The Sindh policy mentions the importance of rapid urbanization and its impact on urban life; however, it does not deal with it as one of its implementation principles. On the other hand the phenomenon of aging and care of the elderly has been dealt with adequately as a policy principle. 


\section{The Challenge of Policy Implementation}

All policies have correctly identified the obstacles of past policies, most notably lack of attention to implementing the policies, and express a resolve to avoid repeating the same mistakes. However, the successful implementation of the new provincial population policies depends on how effectively they are integrated with existing strategies and other provincial policies, especially the provincial development and growth strategies, as well as with international commitments made by the government, such as the Sustainable Development Goals (SDGs) and FP2020. A mechanism for implementing the policies through a multi-sectoral, coordinated approach needs to be identified. But foremost, the policies must be translated into prospective, time-bound realistic plans, with adequate resource mobilization and improved accountability measures, to have the impact envisaged.

\section{Provincial Health and Development Strategies}

In addition to the population policies, we have reviewed the most current health related documents to examine the extent to which they have included FP service provision as a priority. The provinces have all developed Health Roadmaps and Strategies and all three mention FP as a key area that needs to be expanded, including ensuring an uninterrupted supply of contraceptives. This inclusion of FP augurs well for the DoH to expand provision of FP services to contribute towards achieving universal access to services.

Table 5.2: Provincial Health Sector Strategy Objectives

\begin{tabular}{|c|c|c|}
\hline $\begin{array}{c}\text { Punjab } \\
\text { Health Sector Strategy } \\
2012-2020\end{array}$ & $\begin{array}{c}\text { Sindh } \\
\text { Health Sector Strategy } \\
2012-20\end{array}$ & $\begin{array}{c}\text { KP } \\
\text { Health Sector Strategy } \\
2010-2017\end{array}$ \\
\hline $\begin{array}{l}\text { Build an efficient safe and effective } \\
\text { health service delivery system that } \\
\text { caters to the specific needs of all } \\
\text { population groups, with an } \\
\text { enhanced emphasis on MNCH, } \\
\text { emergency care, FP and } \\
\text { institutional services } \\
\text { - Deliver FP services at all levels as } \\
\text { part of Essential Package of Health } \\
\text { Services (EPHS) } \\
\text { Ensure uninterrupted supply of FP } \\
\text { commodities to all the primary and } \\
\text { secondary level health facilities and } \\
\text { outreach workers } \\
\text { Institute mass and interpersonal } \\
\text { communications focusing on key } \\
\text { issues of MNCH, FP and, } \\
\text { Adopt integrated RH service } \\
\text { delivery model that includes SRH, } \\
\text { HIV and FP services }\end{array}$ & $\begin{array}{l}\text { - Formulation of a Minimum } \\
\text { Health Service Package } \\
\text { (MHSP) that includes an } \\
\text { estimate of the required } \\
\text { resources, especially for } \\
\text { MNCH, FP, and nutrition } \\
\text { - Special Areas of Emphasis: } \\
\text { Polio Plus, Nutrition, } \\
\text { MNCH, FP, Non } \\
\text { Communicable Diseases, } \\
\text { Communicable Diseases, } \\
\text { and Disaster Management } \\
\text { Integrate contraceptive } \\
\text { services with maternal care } \\
\text { by } 2016 \text { : Provision of free } \\
\text { contraceptives and training } \\
\text { by PWD to all DOH facilities } \\
\text { for birth spacing; } \\
\text { integration of services with } \\
\text { pregnancy care to reach } \\
\text { out to couples }\end{array}$ & $\begin{array}{l}\text { - At least } 70 \% \text { of the } \\
\text { population to have } \\
\text { access to MHSP for } \\
\text { primary and secondary } \\
\text { healthcare services by } \\
2017 \text { (including FP } \\
\text { services) } \\
\text { - Increase CPR to 55\% by } \\
2017 \\
\text { Revitalize delivery of FP } \\
\text { services in public sector } \\
\text { through a mechanism } \\
\text { for forecasting } \\
\text { contraceptive } \\
\text { requirements and } \\
\text { ensuring the } \\
\text { uninterrupted supply of } \\
\text { contraceptives to } \\
\text { facilities, LHWs, and } \\
\text { CMWs }\end{array}$ \\
\hline
\end{tabular}




\begin{tabular}{ll}
\multicolumn{1}{c}{ Punjab } & \multicolumn{1}{c}{ KP } \\
\multicolumn{1}{c}{ Growth Strategy (2014-18) } & $\begin{array}{c}\text { Integrated Development } \\
\text { Strategy 2014-2018 }\end{array}$ \\
\hline Calls for harnessing the Demographic & The strategy is pro- \\
Dividend and recommends: & poor, people-centric \\
- Increasing current financial & and rights-based \\
$\quad$ allocation for FP activities, & Improved health \\
- Strengthening the ongoing & service delivery, the \\
Population Welfare Program & strategy lists as a major \\
- Developing a Communications and & outcome the universal \\
Social Mobilization Strategy & accessibility of FP and \\
- Improving performance of LHW & RH services \\
program to deliver FP services & \\
using NGOs and CBOs for delivering & \\
FP services in non LHW areas & \\
\hline
\end{tabular}

Overall, gaps in the provincial health and development strategies include an overemphasis on infrastructure expansion, with less focus on improving quality of existing services. Moreover, while service expansion has been mentioned, there is less focus on expanding choices and services through task shifting and task sharing, which are cost effective strategies. Community midwives could be trained and provided kits for IUD insertion and removal, and in manual vacuum aspiration (MVA) equipment use for post-abortion care. Similarly, LHWs could be allowed to administer the first dose of injectable contraceptives and the choice of methods they offer expanded to include ECP and Sayana ${ }^{\circledR}$ Press (which has yet to be introduced but evidence from elsewhere suggests that it can be injected by women themselves and by CHWs). Likewise, LHVs and male doctors could be trained in providing implants.

The main challenge confronting the country is how to improve FP service delivery coverage in the 40 percent of the area that is not covered by the LHWs. This is an area that the health and development strategies should have focused more on in terms of proposing alternative approaches, in non-covered areas, such as using volunteers, that have been tried and tested by other organizations.

A weak element in all the strategies is how to incentivize and engage the private sector to complement and support the public sector in delivering high quality FP services. Strategies for reaching out to the marginalized vulnerable groups have also been dealt with fully.

A glaring weakness in the strategy documents is that the targets that have been identified do not concur with the provincial population policies. Moreover, the metrics that have been recommended for measuring progress are focused more on process indicators than outcomes.

The development of a CIP by Sindh gives it a lead over the other provinces. The province has, for the first time, successfully been able to develop a plan that is based on the inputs of the health department and the vertical programs, such as the LHW and $\mathrm{MNCH}$ programs. However, the CIP also has certain weaknesses. Importantly, the strategic areas identified in the plan have not been linked to measurable objectives, which will make it difficult to monitor and evaluate performance on a regular basis. The costing analysis in the plan could also be more explicit, particularly for media and infrastructure costs. Instead of focusing on infrastructure development, other options, such as sharing or pooling of existing resources, could also have been considered. Like other provincial strategies, the CIP does not contain details about how to engage the private sector. The CIP recommends employing 6,000 village-based FP workers in areas not covered by LHWs; as these areas comprise 54 percent of the province, the recommended number of workers may not be sufficient. Finally, the CIP does not provide details on how to overcome the deficiency in trained human resources, which is a major constraint in providing high quality services. 


\section{Advocacy Successes in the Provinces}

FP in the past in Pakistan has been plagued by wavering political commitment, low priority of the population sector, and neglect of the central position of FP within the development framework. There has also been a persistence of ambiguities in the minds of the people, especially the educated classes, regarding the permissibility of FP in Islam.

Post-devolution, a number of organizations, including the Population Council, FPAP and Pathfinder have been engaged directly with the provinces in advocacy activities funded by UNFPA and the David Lucile Packard Foundation. These efforts have resulted in high level engagement with the leadership of major political parties (the PPP, PMLN, PMLQ, PTI, and MQM) and in all major parties including the population issue in their party manifestos. Meetings with the Speaker of the National Assembly, Chief Ministers of the provinces and Finance Ministers led to an increase in PWD budgetary allocation in all three provinces.

As part of the national consensus, through consultative meetings with prominent religious scholars, 43 religious leaders signed a declaration endorsing birth spacing as permissible in Islam (GoP, UNFPA and Population Council 2015). Later, 500 religious clerics from KP endorsed the consensus reached at the Population Summit 2015 in Islamabad and pledged to take the message to the district level. Sensitization meetings with major media houses, journalists, and anchor persons resulted in increased reporting on population issues in the press and media (Exit Media Consultants 2015).

Three years of advocacy activities culminated in the Population Summit 2015, jointly organized by the Ministry of National Health Services, Regulations and Coordination and the Population Council, with the support of UNFPA. The President of the Islamic Republic of Pakistan, the Chief Ministers and their representatives, and provincial ministers of population and health expressed their commitment on the occasion to enhance access to FP services and raise the CPR to meet the national commitment at the 2012 London Summit on FP. The provincial commitments are provided in Table 5.3.

Table 5.3: National and Provincial Commitments to Achieve FP2020 Targets

\begin{tabular}{lccc}
\hline & $\begin{array}{c}\text { Proportion of the } \\
\text { Country Population }\end{array}$ & $\begin{array}{c}\text { CPR Commitment for } \\
\text { 2020 }\end{array}$ & CPR Composition \\
\hline Punjab & 0.556 & 55 & 30.6 \\
Sindh & 0.230 & 45 & 10.3 \\
KP & 0.134 & 42 & 5.6 \\
Balochistan & 0.050 & 32 & 1.6 \\
ICT Islamabad & 0.006 & 70 & 0.4 \\
FATA/GB & 0.024 & 45 & 1.1 \\
Pakistan (Composite) & & & 49.7 \\
\hline
\end{tabular}

Several advocacy structures are currently available for continued advocacy, such as the FP champions group brought together by the Population Council and others. The Champions Group has worked with government and development partners to ensure that progress is made on achieving the FP2020 targets. There are also various Committees that have been notified by the National and Provincial Assemblies, including: the Standing Committee on Health; Standing Committee on Population Welfare; Standing Committee on Social Welfare and Women's Development, whose members can advocate for enacting legislation, increasing resource allocation, and increasing accountability within the health and population sectors.

Civil society networks, such as the Pakistan Reproductive Health Network (PRHN) and Pakistan Alliance for Post-Abortion Care (PAPAC), can also undertake advocacy for FP. Additionally, several other organizations have also been playing their role in FP advocacy efforts with legislators for passing of legislation to improve women's wellbeing; as a result, bills on early marriages were passed in the Sindh and Punjab assemblies. Advocacy for inclusion of adolescent sexual and reproductive health (ASRH) issues in the population policies and health strategies of the provinces are ongoing. Jhpiego has been advocating with policy makers in Punjab for including postpartum FP indicators in the Chief Minister's roadmap dashboard. 


\section{Provincial Progress towards FP2020 Goals}

Post-devolution, the provinces have faced a number of challenges in implementing FP programming; some have been resolved and provincial Health and Population Welfare departments are now moving ahead in improving their FP service capacities.

\section{Efforts to Enhance Family Planning Service Access}

\section{Punjab}

Punjab reaffirmed its commitment to achieve a CPR of 55 percent by 2020 at the Population Summit 2015. In this regard, to improve capacity for evidence-based decision-making, respondents noted that PWD has set up a research wing in the Population Welfare Training Institutes (PWTI). To seek advice and involve the religious leaders in FP communications and advocacy efforts, a Religious Ulema Advisory Board has also been established. To cater to the needs of the large youth cohort, 14 youth-friendly centers have been set up by the PWD within RHS-A centers, where a trained psychologist is available to counsel young people.

On the part of the Department of Health, a total of 6,000 CMWs have been trained and 2,000 CMWs deployed. All CMWs are mandated to offer FP counseling and services. Currently all the deployed CMWs are being provided with free contraceptives and are being paid Rs. 50 per client for provision of FP services.

To improve access to primary healthcare services, 700 Basic Health Units have been made functional to deliver $24 / 7$ services. The increased working hours will facilitate utilization by clients for all needs, including FP. All LHWs in the province are being trained in Healthy Timing and Spacing of Pregnancies (HTSP), through support from UNFPA.

\section{Khyber Pakhtunkhwa}

Khyber Pakhtunkhwa (KP) has committed to achieve a CPR of 42 percent by 2020. KP's PWD has increased the number of Family Welfare Centers (FWCs) operating in the province from 400 to 632 . In the area of Egovernance, five management software products have been developed to manage human resources (HR), accounts, inventory, and human resource availability. In terms of infrastructure development, the Population Welfare building, housing the office of the DG Population, is nearing completion.

Religious leaders are being recruited as social mobilizers in four districts. The target is to enroll 500 religious leaders, who will preach the benefits of birth spacing according to the precepts of Islam through group meetings and in Friday sermons. Six new RHS-A centers have been established, raising the total number to 29, while four new MSUs have also been established. The RTI in Abbottabad has been upgraded, and 2 RHSA centers, adolescent reproductive and sexual health centers have been established in DI Khan, where two psychologists have been employed. Female staff at the center has been trained in Karachi on adolescent health issues. At present, the focus is on young female clients.

Among efforts by the Department of Health, currently 1,500 out of 1,800 trained CMWs have been deployed out to these. In addition, $120 \mathrm{CMWs}$ have been trained in FP counseling. All LHWs are receiving training in healthy timing and spacing of births from UNFPA.

\section{Sindh}

Sindh has committed to achieving a CPR of 45 percent by 2020. To enhance access, Sindh's PWD has added 333 new FWCs to its network since 2010, for a total of 962. The number of RHS-A centers has also been increased from 67 to 75 .

Within DoH, to refocus LHWs on FP, all LHWs in Sindh are to be trained in HTSP by UNFPA, while LHVs are also being given refresher trainings in IUD insertion.

PPHI is organizing camps for insertion of the implant Jadelle; 16,000 implants have already been dispensed. In addition, 600 service providers, including male doctors, have been trained in implant insertion in Badin, Thatta, and Khairpur districts. PPHI has also been successfully filling most of the vacancies at its facilities. In the 1,139 facilities PPHI operates, it has enabled 125 facilities to offer round the clock (24/7) services. 
To serve young adults' RH/FP needs, an Adolescent Sexual and Reproductive Health Services (ASRH) project has been initiated with UNFPA's assistance, implemented through all RHS-A centers in Ghotki district.

\section{Key Challenges to Enhancing Access}

\section{Need for Service Expansion}

A main challenge in providing universal access to FP services is that PWD facilities are traditionally viewed as the main providers of these services. There are far too few PWD facilities to serve the needs of the population. For example, the KP Integrated Development Strategy calls for universal access to FP/RH services by 2018. The PWD has increased the number of FWCs from 400 to 600 , yet the total FWC coverage is only 30 percent. The government's plan to have one FWC in each Union Council would require the addition of 2,900 FWCs, which is much too ambitious in the current situation.

Moreover, PWD is faced with a human resource crunch in all provinces. Although 400 new FWCs have now been added to Punjab's PWD network, according to senior PWD officials, "Only 250 could be made functional because of lack of resources, as there are no qualified FWWs (Family Welfare Workers) available to fill the newly created posts. Discussions are underway to relax the services rules to enable LHVs to apply for these posts." Currently, only those candidates can apply who have received training at PWD's Regional Training Institutes (RTIs) and have received a diploma. PWD currently has 259 sanctioned posts for Women Medical Officers (WMOs); however, only 125 have been filled.

Universal access demands the full participation of the DoH network of service facilities. The provincial PWD and DoH will have to develop procedures by which DoH can be more fully involved in FP service delivery, including training health and PWD facility providers, and improving coordination for contraceptive procurement.

\section{Coverage Gaps in the LHW Program}

In Punjab, LHWs' coverage is 62 percent (PC-1 Punjab LHW Program 2011), which means 38 percent of the areas are not covered and in need of other sources to fill the gap. Moreover, no new recruitment of LHWs is taking place. As a result, the number of LHWs in Punjab has fallen from 47,000 to 45,000, as nearly 2,000 LHWs have retired. To exacerbate matters, according to a senior official of the DoH, "LHWs are currently overburdened by dengue prevention and administration of polio drops." Meanwhile, although significant numbers of CMWs are receiving training in FP, their deployment is slow: for instance, of the 6,000 trained CMWs in Punjab, for example, only 2,000 have as yet been deployed.

In Sindh, 54 percent of the province (Population Council 2015) is not covered by LHWs, while in KP 40 percent of the population is not covered by LHWs (PC-1 KP LHW Program 2015). At present, Punjab and KP have no clear cut strategy for reaching these areas. The Sindh CIP mentions hiring a 6,000 community health workers, which may not be sufficient to cover the 54 percent of the province without LHWs.

\section{LHWs' Roles}

LHWs are bridges between their communities and the health system, and enjoys community trust. Although LHWs' primary role is FP services (counseling and providing pills, condoms, and second or subsequent injectable doses) and primary healthcare, in recent years their focus has been diverted to immunization and a host of additional tasks, compromising their effectiveness. They need to revert to their original mandate of primary healthcare with a focus on FP. LHWs' role could be enhanced by permitting and enabling their provision of ECP and first dose of injectables, which is being explored in a pilot in Punjab and KP. 
Table 5.4: Stipulated and Additional Tasks assigned to LHWs

\begin{tabular}{|c|c|}
\hline Stipulated Tasks of LHWs & Additional Tasks of LHWs \\
\hline 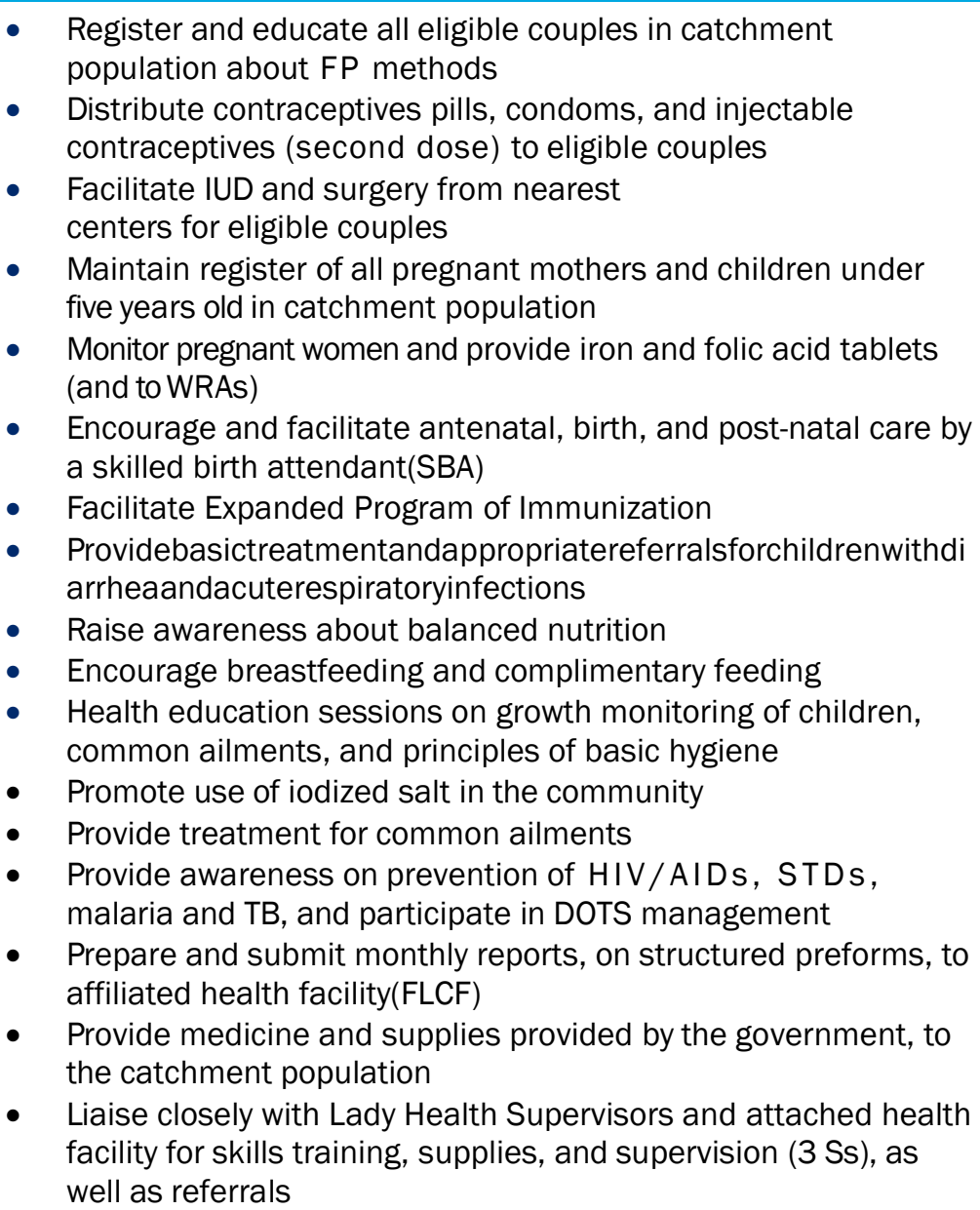 & $\begin{array}{l}\text { - Immunization } \\
\text { - } \\
\text { polios: About } 20 \text { million } \\
\text { administered } \\
\text { by LHWs } \\
\text { - } \text { MNT: LHWs' recognized } \\
\text { in the success of neonatal } \\
\text { tetanus elimination } \\
\text { campaign, vaccinating } \\
\text { hard to reach women } \\
\text { - Measles campaign: } \\
\text { Recent national measles } \\
\text { elimination campaign } \\
\text { achieved almost } 100 \% \\
\text { coverage with LHWs. } \\
\text { - Emergency relief activities } \\
\text { - } \text { Earthquake relief2006 } \\
\text { - } \quad \text { TB Dood relief } 2007-2008 \\
\text { vital role in case detection } \\
\text { and case retention to } \\
\text { enhance treatment } \\
\text { completion and cure rates } \\
\text { Malaria control: RBM } \\
\text { program utilizes LHWs in } \\
\text { various malaria control } \\
\text { activities } \\
\text { Nutrition Program }\end{array}$ \\
\hline
\end{tabular}

DOTS: Directly Observed Therapy Strategy, STD: Sexually Transmitted Diseases, FLCF: First Level Care Facility, NID: National Immunization Days, MNT: Maternal Neonatal Tetanus, RBM: Roll Back Malaria, PHC: Primary Health Care

\section{Regulating Family Planning Service Provision-A Step Towards Improved Quality and Safety}

To improve access to services, the current focus among government departments has mainly been on increasing the number of public sector facilities. Less consideration has been given to exploring existing cost effective alternatives, such as enlisting the private sector to deliver FP services, along with task shifting and task sharing between DoH and PWD providers, and improving quality of care at existing facilities.

Nevertheless, in all three provinces, a number of steps are being taken in these directions, specifically through the enforcement of national standards for FP services, which stipulate which types of service providers can provide various services, and the establishment of health commissions to spearhead the registration and licensing of service providers, which will contribute to improved monitoring of quality and safety aspects. These measures are outlined below.

\section{National Standards for Family Planning}

In 2011, the PWD developed the National Standards for FP in all provinces, which provide explicit directives regarding which contraceptive services may be provided by which types of service providers. The FP services that can be provided by different cadres according to these guidelines are listed in Table 5.5.A main challenge, however, is ensuring maintenance of these standards. 
Table 5.5: Family Planning Methods Service Providers Can Provide per National Standards

\begin{tabular}{|c|c|c|c|c|c|c|c|c|}
\hline Cadre & Condoms & Pills & ECP & Injectables & Implants & IUD & $\mathrm{TL}$ & Vasectomy \\
\hline Male Doctor & $\sqrt{ }$ & $\sqrt{ }$ & $\sqrt{ }$ & $\sqrt{ }$ & $\sqrt{ }$ & NA & NA & $\sqrt{ }$ \\
\hline Female Doctor & $\sqrt{ }$ & $\sqrt{ }$ & $\sqrt{ }$ & $\sqrt{ }$ & $\sqrt{ }$ & $\sqrt{ }$ & $\sqrt{ }$ & NA \\
\hline FWW/FWC & $\sqrt{ }$ & $\sqrt{ }$ & $\sqrt{ }$ & $\sqrt{ }$ & NA & $\sqrt{ }$ & NA & NA \\
\hline Midwife/Nurse/LHV & $\sqrt{ }$ & $\sqrt{ }$ & $\sqrt{ }$ & $\sqrt{ }$ & $P$ & $\sqrt{ }$ & NA & NA \\
\hline CMW & $\sqrt{ }$ & $\sqrt{ }$ & $\sqrt{ }$ & $\sqrt{ }$ & $P$ & $P$ & NA & NA \\
\hline \multirow[t]{2}{*}{ LHW } & \multirow[t]{2}{*}{$\sqrt{ }$} & \multirow[t]{2}{*}{$\sqrt{ }$} & \multirow[t]{2}{*}{$\sqrt{ }$} & $\sqrt{ } 2^{\text {nd }}$ Dose & \multirow[t]{2}{*}{ NA } & \multirow[t]{2}{*}{ NA } & \multirow[t]{2}{*}{$\mathrm{NA}$} & \multirow[t]{2}{*}{ NA } \\
\hline & & & & P 1'st Dose & & & & \\
\hline Dispenser & $\sqrt{ }$ & $P$ & $P$ & $P$ & NA & NA & NA & NA \\
\hline Homeopath/Hakeem* & $\sqrt{ }$ & $\sqrt{ }$ & $\sqrt{ }$ & $2^{\text {nd }}$ Dose & NA & NA & NA & NA \\
\hline Pharmacy (Selling) & $\sqrt{ }$ & $\sqrt{ }$ & $\sqrt{ }$ & $\sqrt{ }$ & $P$ & $P$ & $\mathrm{NA}$ & NA \\
\hline
\end{tabular}

\section{Formation of Health Care Commissions to Regulate Service Delivery}

Recent legislation passed by provincial assemblies has facilitated the establishment of Healthcare Commissions in all three provinces, which will regulate service provision by all types of providers, both public and private. Additionally, providers will continue to be regulated and registered by their respective professional councils and bodies, such as Pakistan Medical and Dental Council (PMDC), Pakistan Nursing Council (PNC), National Council for Tibb (NCT) and National Council for Homeopathy (NCH).

\section{Punjab}

In the province of Punjab, the Punjab Healthcare Commission (PHC) has been established under the Punjab Healthcare Commission Act 2010. It is an independent regulatory body with the mandate to introduce a regime of clinical governance through enforcing Minimum Service Delivery Standards (MSDS) at primary, secondary, and tertiary healthcare establishments in both the public and private sector to improve the quality of healthcare service delivery in Punjab. Under the Punjab Healthcare Commission Act 2010, Act XVI of 2010, a "healthcare establishment (HCE)" is required to implement MSDS to acquire a license to deliver healthcare services in Punjab. The first step in the PHC's regulatory relationship with an HCE is registration whereby preliminary information about the HCE is acquired including providers' qualifications and types of services being provided. Following registration, the HCE is licensed on the basis of demonstrating compliance with the MSDS requirements and allowed sufficient time to ensure implementation. A total of 15,715 HCEs had been registered by the PHC by 2014-2015, while 3,781 had been licensed. HCEs are classified based on their bed strength and range of services.

\section{Khyber Pakhtunkhwa}

In KP, one of the priority areas of the Health Sector Reforms Unit (HSRU) is improving the regulations of the health sector. A Healthcare Commission Act was passed by the KP assembly in 2015 and a Healthcare Commission has been established. The HSRU is currently drafting rules and regulations of the Healthcare Commission. Five committees have been constituted for making the Commission effective. The committees have been tasked to set standards for award of licenses to the public and private sector hospitals, clinics and laboratories with a view to ensuring quality standards at the hospitals and diagnostic centers.

\section{Sindh}

In Sindh, the Sindh Healthcare Commission 2013 Act was passed in 2014 with the aim to improve the quality of healthcare services and check quackery in all its forms and manifestations. The Sindh Healthcare Commission was formed in 2016 to evaluate and monitor performance of both public and private health institutions in the province. Among other monitoring measures, members of the Commission will pay 
frequent surprise visits to public and private facilities and take steps against those who are involved in negligence.

A high-level committee headed by the provincial minister for health has been constituted under Section 5(9) of the Sindh Health Care Commission Act 2013 to monitor public and private hospitals in the province. It will further delegate its powers at division and district level.

\section{Key Challenges to Regulating Services}

The role of the Healthcare Commissions involves two immensely challenging tasks: registering and licensing of all providers, which in itself is a huge undertaking; and, more importantly, ensuring that the MSDS are introduced and maintained by the licensed facilities.

Already, verification of registration of health professionals from their respective professional councils (other than PMDC) is proving time-consuming, as they do not have automated systems that can readily generate information, which in turn is delaying the registration and licensing process. Moreover, most of the private sector facilities are ill-equipped and do not have adequate staff to meet the minimum requirements. Ensuring their compliance will take some time.

Another issue is that the Healthcare Commissions are also mandated to develop service delivery standards for the non-allopathic providers recognized under the Unani, Ayurvedic and Homoeopathic (UAH) Practitioners Act 1965. However, internationally accepted guidelines for these providers are not available. Moreover, the Commission will have to be convinced to include FP counseling and refresher training as part of the MSDS of these providers.

Another challenge in the provision of FP services is that a large body of private sector dispensers who are the main health care providers, especially in rural areas, are not considered as providers by the Health Care Commission. In order for them to dispense medicines they have to be linked to qualified providers. Previous research carried out by the Population Council (Haque et al. 2012) found that these providers, if trained adequately, could be a good source for FP counseling and provision of condoms, pills and injectables. Dispensers represent a huge potential workforce that can significantly enlarge the service provision milieu if they are allowed to participate.

Universal access to FP services will largely depend upon the much larger private sector whose potential has as yet not been tapped; however, their registration and licensing and subsequent training will take a long time in all provinces.

\section{Contraceptive Procurement and Pricing Policy}

The import and registration of contraceptives (excluding condoms) is regulated by the Drug Regulatory Authority under the Ministry of National Health Services, Regulations and Coordination. Licensing new products, at present, is a long, cumbersome process. It takes nearly one to two years for the commercial sector to register its products. This needs to be streamlined for newer products to make their way into the market and thereby increase choice and availability of safer products for clients.

Currently, contraceptives are included in the list of dutiable items. There is a need for the Finance and Economic Affairs Division to take a policy decision to remove contraceptives from this list and allow their "duty free" import so as to reduce their cost and help local distributors to enhance their market share. A policy decision to preferentially consider purchasing locally produced contraceptive products is also needed. This will incentivize the local pharmaceutical industry to lower its prices, once it is assured of a larger market share.

Post-devolution, several promising initiatives have been introduced. Punjab has notified a uniform contraceptive pricing policy under which both facilities of both the Health and the Population Welfare departments will provide contraceptives to clients free (previously, PWD facilities charged a nominal price).

After the end the USAID | Deliver, which was supporting Pakistan in procuring and distributing contraceptives, provinces have taken the bold step of procuring their own supplies. In Punjab, the Health Department has procured contraceptives worth Rs. 748 million for LHWs, MNCH Programs and DoH facilities. For the 
procurement of contraceptives by the Population Welfare Department, a sum of Rs. 2.84 million has been allocated. Due to fiscal limitations, contraceptives have not been procured for tertiary care facilities or for the NGOs, which were catered under the previous arrangement. Contraceptive procurement is currently being carried out with DFID funding, so remains donor dependent.

KP's PWD has allocated a sum of Rs. 166 million for procurement of contraceptives, including Rs. 106 million through Annual Development Plan (ADP) funding and Rs. 60 million through current Public Sector Development Programme (PSDP) funding. The province of Sindh has allocated a sum of Rs. 1.2 billion per year for five years for contraceptive procurement, a total of Rs. 5.4 billion for five years.

In Sindh, joint contraceptive procurement by PWD and the Health Department has been initiated. The prequalification bidding process has been completed and a work order was placed in March 2016. Funds have been allocated by the Government of Sindh to procure for the two departments, the LHW Program, and PPHI. However, supplementary contraceptives have not been procured for the private sector, including NGOs.

At present, provinces lack capacity in developing tenders for bidding competitively in international markets. As a result, in KP and Sindh, the tender placement process was delayed. Furthermore, a huge challenge will remain in tackling supply chain obstacles both in the public and private sectors that need to be overcome to ensure uninterrupted supply of contraceptives at public and private facilities and pharmacies.

\section{Improving Coordination and Monitoring Mechanisms}

Coordination among the concerned departments is a sine qua non for implementing the objectives of a holistic population policy. Since devolution, a number of coordination mechanisms have been instituted in all the provinces at both the provincial and district levels with varying degrees of effectiveness.

A National Vision for Coordinated Priority Actions to Address Challenges of Reproductive, Maternal, Newborn, Child and Adolescent Health and Nutrition has been developed by the Ministry of National Health Service, Regulations and Coordination and is in the process of being shared with the provinces.

Table 5.6: Existing Coordination Mechanisms at the Provincial and District Levels

\begin{tabular}{|c|c|c|}
\hline Punjab & Sindh & Khyber Pakhtunkhwa \\
\hline & \multicolumn{2}{|c|}{ Provincial Coordination Forums } \\
\hline \multirow{4}{*}{$\begin{array}{l}\text { - } \text { Provincial Technical } \\
\text { Committee (Health-PWD) } \\
\text { - } \text { FP-Health Steering } \\
\text { Committee } \\
\text { - } \text { FP Task Force (PWD) for } \\
\text { subject experts } \\
\text { - } \text { Donor Coordination } \\
\text { Committee by the Punjab } \\
\text { Policy and Strategic } \\
\text { Planning Unit (PSPU) }\end{array}$} & \multirow{4}{*}{$\begin{array}{l}\text { - Provincial Technical } \\
\text { Committee } \\
\text { - Sindh Oversight and } \\
\text { Coordination Cell for } \\
\text { Public Health by MNA } \\
\text { - Government-Donor } \\
\text { Liaison Committee } \\
\text { (PSPU) }\end{array}$} & $\begin{array}{l}\text { - Provincial Technical } \\
\text { Committee (PTC) }\end{array}$ \\
\hline & & $\begin{array}{l}\text { - Apex Committee to implement } \\
\text { Strategic Development }\end{array}$ \\
\hline & & $\begin{array}{l}\text { Partnership Framework } \\
\text { (departments and donors) }\end{array}$ \\
\hline & & $\begin{array}{l}\text { - Joint Contraceptive } \\
\text { Procurement Committee }\end{array}$ \\
\hline \multicolumn{3}{|c|}{ District Forums } \\
\hline $\begin{array}{l}\text { - District Technical } \\
\text { Committee (DTC) headed by } \\
\text { District Population Welfare } \\
\text { Officer }\end{array}$ & $\begin{array}{l}\text { District Health and } \\
\text { Population } \\
\text { Management Teams } \\
\text { (DHPMT) headed by } \\
\text { DCO }\end{array}$ & $\begin{array}{l}\text { - DTC meetings headed by } \\
\text { DPWO }\end{array}$ \\
\hline
\end{tabular}

Both federal and provincial coordination efforts are weak. The provincial forums in Punjab and KP are not meeting regularly. This has negatively affected contraceptive procurement in the two provinces: Due to lack of proper coordination, the Health departments were only able to procure contraceptives for the LHW and CMW programs, while primary and secondary care facilities have not been catered for. 
In all three provinces, coordination of the government with donors, as well as SMOs, the commercial sector and civil society organizations, is reportedly weak. As a result, there is duplication of efforts and, according to a donor representative, "poaching of clients" has also been observed by competing agencies working in the same areas. In all three provinces, district coordination seems better. In Sindh, it seems to be due to the efforts of the USAID funded Health System Strengthening Project, while in Punjab it is due to the efforts of the Policy \& Strategic Planning Unit (PSPU). The PSPU is regularly receiving minutes of the meetings of District Technical Committee (DTC) meetings.

A web-based monitoring system has been introduced in Punjab and 116 monitoring and evaluation officers have been appointed who have been provided tablets linked to a central dashboard established by the Punjab Information Technology Board. The Special Monitoring Unit, working directly under the Chief Minister Punjab, is jointly monitoring health and FP activities at the district level. In KP, as part of an e-governance system introduced in the province, five management systems have been developed to manage HR, accounts, inventory and HR availability. LHWs in KP are now reporting monthly; each LHW is registering, on average, 55 clients per month. The Special Monitoring Unit, directly under Punjab's Chief Minister, is jointly monitoring district health and FP activities. DFID has included the number of FP clients registered per month by LHWs as a Disbursement Linked Indicator (DLI). The monthly target for each LHW is 62 clients, and currently, each LHW is registering a monthly average of 55 clients. The PWD of Sindh is using its CLMIS (Contraceptive Logistic Management Information System) for monitoring of contraceptive availability. The PWD MIS data are collated and shared with the Bureau of Statistics and the Health Department.

\section{Family Planning Communications: Provinces Take Ownership and Adopt New Messages}

Since the inception of FP programming in Pakistan in the late 1950s, FP communications and messages have evolved from invoking 'macro' concerns-such as the cause of national development-to more 'micro' concerns such as household welfare and, finally, mother and child health. This is reflected in the key slogans, starting with "bara khandan wabal e jaan" ("Large Family, a Huge Problem"), through "bache do hi achey" ("Better to Have Just Two Children"), to the current message that "birth spacing saves lives," which was introduced as recently as 2009.

Mostly media campaigns have been generic in messaging, and have talked about limiting the number of children. They have not provided specific information, or encouraged inter-spousal communication. Although a key social marketing campaign in early 2000 acknowledged the negative rumors and fear of side effects through tag lines such as “Suni sunai baton par mat jain-waqfay ki tareeqay mehfooz hain” (“Don't Be Influenced by Hearsay-Birth Spacing Methods Are Safe"), they responded only with broad messages and did not provide method details. The social marketing organizations, DKT and Greenstar Social Marketing (GSM) have conducted mass media campaigns to promote their specific brands of IUDs (e.g. Dhanak) and condoms (Sathi and Touch) to minimize the hesitation and stigma attached with sale and purchase of these contraceptives, other information, such as choices of other FP methods, their sources, method information, probable side effects and their management, were not promoted through these recent campaigns.

Moreover, although various campaigns have used multiple channels for reaching out to communitiesincluding interpersonal communication (IPC), such as direct counsel through health workers; community media, e.g., group meetings of men and women or interactive theatre; and the mass media-the media mix has not been used effectively by most.

Among the few campaigns with more effective use of media and addressing communication and information needs through more responsive messaging are the FALAH campaign of 2008 to 2011, and a recent effort by PWD Punjab, which focuses on specific issues, such as choice of methods, management of side effects, sources of FP services, and inter-spousal communication for decision making.

In the pre-devolution period, the designing and airing of the mass media FP campaigns was mainly the responsibility of the Ministry of Population Welfare. As part of their PC1, the provincial population departments' focus was on community media and IPC activities to generate demand for FP services. After devolution, the provinces have been empowered to develop their own behavioral change communications (BCC) campaigns. 


\section{Punjab}

Chief Minister of Punjab has made a grant of Rs 200 million for the development and airing of a Communications Campaign jointly developed by the Population Welfare and Health Departments under the guidance of the Chief Minister's Special Monitoring Unit (SMU). The campaign includes production of TV commercials and use of other advertising channels such as billboards advertising at prominent places e.g. Railway stations, city vantage points, on rickshaws and buses. The campaign focuses on the health benefits of FP, the concepts of birth spacing and identifying location from where FP services can be obtained.

\section{Khyber Pakhtunkhwa}

KP's Population Welfare Department, at present, has no funds for communications activities. However, it has developed a set of compact discs for distribution that has recorded messages of religious leaders sensitized by the PWD so that the message can be widely disseminated.

\section{Sindh}

Through the Health Communications component of the USAID funded MCH program, the Johns Hopkins Center for Communications Programs (CCP) is working with Mercy Corps, Rural Support Program Network and Center for Communications Programs (CCP), Pakistan. The program is working towards bringing a behavioral change within communities. In collaboration with the PWD and DoH, the program has developed a set of mass media messages promoting social and behavioral changes to address myths regarding FP and range of choices available that have been aired through the electronic media.

\section{Private and Commercial Sector Family Planning Campaigns}

Apart from these government campaigns, there have been other FP campaigns, such as method-specific communications campaigns, run by the private and commercial sector to create demand for FP. Although they have had good results, being project based and/or product promotion campaigns, they have been generally time bound and thus have not had time to sustain behavior change.

\section{Gaps in Past and Recent Communication Campaigns}

- Past BCC campaigns have been women centric and men were not targeted extensively. The evidence shows that men are keen to get more information especially for modern methods.

- Campaigns have mostly been generic in terms of messaging and very few have talked about specific issues, such as choice of methods, management of side effects, sources of FP services, etc.

- Campaigns have been erratic and sporadic, project and/or brand based and not sustained for a reasonable and sufficient duration, as a result messages could not be reinforced and had less recall value.

- Evidence shows that although a media mix approach is associated with increased use of modern contraceptives, most of the past campaigns lacked use of integrated communication approaches. (Salem, Bernstein, and Sullivan 2008)

- There is huge potential to involve youth in FP program in Pakistan, whereas analysis of past and current campaigns shows that less effort has been employed to bring them into main stream of the FP communication strategy.

- Use of social media and mobile technology is another avenue to target urban as well as rural educated population especially youth. However, the use of social media has not yet been used extensively in these campaigns.

- A uniform and acceptable program identity has not been established. Instead, each project or government program has its individual identity, logo, themes, and messages, which creates confusion and does not help people relate these efforts for one cause. 
- The logos placed on the government population service outlet and shown on TVs still promote a family with two children, a concept that has not been accepted by people, so does not attract attention.

- There is a high sales tax on promotion or marketing of products through electronic media, which makes the product very expensive (Rs. 250,000 per 60 seconds are charged for airing advertisement on PTV at prime time). PEMRA does not allow free time for airing of FP products or services. A policy decision needs to be taken in collaboration with PEMRA allowing free airtime on the various TV and Radio Channels for broadcasting public benefit messages on birth spacing, its advantages and from where birth spacing services can be obtained.

\section{Encouraging Public and Private Partnerships Models-A Paradigm Shift}

For a number of years, there has been a realization in the public sector that service delivery can be improved through public private partnerships (PPP). As a result, a number of public private partnership models were introduced in the country. The earliest was in 2005, when the Federal Government launched a countrywide program, known as the People's Primary Health Care Initiative (PPHI) (formerly known as President's Primary Healthcare Initiative). The purpose of this initiative was to strengthen the curative and preventive services provided in first level care facilities (FLCFs), by handing over the management and finances of the Basic Health Units-the main type of FLCF in Pakistan-to the rural support programs (RSPs) in their respective provinces. The objective of the initiative was to reorganize and restructure the management of all the BHUs in the districts with a central role for community-based support groups.

Presently, in all three provinces, the government is considering various options of working with the private sector. In Punjab, the DoH is contracting out secondary and tertiary care facilities to private sector organizations in 10 districts initially. The PWD, the Department of Planning and Development (P\&D), and the DoH, support the launching of a Population Innovations Fund to involve the private sector in FP service provision, training and communications. In Sindh, the DoH has outsourced RHCs, and some THQs and DHQs to NGOs under the Public-Private Partnership Act 2010. The KP Health Foundation Act 2015 passed to establish the Health Foundation includes as its mandate improving coverage through Innovative Health Care Delivery Models such as PPP.

\section{Fiscal Allocations for Family Planning}

\section{Federal and Provincial Financial Allocations to the Population Sector in the Past Three Years, and as a percentage of the Total Budget}

Historically, the Population Welfare Program has received federal funding through the development budget. Post-devolution, the program receives both federal and provincial allocations. Financial allocation to Population Welfare to date has been reflected in the Development Scheme (PC-I) by the federal government and the yearly budget committed in the Annual Development Plans and remained funded by the Centre.

Under the $18^{\text {th }}$ Constitutional Amendment, the Provincial Governments have to implement the whole Population Welfare Program, for which the federal government has committed to fund the program until 2015 (extended further until the new NFC award comes into effect). The total allocation by the federal government Public Sector Development Program (PSDP) from 2011-2012 to 2014-2015 are shown in Table 5.7. In addition, two major programs that also support FP activities are the National MNCH program and the National Program for FP and primary health care (commonly referred to as the LHW program). These continue to be mainly federally financed with bridge financing from the provinces. There is a significant increase in the outlay of the Federal budget for Population welfare activities for all three provinces and especially for Punjab. The budget for the NPFP\& PHC has hardly changed in this time period. 
Table 5.7: Federal Government Allocation for Provincial Population Welfare Program and Vertical National Programs Through PSDP FY 2011-2012 to FY 2014-2015

\begin{tabular}{lcrrc}
\hline Project/Area & 2011-2012 & 2012-2013 & 2013-2014 & 2014-2015 \\
\hline PWP - Federal Activity & 507 & - & - & - \\
PWP Punjab & 1,549 & 2,231 & 3,634 & 3,634 \\
PWP Sindh & 885 & 1,259 & 2,082 & 2,082 \\
PWP Khyber Pakhtunkhwa & 477 & 743 & 1,283 & 1,283 \\
PWP Balochistan & 391 & 511 & 806 & 806 \\
PWP Regions, Federal \& FATA & 254 & 333 & 521 & 481 \\
National MNCH Program & 1,046 & 1,046 & 1,320 & 1,046 \\
NP for FP \& PHC & 8,000 & 11,000 & 11,000 & 11,000 \\
Total Allocation in Rupees (million) & 13,109 & 17,123 & 20,646 & 20,333 \\
\hline
\end{tabular}

A comparison of the federal allocations with provincial revised budgets/Accounts from 2012-2013 to 20142015 of Punjab, Sindh, and KP shows that funds for population welfare almost mirror the federal allocations. This may be because provincial releases are made to cover delays in federal releases. Additional funds from provincial revenues to support population activities in recent years are quite insignificant with the exception of Punjab where additional financing from the provincial budget is apparent in 2014-2015. Some slight increases are noted in the 2012-2013 budget for Sindh and 2014-2015 budget for KP as well (Figure 5.1).

Figure 5.1: Comparison between Federal Allocations vs. Provincial Budgets/Accounts of Punjab, Sindh and KP for FY2012-12 to 2014-15

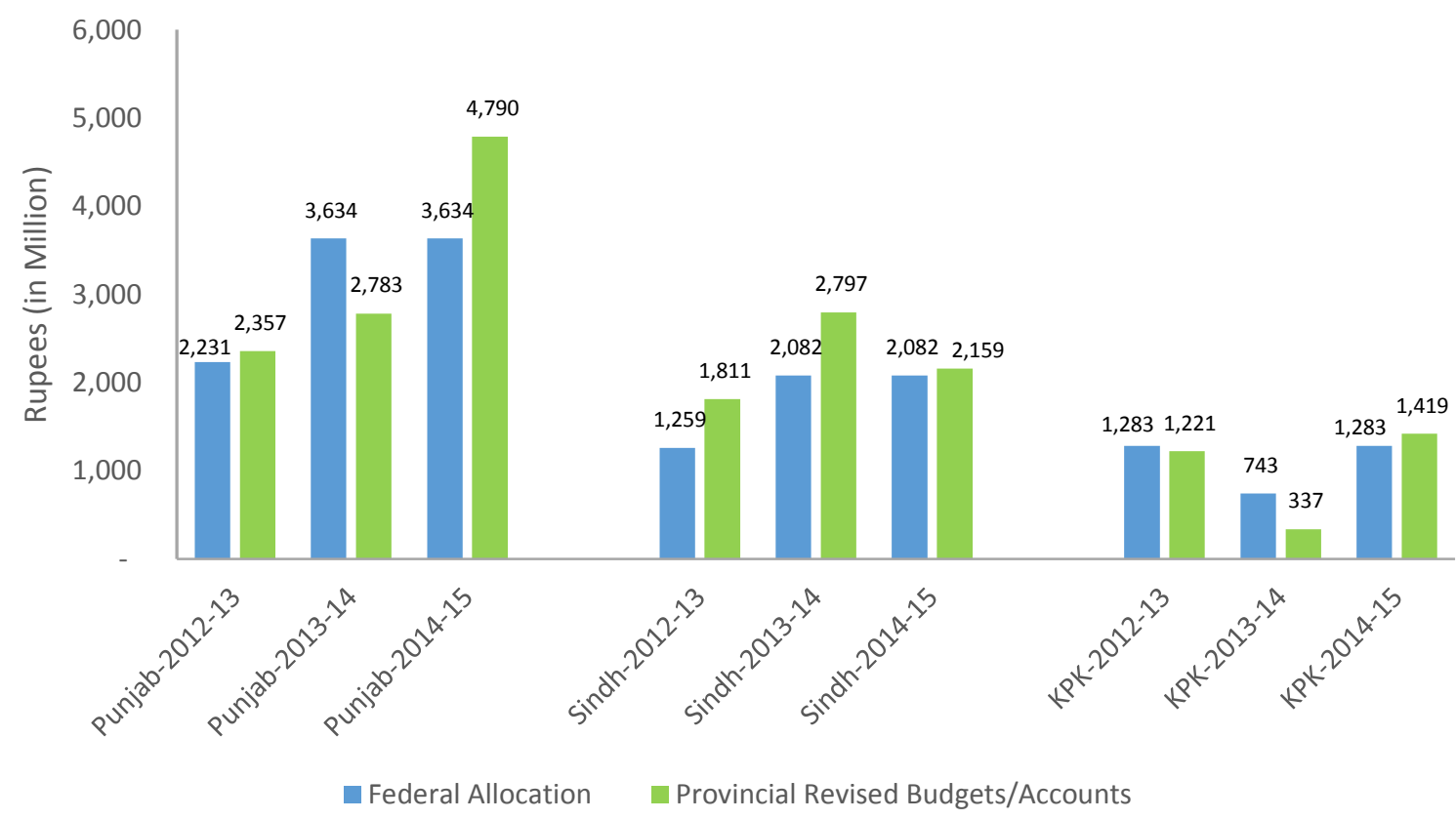

Sources: Ministry of Planning, Development and Reforms, Government of Pakistan, and budget documents of provincial departments

Table 5.8 also reflects these additional provincial resources directed towards provincial population programs. Punjab invested Rs. 1156million, Sindh Rs. 76million, and KPRs. 135million in their Population Welfare programs in 2014-2015. This positive trend of taking ownership of the Population Welfare program by the provinces is likely to expand with provinces budgeting and procuring their own contraceptive commodities in the coming financial year. 
Table 5.8: Federal Allocation and Provincial Resources for 2012-2015

\begin{tabular}{|c|c|c|c|c|}
\hline Province & Federal Allocation & $\begin{array}{l}\text { Provine } \\
\text { Budget }\end{array}$ & $\begin{array}{l}\text { ll Revised } \\
\text { /Accounts }\end{array}$ & $\begin{array}{l}\text { Provincial Resources } \\
\text { in millions }\end{array}$ \\
\hline Punjab 2012-2013 & 2,231 & & 2,357 & 126 \\
\hline Punjab 2013-2014 & 3,634 & & 2,783 & (850) \\
\hline Punjab 2014-2015 & 3,634 & & 4,790 & 1,156 \\
\hline Sindh 2012-2013 & 1,259 & & 1,811 & 552 \\
\hline Sindh 2013-2014 & 2,082 & & 2,797 & 715 \\
\hline Sindh 2014-2015 & 2,082 & & 2,159 & 76 \\
\hline KP2012-2013 & 1,283 & & 1,221 & (62) \\
\hline KP2013-2014 & 743 & & 337 & $(406)$ \\
\hline KP2014-2015 & 1,283 & & 1,419 & 135 \\
\hline Total Rupees (in millions) & 18,233 & & 19,675 & 1,443 \\
\hline \multicolumn{5}{|c|}{$\begin{array}{l}\text { Sources: Ministry of Planning, Development and Reforms, Government of Pakistan, and budget documents of provincial departments } \\
\text { The real change, however, is seen in the huge increases in provincial health budgets from 2011-2012 to } \\
2014-2015 \text {. While the lion's share of these budgets go to tertiary hospitals, and administration among } \\
\text { others, there is a significant portion that funds those outlets such as BHUs, RHC, THQs, and DHQs that are } \\
\text { mandated to provide FP services. Table } 5.9 \text { shows a } 66 \text { percent increase in the Punjab health budget; a } 111 \\
\text { percent increase in the Sindh health budget and a } 104 \text { percent increase in the KP health budget. }\end{array}$} \\
\hline \multicolumn{5}{|c|}{ Table 5.9: Provincial Departments of Health Budgets from 2011-2012 to 2014-2015 } \\
\hline Province & 2011-12 & $2012-13$ & 2013-14 & 2014-15 \\
\hline Punjab & 51,204 & 63,807 & 71,999 & 84,888 \\
\hline Sindh & 25,855 & 47,385 & 46,013 & 54,677 \\
\hline KP & 14,304 & 20,363 & 23,725 & 29,128 \\
\hline Total Rupees (million) & 91,363 & 131,555 & 141,737 & 168,693 \\
\hline
\end{tabular}

We are grateful to TRF for providing: Budget and Expenditure Analysis-Health Department for FY 2014-16, Khyber Pakhtunkhwa, TRF and Govt of Khyber Pakhtunkhwa; Budget and Expenditure Analysis-Health Department for FY 2014-16, Punjab, TRF and Govt of Punjab; Provincial Budget Documents of Finance Department, Government of Sindh.

Punjab budgets have increased steadily. Assuming that even a small proportion of the health budget is spent on FP it is obvious that the departments of health are driving up the levels of spending on FP through these increase, with other components remaining fairly stagnant. 
Figure 5.2: Provincial Departments of Health Budgets from 2011-2012 to 2014-2015

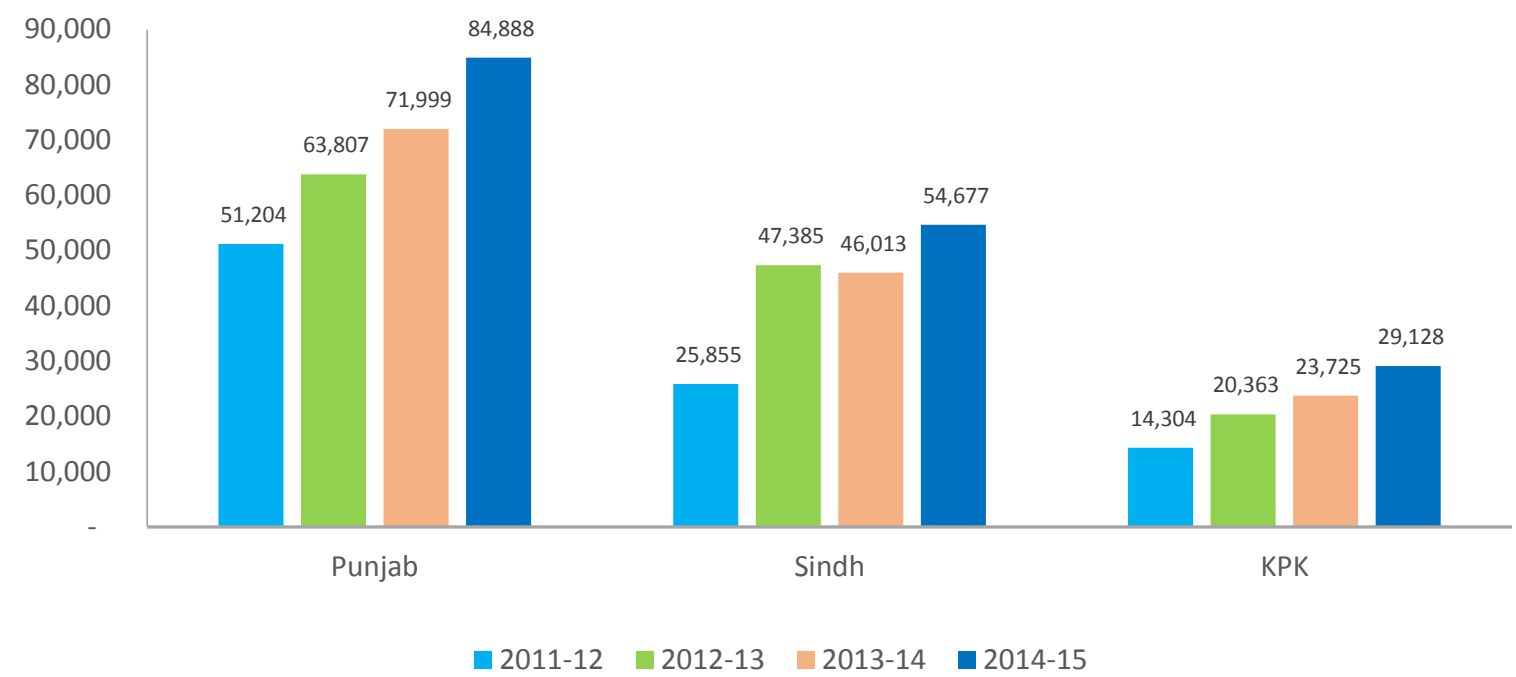

To estimate the total public outlay on FP for the major three provinces we utilize a formula used for the background paper for the London Summit2012 Pakistan statement (Population Council 2012). Assuming that the full Population Welfare budget, 33 percent of the LHW budget, 10 percent of the MNCH budget, and 10 percent of the provincial health budgets all collectively contribute to directly funding FP we see a rise in the overall outlay for FP for the three provinces from 15.3 billion rupees to 27.6 billion (Table 5.10).

Table 5.10: Provincial Budgets for Population from 2011-2012 to 2014-2015

\begin{tabular}{lcccc}
\hline Province & $\mathbf{2 0 1 1 - 1 2}$ & $\mathbf{2 0 1 2 - 1 3}$ & $\mathbf{2 0 1 3 - 1 4}$ & $\mathbf{2 0 1 4 - 1 5}$ \\
\hline Punjab & 8,825 & 10,693 & 12,780 & 14,439 \\
Sindh & 4,144 & 6,914 & 7,608 & 8,467 \\
KP & 2,351 & 3,617 & 3,981 & 4,669 \\
Total Rupees ${ }^{9}$ (million) & 15,320 & $\mathbf{2 1 , 2 2 5}$ & $\mathbf{2 4 , 3 6 8}$ & $\mathbf{2 7 , 5 7 4}$ \\
\hline
\end{tabular}

Table 5.11 presents per capita allocations based on population projections. The highest public allocation for FP is in KP, with the total for the three provinces at Rs. 154.9 (\$1.50) per capita in 2014-2015. This amount is significantly higher than the national estimate of $\$ 0.50$ per capita for the $2012 \mathrm{FP}$ London Summit (Population Council 2012); according to our updated estimates, it was as high as \$0.90in 2011-2012 for the three major provinces. According to this analysis, there has been a 40 percent increase in Punjab, 72 percent in Sindh, and 81 percent in KP on public spending for FP.

Table 5.11: Per Capita Public sector Budget Allocation from 2011-12 to 2014-15 by province

\begin{tabular}{lcccc}
\hline Province & $\mathbf{2 0 1 1 - 1 2}$ & $\mathbf{2 0 1 2 - 1 3}$ & $\mathbf{2 0 1 3 - 1 4}$ & $\mathbf{2 0 1 4 - 1 5}$ \\
\hline Punjab & 0.99 & 1.12 & 1.27 & 1.39 \\
Sindh & 0.98 & 1.53 & 1.58 & 1.69 \\
KP & 0.94 & 1.36 & 1.44 & 1.71 \\
In US Dollars & 0.98 & 1.27 & 1.37 & 1.50 \\
\hline
\end{tabular}

\footnotetext{
9 The figure is calculated as sum of the allocation $100 \%$ of the Population Welfare program; $33 \%$ of the LHW program; $10 \%$ of
} the MNCH program and $10 \%$ of the departments of Health of the provinces. 


\section{Barriers, Challenges, and Gaps}

This study contacted provincial departments for their perspectives on funding challenges:

- Provincial Population Welfare departments are weak in developing Annual Development Plans for funding specific schemes, due to lack of capacities for innovation schemes. Three of the current Annual Development Plans were rejected because they were not feasible.

- Payments are made to the provincial departments by the federal government in quarterly instalments which are often delayed, and PWD has had to resort to bridge financing received from the provincial government.

- Delayed release of funds by the federal government to provincial Finance departments for their Population Welfare departments, and subsequent procedural delays to transfer funds to districts, seriously hampers program management and performance.

- Budget allocated through the Federal PSDP is insufficient to meet provincial demands. In 2015, Rs. 187 million has been released to KP while the need was for Rs. 345 million. The shortfall was met through bridge financing by the provincial government. A review of financing for the last five years in Sindh shows allocations have been far less than demand in the PC-1. Of the total amount needed, the allocated amount has been 52 percent in 2010-11 to 56 percent in 2014-2015. The release of funds by the federal government has been delayed to such an extent that is being met through bridge financing by the Government of Sindh. Although nominal spending on population has increased, yet a very large part of it is eroded by inflation and increase in salaries.

- A significant decline in non-salary allocations and releases affect adversely the output and performance, resulting in loss of time and missed opportunities. For 2015-16, the Punjab PWD received a sum of Rs. 2.4 billion as against a request for Rs. 4.1 billion that included Rs. 3 billion which is the original allocation and Rs. 1.1 billion which amounts to arrears accumulated from the past. The salary component of the budget comes to Rs. 2.5 billion leaving a meager amount to cover developmental activities.

- The shortfalls between provincial requirements and PSDP allocations from 2012 to 2015 are shown in Table 5.8.

\section{Donor Investment}

Current donor commitments for direct and indirect investment population related services and PSDP support shows a total of US\$661 million between 2009 and 2019 (Table 5.12). Assuming this funding is for an estimated seven year period, it translates into an average annual direct support of US\$45 million. Comparing it with the overall public sector allocation estimated for FP at US\$268 million (for 2014-15) the additional contribution by the donor community is in the order of 17 percent.

Table 5.12: Direct and indirect support to FP activities by donors in Pakistan

\begin{tabular}{|c|c|c|c|c|}
\hline \multirow{2}{*}{ Donor } & \multirow[b]{2}{*}{ Period } & Direct Support & Indirect Support & Total \\
\hline & & \multicolumn{3}{|c|}{ USD (millions) } \\
\hline USAID & $2009-19$ & 196 & - & 196 \\
\hline DFID & $2012-17$ & 44 & 233 & 277 \\
\hline Large Anonymous Donor & 2013-16 & 34 & - & 34 \\
\hline UNFPA & $2012-17$ & 15 & - & 15 \\
\hline PACKARD Foundation & $2011-16$ & 12 & - & 12 \\
\hline KFW, GIZ, WHO & 2014-17 & 10 & - & 10 \\
\hline Gates Foundation & 2013-19 & 7 & - & 7 \\
\hline World Bank & & - & 100 & 100 \\
\hline DFAT & & - & 10 & 10 \\
\hline Total & & 318 & 343 & 661 \\
\hline
\end{tabular}




\section{Donor Funding}

As Figure 5.3 shows, at present, overwhelmingly the largest share of funding from development partners to FP efforts is coming from USAID, which has traditionally been a major partner of Pakistan's FP program (other than in periods when development assistance to Pakistan was curtailed). USAID has informed its implementing partners about impending financial cuts to their projects. Furthermore, the David \& Lucile Packard Foundation has announced that it will be withdrawing from Pakistan. Moreover, globally, there has been a reduction by 37 percent of UNFPA funding, which is affecting current activities supported by UNFPA in Pakistan.

Figure 5.3: Donor Investment in RH, including FP (In USD)

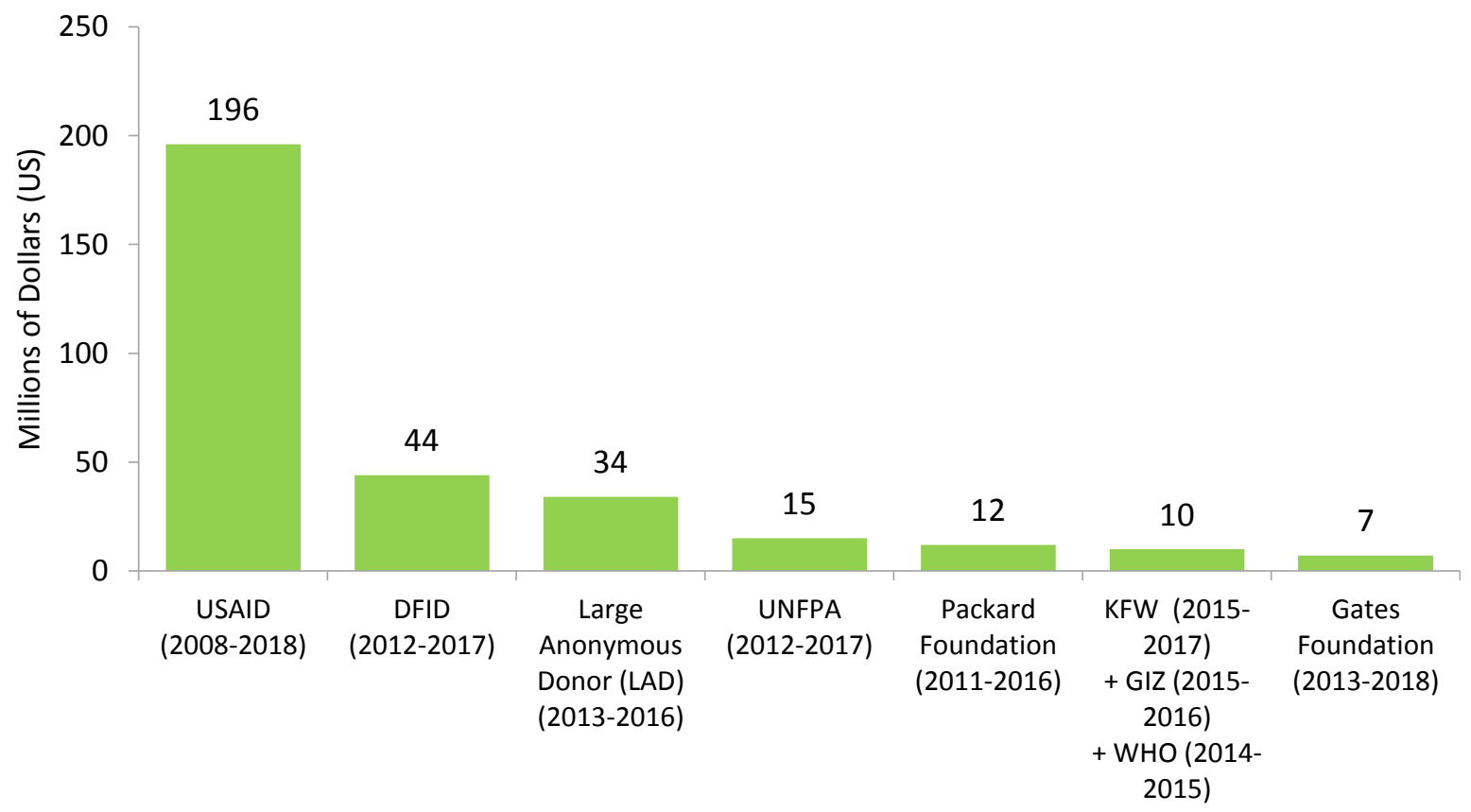




\section{Donor Programming}

A mapping activity identified the major donors working in Pakistan in RH/FP and geographically mapped their major projects and activities implemented, by province and district, specifically in FP and generally in $\mathrm{RH}$. This activity was conducted to help synergize and coordinate efforts, and identify areas for future investment.

\section{Major Donors and Their Program Focuses}

Currently the major development partners (donors) working in Pakistan who are directly supporting provision of FP services, through procurement of contraceptives, logistical support, contraceptives distribution, training, outreach through voucher schemes, or advocacy efforts, include USAID, DFID, Large Anonymous Donor, the David and Lucile Packard Foundation, UNFPA, GIZ, KFW Bank and the Gates Foundation. Indirect support to FP activities is being provided by World Bank, DFAT (Australian government), and the Netherlands government.

\section{Figure 5.4: Location of Donors in Pakistan}

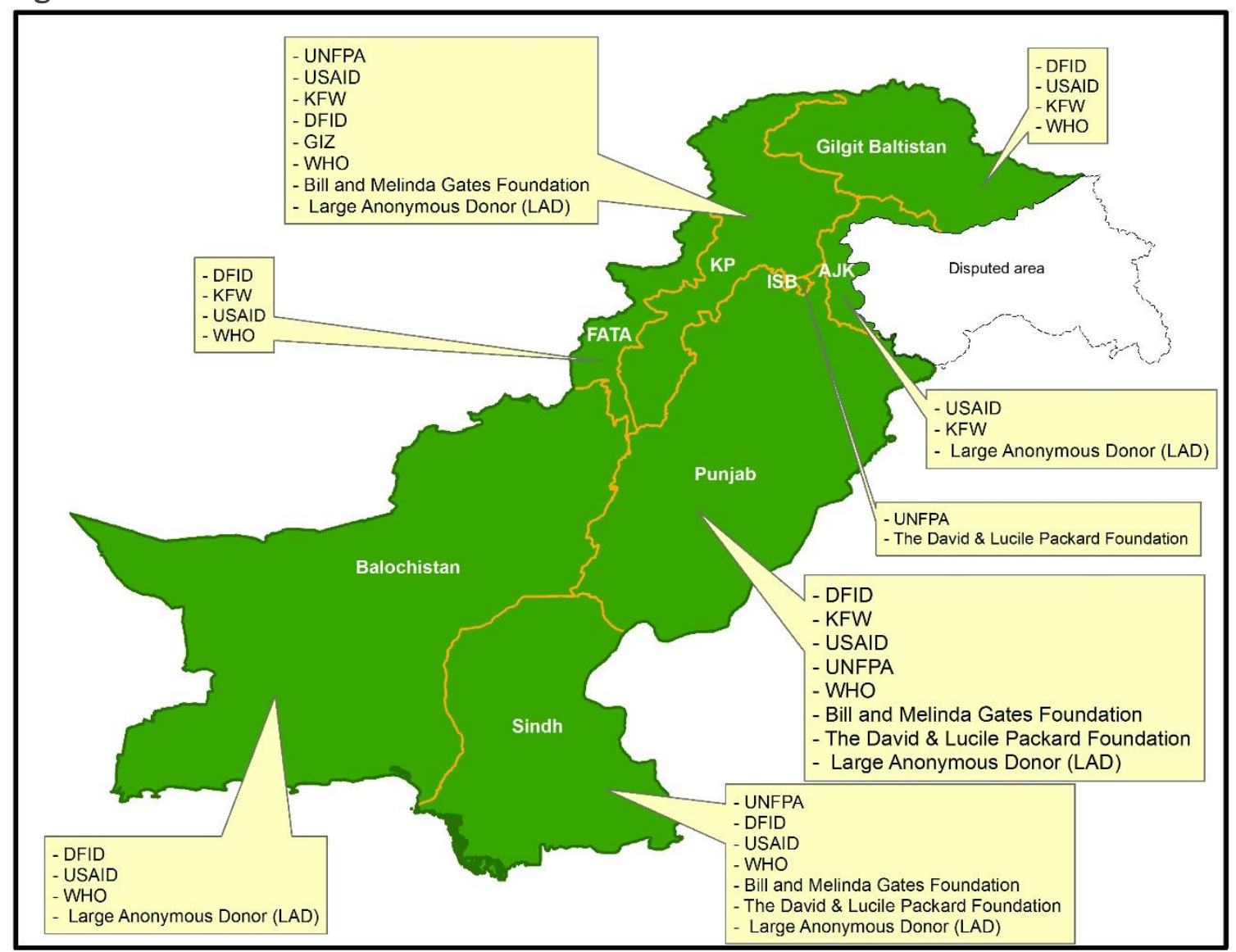


Table 5.13: Programmatic Focus of Donors

\begin{tabular}{|c|c|c|c|c|c|c|c|c|c|c|c|}
\hline Area of Work & USAID & UNFPA & DIFID & PACKARD & GATES & KFW & GIZ & WB & WHO & DFAT & LAD \\
\hline $\begin{array}{l}\text { Provision of } \\
\text { contraceptives }\end{array}$ & $\mathrm{X}$ & & & & & & & & & & \\
\hline Increase access & $x$ & & $x$ & $x$ & $x$ & & $x$ & & & & $x$ \\
\hline Increase demand & & & & $x$ & $x$ & & $x$ & & & & $x$ \\
\hline Vouchers & $x$ & $x$ & & $x$ & & & & & & & \\
\hline $\begin{array}{l}\text { Social franchise \& } \\
\text { social marketing }\end{array}$ & $x$ & & $x$ & $x$ & & & & & & & \\
\hline Postpartum FP & & & & $x$ & & & & & & & \\
\hline Community outreach & $x$ & & & & & & & & & & $x$ \\
\hline Capacity building & $x$ & $x$ & & & & & & & & & \\
\hline $\begin{array}{l}\text { Behavior change } \\
\text { communications }\end{array}$ & $\mathrm{X}$ & & & & & & & & & & \\
\hline $\begin{array}{l}\text { Develop Costed } \\
\text { Implementation Plan }\end{array}$ & & & & & $X$ & & & & & & \\
\hline Landscaping & & & & & $\mathrm{x}$ & & & & & & \\
\hline $\begin{array}{l}\text { Health systems } \\
\text { strengthening (policy) } \\
\text { (PPP) }\end{array}$ & $X$ & & $x$ & & & & & & & & \\
\hline $\begin{array}{l}\text { Reduce Maternal } \\
\text { Neonatal Mortality } \\
\text { Rate }\end{array}$ & & & $\mathrm{x}$ & & & & $\mathrm{X}$ & & & & $x$ \\
\hline $\begin{array}{l}\text { Improve Reproductive } \\
\text { Maternal Neonatal } \\
\text { Child Health and } \\
\text { Nutrition Services }\end{array}$ & & & $\mathrm{x}$ & & & & & & & & \\
\hline $\begin{array}{l}\text { Integrated Maternal } \\
\text { Neonatal Child Health }\end{array}$ & & & & & & & & & & $x$ & \\
\hline $\begin{array}{l}\text { Improvement of } \\
\text { coverage and } \\
\text { utilization of quality } \\
\text { essential and health } \\
\text { services }\end{array}$ & & & & & & & & $x$ & & & \\
\hline $\begin{array}{l}\text { Improve Health } \\
\text { Infrastructure and RH }\end{array}$ & & & $\mathrm{X}$ & & & $\mathrm{X}$ & & & & & \\
\hline Technical assistance & & & & & & & & & $x$ & & \\
\hline FP2020 commitment & & & & & & & $x$ & & & & \\
\hline Advocacy & & $x$ & & $x$ & & & & & & & \\
\hline
\end{tabular}

The following maps show the locations of different FP donors in the three provinces included in the landscape analysis. The FP projects supported by these donors, including the partners implementing them, are detailed in Appendix 9. 
Figure 5.5: Location of Donor Initiatives in Sindh, Punjab and KP
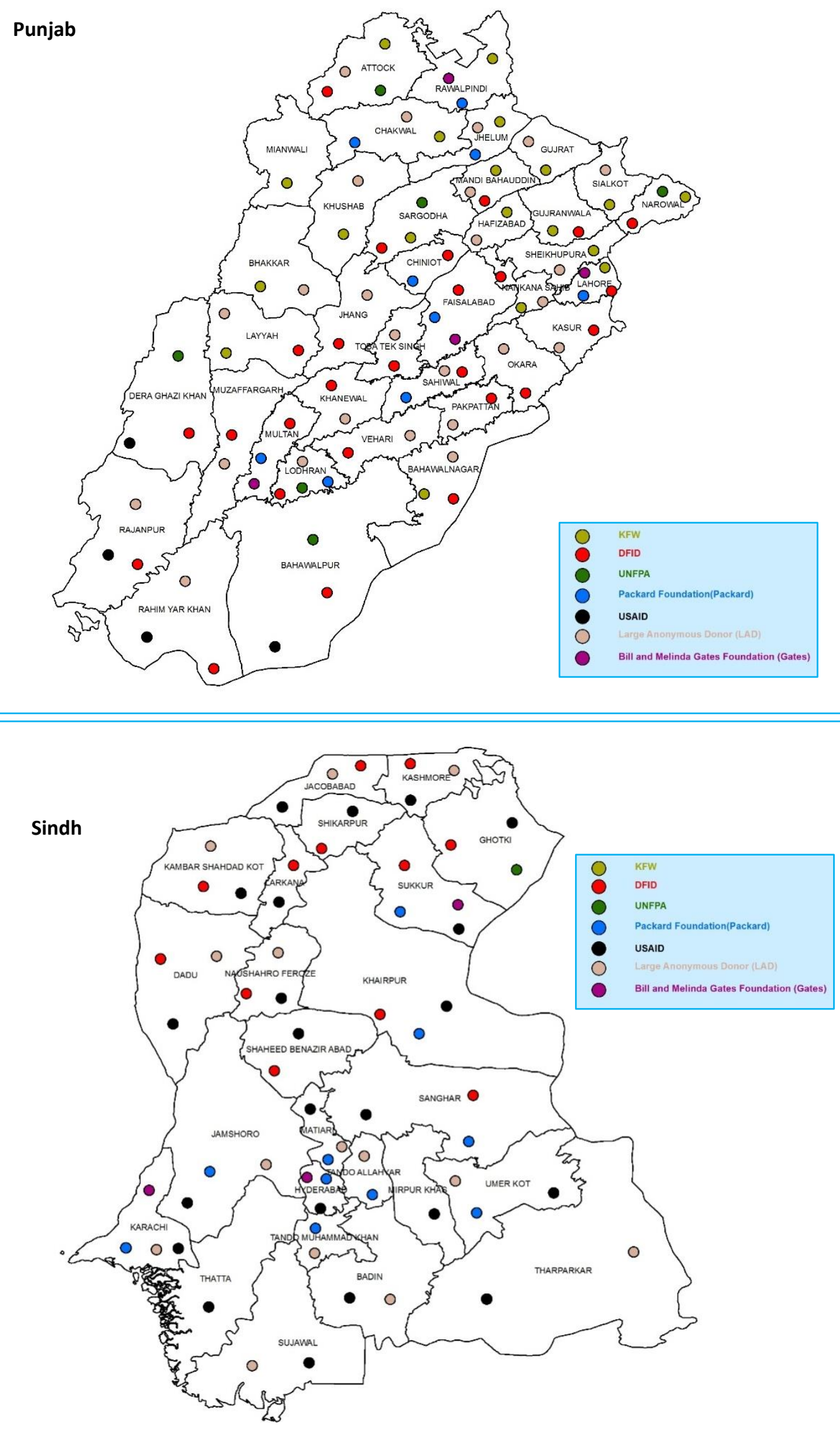


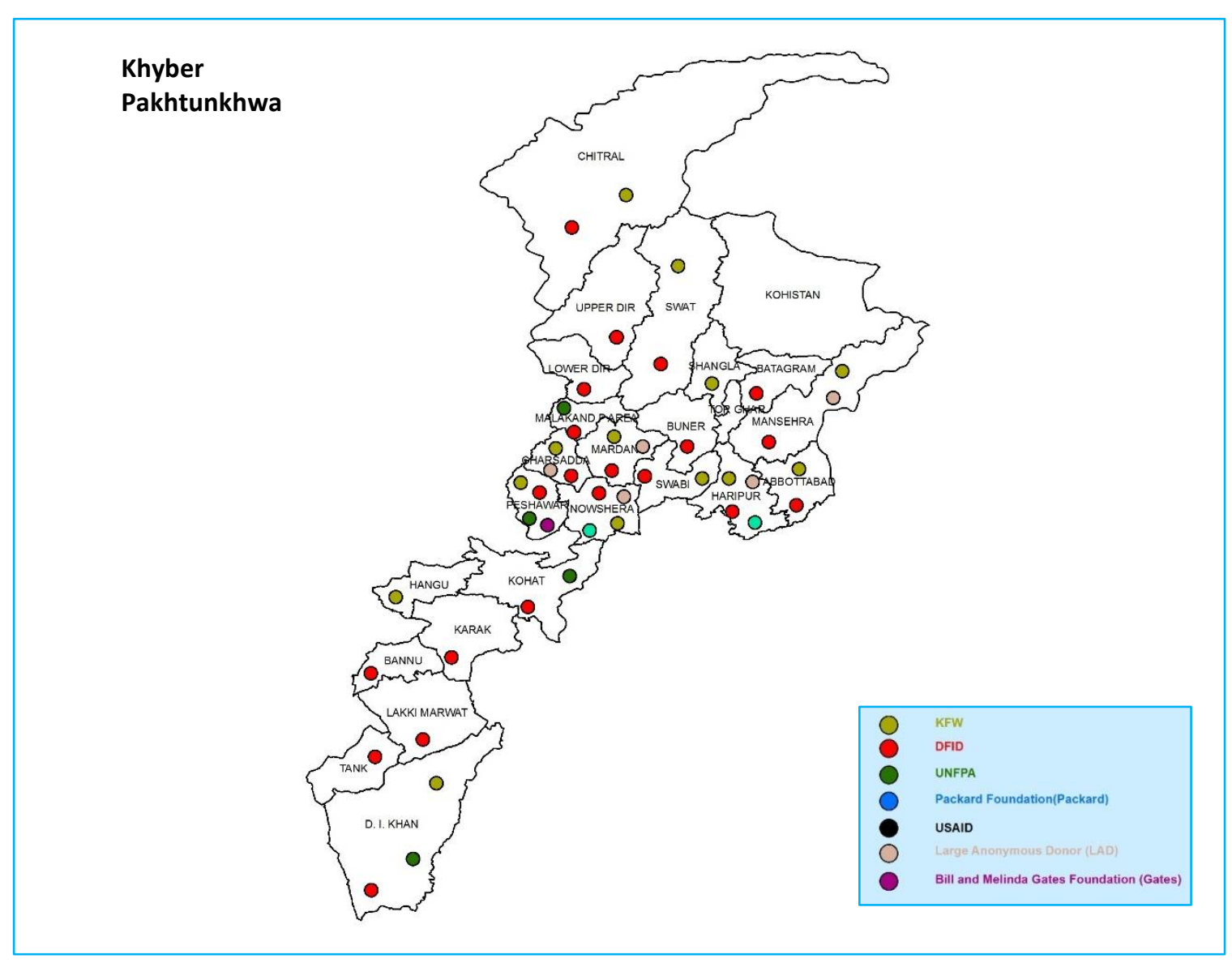

\section{Gaps in Donor Programming}

As can be seen in the district maps, donor funded project activities seem to be concentrated in pockets. In Punjab, donor activities are more focused in central and northern Punjab, with fewer projects in the socioeconomically deprived southern districts. Similarly, the eastern districts of Sindh and northern KP also seem to be less endowed. These are areas where the development partners can work more closely with the government and NGO sectors to sustain efforts for improving access to services and reducing unmet need. 


\section{Summary of Key Points \\ Policy Landscape and Scale of Donor Investments in Family Planning}

\section{Positive Provincial Policy Commitment}

- Post-devolution, provinces have demonstrated many positive changes to accelerate efforts to improve access to FP services:

- There is visible provincial political commitment, including from Chief Ministers, and a consensus on provincial FP2020 CPR goals.

- Provinces have in place FP-focused policies, and some have or are developing FP costed implementation plans.

- The provincial health strategies also give due importance to delivering FP services.

Need for a Focus on Policy Implementation and Coordination

- There is, however, an urgent need to focus on implementation of the policies, including through stronger coordination mechanisms that monitor progress in policy implementation and make adjustments, as needed, to ensure achievement of policy goals, including achieving FP2020 CPR goals.

- Coordination amongst departments, especially the PWD and DoH, is weak, which is leading to less than optimal complementarity and, at times, duplication of efforts.

\section{The Fiscal Landscape for FP is Shifting}

- While donors are supporting Pakistan and some provinces in particular in meeting their FP goals, donor investments are not currently equitably distributed among provinces, leaving some provinces with little funding for FP.

- Despite a budgetary crunch due to capping of federal funding that the provinces are to receive till 2018, through provincial bridge financing, the provinces have initiated a number of development schemes.

- The three major provinces are allocating more of their own resources for FP services. At the moment, the lion's share of allocations that can be utilized for FP is in the provincial health programs.

- Very recently, the provincial population welfare programs have increased their allocations for the procurement of contraceptives, mainly for the public sector.

- Government spending on FP per capita has gone up in Punjab, KP and Sindh.

\section{Remaining Challenges to the Provinces}

- As the provinces accelerate efforts to reach their FP2020 goals, they face the following challenges:

- Nearly $40 \%$ of areas are not covered by LHWs, posing a major obstacle in achieving universal access to FP services, which will require a well thought-out strategy to resolve.

- While the provincial policies acknowledge a role for the private sector in delivering FP services, mechanisms to operationalize private sector provision remain unresolved.

- Communications efforts, especially in terms of reaching out to men and youth, are weak.

- Provincial capacities need to be improved, particularly for preparing Annual Development Plans (ADPs), to secure funding for development schemes. 


\section{Chapter 6. Recommended Areas for Investment}

On the basis of the wide ranging findings of this extensive situation analysis of the family planning landscape, we propose a range of investments to overcome the communication and information gaps that perpetuate suboptimal use and provision of family planning services; expand access to family planning services through task shifting, task sharing, greater participation of private and male providers, and improved quality of care; expand contraceptive choices for consumers through introduction of new methods, task shifting, and improved mechanisms for contraceptive supply; and drive the required evidence-based policy changes to effect programmatic improvements and upscale successful initiatives.

\section{Launch a transformative communication strategy targeting all stakeholders}

We strongly recommend a comprehensive communication campaign designed not only to meet the awareness and information needs of consumers, but also to galvanize the health community, pharmacists, commercial suppliers, civil society, and policy makers at all relevant levels. A good strategy would:

- Frame its messaging in the successfully tried paradigm of healthy timing and spacing (HTSP) of births, and position modern contraceptive methods as health products;

- Inform and guide all segments of current and potential consumers regarding available choices and sources, and urge them to be assertive in getting the information and care they need, paying special attention to the needs of men and of youth, which are discussed in more detail in the following recommendations;

- Dispel myths and misconceptions about family planning but at the same time honestly acknowledge the possible side effects, and reassure users that these effects are manageable and temporary;

- Increase awareness and spur discussion in the health community regarding the importance of family planning as a health intervention, and how to strengthen existing protocols and systems to mainstream service provision at all levels of healthcare;

- Increase awareness among pharmacists regarding the need and latent demand for family planning, and their own potential role (and benefits) in provision of information and counsel;

- Capitalize on the recent endorsement of birth spacing by Pakistani religious leaders at the recent Population Summit 2015 to remove lingering doubts in the minds of the general public, service providers, pharmacists, and policymakers; and

- Tap into multiple channels-combining interpersonal communication with the growing influence of mass media and social media.

\section{Engage men with family planning information and services}

One of the most significant shifts confirmed by this landscape analysis relates to the growing interest and role of men in family planning. Men have always been key decision-makers for contraceptive use, but while they were once seen as common sources of resistance, there is now clear evidence that they are highly motivated to use and support contraception. With almost 60 percent of use dependent on male methods, we believe the time has come for a more gender-balanced approach to family planning programming that includes a comprehensive strategy for meeting the communication, information, and service needs of men.

FP program services for men has been generally lacking and apart from the male mobilizers introduced by the Population Welfare Department in the early 2000 s and male support group meetings organized 
under the Family Advancement for Life and Health (FALAH) Project in 2008-2012, there have been few efforts to get information directly to men. Both these schemes have mostly dwindled away.

Ensuring men receive information about methods-for themselves and their partners-from a range of sources is critical. Expecting women to educate their partners about contraception is unrealistic and ignores existing gender norms. Informed men could help spread the word about contraceptive choice and use. Young men would also benefit from expanding sources of information. Yet, at present, men are largely restricted to using withdrawal and condoms which they know about, find relatively easy to use and access, and consider safe for their wives and themselves.

In our interviews with consumers in general and men in particular, the gaps in sources of information have emerged clearly as a major obstacle for couples wanting to adopt contraception. This barrier exists across the board, even in large cities, where significant numbers are turning instead to the use of traditional methods and condoms. Men lack avenues for getting information about the range of contraceptive methods, which is a critical precursor to making any decisions about starting and switching.

We therefore strongly recommend the development and implementation of a holistic and comprehensive strategy for meeting men's family planning needs. The elements of such a strategy are indicated within the context of the other recommendations in this section, but it is pertinent to collectively outline them here as well.

Men want specific information about method use and have few opportunities to interact with service providers. A new communications strategy, as recommended above, should therefore have messages for men. The recent surge in social media use in Pakistan can be exploited to convey specific contraceptive safety messages, particularly to allay fears about side effects and to inform potential users about where they can obtain various contraceptive methods. A mobile app for SDM could be appealing to men, who are enthusiastic about the method. Women also support the idea that men should receive information on mobile phones, on which they spend considerable time for other uses.

In terms of service provision for men, this study shows several avenues for involving male providers and additional outlets, such as pharmacies and shops, to supplement current sources of FP information, services, and products. There is huge potential for involving male providers, such as hakeems and homeopaths and male dispensers, as well as male doctors and paramedics. Hitherto largely excluded from FP training and service delivery, their inclusion would be a game changer, particularly because men usually interact with these providers for their other health needs. These additional providers are well positioned and would require only a very minimal level of training to counsel on contraceptive choices and actually dispense some basic methods during the numerous occasions that they see male clients.

\section{Undertake youth-frlendly approaches to reach the next generation with family planning Information}

Youth comprise another segment of potential users who have hitherto been neglected in family planning programming. Pakistan has a massive cohort of young people entering reproductive age who are hungry for reproductive health $(\mathrm{RH})$ information. Previous studies on family planning have avoided talking to young people who were unmarried; in this landscape analysis, we sought the views of single young people, both male and female, who expressed the desire for information on $\mathrm{RH}$ and contraception. Young people have questions and want clear and accurate information about contraceptive methods, their mechanism of action, their relative advantages and disadvantages, how to use various methods effectively, and issues related to return of fertility, among other issues. Their primary source of information is their friends, peers or parents or the mass media, which provides only limited information influenced by social taboos and the erroneous belief that more knowledge would lead to premarital sexual activity.

Based on the discussions with young people conducted during this study, it is clear that they are open to-and in need of-RH and family planning information within some limits of privacy.

In addition to whatever they can learn through the school curriculum, younger persons do explore avenues through social media and the Internet. Pakistan's mobile phone density, with most households 
having at least one, along with cheap internet rates, can provide information access to more than one member of a household. Providing youth with information via mobile phones and the Internet is highly recommended. Experience demonstrates that when such information is available, both young men and women avail themselves of it (Hardee et al., forthcoming).

\section{Catalyze private servlce provlsion to expand access}

Private providers generally outnumber public sector providers, and consumers express preference for private facilities for reproductive healthcare. Increasing private sector involvement is necessary especially in areas that are underserved by the public sector. Proposed measures include:

Galvanizing a focus on family planning in the health community in both sectors through communication on FP's links with $\mathrm{MCH}$ and economic development, by fostering champions of family planning within the associations of gynecologists and pediatricians, and by introducing new methods.

Improving policies and mechanisms to encourage, guide, and monitor private provision. The public sector will have to acknowledge clearly that it wants the private sector to play a significant partnership role, and institutional mechanisms will be required to support this strategic change. In particular, the recently established Health Commissions have an important role in setting and ensuring standards that incorporate family planning service provision, including appropriate management of side effects, and identifying private providers to support.

Identifying priority regions for private provider involvement: Mapping of health services can help identify both the areas where services are most urgently needed, and the cadres of local providers available who may be taken on board.

Training private providers to provide safe family planning services: This should include method-related training as well as training in client-centered care and side effect management. We recommend a drive, mainly through Regional Training Institutes and reproductive Health Centers of the Population Welfare Department, to conduct state-of-the-art training of private providers, catering not only to female providers, but also on the cadres recommended for task shifting below, i.e., male doctors, midlevel female providers, dispensers, and hakeems and homeopaths.

Incentivizing private providers: Private providers may initially need incentives to offer family planning services, especially in areas of low demand and where contraceptive supply channels are weak. Funding mechanisms, such as the emerging Punjab Population Innovations Fund, can be used. However, we recommend that this assistance also be used as an opportunity for a closer study of the economics of private family planning service provision, with a view to evolving mechanisms that lead ultimately to financially self-sustaining provision.

\section{Conduct implementation research and advocacy for task shifting to midlevel providers, male providers, and traditional providers to expand access as well as cholce}

Historically, family planning provision in Pakistan focused on doctors, and primarily female doctors. The introduction of village-based family planning workers in 1992 and Lady Health Workers in 1994 led to a radical shift towards community-based provision of the services which now needs further expansion, and there should be a continued shift to programming that is a less doctor-centric and more focused on lower level providers to ensure widespread availability of methods. Findings of the analysis confirm that midlevel providers are a more motivated and available channel (especially in rural areas) to focus in family planning providers.

Moreover, there is huge potential for involving male providers, such as hakeems and homeopaths and male dispensers, as well as male doctors and paramedics. Not only are male providers more widely available in rural areas, but as mentioned earlier, they are necessary to cater to the growing numbers of men who want to practice family planning and desperately need information about specific methods, including methods their wives might use, as well as counseling and services.

In this regard, we recommend that implementation research be conducted on a fast footing to test out a number of promising task shifting ideas, which can be used as evidence to convince policymakers to 
allow the more numerous, widely accessible, and motivated cadres to provide family planning services, including additional methods. Proposed task shifts include the following:

- LHWs to provide the first dose of injectables, as well as three additional methods, i.e., emergency contraceptive pills (ECP), the Standard Days Method (SDM) and Sayana Press;

- Traditional providers, homeopaths and hakeems, be trained to provide OCPs, ECPs, SDM and injectables, and counseling on other methods;

- Dispensers to provide counseling, pills, ECPs,and injectables by teaming up with doctors, whereby they would have permission to provide services;

- Male doctors, LHVs, and Male Health Technicians (MHTs) to provide implants; and

- Pharmacists to be involved in provision of counseling and information on condoms, OCPs, ECPs, and eventually injectables.

\section{Groom pharmacles as the first stop for family planning advice and counselling}

Pharmacies are quite widespread and an important potential source of not only contraceptive commodities but also information and counsel for men and women. At the moment, pharmacies mainly sell condoms, and to a lesser extent, oral contraceptive pills. They could be providing additional methods to a larger scale, in addition to providing information about a range of methods.

To stimulate this channel, we propose:

- Ensuring an uninterrupted supply of contraceptives, especially reaching out to rural pharmacies;

- A communication campaign to remove doubts in the minds of pharmacists, as well as wholesalers, about the religious permissibility of family planning, and apprise them of the many forms of latent demand in the market;

- Training of pharmacists to enable them to facilitate shy or reluctant customers, and provide counseling and information about specific methods; and

- Encouraging pharmacists to offer a wider range of methods.

\section{Introduce new methods whlle ensuring high quality of care}

Women and men in Pakistan are open to trying out new methods, and introducing these could expand choice and inject new enthusiasm about contraception. However, in order to prevent future switching and discontinuation, any new method will need to be introduced with accompanying high quality counseling and services. These standards must be maintained in a careful rollout to retain satisfied users and build a sustained market.

Methods that could really meet with huge traction in the rural and more remote urban slums would be injectables, including Sayana ${ }^{\circledR}$ Press, the Standard Days Method, and emergency contraception. In discussions during this study, SDM was well received by men and Sayana ${ }^{\circledR}$ Press by women, largely because the methods can help overcome problems of access and can be used with more privacy.

- SDM can serve as an introductory method to be used in conjunction with condoms, withdrawal, or abstinence. As it is side effect-free, it could encourage users to eventually transition to more reliable methods. We propose it be added to the methods provided by LHWs, CMWs, LHVs, hakeems and homeopaths, and dispensers.

- Sayana ${ }^{\circledR}$ Press, which women respondents were most interested in, could be a real game changer especially if available through LHWs and CMWs and eventually for self-administration in areas not covered by LHWs, through pharmacies.

- While injectables are not new, their expansion is highly recommended. They are especially suitable for women with unmet need for spacing and can also be provided by a larger range of 
cadres, including male providers. We also recommend that LHWs be encouraged to give the first dose of injectables, and this idea is now being piloted in Punjab.

- We are recommending that pharmacists in particular play an active role in provision of injectables, including potentially administering the injection, as is being investigated in other countries.

- In order to expand the choices for longer acting hormonal contraceptives, implants should be made more widely available through trained male and female doctors and paramedics. However, as mentioned above, quality of care must be ensured to reduce discontinuation and negative advocacy from users. Our discussions with past users indicate that providers must be properly trained in insertion and removal techniques, infection prevention requirements must be met, and women should be counseled in detail, for example, regarding whether the method is safe to use while breastfeeding. Opportunities for follow-up care must be made available and communicated to couples, especially when implants are provided through temporary camps.

We recommend an implementation science approach to rolling out new methods, specifically SDM and Sayana ${ }^{\circledR}$ Press, to ensure that the needs of quality counseling and side effect management are met and enthusiasm among users is retained.

\section{Ensure a strong supply chain of contraceptives for the public and private sectors}

In the private sector, improved supply and availability of contraceptives is likely to result indirectly from efforts that increase demand among consumers, as well as the recommended engagement with pharmacies. In addition, interest in stocking and providing injectables and IUDs/implants can be improved among service providers and pharmacists by introducing new brands and associating them with positive images of health and prestige for all segments of users. The market that we recommend for immediate growth is that of a wider distribution of injectables, including Sayana ${ }^{\circledR}$ Press.

Thus far, there are only a very small proportion of pharmacies and providers supplying injectables. While the provision of injectables does definitely carry the need for accurate information especially about regularity of dosage and side effects, it is especially suitable for women with unmet need for spacing and can also be provided by a large number of types of providers, including male providers. We therefore recommend a larger role for LHWs and pharmacists in the provision of this method to help grow the market.

To improve the availability contraceptives at health facilities, during efforts to train and involve private providers in family planning, clusters of providers could be linked with a licensed local pharmacy catered by a distributor, with a two-way referral system in place. In the public sector, persistence of high levels of contraceptive stock out indicates the importance of continuing efforts to improve the contraceptive supply chain. Investments could be considered in areas such as building capacity to ensure that the LMIS is fully utilized for improved reporting, monitoring, and decision-making; building capacities and improving processes for forecasting and procurement at all levels; improving storage arrangements at provincial and district level; and minimizing the need for facilities to collect supplies from district stores by ensuring delivery of supplies to the last mile-if necessary, through innovative practices, such as the informed push model of contraceptive supply piloted recently in Senegal, and similar cooperative arrangements with the private sector. It is likely that such solutions will have to be tailored to local circumstances, and may vary across districts and urban/rural setting.

\section{Support commercial marketing and distribution of condoms}

Condom import has attracted considerable commercial interest, which can be harnessed for efficient and sustainable market expansion. A major commercial importer expressed interest in launching a lowcost but full-priced condom brand, with initial support for marketing, as a commercial substitute for subsidized products. Support could also be provided by incentivizing distribution of condoms to rural areas and through consumer goods channels, which are currently underutilized by some commercial 
importers. We should also consider the potential viability of manufacturing condoms within the country since there is fairly large market.

\section{Improve quality of counseling and method provision}

The landscape confirms huge discontinuation, particularly of modern contraceptive methods, driven to a great extent by untreated side effects and lack of information among users. Since stemming this leakage of consumers is at least as important as taking new users on board, we recommend a range of interventions. These include development/adoption of standard protocols and guidelines for provision of specific family planning methods, especially counseling, information provision, management of side effects, and follow-up, and training of providers.

Research should be conducted to identify priority elements of quality of care necessary to improve continuation rates, based on provider and client perspectives. This can be used both to assess provider training needs and also to develop quality standards, and monitoring and accountability mechanisms.

We also recommend a shift from strongly CYP-centered approaches in programming to a greater emphasis on measuring of community based prevalence and satisfaction of needs and prioritizing retention of users/methods.

In the public sector, accountability could be improved by enabling clients to send SMS-based complaints about service providers to a monitoring cell, and linking performance appraisals of providers with client feedback.

\section{Mainstream ownership of the family planning mandate in the health system}

A most compelling need is for the public health department to be more responsive and take greater responsibility for the provision of family planning services as a routine and regular part of its mandatory services.

Post-partum family planning, antenatal and postnatal checkup and post abortion, and child care must be utilized as opportunities, as they are currently often overlooked by overworked and pressed health care providers.

Effective partnership between the Population Welfare Department and Department of Health could include expanded timings in the public sector and setting up of separate family planning service centers within all public health outlets.

\section{Develop a multi-sectoral coordination mechanism for provincial policy Implementation and underpin strategles with strong monitoring, evaluation and learning}

New provincial population policies have been developed with good intentions but may face the same fate as previous policies if their implementation remains weak owing to placing the entire responsibility of implementation on the Population Welfare Department (PWD) alone. Provincial governments, powerful medical and professional bodies, and donors need to work together to ensure that resources both human and financial are made available and significant programmatic changes do occur.

This will require political will and commitment and enhanced accountability at all levels within a multisectoral framework. The existing coordination forums, should be placed in a platform headed preferably by the Chief Secretary of the province, that brings together, every month, all related government departments, representatives of provider associations, civil society, researchers andthe donor community, with the aim of operationalizing and implementing the population policy and related plans, and monitoring the progress of implementation, making mid-course adjustments, as needed.

As Pakistan moves towards achieving its FP2020 goals, provinces and development partners should also undertake strong monitoring and evaluation of programming to gauge progress. Reliable data for 
periodic (preferably annual) monitoring is a must. At the moment, data gaps and inconsistencies do not allow for progress to be gauged on a provincial and district level.

More importantly, ensuring that the evidence informs policy decisions and guides implementation is critical. There is a need for implementation research to test feasibility and to guide upscaling of new interventions.

While development partners can provide evidence of best practices tried and tested in similar settings globally, in reality, policy makers want evidence from their own countries to make policy decisions. Feasibility testing will be important, and must be undertaken with upscaling in mind.

\section{Prioritize family planning at the highest policy levels and in Investments}

Population issues more broadly and family planning more specifically, must be included in all deliberations at the federal and provincial levels with regards to attaining the SDG agenda, availing the demographic dividend and other sectoral policies, development strategies and road maps currently being developed or to be developed in the future.

We recommend that donor investments in family planning should be made in greater coordination, so they can be pooled for concerted action on jointly identified priorities. The advantages of the prevalent practice of folding family planning into maternal and child health programs should be carefully weighed against the risks of compromising focus on this important preventive measure within a host of other competing-and ultimately linked-issues of delivery, child survival and malnutrition. 


\section{References}

Ali, K. 2016. Pemra withdraws ban on contraceptive ads. Dawn. May 29. Available at: www.dawn.com/news/1261330 [Accessed June 2016].

Bureau of Statistics Punjab, Planning and Development Department, Government of the Punjab and UNICEF Punjab. 2016. Multiple Indicator Cluster Survey, Punjab 2014, Final Report, Pakistan. Bureau of Statistics Punjab, Planning \& Development Department, Government of the Punjab and UNICEF Punjab.

Daff, B.M., Seck, C., Belkhayat, H., and Sutton, P. 2014. Informed push distribution of contraceptives in Senegal reduces stock outs and improves quality of FP services. Global Health: Science and Practice, 2(2), 245-252.

Exit Media Consultants. 2015. Media Content Analysis - Endline Survey 2015, Exit Media Consultants. Islamabad.

Government of Khyber Pakhtunkhwa. 2010. Khyber Pakhtunkhwa Health Sector Strategy 2010-2017. Department of Health, Government of Khyber Pakhtunkhwa. Peshawar.

Government of Khyber Pakhtunkhwa. 2014. Integrated Development Strategy 2014-2018. Government of Khyber Pakhtunkhwa. Peshawar.

Government of Khyber Pakhtunkhwa. 2015. Population Policy 2015-Khyber Pakhtunkhwa. Population Welfare Department, Government of Khyber Pakhtunkhwa, Peshawar.

Government of Pakistan, UNFPA and Population Council. 2015. Unveiling the Consensus: Putting People First in Pakistan's Development Agenda. Population Summit Islamabad: GOP, UNFPA and the Population Council.

Government of Pakistan. 2002. National Population Policy, Ministry of Population Welfare. Government of Pakistan, Islamabad

Government of Pakistan. 2011. Public Sector Development Programme 2011-12. Ministry of Planning, Development and Reform Planning Commission. Government of Pakistan, Islamabad.

Government of Pakistan. 2012. Public Sector Development Programme 2012-13. Ministry of Planning, Development and Reform Planning Commission. Government of Pakistan, Islamabad.

Government of Pakistan. 2013. Public Sector Development Programme 2013-14. Ministry of Planning, Development and Reform Planning Commission. Government of Pakistan, Islamabad.

Government of Pakistan. 2014. Public Sector Development Programme 2014-15. Ministry of Planning, Development and Reform Planning Commission. Government of Pakistan, Islamabad.

Government of Pakistan. 2015. National vision for coordinated priority actions to address challenges of reproductive, maternal, newborn, child and adolescent health and nutrition (2016-2025). Ministry of National Health Services, Regulations and Coordination. Islamabad, Pakistan.

Government of Punjab. 2012. Punjab Health Sector Strategy 2012-2020. Punjab Health Sector Reforms Programme, Government of Punjab. Lahore.

Government of Punjab. 2015. Punjab Growth Strategy 2018: Accelerating Economic Growth and Improving Social Outcomes. Planning and Development Department, Government of the Punjab. Lahore.

Government of Punjab. 2015. Punjab Population Policy for Development: Directions and Leadership (Draft). Population Welfare Department, Government of Punjab. Lahore: 2015

Government of Sindh. 2012. Health Sector Strategy 2012-2020, Health Sector Reform Unit, Technical Resource Facility. Sindh. 
Government of Sindh. 2015. Costed Implementation Plan on FP for Sindh (2015-2020). Population Welfare Department Government of Sindh, Karachi, Pakistan.

Government of Sindh. 2015. Population Policy Sindh 2015: Improving the Quality of Life of Women and Children (Draft). Population Welfare Department, Government of Sindh. Karachi.

Gul, R., Kamran, I., Muhammad, K., Niazi, R., and Parveen, T. 2015. The Availability and Quality of FP Services across Eight Districts in Pakistan: The Potential and the Constraints. Islamabad: Population Council.

Hafeez, A., Mohammad, B.K., Sheikh, M.R., Shah, S.A.I., and Jooma, R. 2011. Lady Health Workers programme in Pakistan: challenges, achievements and the way forward. JPMA-Journal of the Pakistan Medical Association 61(3), 210.

Haque, M.U., Miller, P.C., Kamran, I., and Parveen, T. 2012. Role of private sector in delivering birth spacing services in FALAH districts. Islamabad: Population Council.

Hardee, K., M. Croce-Galis, and J. Gay. Forthcoming. "Men as FP Users: Programs and Evidence.” Working Paper. Washington, DC: Population Council, Evidence Project.

Health Systems Strengthening Component of USAID's MCH Program. 2015. Final Report on Assessment of Lady Health Workers (LHWs) Program, Sindh. Population Council. Islamabad.

Intra Health International. 2015. Senegal Wins 2015 Resolve Award for Informed Push Model of Contraceptive Distribution. Available at: www.intrahealth.org/page/senegal-wins-2015-resolve-awardfor-informed-push-model-of-contraceptive-distribution [Accessed: May 2016].

Kamran, I., Khan, M., and Tasneem, Z. 2013. Involving Men in Reproductive and Fertility Issues: Insights from Punjab. World Bank, Washington, DC. World Bank.

Kamran, I., Tasneem, Z., Parveen, T., and Zaidi, Y. 2015. Investigating the low patterns of modern contraceptive use in Pakistan. Islamabad: Population Council.

Kamran, I., Tasneem, Z., Parveen, T., and Zaidi, Y. 2015. Investigating the low patterns of modern contraceptive use in Pakistan. Islamabad: Population Council.

Mahmood, A. 2012. Birth spacing and FP uptake in Pakistan: Evidence from FALAH. Islamabad: Population Council.

National Institute of Population Studies (NIPS) and ICF International. 2013. Pakistan Demographic and Health Survey (PDHS) 2012-13. Islamabad, Pakistan, and Calverton, Maryland, USA: NIPS and ICF International.

National Institute of Population Studies (NIPS) and Macro International Inc. 2008. Pakistan Demographic and Health Survey (PDHS) 2006-07. Islamabad, Pakistan: NIPS and Macro International.

Pakistan Bureau of Statistics (PBS). 2014. Contraceptive Performance Report, 2013-2014. Government of Pakistan Statistics Division, Pakistan Bureau of Statistics, Islamabad

Pakistan Bureau of Statistics (PBS). 2015. Pakistan Social and Living Standards Measurement (PSLM) Survey (2014-15) Islamabad, Pakistan: Government of Pakistan, Statistics Division, Pakistan Bureau of Statistics, Islamabad

Pakistan Logistics Management Information System (LMIS). 2016. Available at: http://c.Imis.gov.pk [Accessed May 2016].

PC-1 National Program for FP \& PHC 2015-16 to 2017-18. 2015. Department of Health, Government of Khyber Pakhtunkhwa. Peshawar.

PC-1. The Lady Health Workers Programme: July 2011-June 2017. 2011. National Programme for FP and Primary Health Care, Department of Health, Government of Punjab. Lahore. 
Population Council. 2007. Family advancement for life and health (FALAH). Available at:

www.popcouncil.org/research/family-advancement-for-life-and-health-falah [Accessed 31 May 2016].

Population Council. 2012. FP: An Imperative for Pakistan's Development. Background paper for London Summit on FP 2012. Population Council, Islamabad, Pakistan.

Population Council. 2015. Consumer demand for FP in Pakistan: Review of secondary data. Landscape Analysis of FP Demand and Delivery in Selected Areas of Pakistan. Population Council, Islamabad, Pakistan.

Population Council. 2015. Revised Population Projections. Population Council, Islamabad, Pakistan.

Salem, R.M., Bernstein, J., and Sullivan, T.M. 2008. Tools for behavior change communication," Info reports, No. 16. Baltimore: INFO Project, Johns Hopkins Bloomberg School of Public Health.

Sathar, Z.A., Singh, S., Shah, Z.H., Rashida, G., Kamran, I. and Eshai, K. 2013. Post-Abortion Care in Pakistan: A National Study. Islamabad: Population Council.

Sindh Bureau of Statistics and UNICEF. 2014. Sindh Multiple Indicator Cluster Survey 2014, Key Findings. Karachi, Pakistan: UNICEF and Sindh Bureau of Statistics.

Technical Resource Facility. 2012. Health Facility Assessment - Pakistan National Report: TRF.

United Nations Pakistan. 2014. Pakistan Donor Profile and Mapping. United Nations in Pakistan. Available at: www.un.org.pk/wp-content/uploads/2014/04/Pakistan-Donor-Profile-and-Mapping-by-UN.pdf [Accessed May 2016]. 


\section{Appendices}

\section{Appendix 1: List of Interviewed Policy Makers}

Type

Total Number

Federal Government

Director (Programs), Ministry of National Health Services, Regulation \&

Coordination, Government of Pakistan

Government of the Punjab Officials;

Additional Secretory (Tech) \& Additional Director General Health Services and Managers of Health Department i.e. IRMNCH, PRSP \& LHW Program.

Member Social Sector- P\&D Department.

Director (Clinical Governance \& Organizational Standards)-Punjab Health Care Commission.

Secretary, Deputy Secretory \& Director General of PWD.

Government of Sindh;

Technical Advisor on Oversight and Coordination Cell for Preventive Health Care Program. Additional Secretary Health, Secretary \& Additional

Secretary PWD.

Program Managers of Health department i.e. MNCH \& PPHI).

Government of Khyber Pakhtunkhwa;

Director Health Services and Program Managers of Health department i.e. $\mathrm{MNCH}, \mathrm{PPHI} \&$ LHW Program.

Director General Population Welfare Department

Importers/Distributors of contraceptives

Donors

NGOS 


\section{Appendix2: Profile of Never Users with Unmet Need at Provincial Level}
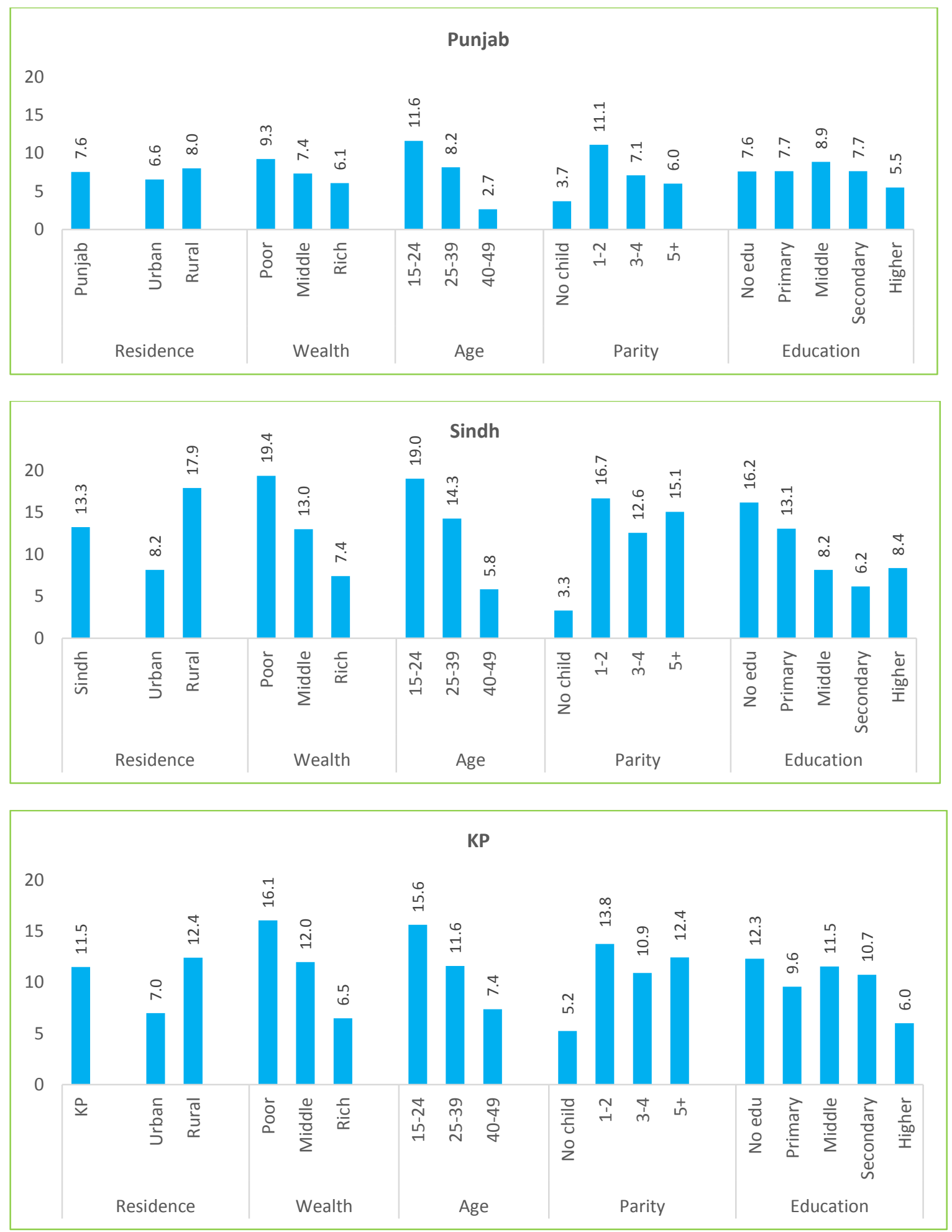


\section{Appendix 3: Barriers of Never Users with Unmet Need by Segment}

\begin{tabular}{|c|c|c|c|c|c|c|}
\hline \multirow[b]{2}{*}{ Barriers } & \multicolumn{2}{|c|}{ By age } & \multicolumn{2}{|c|}{ Income groups } & \multicolumn{2}{|c|}{ Residence } \\
\hline & $\begin{array}{l}\text { Younger Age } \\
(15-30)\end{array}$ & $\begin{array}{l}\text { Older age } \\
(31-45)\end{array}$ & Poor & Middle & Rural & Urban \\
\hline Lack of information & 1 & 1 & 1 & 2 & 1 & 1 \\
\hline Access issues & - & - & 1 & - & 1 & - \\
\hline Cost issues & - & - & - & - & - & - \\
\hline $\begin{array}{l}\text { Poor quality of } \\
\text { services at public } \\
\text { facilities }\end{array}$ & - & - & - & - & - & - \\
\hline $\begin{array}{l}\text { Fear of side effects of } \\
\text { modern methods }\end{array}$ & 2 & 1 & 1 & 2 & 2 & 3 \\
\hline Religion & - & 3 & 3 & 3 & 3 & 3 \\
\hline $\begin{array}{l}\text { Embarrassment in } \\
\text { discussing and buying } \\
\text { contraceptives }\end{array}$ & 2 & 3 & 3 & - & 2 & - \\
\hline
\end{tabular}




\section{Appendix 4: Profile of Past Users with Unmet Need at Provincial Level}
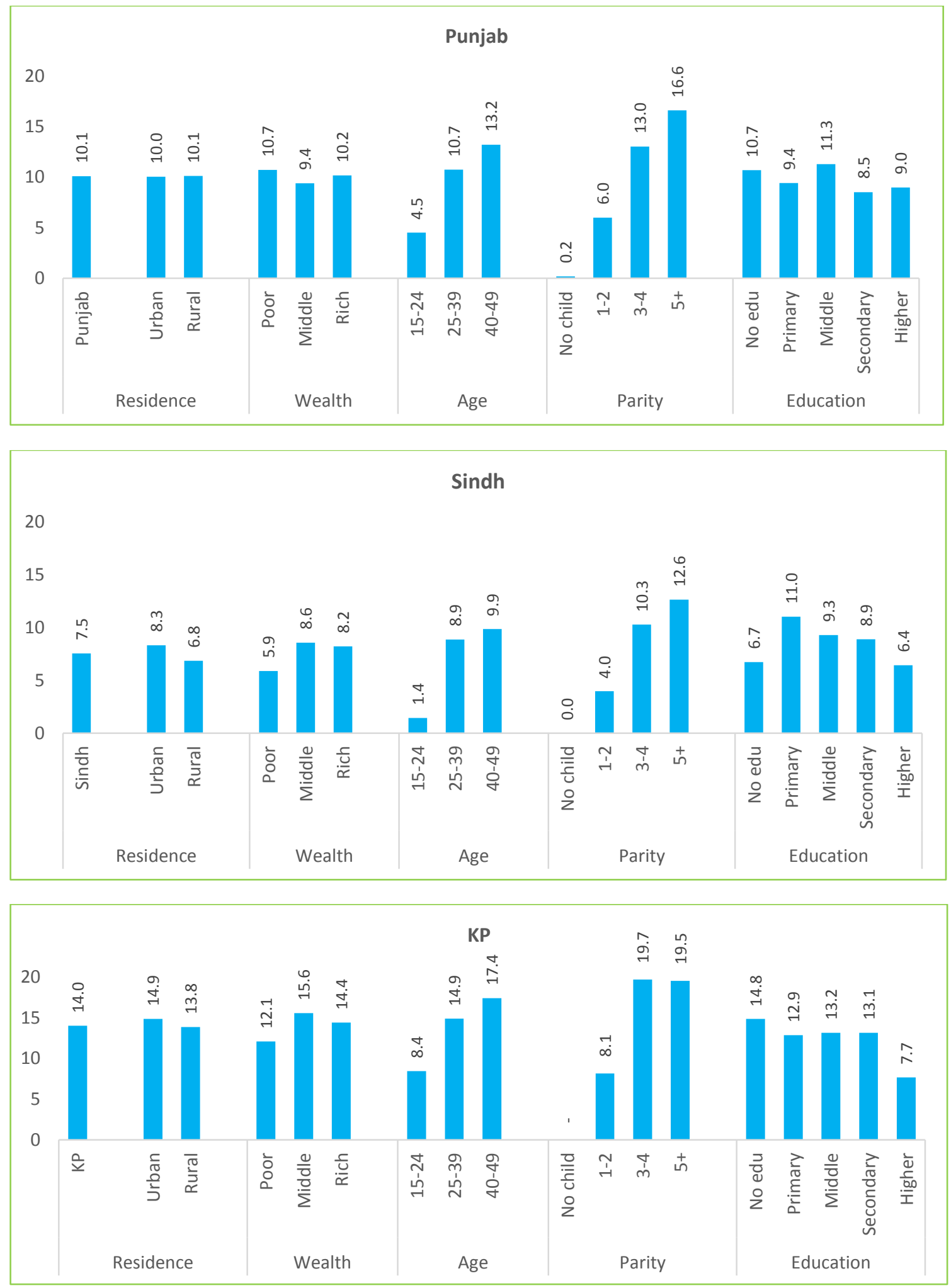


\section{Appendix 5: Barriers of Past Users with Unmet Need by Segment}

\begin{tabular}{|c|c|c|c|c|c|c|}
\hline \multirow[b]{2}{*}{ Barriers } & \multicolumn{2}{|c|}{ Age } & \multicolumn{2}{|c|}{ Income groups } & \multicolumn{2}{|c|}{ Residence } \\
\hline & $\begin{array}{c}\text { Younger } \\
\text { Age (15 } \\
-30)\end{array}$ & $\begin{array}{l}\text { Older } \\
\text { age } \\
(31-45)\end{array}$ & Poor & Middle & Rural & Urban \\
\hline Lack of information & 2 & 2 & 1 & 1 & 1 & 2 \\
\hline Access issues & 3 & 3 & 3 & - & 3 & - \\
\hline Cost issues & 1 & 1 & 1 & 2 & 1 & 1 \\
\hline $\begin{array}{l}\text { Poor quality of services at public } \\
\text { facilities }\end{array}$ & 1 & 1 & 1 & 2 & 1 & 1 \\
\hline $\begin{array}{l}\text { Experience of side effects of } \\
\text { modern methods }\end{array}$ & 1 & 1 & 1 & 1 & 1 & 1 \\
\hline $\begin{array}{l}\text { Fear of side effects of modern } \\
\text { methods }\end{array}$ & 3 & 3 & 2 & 3 & 2 & 3 \\
\hline $\begin{array}{l}\text { Cost for the management of side } \\
\text { effects }\end{array}$ & 2 & 2 & 1 & 2 & 2 & 2 \\
\hline $\begin{array}{l}\text { Fear of being unable to fulfill } \mathrm{HH} \\
\text { responsibilities due to side effects }\end{array}$ & - & 3 & - & 3 & - & 3 \\
\hline
\end{tabular}

$1=$ Strong,$\quad 2=$ Medium,$\quad 3=$ Low 


\section{Appendix 6: Profile of Current Traditional Users at Provincial Level}
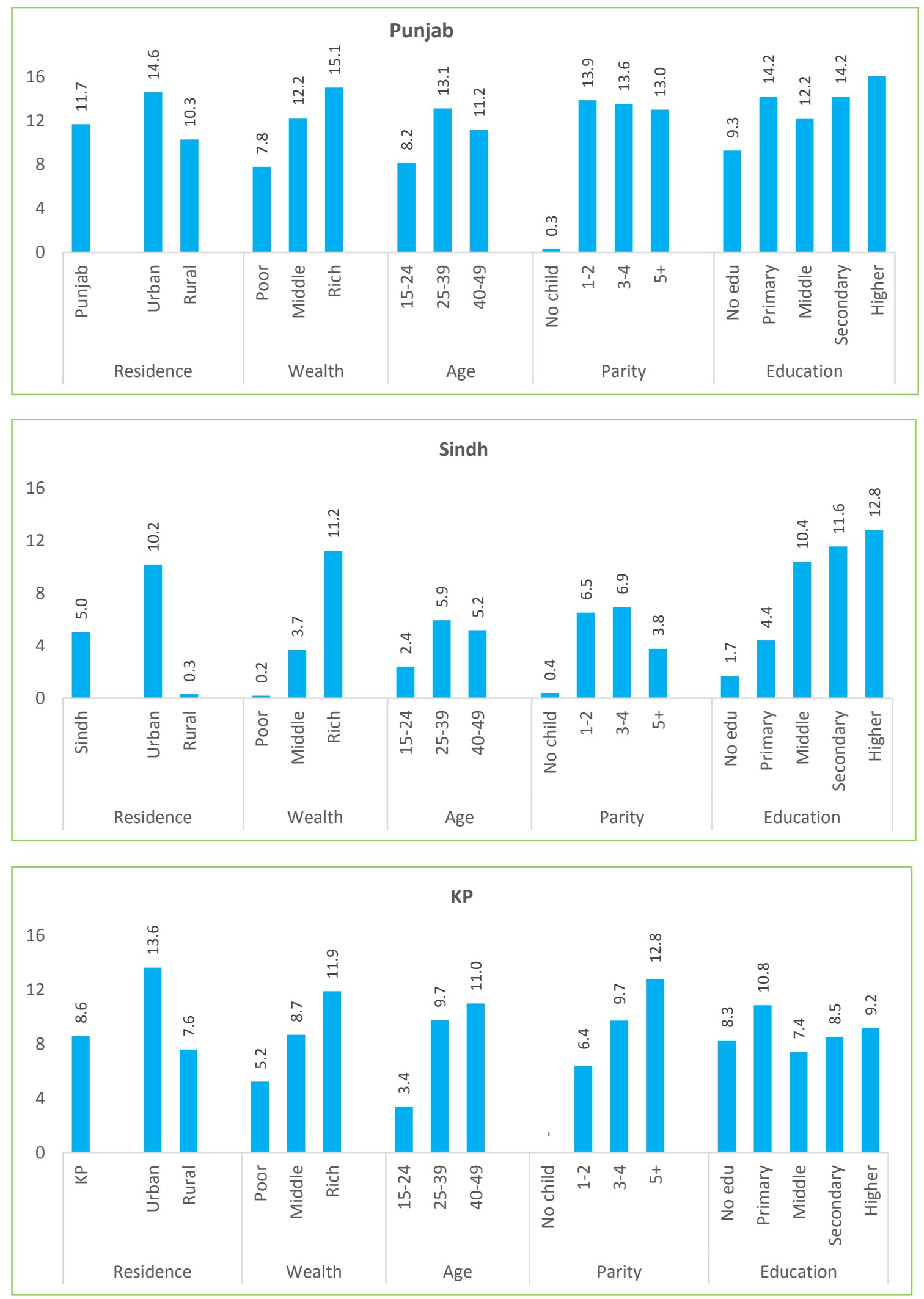


\section{Appendix 7: Barriers of Traditional Users to Adopt Modern Contraceptives by Segment}

\begin{tabular}{|c|c|c|c|c|c|c|}
\hline \multirow[b]{2}{*}{ Barriers } & \multicolumn{2}{|c|}{ Age } & \multicolumn{2}{|c|}{ Income groups } & \multicolumn{2}{|c|}{ Residence } \\
\hline & $\begin{array}{l}\text { Younger } \\
\text { Age (15 - } \\
30)\end{array}$ & $\begin{array}{c}\text { Older } \\
\text { age } \\
(31-45)\end{array}$ & Poor & Middle & Rural & Urban \\
\hline $\begin{array}{l}\text { Lack of information of modern } \\
\text { methods }\end{array}$ & 2 & 1 & 1 & - & - & 1 \\
\hline $\begin{array}{l}\text { Access issues of modern } \\
\text { methods }\end{array}$ & - & 2 & 2 & - & 2 & - \\
\hline Cost issues of modern methods & 3 & - & 3 & - & - & 3 \\
\hline $\begin{array}{l}\text { Poor quality of services at } \\
\text { public facilities }\end{array}$ & 3 & 2 & 2 & - & 3 & 3 \\
\hline $\begin{array}{l}\text { Fear/ experience of side } \\
\text { effects of modern methods }\end{array}$ & 1 & 1 & 1 & 1 & 1 & 1 \\
\hline Religion & - & 3 & 3 & - & 3 & - \\
\hline Privacy not maintained & - & 2 & 2 & 2 & 2 & 2 \\
\hline $\begin{array}{l}\text { Embarrassment in purchasing } \\
\text { condoms }\end{array}$ & - & 3 & 3 & - & - & 3 \\
\hline
\end{tabular}




\section{Appendix 8: Profile of Current Modern Contraceptive Users at Provincial Level}
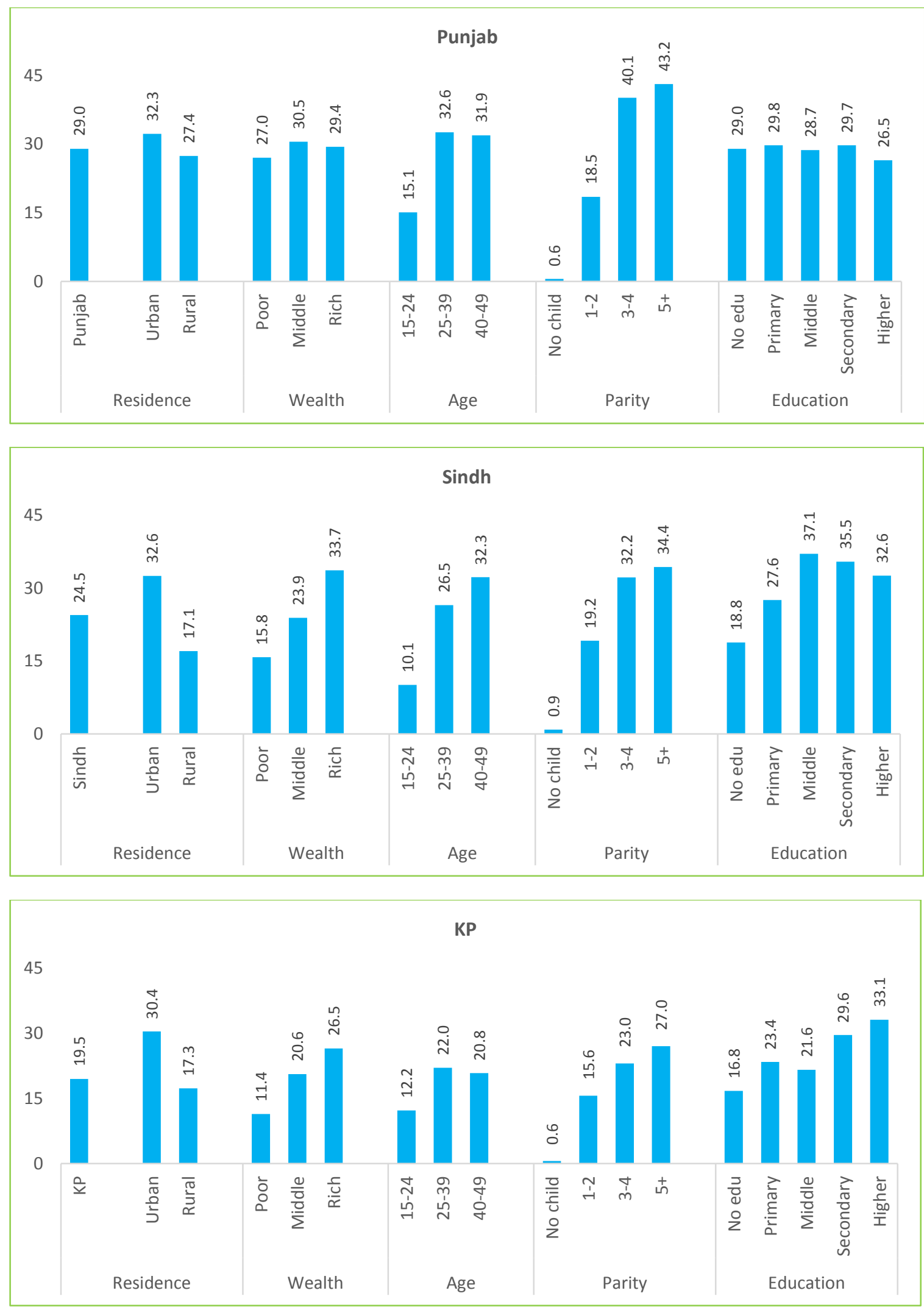
Appendix 9:Development Partners, Projects, Focus, Location, and Funding

\begin{tabular}{|c|c|c|c|c|c|c|}
\hline No & Donor Name & Program/Project Title & Implementing Partners & $\begin{array}{l}\text { Thematic focus in the area of health } \\
\text { and population/ FP }\end{array}$ & Geographical Focus & $\begin{array}{l}\text { Total Funding/ } \\
\text { Commitment }\end{array}$ \\
\hline 1 & DFID & $\begin{array}{l}\text { Delivering Reproductive } \\
\text { Health Results (DRHR) } \\
\text { (2012-2017) }\end{array}$ & $\begin{array}{l}\text { Population Services } \\
\text { International (PSI)/ Greenstar } \\
\text { Social Marketing (GSM) (3 } \\
\text { areas - KP, Punjab \& Sindh) } \\
\text { Marie Stopes International: } \\
\text { Reproductive Health Franchise } \\
\text { - (3 areas - KP, Punjab \& } \\
\text { Sindh) } \\
\text { DKT International/Pakistan ( } 2 \\
\text { areas - KP, Balochistan) }\end{array}$ & $\begin{array}{l}\text { Reduce maternal and newborn } \\
\text { mortality } \\
\text { Life-saving FP interventions and } \\
\text { strengthening the health system } \\
\text { Improved access to contraception } \\
\text { Social marketing and social franchising }\end{array}$ & $\begin{array}{l}\text { Sindh: } 12 \text { districts } \\
\text { Punjab: } 26 \text { district } \\
\text { KP: } 21 \text { districts } \\
\text { Balochistan: } 5 \\
\text { districts } \\
\text { AJK: } 1 \text { district } \\
\text { Gilgit/Baltistan: } 2 \\
\text { districts } \\
\text { FATA: } 13 \text { regions and } \\
\text { agencies }\end{array}$ & $\$ 43,721,400$ \\
\hline 2 & $\begin{array}{l}\text { Deutsche } \\
\text { Gesellschaft fuer } \\
\text { Internationale } \\
\text { Zusammenarbeit } \\
\text { (GIZ) GmbH } \\
\text { (Technical } \\
\text { Agency) }\end{array}$ & $\begin{array}{l}\text { Reproductive Maternal \& } \\
\text { Newborn Health Project } \\
\text { (RMNHP) } \\
(2015-16)\end{array}$ & $\begin{array}{l}\text { Lead Partners: } \\
\text { Population Council } \\
\text { Department of Health, KP } \\
\text { Others include: } \\
\text { MNCH Programme KP } \\
\text { LHW Programme KP } \\
\text { Population Welfare Department } \\
\text { KP } \\
\text { PPHI KP } \\
\text { University of Göttingen, } \\
\text { Germany }\end{array}$ & $\begin{array}{l}\text { GIZ is working in the abovementioned } \\
\text { thematic field via its "Reproductive } \\
\text { Maternal and Newborn Health Project" } \\
\text { (RMNHP) along two result areas: } \\
\text { Activity package A - Quality \& Patient } \\
\text { Safety in Obstetrics (QUAPASO): } \\
\text { A 1. Implementing the WHO-Safe- } \\
\text { Childbirth Checklist (SCC) in all health } \\
\text { facilities and among all CMW } \\
\text { A 2. Strengthening referral of MNCH } \\
\text { patients between LHWs, CMWs, and } \\
\text { health facilities } \\
\text { A 3. Development, implementation and } \\
\text { validation of an integrated WHO- } \\
\text { SCC/EmONC training package } \\
\text { A 4. MADE-IN/MADE-FOR district- } \\
\text { specific MMR estimation } \\
\text { Result area B: FP, Reproductive Health } \\
\text { \& Rights } \\
\text { Enhance FP and reproductive health } \\
\text { and rights education in the two districts } \\
\text { of Haripur and Nowshera. }\end{array}$ & KP: 2 districts & $\begin{array}{c}\$ 3,460,000 \\
\\
\text { Technical } \\
\text { Cooperation } \\
\text { measures, } \\
\text { contribution in kind }\end{array}$ \\
\hline
\end{tabular}




\begin{tabular}{|c|c|c|c|c|c|c|}
\hline No & Donor Name & Program/Project Title & Implementing Partners & $\begin{array}{l}\text { Thematic focus in the area of health } \\
\text { and population/ FP }\end{array}$ & Geographical Focus & $\begin{array}{c}\text { Total Funding/ } \\
\text { Commitment }\end{array}$ \\
\hline 3 & $\begin{array}{l}\text { KFW (German } \\
\text { Development } \\
\text { Bank) }\end{array}$ & $\begin{array}{l}\text { KFW focuses its } \\
\text { development cooperation } \\
\text { work in the north-west of the } \\
\text { country on the topics of } \\
\text { reproductive health and } \\
\text { health protection. At } \\
\text { national level KFW is } \\
\text { promoting the development } \\
\text { of blood banks and in Azad } \\
\text { Jammu \& Kashmir, the } \\
\text { Infrastructure of hospitals. } \\
\text { Support till } 2015 \text { included } \\
\text { providing basic health } \\
\text { equipment to Basic Health, } \\
\text { Basic Health Projects in GB } \\
\text { and FATA. }\end{array}$ & $\begin{array}{l}\text { Department of Health, Khyber } \\
\text { Pakhtunkhwa and other } \\
\text { provinces } \\
\text { Greenstar Social Marketing \& } \\
\text { DKT } \\
\text { Aga Khan Foundation \&FP } \\
\text { Association of Pakistan }\end{array}$ & $\begin{array}{l}\text { 1: Health Infrastructure } \\
\text { 2: Reproductive Health }\end{array}$ & $\begin{array}{l}\text { Punjab: } 17 \text { districts } \\
\text { AJK: } 6 \text { districts } \\
\text { GB: } 3 \text { districts } \\
\text { KP: } 13 \text { districts } \\
\text { FATA: } 1 \text { agency }\end{array}$ & $\$ 6,486,600$ \\
\hline 4 & $\begin{array}{l}\text { Bill and Melinda } \\
\text { Gates } \\
\text { Foundation }\end{array}$ & $\begin{array}{l}\text { Building Blocks for FP in } \\
\text { Pakistan - Developing a } \\
\text { Costed Implementation Plan } \\
\text { for Sindh and Punjab. } \\
(2013-2015)\end{array}$ & Pathfinder International & $\begin{array}{l}\text { FP } 2020 \text { Commitment of Government } \\
\text { of Pakistan }\end{array}$ & Sindh \& Punjab & $\$ 750,000$ \\
\hline 5 & $\begin{array}{l}\text { Bill and Melinda } \\
\text { Gates } \\
\text { Foundation }\end{array}$ & $\begin{array}{l}\text { Sukh Initiative } \\
(2014-2018)\end{array}$ & $\begin{array}{l}\text { Aman Health Care } \\
\text { Co-partners: } \\
\text { Aahung, AMANTELEHEALTH } \\
\text { Jhpiego } \\
\text { AKU }\end{array}$ & $\begin{array}{l}\text { 1. Increased demand for FP services } \\
\text { 2. Improved access to FP services (by } \\
\text { method) and with improved quality of } \\
\text { service } \\
\text { 3. Ensured long-term sustainability of } \\
\text { program focus }\end{array}$ & Karachi (Sindh) & $\$ 5,000,000$ \\
\hline 6 & $\begin{array}{l}\text { Bill and Melinda } \\
\text { Gates } \\
\text { Foundation }\end{array}$ & $\begin{array}{l}\text { Landscape Analysis of the } \\
\text { FP Situation in Pakistan } \\
(2015-2016)\end{array}$ & Population Council & FP 2020 Commitment & $\begin{array}{l}\text { Sindh }: 3 \text { districts } \\
\text { Punjab: } 4 \text { districts } \\
\text { KP: } 1 \text { district }\end{array}$ & $\$ 1,000,000$ \\
\hline 7 & $\begin{array}{l}\text { The David \& } \\
\text { Lucile Packard } \\
\text { Foundation }\end{array}$ & $\begin{array}{l}\text { Sukh Initiative } \\
(2014-2018)\end{array}$ & $\begin{array}{l}\text { Aman Health Care } \\
\text { Co-partners: } \\
\text { Aahung } \\
\text { AMANTELEHEALTH } \\
\text { Jhpiego } \\
\text { AKU }\end{array}$ & $\begin{array}{l}\text { Increased demand for FP services } \\
\text { Improved access to FP services (by } \\
\text { method) and with improved quality of } \\
\text { service }\end{array}$ & Karachi (Sindh) & $\$ 5,000,000$ \\
\hline 8 & $\begin{array}{l}\text { The David \& } \\
\text { Lucile Packard } \\
\text { Foundation }\end{array}$ & $\begin{array}{l}\text { Meeting Birth Spacing } \\
\text { Needs of the Underserved in } \\
\text { Punjab Districts. (2011- } \\
\text { 2015) }\end{array}$ & MSI/MSS & FP Voucher & Punjab (Chakwal) & $\$ 900,000$ \\
\hline
\end{tabular}




\begin{tabular}{|c|c|c|c|c|c|c|}
\hline No & Donor Name & Program/Project Title & Implementing Partners & $\begin{array}{l}\text { Thematic focus in the area of health } \\
\text { and population/ FP }\end{array}$ & Geographical Focus & $\begin{array}{l}\text { Total Funding/ } \\
\text { Commitment }\end{array}$ \\
\hline 9 & $\begin{array}{l}\text { The David \& } \\
\text { Lucile Packard } \\
\text { Foundation }\end{array}$ & $\begin{array}{l}\text { Demand-Side Financing for } \\
\text { Increasing Demand and } \\
\text { Utilization of Contraception } \\
\text { for Birth Spacing in Punjab } \\
\text { Province, Pakistan } \\
\text { (2011-2015) }\end{array}$ & $\begin{array}{l}\text { Population Services } \\
\text { International } \\
\text { Greenstar Social Marketing }\end{array}$ & FP Voucher & Faisalabad & $\$ 900,000$ \\
\hline 10 & $\begin{array}{l}\text { The David \& } \\
\text { Lucile Packard } \\
\text { Foundation }\end{array}$ & $\begin{array}{l}\text { Comparative Impact } \\
\text { Evaluation: Demand Side } \\
\text { Financing for Increasing } \\
\text { Demand and Utilization of } \\
\text { Birth Spacing in Punjab } \\
\text { Province, Pakistan } \\
\text { (2011-2015) }\end{array}$ & WHO & FP Voucher & Punjab : 2 districts & $\$ 250,000$ \\
\hline 11 & $\begin{array}{l}\text { The David \& } \\
\text { Lucile Packard } \\
\text { Foundation }\end{array}$ & $\begin{array}{l}\text { Increasing Access and Use } \\
\text { of Contraceptives in } \\
\text { Punjab/Sindh: Keeping } \\
\text { Momentum \& Innovating for } \\
\text { Success. 2012-2015 }\end{array}$ & DKT Inc & Access to FP Services & $\begin{array}{l}\text { Sindh: } 3 \text { districts } \\
\text { Punjab: } 3 \text { districts }\end{array}$ & $\$ 400,000$ \\
\hline 12 & $\begin{array}{l}\text { The David \& } \\
\text { Lucile Packard } \\
\text { Foundation }\end{array}$ & $\begin{array}{l}\text { Improve Reproductive } \\
\text { Health and FP in } \\
\text { marginalized communities } \\
\text { of Sindh, Pakistan through } \\
\text { viable and demonstrable } \\
\text { initiatives. 2007-2015 }\end{array}$ & HANDS & $\begin{array}{l}\text { Access to FP services in rural } \\
\text { marginalized communities }\end{array}$ & Sindh (Umerkot) & $\$ 2,000,000$ \\
\hline 13 & $\begin{array}{l}\text { The David \& } \\
\text { Lucile Packard } \\
\text { Foundation }\end{array}$ & $\begin{array}{l}\text { Achieving MDG5 - } \\
\text { Continuing Momentum, } \\
\text { Building Champions. 2012- } \\
2015\end{array}$ & $\begin{array}{l}\text { Shirkat Gah Women Resource } \\
\text { Centre }\end{array}$ & Advocacy on FP & $\begin{array}{l}\text { National level across } \\
\text { all provinces }\end{array}$ & $\$ 250,000$ \\
\hline 14 & $\begin{array}{l}\text { The David \& } \\
\text { Lucile Packard } \\
\text { Foundation }\end{array}$ & $\begin{array}{l}\text { Quality FP and Reproductive } \\
\text { Healthcare Through } \\
\text { Community Mobilization: } \\
\text { From Rhetoric to Reality. } \\
\text { 2013-2015 }\end{array}$ & $\begin{array}{l}\text { Strengthen Participatory } \\
\text { Organization }\end{array}$ & Advocacy on FP & $\begin{array}{l}\text { Sindh : } 3 \text { districts } \\
\text { Punjab:1 district }\end{array}$ & $\$ 250,000$ \\
\hline 16 & $\begin{array}{l}\text { The David \& } \\
\text { Lucile Packard } \\
\text { Foundation }\end{array}$ & $\begin{array}{l}\text { Strengthening and } \\
\text { Sustaining Postpartum FP in } \\
\text { Pakistan. 2013-2015 }\end{array}$ & JHU - JHPIEGO & FP Services & $\begin{array}{l}\text { Punjab } 5 \text { districts } \\
\text { Sindh: } 1 \text { districts }\end{array}$ & $\$ 700,000$ \\
\hline 17 & USAID & $\begin{array}{l}\text { Deliver Project } \\
(2008-2016)\end{array}$ & $\begin{array}{l}\text { Planning Commission of } \\
\text { Pakistan } \\
\text { Ministry of Health }(\mathrm{MOH}) \\
\text { Provincial and Regional } \\
\text { Departments of Health and } \\
\text { Population } \\
\text { UNFPA } \\
\text { NGOs }\end{array}$ & $\begin{array}{l}\text { Contraceptive forecasting } \\
\text { Procurement planning } \\
\text { Warehouse management } \\
\text { Supply chain strengthening } \\
\text { Automation of warehouse and logistics } \\
\text { management information systems } \\
\text { (LMIS) }\end{array}$ & $\begin{array}{l}\text { In all } 136 \text { districts of } \\
\text { Pakistan }\end{array}$ & $\$ 139,000,000$ \\
\hline
\end{tabular}




\begin{tabular}{|c|c|c|c|c|c|c|}
\hline No & Donor Name & Program/Project Title & Implementing Partners & $\begin{array}{l}\text { Thematic focus in the area of health } \\
\text { and population/ FP }\end{array}$ & Geographical Focus & $\begin{array}{l}\text { Total Funding/ } \\
\text { Commitment }\end{array}$ \\
\hline 18 & UNFPA & $\begin{array}{l}\text { Public Private Partnership in } \\
\text { provision of FP Services } \\
2014-2017\end{array}$ & $\begin{array}{l}\text { MSS } \\
\text { Population Welfare } \\
\text { Departments }\end{array}$ & FP Voucher & $\begin{array}{l}\text { Punjab: } 6 \\
\text { KP: } 4 \\
\text { Sindh: } 1\end{array}$ & $\$ 5,000,000$ \\
\hline 19 & UNFPA & $\begin{array}{l}\text { Capacity building of female } \\
\text { service providers enhanced } \\
\text { in FP } \\
2014-2017\end{array}$ & $\begin{array}{l}\text { Population Welfare } \\
\text { Departments } \\
\text { MNCH Programs } \\
\text { LHWs Program }\end{array}$ & Capacity building of service providers & $\begin{array}{l}\text { Punjab } \\
\text { Sindh } \\
\text { KP }\end{array}$ & $\$ 5,000,000$ \\
\hline 20 & UNFPA & $\begin{array}{l}\text { Advocacy for universal } \\
\text { access to reproductive } \\
\text { health and to integrate in } \\
\text { provincial health policies, } \\
\text { plans and budgetary } \\
\text { frameworks } \\
(2012-2017)\end{array}$ & $\begin{array}{l}\text { Population Welfare } \\
\text { Departments } \\
\text { Population Council } \\
\text { Pathfinder } \\
\text { Ministry of National Health } \\
\text { Services, Regulations and } \\
\text { Coordination }\end{array}$ & Advocacy on population and FP & $\begin{array}{l}\text { National level across } \\
\text { all provinces }\end{array}$ & $\$ 5,000,000$ \\
\hline 21 & USAID & $\begin{array}{l}\text { FP and Reproductive Health } \\
\text { Services. } \\
\text { 2013-2017 }\end{array}$ & Marie Stopes Society & $\begin{array}{l}\text { Social franchise capacity building and } \\
\text { quality improvement }\end{array}$ & $\begin{array}{l}\text { Sindh: All districts } \\
\text { Punjab: } 4 \text { districts }\end{array}$ & \multirow{4}{*}{$\begin{array}{l}\text { Total funding for } \\
\text { these } 4 \text { projects } \\
\text { funded by USAID is } \\
\$ 48,200,000\end{array}$} \\
\hline 22 & USAID & $\begin{array}{l}\text { FP and Reproductive Health } \\
\text { Services } \\
2013-2017\end{array}$ & Marie Stopes Society & Voucher schemes & $\begin{array}{l}\text { Sindh: All districts } \\
\text { Punjab: } 4 \text { districts }\end{array}$ & \\
\hline 23 & USAID & $\begin{array}{l}\text { FP and Reproductive Health } \\
\text { Services } \\
2013-2017\end{array}$ & Marie Stopes Society & Community outreach & $\begin{array}{l}\text { Sindh: } 15 \text { districts } \\
\text { Punjab: } 2 \text { districts }\end{array}$ & \\
\hline 24 & USAID & $\begin{array}{l}\text { FP and Reproductive Health } \\
\text { 2013-2017 }\end{array}$ & Marie Stopes Society & Health system strengthening & All districts of Sindh & \\
\hline 25 & USAID & $\begin{array}{l}\text { Maternal and Child Health } \\
\text { Integrated Program (MCHIP) } \\
\text { 2013-2017 }\end{array}$ & Jhpiego & Training on FP & Sindh : 15 districts & $\$ 5,500,000$ \\
\hline 26 & USAID & $\begin{array}{l}\text { Health Policy Plus (HP+) } \\
2015-2018\end{array}$ & Palladium Pakistan Pvt. Ltd & $\begin{array}{l}\text { To strengthen and advance developing } \\
\text { country health policy and financing for } \\
\text { FP }\end{array}$ & National & $\$ 3,600,000$ \\
\hline
\end{tabular}




\begin{tabular}{|c|c|c|c|c|c|c|}
\hline No & Donor Name & Program/Project Title & Implementing Partners & $\begin{array}{l}\text { Thematic focus in the area of health } \\
\text { and population/ FP }\end{array}$ & Geographical Focus & $\begin{array}{l}\text { Total Funding/ } \\
\text { Commitment }\end{array}$ \\
\hline 27 & $\begin{array}{l}\text { World Health } \\
\text { Organization } \\
(\mathrm{WHO})\end{array}$ & $\begin{array}{l}\text { Provide technical assistance } \\
\text { for the development of a } \\
\text { unified care provider's } \\
\text { manual on FP based on the } \\
\text { WHO Handbook on FP. After } \\
\text { technical consultation with } \\
\text { national counterparts and } \\
\text { partners (planned in early } \\
\text { December), utilize the } \\
\text { manual in training core } \\
\text { teams and later roll out of } \\
\text { the training across all } \\
\text { provinces. }\end{array}$ & $\begin{array}{l}\text { Ministry of National Health } \\
\text { Services Coordination and } \\
\text { Regulation } \\
\text { MNCH programs within } \\
\text { provincial departments of } \\
\text { Health } \\
\text { UNFPA } \\
\text { Population Council } \\
\text { GIZ } \\
\text { USAID } \\
\text { Others }\end{array}$ & $\begin{array}{l}\text { Technical assistance } \\
\text { Adaptation of WHO Standards and } \\
\text { subsequent development of national } \\
\text { guidelines on FP } \\
\text { Building capacity of health care } \\
\text { providers } \\
\text { Advocacy for FP }\end{array}$ & $\begin{array}{l}\text { All districts of } \\
\text { Pakistan }\end{array}$ & $\begin{array}{l}\text { 22,000 USD for } \\
\text { development of FP } \\
\text { guidelines based on } \\
\text { WHO Global } \\
\text { handbook on FP } \\
\text { and technical } \\
\text { meetings for } \\
\text { revision } \\
\text { Funding for capacity } \\
\text { building activities in } \\
\text { FP is integrated } \\
\text { within WHO training } \\
\text { packages, and is } \\
\text { not stand-alone. In } \\
\text { the last biennium } \\
2014-15 \text {, this } \\
\text { capacity building } \\
\text { funding was } \\
\text { approximately } \\
300,000 \text { USD) }\end{array}$ \\
\hline 28 & $\begin{array}{l}\text { Large } \\
\text { Anonymous } \\
\text { Donor (LAD) }\end{array}$ & $\begin{array}{l}\text { National Expansion Project } \\
\text { Phase III }\end{array}$ & Marie Stopes Society & $\begin{array}{l}\text { Reproductive health } \\
\text { Reducing maternal mortality }\end{array}$ & $\begin{array}{l}\text { Punjab: } 26 \text { districts } \\
\text { Sindh: } 17 \text { districts } \\
\text { KP: } 5 \text { districts } \\
\text { AJK: } 1 \text { district } \\
\text { Balochistan: } 5 \\
\text { districts }\end{array}$ & 15 million USD \\
\hline 29 & $\begin{array}{l}\text { Large } \\
\text { Anonymous } \\
\text { Donor (LAD) }\end{array}$ & $\begin{array}{l}\text { Increasing Access to and } \\
\text { use of Long Term Methods } \\
\text { of FP and PAC Services in } \\
\text { Pakistan } \\
(2014-16)\end{array}$ & Greenstar Social Marketing & $\begin{array}{l}\text { Improved Women Health } \\
\text { FP } \\
\text { Adoption of long-term FP methods; } \\
\text { Enhanced post-abortion care (PAC) } \\
\text { services }\end{array}$ & National & US\$19 million \\
\hline
\end{tabular}


